\title{
Life-cycle-assessment of industrial scale biogas plants
}

\author{
Dissertation \\ zur Erlangung des Doktorgrades \\ der Fakultät für Agrarwissenschaften \\ der Georg-August-Universität Göttingen
}

\author{
vorgelegt von \\ Joachim Kilian Hartmann \\ geboren in Marbach am Neckar
}

Göttingen, Juli 2006 
1. Referentin/Referent: Prof. Dr. Wolfgang Lücke

2. Korreferentin/Korreferent: Prof. Dr. Michael Nelles

Tag der mündlichen Prüfung: 13.07.2006 


\section{Indices}

\section{Table of contents}

Indices

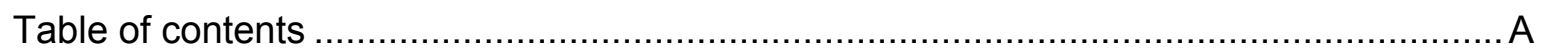

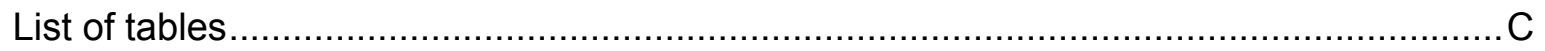

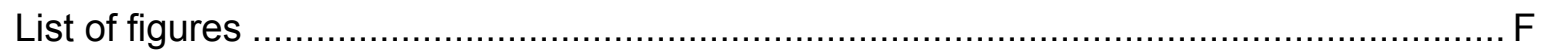

1 Introduction

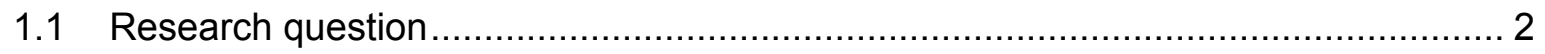

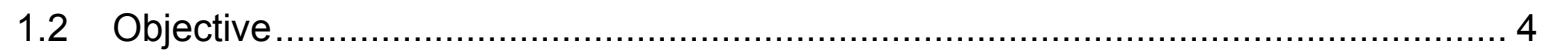

2 Materials and methods __ 6

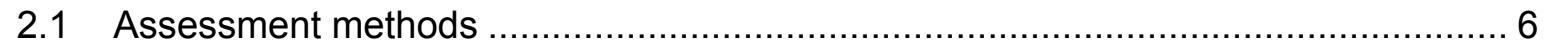

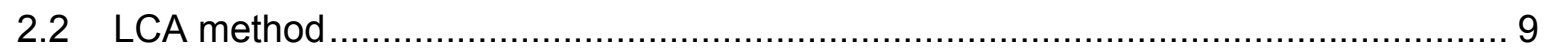

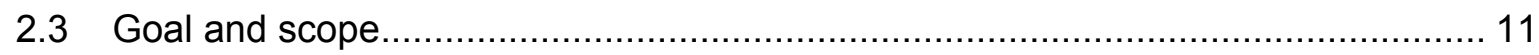

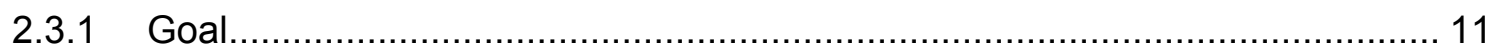

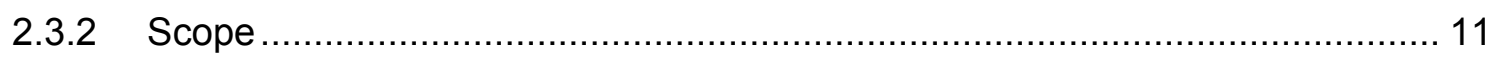

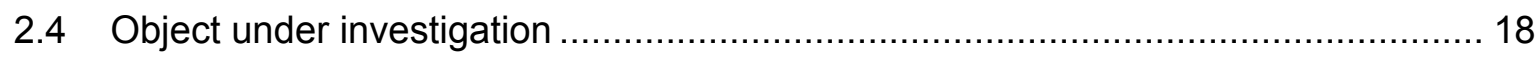

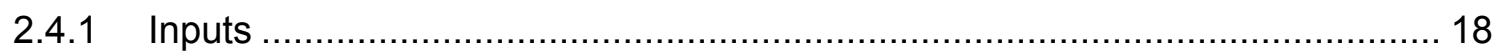

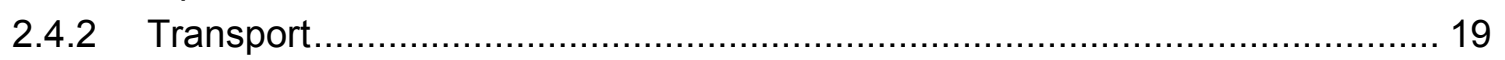

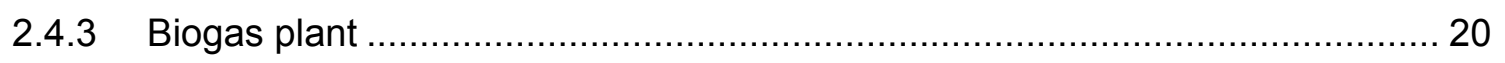

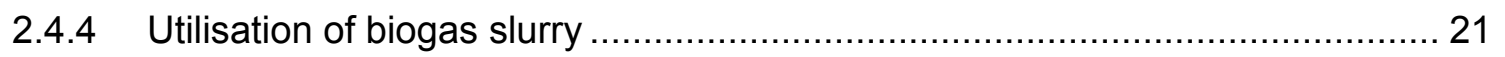

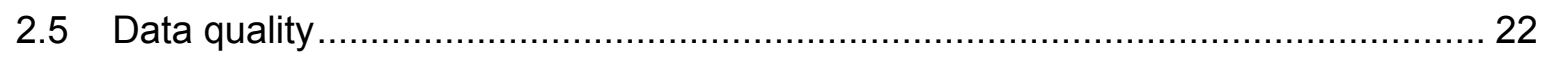

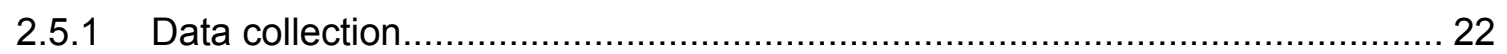

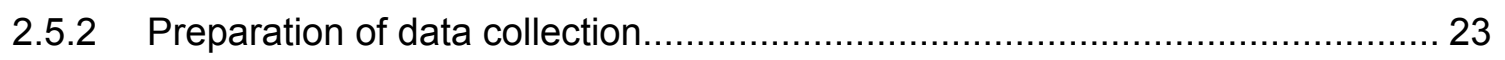

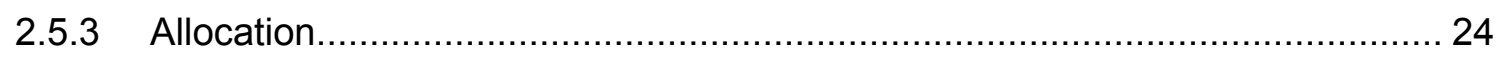

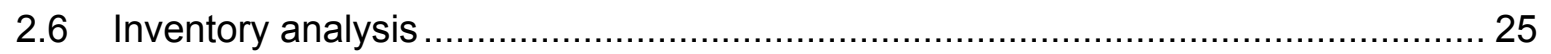

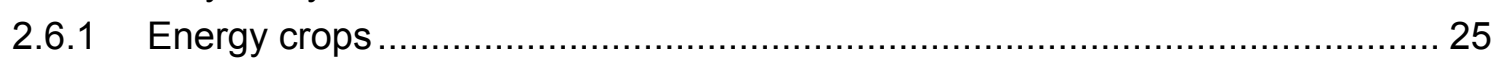

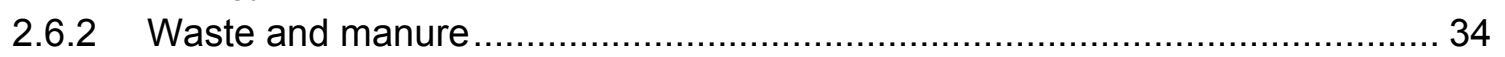

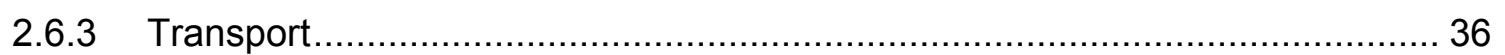

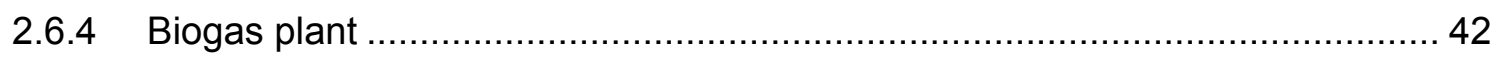

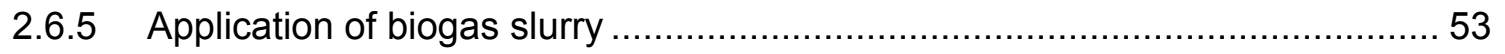

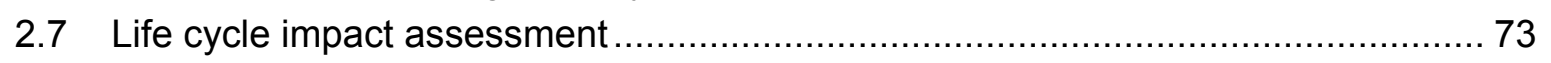

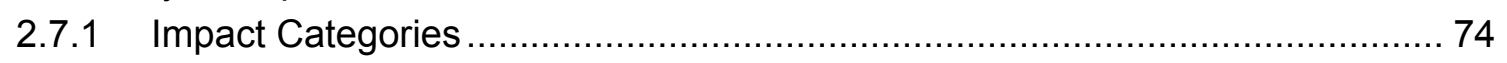

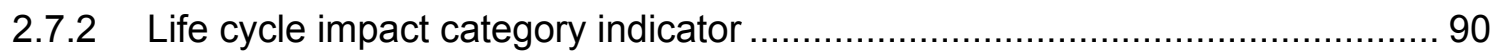

2.7.3 Assessment via damage-oriented methods ............................................... 91

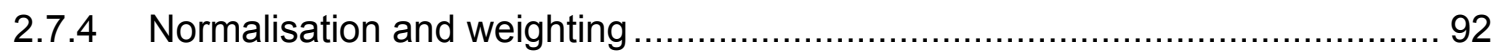

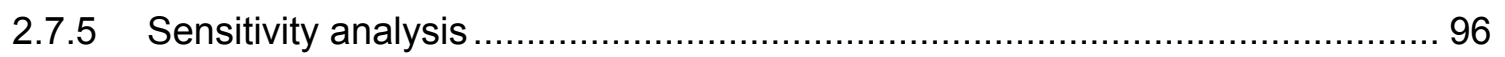

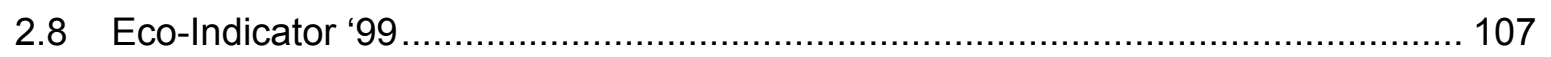

2.8.1 Damage categories and normalisation.................................................. 107

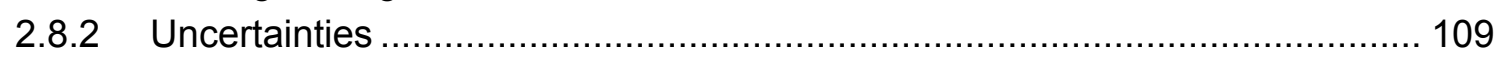

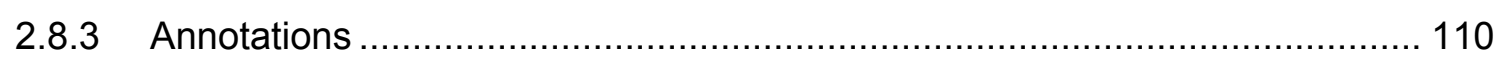

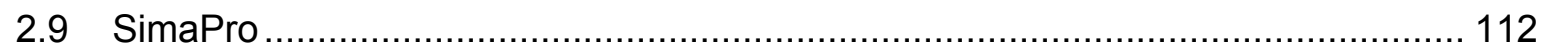


3 Results 113

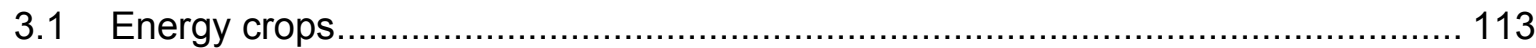

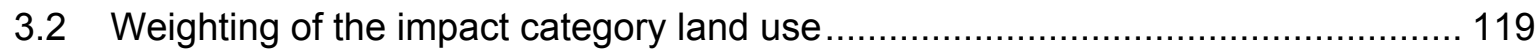

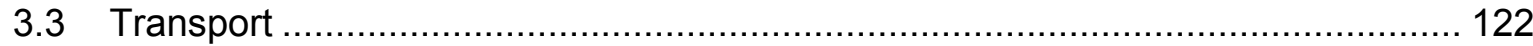

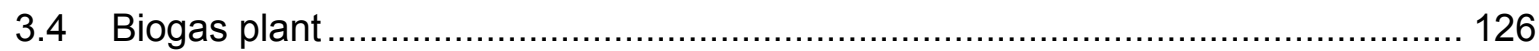

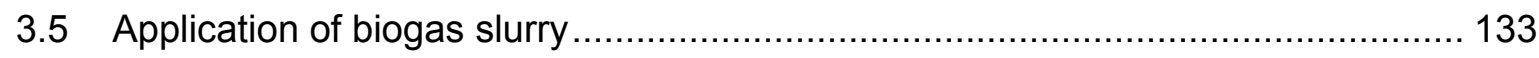

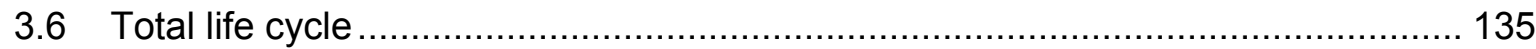

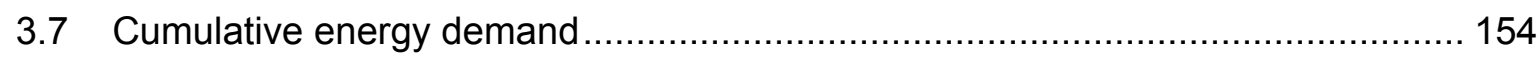

4 Discussion 160

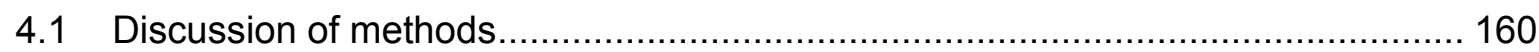

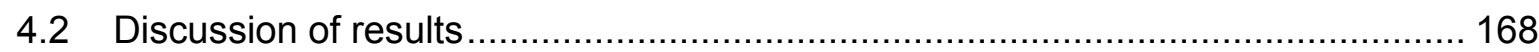

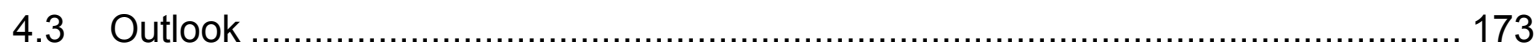

5 Summary _ 175

6 Sources 179

7 Annex 195 


\section{List of tables}

Table 2.1: Data quality requirements

Table 2.2: $\quad$ Gas yields for different kinds of energy crops [HASSAN2003,

HÄRDTLEIN2003, MÄHNERT ET AL.2002, FNR2004, KORFF ET AL.2005,

FRITZ2006, LAURENZ2005].

Table 2.3: $\quad \mathrm{LCl}$ of silage maize for the generation of $1.0 \mathrm{TJ}$ electric energy ......................31

Table 2.4: $\quad \mathrm{LCl}$ of silage rye for the generation of $1.0 \mathrm{TJ}$ electric energy .............................32

Table 2.5: $\quad \mathrm{LCl}$ of silage grass for the generation of $1.0 \mathrm{TJ}$ electric energy .......................33

Table 2.6: $\quad \mathrm{LCl}$ of forage beets for the production of one functional unit...........................34

Table 2.7: $\quad$ Amount of farm manure in Germany, 1994-2003 [SCHWAB2004].....................36

Table 2.8: Potential biogas production from manure in Germany, year 2003 ...................36

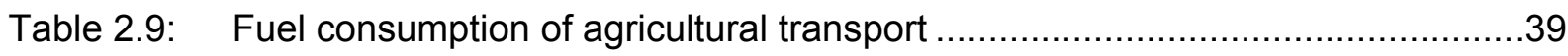

Table 2.10: Gaseous emissions from agricultural transport ............................................. 40

Table 2.11: Standard input mixture used as reference input [Mg/TJ] ...............................40

Table 2.12: LCl of agricultural transport of energy crops needed for $1.0 \mathrm{TJ}$ electric energy

Table 2.13: $\mathrm{LCl}$ of agricultural transport of biogas slurry resulting from $1.0 \mathrm{TJ}$ electric energy

Table 2.14: LCl of management and technology building for $1.0 \mathrm{TJ}$ electric energy ...........43

Table 2.15: $\quad \mathrm{LCl}$ of the weighbridge for $1.0 \mathrm{TJ}$ electric energy ........................................44

Table 2.16: $\mathrm{LCl}$ of the storage vessel related to one functional unit .................................44

Table 2.17: $\mathrm{LCl}$ of the heat exchanger device related to one functional unit ........................45

Table 2.18: $\mathrm{LCl}$ of a hygienisation unit for one functional unit.........................................46

Table 2.19: $\quad \mathrm{LCl}$ data of the main reactor for one functional unit ...................................47

Table 2.20: $\mathrm{LCl}$ of the gassing reactor related to one functional unit ..................................47

Table 2.21: $\mathrm{LCl}$ date of the gas purification system for the generation of $1.0 \mathrm{TJ}$

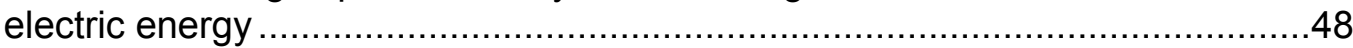

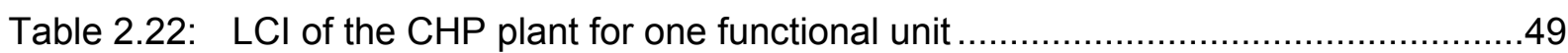

Table 2.23: $\quad \mathrm{LCl}$ of the hydraulic facilities for one functional unit ........................................49

Table 2.24: $\mathrm{LCl}$ of energy consumption related to one functional unit ..............................50

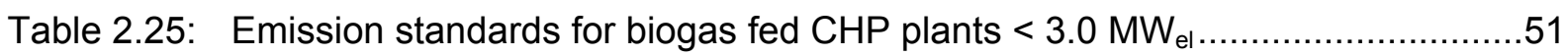

Table 2.26: Emissions of $1.0 \mathrm{MW}_{\text {el }}$ biogas fuelled CHP plants ...........................................51

Table 2.27: $\mathrm{LCl}$ of gaseous emission from the CHP related to one functional unit ..............51

Table 2.28: Dry matter, $\mathrm{N}$ and $\mathrm{NH}_{4}-\mathrm{N}$ content of different organic fertilizers ......................61

Table 2.29: Nutrient contents of substrates derived from biogas slurry [WEILAND2004] ......63

Table 2.30: Emissions from biogas slurry cleared by avoided emissions from manure

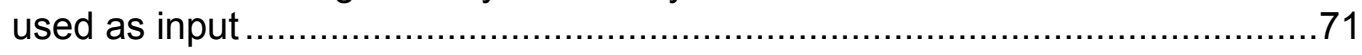

Table 2.31: LCl data for biogas slurry application scenarios.........................................72

Table 2.32: Impact categories and indicators of agricultural production systems ................75

Table 2.33: Impact categories and indicators in the transport module [BORKEN ET

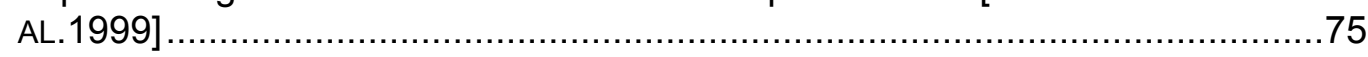

Table 2.34: Impact categories in the module biogas plant [EDELMANN ET AL.2001] .............76

Table 2.35: PDF values for local effects of land-use [KöLLNER2000 cited in

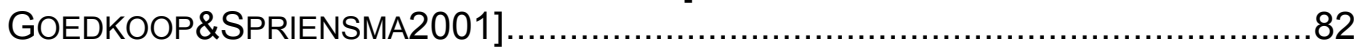

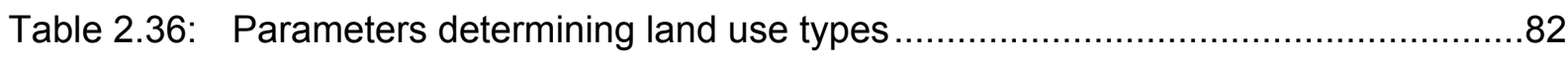


Table 2.37: Characterisation factors of the impact category ozone layer depletion

used in this study depending on the El '99 method

Table 2.38: Normalisation values for Europe [BLONK ET AL.1997 in GOEDKOOP\&SPRIENSMA2001].

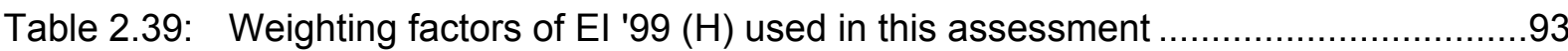

Table 2.40: Estimate of rounded weighting factors [METTIER in GOEDKOOP\&SPRIENSMA2001]

Table 2.41: Replaced heatings from $61.7 \mathrm{MWh}$ fed to a heat grid. ..................................96

Table 2.42: LCl of a MCFC fuel cell of $1.0 \mathrm{MWel}$ power related to one functional unit ........99

Table 2.43: Emissions from a $1.0 \mathrm{MW}_{\mathrm{el}}$ fuel cell related to one functional unit ..................100

Table 2.44: $\quad \mathrm{LCl}$ of high yield maize related to one functional unit .................................100

Table 2.45: Energy content of waste from the food industry .........................................101

Table 2.46: Mixture of waste materials for the production of one functional unit ..............101

Table 2.47: $\mathrm{LCl}$ of input transports of waste for one functional unit ................................102

Table 2.48: $\mathrm{LCl}$ of transport efforts of a $2.0 \mathrm{MW}_{\mathrm{el}}$ biogas plant related to one functional unit

Table 2.49: $\quad \mathrm{LCl}$ data of silage maize for one functional unit, considering an extensive production system as reference unit for land use.

Table 2.50: $\quad \mathrm{LCl}$ of silage maize production for one functional unit, without calculating land occupation

Table 2.51: LCl of installations and consumptions for biogas slurry treatment related

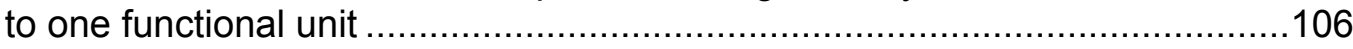

Table 2.52: Normalisation-Weighting set Europe El 99 H/A ......................................108

Table 3.1: $\quad$ Weighted Effects (El '99H) of maize silage production .................................113

Table 3.2: $\quad$ Weighted Effects $(\mathrm{El}$ ' $99 \mathrm{H})$ of silage grass production ..................................114

Table 3.3: Weighted Effects $(\mathrm{El}$ ' $99 \mathrm{H})$ of rye silage production ...................................114

Table 3.4: Weighted Effects (EI ' $99 \mathrm{H})$ of silage from forage beet production....................115

Table 3.5: $\quad$ Weighted Effects (EI '99H) from the standard input mixture .........................116

Table 3.6: Weighted Effects (EI '99H) of high yield silage maize ..................................116

Table 3.7: Weighted effects $(\mathrm{El} ' \mathrm{'} 9 \mathrm{H})$ of the silage maize production, using an extensive production system as reference system for land use effects ..........119

Table 3.8: Weighted effects (EI ' $99 \mathrm{H}$ ) of the silage maize production, considering no land use impacts ........................................................................... 120

Table 3.9: Weighted effects $(\mathrm{El} ' \mathrm{\prime} 9 \mathrm{H})$ of the agricultural transport of input and output substrates of a $1.0 \mathrm{MW}_{\mathrm{el}}$ biogas plant, considering energy crops as input substrates.

Table 3.10: Weighted effects (El ' $99 \mathrm{H}$ ) of biogas slurry treatment facility related to one functional unit

Table 3.11: Weighted effects $(\mathrm{El} ' \mathrm{~g} \mathrm{H})$ of the reduction of transport efforts due to the biogas slurry treatment.

Table 3.12: Weighted effects (El ' $99 \mathrm{H})$ of installation and operation of a $1.0 \mathrm{MW}_{\mathrm{el}}$ gas engine.

Table 3.13: Weighted effects $(\mathrm{El} ' 99 \mathrm{H})$ of installation and operation of a $1.0 \mathrm{MW}_{\mathrm{el}}$ fuel cell.....

Table 3.14: Weighted ecological effects (EI ' $99 \mathrm{H}$ ) of the emissions of the conventional CHP per functional unit

Table 3.15: Weighted ecological effects $(E \mathrm{I} ' 99 \mathrm{H})$ of the emissions from a $1.0 \mathrm{MW}_{\mathrm{el}}$ fuel cell per functional unit. 
Table 3.16: Weighted results of the biogas slurry treatment scenarios per functional unit.

Table 3.17: Weighted ecological effects of the standard scenario, electricity generation from biogas produced in industrial scale biogas plants

Table 3.18: Weighted ecol. effects of the no occ. arable area scenario, electricity generation from biogas produced in industrial scale biogas plants

Table 3.19: Weighted ecol. effects of the fuel cell scenario, electricity generation from biogas produced in industrial scale biogas plants

Table 3.20: Weighted ecol. effects of the food waste scenario, electricity generation from biogas produced in industrial scale biogas plants

Table 3.21: Weighted ecol. effects of the application below gap scenario, electricity generation from biogas produced in industrial scale biogas plants

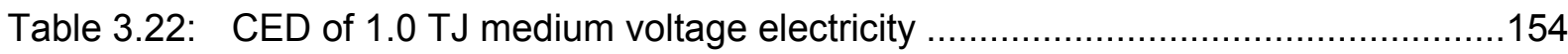

Table 3.23: CED of 1.0 TJ electricity, standard scenario ...........................................155

Table 3.24: CED of 1.0 TJ electricity, utilisation of waste heat scenario ............................155

Table 3.25: CED of 1.0 TJ electricity, fuel cell scenario ................................................156

Table 3.26: CED of 1.0 TJ electricity, high yield energy maize scenario ...........................156

Table 3.27: CED of $1.0 \mathrm{TJ}$ electricity, food waste scenario .............................................157

Table 3.28: CED of 1.0 TJ electricity, biogas slurry treatment scenario...........................157

Table 3.29: CED of 1.0 TJ electricity, biogas slurry application below gap standard scenario.

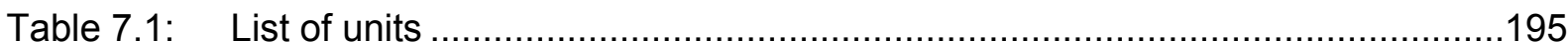

Table 7.2: Definition and description of Hemeroby classes and the Natural Degradation Potential (NDP) [KoWARIK1999, RÜHS2001] ............................198

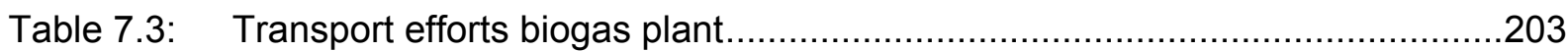

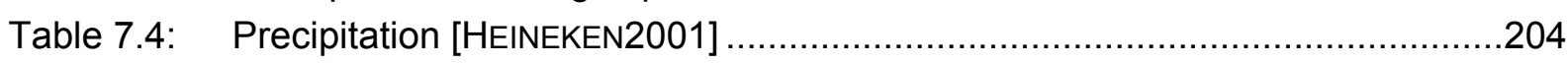




\section{List of figures}

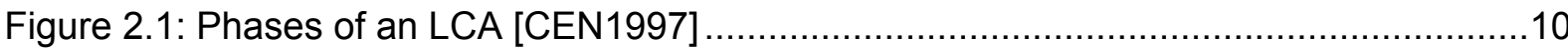

Figure 2.2: $\mathrm{CH}_{4}, \mathrm{~N}_{2} \mathrm{O}$, and $\mathrm{NH}_{3}$ emission rates of artificial pig dung stored at $25^{\circ} \mathrm{C}$ in 100 I vessels [WOLTER in CLEMENS ET AL.2002]

Figure 2.3: $\mathrm{CH}_{4}$ emissions after application of differently treated manure [AMON ET AL.2002]

Figure 2.4: Nitrification and denitrification based $\mathrm{N}_{2} \mathrm{O}$ generation and bonding in soils [LEICK2003]

Figure 2.5: $\mathrm{N}_{2} \mathrm{O}$ emissions after application of differently treated manure [AMON ET AL.2002]

Figure 2.6: $\mathrm{N}_{2} \mathrm{O}$ generation of $\mathrm{NH}_{3}$ emissions from agriculture [SCHÖN ET AL.1993] .............57

Figure 2.7: Model of $\mathrm{NH}_{3}$ evaporation from liquid systems.

Figure 2.8: $\mathrm{NH}_{3}$ emission after application of differently treated manure [AMON ET AL.2002]

Figure 2.9: $\quad \mathrm{NH}_{3}$ losses after application of untreated and separated manure concerning different incorporation methods

Figure 2.10: Field trial on emissions from biogas slurry substrates....

Figure 2.11: Arrangement plot of the field trial on emissions from biogas slurry substrates

Figure 2.12: $\mathrm{CH}_{4}$ emissions after application of differently treated biogas slurry

Figure 2.13: $\mathrm{N}_{2} \mathrm{O}$ emissions after application of differently treated biogas slurry

Figure 2.14: $\mathrm{NH}_{3}$ emissions after application of differently treated biogas slurry

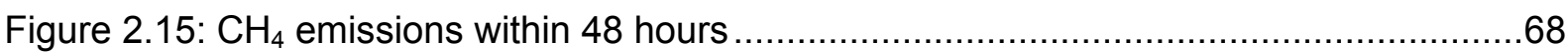

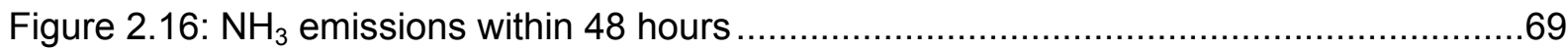

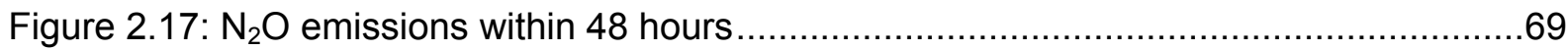

Figure 2.18: Core concept of El'99 [GOEDKOOP\&SPRIENSMA2001] ....................................74

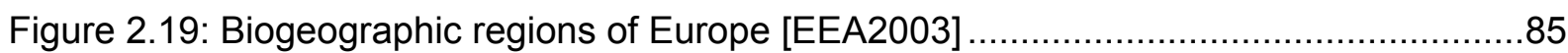

Figure 2.20: Relation of farming intensity and number of game herbs ............................... 87

Figure 2.21: Schematic energy flow in Germany (1990) [MOERSCHNER2000].......................89

Figure 2.23: Relative contribution of the impact categories to the European damage

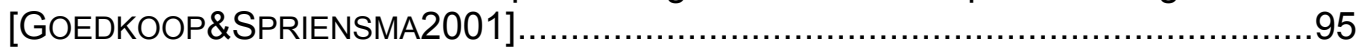

Figure 2.24: Scheme of a molten carbonate fuel cell (MCFC) [BERGER2006] ........................98

Figure 2.25: Emissions from fuel cells compared to gas turbine and gas engine..................99

Figure 2.26: Five archetypes grid-group dependency of the Cultural Theory......................109

Figure 2.27: General representation of the El'99 methodology according to [GOEDKOOP\&SPRIENSMA2001].

Figure 3.1: Comparison of the ecological effects (normalised values) from energy crops used as input per functional unit

Figure 3.2: Comparison of the total ecological effects from different energy crops and the standard input mixture used in this LCA.

Figure 3.3: Characterisation of the $\mathrm{LCl}$ data of the three sensitivity analysis considering the influence of the impact category land use.....

Figure 3.4: Comparison of the weighting methods influence on the total ecological effects

Figure 3.5: Comparison of the normalised values of the transport scenarios.

Figure 3.6: Comparison of the weighted ecological effects $(\mathrm{EI} ' \mathrm{~g} \mathrm{H})$ of the assemblies

of the biogas plant 
Figure 3.7: Normalised results per impact category of the electricity consumption $(0.1$

TJ)

Figure 3.8: Comparison of the ecological effects of a conventional gas engine and fuel cell (normalised)

Figure 3.9: Comparison of the normalised values of the emissions from the conventional CHP plant and the fuel cell, both fed with biogas, related to one functional unit

Figure 3.10: Comparison of the normalised results of the impacts to the environment from technical installations, electricity consumption, and emissions from the CHP plant related to the module biogas plant.

Figure 3.11: Comparison of the characterisation step results of the three objected scenarios

Figure 3.12: Share [\%] of the single modules of the biogas production in industrial scale biogas plants per impact category (characterised), standard scenario

Figure 3.13: Network of the standard scenario (cut-off $1.3 \%$ ecological effect)

Figure 3.14: Share [\%] of the single modules of the biogas production in industrial scale biogas plants per impact category (characterised), no occ. arable scenario

Figure 3.15: Weighted effects $(\mathrm{El}$ ' $99 \mathrm{H})$ of the electricity generation from biogas, considering no occupation of arable area for the crop production

Figure 3.16: Share [\%] of the single modules of the biogas production in industrial scale biogas plants per impact category (characterised), utilisation of waste heat scenario

Figure 3.17 Network of the fuel cell scenario (cut-off $1.7 \%$ ecological effect)

Figure 3.18: Share [\%] of the single modules of the biogas production in industrial scale biogas plants per impact category (characterised), high yield maize scenario

Figure 3.19: Share [\%] of the single modules of the biogas production in industrial scale biogas plants per impact category (characterised), food waste scenario

Figure 3.20: Comparison of all scenarios (normalised data)

Figure 3.21: Comparison of the CED values of the different scenarios.....

Figure 7.2: Scheme of a possible biogas plant configuration for $\mathrm{LCI}$ data collection 199

Figure 7.3: Scheme of biogas slurry utilisation after slurry treatment.

Figure 7.4: Transported masses and transport distances per month [HARTMANN2006] 205 


\section{Introduction}

Energy supply is considered worldwide as one of the most important challenges of the future. This challenge has ecological and economical aspects that are affiliated with each other. Today, the energy sector together with the transport sector is the main driver of the greenhouse effect, causing global climate changes [WHO2005]. Additional effects such as resource depletion and acidification are caused by state of the art energy generation. In the future, due to our present level of energy consumption, it is predicted that there will be a $66 \%$ increase in the demand for worldwide energy by the year 2030 [IEA2005]. Even if there is not a shortage of fossil energy resources during the next decades, it is common sense that these resources are finite and therefore must be saved [TRINNAMAN2004].

Renewable energy sources are considered to be a solution to these problems. They are endless and regarded as environmentally friendly. Biomass, e.g. crops and biodegradable waste, is one kind of renewable energy source. Biogas production is one possibility to produce electricity and heat from this biomass. Within the biogas process, bacteria degrade carbonhydrogen compounds in an anaerobe atmosphere. Methane, carbon dioxide, some trace gases, and a nutrient rich slurry are produced by this biogas process. The originated methane can finally be used for heating, electricity generation or fuel production.

In recent years the development of the utilisation of renewable energies has been legally enforced in Germany due to the creation of various legal acts [EEG2000, EEG2004]. In the year 2002 biogas production increased due to the [EEG2000] and was boosted in 2004 by the revision of this law [BLFU2004, IER2004]. Since 2004, the technology and the inputs to the biogas process have changed. Biogas plants have become larger and have now reached industrial scale. Furthermore, the inputs are changing from slurry and waste to slurry and specially produced energy crops or solely energy crops. These changes influence all parts of the biogas process, from agricultural production of crops at the beginning of the process to the emissions from the biogas plant at the end of the process.

The utilisation of renewable energies aims at the protection of human health, nature and resources as stated above. However, like any other kind of energy generation, the biogas process has an effect on the environment. In order to permit further development of energy technologies, it is important to be aware of the quality and quantity of effects caused. Effects on the environment can be measured by various methods. The most developed method for this purpose is the life-cycle-assessment (LCA). Formerly developed to assess industrial production processes, it is nowadays improved for the assessment of different kinds of production systems. It is also the only method based on standards according to the International Standardisation Organisation. This grants comparability and transferability of the results of a LCA study to related subjects. 


\subsection{Research question}

Energy conversion plants, using renewable energy sources like biomass, are considered to be environmentally friendly by a broad public. The production and utilisation of biogas is one of these conversion technologies utilising renewable resources such as, manure, energy crops, and organic waste. Considerations of the environmental friendliness of renewable resources consuming processes are based firstly on the saving of fossil resources on the input side of the system and secondly on the emission of carbon dioxide $\left(\mathrm{CO}_{2}\right)$, which does not enhance the green house effect due to its renewable sources offspring on the output side of the process. The purpose of the Renewable Energy Sources Act amends these considerations by the protection of environment and nature, reduction of energy costs, incorporation of unspecific long-term effects, the avoiding of conflicts over fossil fuels, and the further promotion of renewable energies [EEG2004]. These are facts that have an important influence on the considerations of a future with sustainable development of the power industry. In this study, only environmental effects will be considered.

In this case, environmental friendliness is solely seen as a question of sustainability in the fields of fossil resources and climate. It is not considered that the production and transport of energy crops consumes mass and energy flows, uses land and produces emissions [cf. RODE ET AL.2005]. Moreover, manure and organic waste must be transported, leading to fuel consumption and emissions. The production and consumption of biogas leads to gaseous emissions, which threatens both humans and the environment. Mass and energy flows are caused by the construction and demolition of the biogas plant itself. Finally the biogas plant generates waste, which has to be disposed of. This disposal can cause positive and negative effects on the environment. In the assessment of the environmental effects of electricity generation from biogas produced by an industrial scale biogas plant, it is imperative to consider each individual effect. In calculating all of the effects only then can valid results be produced.

The first assessments of the ecological effects from the production of biogas were carried out by [EDELMANN ET AL.2001] for the Swiss Federal Office of Energy. This study considers small and technological simple biogas plants and presents the results as a life-cycle-assessment (LCA) to the public. The results of this study are based on agricultural biogas plants in Switzerland and therefore only ideas can be taken from this study, but effects based on this biogas technology cannot be taken into account. Furthermore, the production of energy crops, as strengthened by [EEG2004] in Germany, is not considered in this LCA. In contrast to these differences between the objects under investigation some important information on ecological hot spots from the biogas production are given by this study. The ammonia emissions from storage and application of biogas manure especially come to the fore of ecological effects from the biogas production. At the start of this study, the ammonia emissions are considered the most important part of the electricity generation from the investigated object and are therefore closely analysed. 
The ecological effects caused by up- and downstream processes related to the biogas plant are the objects of several studies within the fields of agriculture and soil science. These studies take into account the gaseous emissions from the biogas process itself, the storage, and the application of biogas manure. These studies also provide important information with regards to the fertilizing effects of biogas manure due to its nutrient content and its type of chemical bond. The existing studies show quite different results depending on the kind of input substrates to the biogas process, technology of the plant, meteorology, and the analytic methods used. None of the existing studies take into account the high energy content of state of the art crops found in most biogas plants which produce electricity according to the rules of the [EEG2004] and emissions from special biogas manure.

The object of several studies has been the treatment of manure to reduce emissions when distributed on fields. The treatment of biogas slurry has not yet been probed and it is uncertain if the results from slurry studies can be put into practice. Different biogas plants are using technologies to treat their slurry. This can lead to a reduction of climatic effective, acidic, and eutrophic emissions and therefore improves the environmental effects caused by biogas production.

The utilisation of waste from the biogas process, the biogas slurry, leads to a recycling process within the production system. The nutrients from the energy crops are included in the biogas process and there are transformed into biogas slurry. In this way, the nutrients are put back into the agricultural production system in their original form with the application of the biogas slurry on the fields. This is different to conventional energy production processes, where inputs are transformed to waste and afterwards disposed of. There is little information to be found in existing literature regarding the fertilizing effects from biogas slurry.

The first LCAs that the author had done in this field show the important influence of agriculture on the overall effects on the environment from the biogas process. As will be shown, the assessment of agricultural production systems is quite complicated and involves special requirements. [GEIER2000] stresses these special requirements, assessing the ecological effects of agricultural production systems. Special attention is paid to the inclusion of animals and plants into the production process, the potential ecological achievements, and the very high land-use factor, which distinguishes agricultural and industrial production systems. This leads to the conclusion that special impact categories should be created to aid the assessment of agricultural production systems, which take into account biodiversity, landscape, soil function, quality of groundwater and animal protection. 


\subsection{Objective}

The aim of this study is to acquire an answer to the question regarding the ecological effects of electricity generation from biogas generated by industrial scale biogas plants. The object under investigation will be a hypothetical biogas plant with an installed electric power of 1.0 MW, fed by biomass from energy crops and manure in accordance with the rules of the [EEG2004]. Mass and energy balances resulting from a life-cycle-assessment will determine the ecological effects. Data for the mass and energy balances will be taken from measured data from existing biogas plants, calculation from similar objects and estimations where no available data exists. The object under investigation is the biogas plant itself and up- and downstream processes related to the power plant. The scope of the data collection will be determined and adjusted within the LCA. Furthermore, all single unit processes will be defined in the life-cycle-assessment.

The upstream process of the biogas plant and the production of renewable energy crops will both be analysed in detail by considering all mass and energy flows going into this process, emissions from the area under cultivation, and the effects on biodiversity from land use. The ecological effects produced by the use of specially produced energy crops have yet to be considered as an objective of scientific studies. Moreover, the nutrient recycling process of the biogas slurry as an organic fertiliser as defined by [\$1 (2) DÜNGMG] and the effects on the ecological burden of the crop production have not been previously explored. A closed nutrient loop is only possible, if no nutrients are lost via evaporation or leaching. In this way crop production can be accomplished without the need of additional mineral fertilisers. The amount of nutrients put back into the fields could have a tremendous influence on the LCA results. Part of this study will examine to what extent this method of crop production can be realized.

The ecological effects produced by the utilisation of organic waste as input to the biogas process will also be assessed in this study. Even if the amount of useable organic waste is comparatively small in regards to the possible amount of energy crops, additional waste matter can be acquired regionally. The calculation of the organic waste does not take into account its ecological effects as they are solely related to the main product, and therefore the waste is calculated without any ecological burden. The processes needed for the activation of this waste e.g. transport and treatment will only be taken into account. Assessing this information permits an ecological consideration of different inputs of the biogas process.

The biogas plant is the procedural core of electricity generation in the biogas process. From related studies, it can be assumed that only small parts of the overall ecological effects are related to the plant [EDELMANN ET AL.2001]. Results from this existing study will be assessed in this investigation and adopted to industrial scale biogas plants. Process engineering, inputs, goal definition and transport will be researched in detail regarding industrial scale biogas plants. 
The transport efforts of in- and outputs of the biogas plant will be analysed, with special focus on their involved role in relation to the overall ecological effect. Additionally, the effects of some biogas slurry treatments will be investigated. From these results, extrapolations on the influence of the size of the biogas plant and the inputs and outputs of the transport efforts will be derived.

An analysis will be carried out in order to monitor the acidification and eutrophication from biogas slurry after its distribution in fields. In order to do this, data from literature and field trials will be taken as a base for estimations. Approximations can be given for some possible scenarios due to the large variety of existing influences on emissions from biogas slurry (e.g. inputs, speed of wind, soil type). The possibility of biogas manure treatment and its influence on the emission scenario will also be analysed. When assigning the results of this study to further or more detailed studies, the scientific background of these estimations will be shown explicitly.

Given that the biogas process generates electric and thermal energy, it is important to primarily understand the relation between energy used in the power plant itself and the production of the inputs and secondly the energy fed into the grid. This cumulative energy demand will be calculated for the system under investigation with the inclusion of all stages of the upand downstream unit process and will then be related to the energy produced. This will provide clear information concerning the energetic reasonability of the electricity generation from biogas.

The aim of this study is to obtain an overview of the ecological effects of electricity generation from biogas via industrial scale biogas plants. Suggestions for ecological improvements of the industrial scale biogas process will be made in light of the results gathered. 


\section{Materials and methods}

\subsection{Assessment methods}

The assessment of ecological effects started in the 70 s and 80 s of the last century. It was during this period that people became increasingly aware of the ecological risks of industrial production systems. A variety of methods have been developed for the assessment of ecological effects that could potentially be used in the case of electricity generation via biogas. With regards to the topic under investigation, two different kinds of production systems have to be taken into account. Firstly, there is a conventional industrial production system; the biogas plant. Secondly, there is the agricultural production of energy crops, which are used as a renewable energy source in the power plant (cf. GEIER2000, chapter 1.1). System assessment methods have been developed for both kinds of productions, which take into account the goal and scope of each system. A problem of these agricultural and industrial production systems is that they do not account for the same safeguard subjects and can therefore not be combined. Some existing assessment methods will be presented in the following paragraphs.

In all assessment methods mentioned, there are at least two steps involved. The first step is data collection from the system under investigation and the second is the analysis or assessment of the collected data. Where the first indicative step is based on natural science, the second normative step can include political and social values. The reliability of the results of the assessment can be increased by this normative step, while it gets easier to present and explain the outcome of the collected data. Assessment methods should therefore be clearly split into the indicative and the normative step, so that the basic data could be used for scientific assessment, while the results of the second step could be used in the presentation of the results to public and policy [cf. FÜRST\&SCHOLLES2001].

The assessment methods could be divided into two methodological and two system related groups. From the methodological point of view, purely indicative and mixed systems can be differentiated and systematic agricultural and industrial assessment methods can be distinguished. As stated above, only mixed systems that have clear defined indicative and normative parts will be included in this study. The following list will differ in industrial and agricultural assessment methods.

> Life-cycle-assessment (LCA), a product based environmental assessment method. This method takes into account all environmental effects of a product, including exploration of the resources, transport, manufacturing, emissions, and disposal (cradleto-grave). The environmental effects are clustered into impact categories, in which the collected data are correlated with each other. LCA is the most developed assessment tool for whole product systems. LCA provides background information for discussion within the expert public. They identify ecological needs and potential improvements in processes. Due to the flexibility of this method it can be applied to all types of production sectors, i.e. agriculture and forestry, industry, and service. 
This method can be amended by economical and social parameters, leading to the product-line-analysis (dt. Produktlinienanalyse).

> Environmental (Impact) Assessment (EIA) is carried out in order to forecast the ecological effects resulting from larger measurements e.g. building of industrial complexes. Specialists and the public contribute to the inputs and the results of the assessment. The requirement for EIA is derived from the European Directive 85/33/EEC (as amended by 97/11/EC). The procedure requires the developer to compile an Environmental Statement (ES), which describes the likely significant effects of the development on the environment and proposed mitigation measures. The ES must be circulated to statutory consultation officials and made available to the public for comment [ODPM2006]. EIA is not practiced in order to gain comparisons between two or more alternatives; therefore no statistical elements are included in this assessment method.

$>$ Risk analysis was first used in the ecological assessment of the proposed application of natural resources in a large scope planning perspective. From this point, it was developed as part of EIA and is now viewed as a standard method for assessing effects to the environment during the planning phase. The goal of environmental risk analysis is the assessment of ecological compatibility with uncertain data given [SCHOLLES2001]. The intensity of a measure, measure sensibility, and the risk of impairment are taken into account for the assessment.

$>$ Kriterien umweltverträglicher Landbewirtschaftung (KUL, engl. "criteria for an environmentally compatible agriculture"), a method using 20 criteria to describe the "... environmental state and sustainability of different farm enterprises and land farm operations" [ECKERT ET AL.1999]. With this method, significant risk potentials are identified and ranges for their tolerability are set. It is a method to assess single subjects in detail, taking into account regional data. A self-control ecological effects mechanism is given to the farmers with this method, helping them to assess and document the ecological effects of their production system [ROEDENBECK2004]. It has two basic principles: (1) agricultural soil must be saved, and (2) agricultural production must not severely harm other functions of the ground, e.g. biotope or regulation, [SCHREINER ET AL.2001]. In addition to this, air, landscape, diverse energy and $\mathrm{CO}_{2}$-balances are also taken into account. Data for best, acceptable and unacceptable levels within the 20 criteria are given [TLL2005]. This method places agricultural production first, followed by environmental aspects, as shown in the following statement: "An environmentally sound and sustainable agriculture is defined as ... farming which uses ... resources as efficiently as possible, but ... keeps undesirable impacts on soils, water, air and biota within acceptable limits" [ECKERT ET AL.1999]. This method shows that farming intensity is not generally responsible for the extent of adverse effects. It must be acknowledged that the KUL method only deals with agricultural impact categories. The limitation to single farm data avoids general information on special production systems. 
$>$ REPRO, a tool for analysis and assessment of mass and energy flows in relation to farm structure, farming intensity and processes for single farm assessment. Within this method, it is assumed that a system's material and energy flows threaten the environment and therefore represent significant assessment indicators. REPRO aims at the assurance of a sustainable agriculture with close-loop production systems, low consumption of mineral and fossil resources, and that has a generally low impact on the environment. The assessment shall be done with as little as possible indicators [ROEDENBECK2004]. Therefore only material and energy flows are assessed at farm level. The assessment methods are derived from regional long-term field trials, calculations and on-farm material flow assessments for each object under investigation. Furthermore, it is assumed that materials on the farm are in loop processes. REPRO includes humus, nutrient, fodder, and energy balances [DUBSKY ET AL.1997, HÜLSBERGEN\&DIEPENBROCK1997]. Therefore, REPRO is also viewed as a specialised tool for single farm assessments. The results of these assessments can hardly be compared with results from other assessments, due to the on-farm level method.

While the methods KUL and REPRO were designed to assess ecological effects caused by agricultural production processes at an on farm level, LCA and risk-analysis were designed to deliver information to politics and assist scientific processes [WAHMHOFF1997]. Only three of the methods, environmental impact assessment, risk analysis, and life-cycle-assessment could be used independent from site and produce holistic ecological results. Only these methods can give general and holistic information about the ecological effects related to a product [KALTSCHMITT\&REINHARDT1997]. While EIA is carried out in order to assess single measures, which have a high probability of effecting the environment, it cannot be used for comparisons between different objects. Another factor to take into consideration is that the reproducibility of the results gained by this method is limited due to a lack of statistical modules. Ecological risk analysis suffers from the same problems as EIA. The possibility of reproducing the results of the assessment is reduced by the use of uncertain data and estimations without a defined standard methodology to handle data quality. Some assessment methods mentioned such as KUL and REPRO are specially designed for agricultural production systems. They would not be able not be used in assessing the industrial part of this LCA due to their specialisation in agricultural farming systems

During the last years LCA has been to be the most flexible instrument when assessing ecological effects. The development of the LCA method was given the most support in relation to other approaches and therefore today LCA is the most comprehensive ecological assessment method [GEIER2000], e.g. in contrast to other methods LCA includes direct and indirect ecological effects [ARMAN2004, MOERSCHNER\&LÜCKE2000]. In this case, indirect ecological effects include effects that are related to upstream processes of the process under investigation, while direct effects are directly related to the object under investigation. Balances of a more specialised nature, specifically used in assessing agricultural production systems, e.g. energy b., resource b., emission b., nutrient b., mass flow b., could be included in the LCA method [cf. MORSCHNER2000]. This permits the analysis of the ecological effects of the system under investigation from a holistic perspective, "wherever and whenever these impacts 
have occurred, or will occur" [GUINĖE2001]. The ecological assessments of agricultural production systems by [MORSCHNER2000, BRENTRUP2003] show that LCA could not only be used in industrial but agricultural production systems, too. The recently created definition of international standards has helped in making the results of a single LCA appear understandable and comparable all over the world.

\subsection{LCA method}

Life-cycle-assessment starts with the definition of goal and scope of the LCA study. At this stage, the goal of the study is defined and in addition, all energy and material flows that are to be taken into account are defined. The definitions have to be thoroughly explained and must be consistent with the intended application. In addition to this, the object under investigation must be defined and described, and also the time when the investigation takes place. Data quality is defined by time, place, technology, and registration method, e.g. measured data or calculated data. Finally, impact categories and functional unit are stated. With these definitions complete, the frame of a LCA study is made. The goal and scope definition phase is stated in detail in the chapters one to five of the EN ISO 14040 [CEN1998].

The second step involves the construction of the inventory analysis, a systematic inventory of all energy and material flows, and emissions connected to the object under investigation during its entire life cycle. All data related to this constructed model are measured, calculated or estimated in regard of the data quality requirements defined in the goal and scope definition phase. As far as possible, data of single steps from the overall investigated process are collected in unit processes, which are small logical parts of the whole process, e.g. transport or storage. The result of this inventory is a list of emissions, consumed resources, and nonmaterial impacts e.g. land-use. This table is termed the inventory result and defined in chapter six of EN ISO 14040 [CEN1998]. Additionally, chapter seven of EN ISO 14040 describes the basic rules for interpreting the inventory result. These rules are concerned with the meeting of the defined goal and scope definition, data quality assessment, and an assessment of uncertainty of results. It is important to realise that this interpretation does not include ecological effects or impact categories, but merely includes the framework of the LCA and data inventory. [KALTSCHMITT\&REINHARDT1997] call the inventory analysis the heart of a LCA. This name is given, due to the fact that all basic data for further calculations are collected at this step. These data are directly related to the object under investigation; any further findings are results of natural and social sciences based calculations and therefore only indirectly related to the object under investigation.

Following the guidelines of the inventory analysis of this study, an impact assessment is carried out. As stated above, this step leads to results that are indirectly related to the object under investigation and can therefore lead to different interpretations of the basic data. Even so, this impact assessment is carried out as inventory tables are often lengthy and difficult to interpret. So it is therefore logical to group the results of the inventory table into impact categories ("classification" cf. chapter 2.7.1). Impact categories combine material and energy flows leading to the same kind of impact e.g. greenhouse effect, ozone layer depletion, acidi- 
fication, etc. A characterisation is done in order to calculate the influence of these different kinds of impacts to the same impact category, for example, sulphur dioxide and ammonia would both be counted for as acidification. This step aggregates the influence of each impact by a characterisation factor, which reflects an equivalent of an impact related to a basic value for each category [CEN200a]. This is the last step in LCA based on natural science methods. In the next step ("weighting" procedure) social science related methods are incorporated.

Finally, a normalisation step is be added, which includes grouping and weighting of the impact category results. Grouping is a step to sort and rank the impact categories, while weighting uses numerical factors to convert and aggregate indicator results across impact categories [CEN2000a]. How these impact categories have to be weighted is less obvious. Two kinds of assessment methods are discussed by experts. On the one hand there are discussion methods, giving information for each impact category, which are not comparable with each other. On the other hand aggregation methods are used resulting in an overall score for the ecological effects. Aggregation methods and their single score results make it easy to compare the results of different LCAs or sensitivity analysis. The methods for calculating this overall score are based on social science methods. For this reason, it is often the case that the result of a LCA study lacks clarity in its interpretation. A wide variety of weighting methods are used for assessing LCA results, however, for the purpose of this study, the Eco indicator '99 method of [GOEDKOOP\&SPRIENSMA2001] is applied. For detailed information about this method confer to chapter 2.7 .

The following figure gives a simple overview of the LCA steps and the relation between each one. The arrows between the single steps indicate that the process of a LCA study is an iterative act. There is a set sequence to the steps, but there is always the prospect of returning to an earlier step and changing parameters or adding information if required. Even if the impact assessment is completed, it is mandatory to go back to the goal and scope definition in order to verify that the results fulfil the requirements of the goal definition and whether any correction of the scope is needed. Finally, the LCA study is repeated several times until the goal of the study is reached.

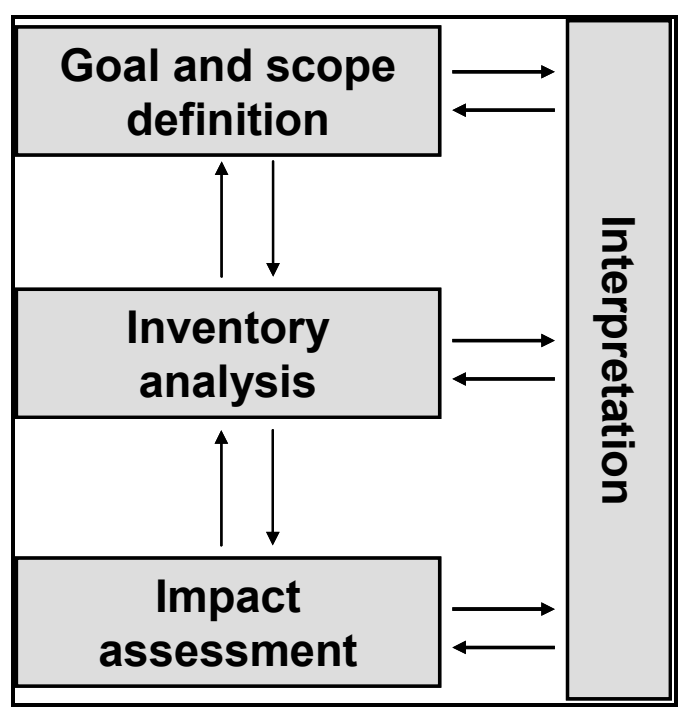

Figure 2.1: Phases of an LCA [CEN1997] 


\subsection{Goal and scope}

\subsubsection{Goal}

Today, hardly any information exists relating to the ecological effects from large biogas plants, as they have been built since the establishment of the [EEG2004]. Therefore, the main aim of this study is to give a summary of the environmental effects caused by the electricity generation from biogas in industrial scale biogas plants. Within this study, sensitivity analysis, e.g. inputs or conversion methods, are done to demonstrate the influence of different unit processes of the object under analysis. The differing results of the sensitivity analysis are comparable and allow the creation of environmental friendly alternatives of the production system. The results of this analysis could also be compared to other electricity generation processes, but only from an informative point of view. Differing goal and scope definitions make it impossible to compare results gained in different studies with different objects.

Secondary goals can be derived from this primary goal. Public relation work within all levels of biogas industry can be improved with the results of this study. Based on the results of this study, ecological improvements in the biogas process can be made. Taking into account the results of the assessment of unit processes, improvements can be progressively made, starting from the greatest threats. The assessment method developed in this study can be used as a guideline for the evaluation of biogas plants, especially in the planning phase. This helps to avoid menaces to the environment from an early stage. The primary results can also be used for public administration authorities or funds. In the future it will be possible to connect funds to special environmentally friendly procedures related to the biogas production, such as special energy crop production systems or manure treatment processes.

This study is addressed to the expert public in the field of biogas. This includes scientists, plant developers, licensing authorities, and politicians. The knowledge about the ecological effects from biogas shall be communicated to this audience in order to help improve the ecological effects produced by electricity generation using biogas produced in large biogas plants.

\subsubsection{Scope}

In this section, the methodological background of life-cycle-assessment is presented according to the rules of ISO 14040 concerning definition and selection of relevant parameters. The scope of this study is defined according to the specifications of this standard. This means that the scope has to be defined in enough detail to assure that quality, quantity, and details are consistent and adequate to the goal defined. Due to the iterative character of LCA studies it is possible to adapt the scope of the study. This can be essential due to the availability of new information, which can help obtain further detailed results in this study.

This iterative aspect makes it possible to change parameters after the first scope definition. Following iterations can therefore be done with an adapted scope. Data collection and assessment of a LCA are therefore seen as a dynamic process. 


\section{Functional unit and reference unit}

According to the definition of ISO 14040 the functional unit is "...a measure of the performance of the functional outputs of the product system" [CEN1997]. All material and energy flows and all effects resulting from these flows are related to the functional unit. This makes the functional unit a base for all comparisons between sensitivity analysis and different objects under investigation within the same functional unit. Relating all data to one functional unit makes the results of different studies comparable. The ISO 14040 standards demand that functional units are clearly defined, measurable, and relevant to input and output processes [SETAC1993, CEN1997].

The functional unit influences the results of a LCA study in a wider level. The results of comparative LCA studies can vary depending on the functional unit. So, a system can be favourable according to the reference unit. It can become disadvantageous, if the reference unit is changed. This will be shown in the following example:

Research on the ecological effects of extensive cultivation of corn and rape show the possible influence of the selected functional unit on the results of the study [GAILLARD\&NEMECEK2002]. In this study, data from the inventory analysis are related to the functional units' area and mass. This work area means an area needed for the production of the crops, while mass connotes the mass of corn produced within the investigated system. It is shown that extensive crop production systems have a lower input of fossil resources related to the functional unit area. Therefore, extensive systems could be regarded as more environmentally sound than conventional systems. In relation to the mass of produced corn, intensive production systems consume less fossil resources. This depends on the fact, that intensive production systems need more fossil resources due to their higher demand of mineral fertilisers, and fuels per area unit but also the productivity per area unit is increased disproportionately.

This example shows that the functional unit selected has to be in accordance to the goal definition of the performed LCA study. In some LCA studies it can be helpful to use several functional units. If this is the case it must be explained in detail. For the given example, the goal definition has to clarify, if the comparison between the production of crops or the cultivation of land is the object of the study.

In this LCA, which deals with electricity generation from biogas produced in industrial scale biogas plants, electricity as a chief product in addition to thermal energy and biogas slurry as by-products is generated. As the biogas production aims at the generation of electric energy only this alone will be seen as the function of biogas production. A further study could question the fact that thermal energy could be a probable function if biogas plants are built to produce thermal energy for heating or industrial processes and the produced electricity is just a by-product. The possibility of producing biogas as an input to the natural gas grid could lead to the function of natural gas equivalents. The function for this LCA study will be therefore be defined as following:

The function of the system under investigation is the generation of electric energy fed in the public electricity network. 
The function of the system under analysis must be quantified to be comparable within different systems. It therefore has to be to be accountable and clearly defined. A function calculated in this way is called a functional unit. For the purpose of this study, the functional unit of electric energy produced by the biogas plant is defined as:

The functional unit is one terajoule electricity fed into the public electricity network.

According to the definition of the functional unit, the number of product units needed in order to fulfil the requirements of the functional unit, the so called reference flow, is determined. As product and functional unit of the system under analysis are the same and measured as terajoule of electric energy, the reference flow is defined as following:

\section{The reference flow is one terajoule electricity fed to the public electricity network by the combined heat and power plant.}

Due to few feed losses the assumption is made that reference flow and functional unit are of the same quantity. This applies that reference flow equals functional unit.

Addendum: one terajoule equals $277,778 \mathrm{kWh}$

\section{System boundary}

The definition of system boundaries determines which modules have to be part of the LCA. Various factors, such as time, money, and determinability of data influence the system boundaries. Ideally the system under investigation is defined in such a way that input and output flows are elementary flows at the point of the system boundaries. The modules which shall be included and which data quality should be obtained for each module of the LCA will be determined. Equally, each output flow has to be determined.

The production of chief products and by-products within the investigated system can lead to problems in boundary definition. The system boundaries have to be designed including all processes, depending on the number and kind of products. This can lead to large life-cycleinventories, which cannot be dealt with. On the one hand biogas is produced, which is later converted to electricity and heat. On the other hand biogas slurry is produced, which is used as an organic fertiliser for crop production. This problem can be solved by classification of impacts according to the price of the different products. If no price can be obtained for a byproduct, or even money has to be spent on its disposal, all effects of the by-product are assigned to the chief product. It has to be said that normally, biogas slurry cannot be sold. This approach therefore leads to the assumption that the definition of system boundaries should be geared at the chief product [HOCHFELD\&JENSEIT1998].

Furthermore, material and energy flows, as well as related emissions to the environment have to be allocated to each single product, if there are several products, by properly defined methods. This is especially so in the case of recycling processes. This allocation has to be done with prudence, according to ISO 14041 [CEN2001]. A recycling case dealt with in this study is the utilisation of biogas slurry as an organic fertiliser for the production of energy crops, which are produced as feed into the biogas plant. 
Regarding the specific parameters of the system under investigation, i.e. electricity production according to the rules of the [EEG2004], no contribution of thermal energy, and recycling of biogas slurry. This means that all effects on the environment are related to the electricity generation.

According to the definition of system boundaries of the system under analysis, the following will be taken into account:

$>$ All energy crop inputs to the biogas plant shall be analysed completely. This is done by calculations and operating journals of existing biogas plants. All energy crops associated to upstream processes are calculated using the input data. This includes all material and energy flows related to the crop production.

$>$ Inclusion relevance is set to $1.0 \%$ for all modules. This means, masses smaller than $1.0 \%$ of the total mass of each module, or energy and material flows meaning less than $1.0 \%$ of the ecological effects of a module do not need to be recorded in the lifecycle-inventory. With this, the ecological effect is calculated depending on Eco indicator '99 approach (cf. chapter 2.8).

$>$ With regards to the application of the biogas slurry, the nutrients nitrogen, phosphorus, and potassium in the slurry as well as the gaseous emissions, i.e. carbon dioxide, laughing gas, and ammonia are all documented. All expenditures concerning machinery and related upstream processes are also documented.

\section{Data quality requirements}

In this section, the determinations of data quality requirements are given. In order to fulfil these requirements data quality indicators (DQI) are defined. DQI appoint which data are meeting the specifications of the scope definition and will therefore be seen as valid data. These indicators set presets for data that should be taken into account. The definitions given in Table 2.1 are done according to LCA software Sima Pro 7.0.0 (cf. chapter 2.9) for the parameters: time, geography, type, allocation, and so called system boundaries. Detailed information about data quality resulting from these indicators is given in chapter 2.5 . No formal standard has yet been developed for data quality indicators, but the system used in Sima Pro is a result of the requirements mentioned in ISO 14041 [SIMAPRO2006]. 
Table 2.1: Data quality requirements

\begin{tabular}{|c|c|}
\hline Data quality indicator & parameter \\
\hline time periods & 2000-2004, 1995-1999 \\
\hline geography & mixed data, Western Europe \\
\hline type of technology & average, modern, and best available technology \\
\hline $\begin{array}{l}\text { type of representative- } \\
\text { ness }\end{array}$ & $\begin{array}{l}\text { mixed data, data from a specific process or company, average } \\
\text { from a specific process, average from process with similar out- } \\
\text { puts, average of all suppliers, theoretical calculation, data based } \\
\text { on input/output tables, estimations }\end{array}$ \\
\hline multiple output allocation & not applicable \\
\hline Substitution allocation & actual substitution, substitution by similar processes \\
\hline $\begin{array}{l}\text { waste treatment alloca- } \\
\text { tion }\end{array}$ & $\begin{array}{l}\text { close loop assumption, full substitution by similar or different } \\
\text { processes, partial substitution with physical basis for cut-off }\end{array}$ \\
\hline system boundaries & material and energy flows including operations \\
\hline cut-off rules & less than $1.0 \%$ physical, less than $1.0 \%$ ecological relevance \\
\hline boundary with nature & agricultural production is part of the production system \\
\hline
\end{tabular}

As can be seen in Table 2.1 narrow confines are drawn between the indicators time, geography and technology concerning data collection. Narrow confines for these indicators can be drawn according to measurable data from existing plants. This is traceable according to the data collection protocol regarding the indicators time and geography. Geographic relation does not play an important role in the case of building materials for the biogas plant, as steel and concrete are produced with similar technologies all around Europe. For this type of data, European or mixed data will be taken into account. With regards to the production of energy crops climatic influences and national laws influence data collection. These data therefore depend on their regional provenance. Therefore it is decided that only data of crops produced in Germany should be taken into account. The author clearly states that there are different climatic areas influencing the arable production within these borders, however further limitations would alarmingly decrease the available data.

In reference to indicator technology, expert knowledge is needed in the field of biogas technology. This knowledge shows that in ecological terms there is no connoting technological differences between biogas plants built in the last decade [HARTMANN\&NELLES2006]. Only if data matching the DQI are unavailable, other data which meet the criteria to be according to the state-of-the-art are accepted. These confined barriers must be enlarged for the representing indicator to give a comprehensive overview. The modules transport and utilisation of biogas slurry especially depend on the use of general data and average values in order to apply measured data on a large scale.

The defined cut-off rules instruct that data contributing to more than one percent of mass per module have to be collected. Furthermore, all data contributing to more than one percent of ecological effects within each module have to be acknowledged. Data below these cut-off rules can also be taken into account if on-hand. Cut-off rules are therefore minimum specifications. 
An allocation of ecological effects is not done, as only one product from the object under analysis is taken into account. If by-products, e.g. heat and biogas slurry, were be taken into account, the ecological effects would have to be allocated to all of these products. The recycling of nutrients from biogas slurry used as organic fertiliser leads to substitutions of mineral fertilisers. Recycling is also done in the form of disposal and utilisation of construction waste from the biogas plant. So, metallic waste is counted as substitutes for metal ores in production processes.

Due to problems in collecting valid data within the field of emissions and the utilisation of biogas slurry, the DQI parameters were set as far as possible without affecting the validity of the overall result. This allows, at all levels of the LCA process, flexible adaptations of changes in data availability.

The definition of DQI parameters for the system boundaries permits the collection of mass flows, in addition to energy flows and radiation, which are second order system boundaries. Third order objects such as capital goods are not taken into account, as they are of no relevance to this study. Additional system boundaries, using agricultural production, are caused by the up-stream production systems of the biogas plant. A boundary definition is essential due to the great contribution of the agricultural production system on the overall ecological effects.

\section{Comparison between systems}

Explicit approvals of the same functional unit have to be given if comparisons are to be drawn between production systems. Moreover, equivalent methods and parameters have to be used for performance, system boundaries, data quality, allocation, and assessment rules of inputs and outputs. If additional functions are part of one of the compared systems and are not taken into account when comparing the functions of the systems under investigation, then this elision must be documented.

During this study, comparisons are drawn between different energy crops, conversion technologies, plant sizes, and slurry treatments. For this, all modules except the modules under investigation are kept 'ceteris paribus'. During these assessments, differences in the function of the systems under investigation or the functional unit can be avoided. Comparisons between these systems are therefore feasible. Comparisons with other energy conversions systems, especially those which consume fossil resources, are not totally comparable due to different system boundaries and functions of the production systems. If the agricultural production of energy crops were not factored, it would become more comparable to fossil energy production systems. As will be seen in chapter 2.7.1 agricultural production systems are quite complicated when dealt with in LCA studies. Even if there was no energy crop production for biogas plants, agricultural production would still exist, causing effects on the environment, while effects from the exploitation of fossil resources are directly related to the energy production. 


\section{Critical review process}

On completion of a LCA study, a critical review can be done. It shall ensure that: the ISO standards are fulfilled, goal and scope are kept, methods used are scientifically valid, and the report is transparent and consistent. If a LCA study is be reviewed, then this must already be specified within the goal and scope definition (see above). The critical review shall show which methods were used for reviewing, and the reasons for why the review was done. Furthermore, it is to be noted that the peers shall be named.

In most cases, the critical review is a voluntary process, in which internal or external experts, as well as interested parties assess the quality of a LCA study. This review improves the credibility and the understanding of a LCA study. According to ISO 14040 and 14043, LCA studies, which shall be published and include comparisons between different production systems, must be peer reviewed by interested parties [CEN1997, CEN2000b]. Even if a study is examined by a critical review, this does not imply an endorsement of any comparative assertion based on this study [CEN1997]. As this study is done in the form of a PhD-thesis and not primarily done to support a comparative assertion, the critical review process is completed by the PhD supervisors as internal and external experts.

\section{Data categories}

Input and output flows of each module are defined quantitatively using data, which are measured, calculated or estimated. Most data belong to one of the following main data categories [CEN1997]:

$>$ energy inputs, raw material inputs, supply inputs, and other physical inputs,

$>$ products, and

$>$ emissions to air, water, and land as well as other environmental aspects.

Within each main data category, more detailed categories can be defined. For example, in the category, emissions to air carbon monoxide, carbon dioxide, and sulphurous oxide are collected. These more detailed categories help to identify the influence of each single substance to the overall ecological effect.

\section{Collection of input and output data}

A pre-selection of input and output flows for the first life-cycle-inventory is stated in the definition of the scope. Typically, the first data collected are limited to input data, given that most emission flows are related to the input flows. With this data set a first LCA study is done, showing the relevance of the data taken into account. This data set is adapted to these first results due to the iterative character of LCA studies. When considering adaptation, irrelevant data are singled out, while the most relevant data are assessed in detail. This process aims at the collection of solely relevant inputs and outputs of each module. Once the collection of data has been accomplished, data quality indicators are used to assess the relevance of input and output flows. Data quality indicators are explained above (cf. chapter 2.5). 


\subsection{Object under investigation}

This chapter is dedicated to the description of the object under analysis, i.e. an industrial scale biogas plant and it's related up and down stream processes. Within this description, functional interrelations and relevant parameters are explained. Theses descriptions define the scope from which data for the life-cycle-inventory are collected. In various modules, parts, if considered to be of subordinate importance, are explained in a brief manner. There is therefore no appraisement regarding the importance of single unit processes within the total biogas process in the description given below. Detailed information on calculated mass and energy flows is given in the live-cycle-inventory (cf. chapter 2.6).

\subsubsection{Inputs}

All substances brought into the fermenter of the biogas plant as raw material of the biogas production are ranked among inputs. The ecological effects resulting from the pure and combined usage of energy crops, specially produced for this purpose, in addition to other renewable resources, i.e. manure from livestock husbandry or biodegradable waste, are assessed within this chapter (cf. Figure 7.1).

The module inputs consist of two kinds of materials. The first group is made up by manure from livestock husbandry of cows and pigs and biodegradable waste from starch production. These materials are biodegradable waste from production processes aimed at products for the food sector. These materials are calculated without ecological effects from related upstream processes owing to their waste character. In production processes, ecological effects are allocated to chief products and probable by-products; waste is not charged with any ecological burden (cf. chapter 2.5.3).

The second group is made up of energy crops that are specially produced in agricultural production systems as renewable resources for biogas production. Taken into account are input and output processes of ecological relevance from the crop production, raw materials and supplies, waste, sewage and emissions from the production itself and upstream processes. In addition, machinery use within the arable production is calculated with all related upstream processes and the utilisation itself.

Within the field of crop production an open loop process occurs, when using the biogas slurry, which partly consists of energy crops, as an organic fertiliser [§ 1 (2a) DüMG] for crop production. The special ecological effects from this recycling process e.g. nitrate leaching or emissions are regarded in chapter 2.6.5. In the production of energy crops, ecological savings can occur by the use of nutrients in the biogas slurry, leading to an expected reduction of mineral fertiliser efforts.

Additional precipitation and drinking water are calculated as inputs. Precipitation from sealed surfaces of the biogas plant and additional drinking water are fed to the biogas vessels, if the dry matter content in the vessels reduces the performance of the biogas process. When feeding high amounts of energy crops additional water is especially needed in order to stabilise the process. Run-off rain water is collected in the plant's sewage system and transported 
to the preparation vessel, where it is mixed in with the organic inputs. As water does not contain any hydrocarbons, it does directly not contribute to the biogas production. However it does increase the throughput and the size of the plant's vessels and processes and finally the mass of biogas slurry that must be transported and recycled.

\subsubsection{Transport}

Existing LCA studies on farm biogas plants do not take into account the ecological efforts of transport, given that only manure and biodegradable waste from the farm itself are calculated as inputs [EDELMANN ET AL.2001]. The assessment of ecological relevant effects from transport processes of energy crops, biodegradable waste from the food industry, manure, and biogas slurry therefore take an important stand. It is expected that the size and performance of the object under investigation will cause logistical efforts, which are related to relevant effects to the environment. The amount of logistic efforts needed cannot be estimated validly, so that data from existing plants will be measured.

The amount of logistics needed depends on several influences. First of all, the amount of inputs influences the delivery efforts. This means, substrates with a higher energy content, e.g. silage maize instead of manure, cause less transport per functional unit. Also the efficiency of the conversion process influences the amount of inputs needed to generate one functional unit, causing varying input and output flows.

Different methods of slurry treatment, especially separation of solid and liquid phases of the slurry followed by a return of the liquid phase to the biogas vessel, reduce the amount of transports needed for biogas slurry up to $62 \%$. This can be seen in the calculation (equation (1)) of a special biogas slurry facility [HEIDLER2002]. This will be object of a sensitivity analysis.

solid / liquid separation:

$$
\begin{aligned}
m_{\text {tot }} \times C_{D M, \text { tot }} \rightarrow & m_{D M, \text { solid phase }} \times C_{D M, \text { solid phase }} \\
& m_{D M, \text { liquid phase }} \times C_{D M, \text { liquid phase }} \\
1.0 \mathrm{Mg}, 6 \% \mathrm{DM}(60 \mathrm{~kg}) \rightarrow & 171.4 \mathrm{~kg}, 28 \% \mathrm{DM}(48.0 \mathrm{~kg}) \\
& 828.6 \mathrm{~kg}, 1,5 \% \mathrm{DM}(12.0 \mathrm{~kg}) \\
m_{\text {liquid phase }} \rightarrow & m_{\text {condensate }}+m_{\text {concentrate }} \times C_{D M, \text { concentrate phase }} \\
& 828.6 \mathrm{~kg} \stackrel{\text { evaporation }}{\longrightarrow} 621.5 \mathrm{~kg} \\
& 207.2 \mathrm{~kg}, 5,8 \% \mathrm{DM}(12.0 \mathrm{~kg}) \\
m_{\text {solids }}+m_{\text {concentrate }} \rightarrow & m_{\text {biogas slurry for transport }} \\
171.4 \mathrm{~kg}+207.2 \mathrm{~kg} \rightarrow & 378.6 \mathrm{~kg}
\end{aligned}
$$

Finally, the energy performance of the plant affects the transport efforts. Larger plants create more total transport; however related to the functional unit, larger plants cause less logistical efforts. This is quite different in the case of energy crops, which are produced around the plant. In this case the area under cultivation is increased by a factor related to the circular area. The average transport distance depends on the radius of the circular. So, the area un- 
der the crops grows faster than the average transport distance. This can be seen below in equation $(2)+(3)$ :

circular area $: A_{\text {circular }}=r^{2} \pi=\frac{d^{2} \pi}{4}$ cirular area / radius $: \frac{r^{2} \pi}{r}$

Depending on the functional unit used, the potential area under crops grows faster than the average transport distance (factor $r \times \pi$ ). Additionally, a factor for the proportion of arable area in the area under investigation has to be added in order to obtain data on the available agricultural area, which can be used for crop production. This consideration leads to the point that large biogas plants in comparison to smaller plants cause comparatively less environmental effects resulting from logistical efforts. Sensitivity analysis will prove this.

\subsubsection{Biogas plant}

A biogas plant consists of various biological, procedural, and energy conversion steps. The main item is the biogas vessel. Herein hydrocarbons are degraded into methane, carbon dioxide, trace gases, and biogas slurry by anaerobic bacteria. There are installations for mixing and heating its contents inside the vessel. Typically, combined heat and power plants (CHP) are attached to this vessel. In these CHP, biogas is converted into electric and thermal energy. Subsidiary installations e.g. pipes, pumps, hygiene installations, storages, gasconditioning facilities etc. are required to operate the plant. The majority of biogas plants are unique in form, so therefore a general example of a typical plant cannot be given. One possible construction is shown in Figure 7.2. More examples of possible biogas plant configurations can be found in some recently published studies [FNR2004, FNR2005].

Within the biogas plant module, the relevant material and energy flows are detected for the building and operation of the plant. Material flows, land-use connected to the plant building, as well as emissions from the CHP plant and waste from plant operation are calculated. First assessments of the electricity generation from biogas show that emissions from the CHP plants cause a great part of the ecological effects of this module. The electricity generating processes will therefore be taken into account in detail, using a separate sensitivity analysis. In addition, data are collected on emissions, waste, and sewage related to the demolishing of the plant.

As energy flows, the consumption of electric and thermal energy is considered. Different processes within varying plant operations can cause differences in the respective energy consumptions. Furthermore, the dependency on energy consuming processes of the plant and energy consuming processes in the following transport and utilisation processes of the biogas slurry will be analysed (cf. Figure 7.2).

General experiences from industrial economics show that the output of the plant is disproportional to its size. With regards to the object under analysis, this leads to the assumption that the influence of the ecological building efforts of the plant when related to the functional unit 
becomes less important with increasing size. Influences on the ecological effects related to the size of the plant are not expected given that the emissions from plant operations are more or less directly related to plant size and the amount of throughput. The kind of CHP plant influences conversion efficiency and gaseous emissions and is expected to influence the ecological effects and consequently the ecological effects per functional unit.

\subsubsection{Utilisation of biogas slurry}

The fourth module considers the ecological effects from the liquid and solid outputs of the biogas process. Gaseous and energy outputs of the process are already considered within the biogas plant module. These outputs are organic fertilisers according to legal terms of [§1 (2) DüNGMG]. The biogas slurry is therefore used in the same way as conventional organic fertilisers, i.e. manure from livestock husbandry, and can be applied with existing machinery.

The question of evaporation and leaching of nutrients from organic fertilisers is an important threat to the environment, especially from biogas slurry [EDELMANN ET AL.2001]. This is caused by higher contents of mineralised nitrogen and higher $\mathrm{pH}$-values in biogas slurry in respect to conventional manure, as will be explained in further detail in chapter 2.6.5. Due to the unknown influence of slurry treatment on nutrient composition and on other physical and chemical aspects of biogas slurry it has been selected as an integral part of this study. Initial studies investigating the treatment of biogas slurry show that the nutrient composition is changed [WEILAND2003, WEILAND2004]. These results consolidate the assumption that the treatment process also influences the nutrient losses from this organic fertiliser.

An additional contentious issue is the question of nutrient recycling. Recycling takes place, when the nutrients included in the energy crops and converted through the biogas process into the biogas slurry are returned to the agricultural production system and used as a surrogate for mineral fertilisers. The kind of allocation process used in this case has to account for the possible occurrence of the aforementioned nutrient losses. This nutrient recycling process can influence the ecological effects related to the energy crop production for use in biogas plants by saving mineral fertilisers. Mineral fertilisers are assumed to have an important influence on the environmental effects of crop production (cf. chapter 2.6.1). Additionally, storage of slurry from the biogas process causes gaseous emissions that can considerably influence the overall ecological effects from biogas production [EDELMANN ET AL.2001]. These gaseous emissions lead to the loss of nutrients as well as acidification and eutrophication. Herein, different kinds of storage facilities have to be considered. While open vessels dominated the slurry storage technology in the past, covered vessels used for storage and gas production vessels prevail at present. The slurry application process also has an effect on the emissions. Several methods have been tested in the past (cf. chapter 2.6.5) displaying differences, which are alleged to be increased by the physical and chemical content of biogas slurry. The expected emissions in this study will be related to technologies, which fulfil the requirements of good agricultural practice. The data quality indicator defined for technologies must also be taken into account (cf. chapter 2.3.2). This therefore means that several methods will be excluded from this study. 


\subsection{Data quality}

\subsubsection{Data collection}

Data quality requires that data collected in the $\mathrm{LCl}$ are: precise, complete, and deviate systematic as little as possible. These quality parameters shall be explained in the definition of data quality indicators (DQI), which are valid for all data sets collected in the LCI. These LCI make the quality of data measurable [CEN1998]. Detailed information on DQI is given in chapter 2.3.2.

Comparing the data used and related data from comparable fields of work will attain precise data. This comparison helps to set data into a broader thematic scope. With this broader scope misleading data sets can be detected at an early stage. A general plausibility check of all data taken into account is done.

Systematic deviance is an effect caused by the kind of data collection and data processing, which can lead to errors in calculation processes based on these data. Following the $1 \%$ criterion of DQI can minimize mistakes in data collection. Furthermore, the definition of the system under analysis and the iterations of the LCA stages help to eliminate systematic deviances. The calculation of systematic deviances in LCA is a rather novel and complicated method. Several methods, especially Monte Carlo Analysis, were developed for this problem [CIRCOTH2001]. Due to the general approach of this LCA study and the partial general data used, a calculation of systematic deviances would not lead to significant results and therefore will not be done.

Reliability of data will be achieved by a comparison between available and used data within the iterations of the LCA process. If gaps in the use of data occur they will be filled with best available data. The iterations of the LCA process also show if the scope definition must be corrected to achieve completeness of data (cf. chapter 2.3.2). Additional to the criteria mentioned above [SETAC1994] suggests meeting the following requirements in order to assure that the best possible data quality is achieved.A representative check should be done, verifying that the data collected in $\mathrm{LCl}$ are comparable to results from analogue studies. This requirement is congruent to the precise requirement mentioned above. As said in the description of the biogas plant module (cf. chapter 2.4.3) no direct relations can be drawn between inputs and outputs of the biogas process. The production of crops is also related to a wide variety of influences, making it impossible to define a representative production system.

Data should be consistent. In this case the consistency of data means an illustrative scenario for the production of energy crops and other inputs for the biogas plant. The energy crops should therefore be determined on the basis of similar production procedures [AUDSLEY ET AL.2003]. Goal, scope, and functional unit as well as data taken into account shall be defined in such a way that makes improvements, assessments, and comparisons after the first possible LCA level. Within LCA studies, consistency of data from the system under analysis has to be given. Due to the biological character of the agricultural production system and the biogas process, this requirement for consistency is connected to a high variance. For the agri- 
cultural production system it has to be said that there are a great deal of influences on growing crops, related to region, soil type, and climate conditions [AUDSLEY ET AL.2003]. Similar limitations have to be considered for the biogas production system. There are a wide variety of unknown factors influencing the biogas production; therefore no direct relation can be made between input and output of this process. When determining data quality, it must be recognised that the goal and scope definition of a LCA is preliminary and has to be adapted through the several iterations of LCA. Adaptation criteria are defined by the importance of single modules to the overall ecological effects, the availability of data, and the efforts made to achieve data. These several iterations make it possible to select the most adequate combination of data quality goals and data collected. Here, the reliability of the results of the study depends on data quality. The quality of results always has to be on the same level as the importance of the decision stuck to the study [BERG ET. AL1999].

\subsubsection{Preparation of data collection}

Criteria consistency and congruence of procedure within iterative data collection procedures have to be maintained in order to achieve the goal of data quality. This means that when repeating data collection for a special unit process the same kind of form and similar requested data should always be used. To ensure consistency of data within this study, preparation of data collection will be done according to chapter 6.2 (preparing for data collection) of [CEN1998].

Data collection is done for data, which are previously defined for each module and data category within the scope definition. Due to the number of data from internal as well as external sources, several steps have to be done to ensure consistent and coherent results from the LCI modelled with this information [CEN1998]:

$>$ A flow chart of the system under analysis should be done, including all modules and their unit processes as well as the interrelations between these objects. This has been done for this study as can be seen in Figure 7.1 - Figure 7.3. Due to the size of the system under investigation the flow chart is split up into three charts.

$>$ A description of each module and listings of data categories connected to each module should be done. Module descriptions can be found in chapter 2.4, while the data categories lists can be siphoned from the inventory analysis (chapter 2.6) per unit process for each module.

$>$ A list of units used in the study should be prepared. This listing can be found in the annex (cf. Table 7.2). This listing is completed in accordance to the metric units which appear in the LCA software used (cf. chapter 2.9).

$>$ The requested description of data collection and calculation techniques to assist reporting locations is not done, as the author of this study is the sole reporter. Open questions concerning data that has been collected by other people must be orally clarified with the author. Due to this reason, the requested documentation of irregularities and special classes is not done. 


\subsubsection{Allocation}

As far as possible, simple material and energy flows are used in LCA. Flows should be based on material balances between input and output of unit processes or the whole system under investigation. In many cases processes result in more than one product, e.g. electricity generation via combined heat and power processes also produces thermal energy that can be used. Another possibility is that waste from the production process is recycled and used again in this process. If there is more than one product out of one process (couple product) allocations must be used to distribute the input flows exactly to the single products. This distribution is called allocation. Regarding allocation the following guidelines, according to EN ISO 14041 should be consulted: 1. Processes shared with other product systems should be identified by the study and 2. "The sum of the allocated inputs and outputs of a unit process shall equal the unallocated inputs and outputs of the unit process" [CEN1998].

In this study, the biogas slurry originated from inputs to the biogas process could be viewed as a couple product due to its plant nutrient content and its utilisation as an organic fertiliser. The resulting replacement of mineral fertilisers consequently leads to the assumption that biogas slurry could be classified as a couple product. In addition to this, the thermal energy produced in the CHP plants is used for heating the biogas vessels and input sanitation. In the sensitivity analysis waste heat from the CHP is used for thermal treatment of the biogas slurry and heating of buildings.

There is no real allocation in this study; the allocation in this study is a recycling process. This process recycles the nutrients from the biogas slurry in agricultural production systems. The waste heat from the CHP plants is a by-product of the electricity generation that cannot be sold and will therefore not be allocated. In the object under investigation, biogas slurry is used as an organic fertiliser for all kinds of crops produced by the farmers delivering inputs for the biogas plant. Furthermore, [AUDSLEY ET AL.2003] stresses the importance of manure distribution as a recycling product.

As the biogas slurry leaves the biogas plant and becomes incorporated into a crop production system, it leaves the system under investigation for a short moment to returns as a substitute for mineral fertilisers. It is plausible that the slurry would be used in the production of new inputs to the plant, but this is not certain. This is the case of an open-loop recycling process, as described in [CEN1997, CEN1998, AUDSLEY ET AL.2003]. A method based on composites of the slurry is used in the allocation of ecological effects to the biogas slurry leaving the system under analysis. This composite based method should only be used, if there is a strong relation between the component and the replaced product. (35)Therefore credits will be awarded to the nutrient content of the biogas slurry replacing mineral fertilisers. The nutrient content of the slurry is measured in order to calculate the contribution of this process. The measured value of ammonium is calculated as an equivalent of mineral ammonium. Other nutrients are not calculated, as they would also be used in alternative calculation scenarios (nutrients in manure, cf. chapter 2.6.5). 


\subsection{Inventory analysis}

This chapter gives a detailed description of the data revised in this study. This description meets the requirements of chapter 2.5.2 concerning the preparation of data collection. Both the functions of the several modules and data used are illustrated.

The inputs to the biogas plant are energy crops originated from agricultural production processes, waste from the processing of arable crops, and waste from livestock husbandry. These inputs and their related data collected in the $\mathrm{LCl}$ are explored in the following paragraphs. All data available concerning material and energy flows are collected in the ecological assessment of agricultural production of the energy crops. Waste materials from livestock husbandry, i.e. manure from pigs and cows as well as dung from chickens are excluded from this collection. Due to their waste character, they are dealt with in such a way that does not take into account any related upstream processes. This waste character and its way of calculation are explained in chapter 2.3.2. Moreover, all other waste, especially from comestible production e.g. bleaching earth, fat sludge, potato pulp and juice, used as inputs to the biogas process is calculated in the same way. Only transport efforts, which are directly related to the biogas production, are taken into account as ecologically relevant data in the case of waste.

\subsubsection{Energy crops}

The production of energy crops is a new field of agriculture in Europe especially Germany, enforced by the Renewable Energy Sources Act [EEG2004]. The production of already produced crops can be enlarged for the energy crop production. Even existing crop contingents could be used for energy production [RODE ET AL.2005]. Already before the ecological effects from this new field of agriculture were observed by [KALTSCHMITT\&REINHARDT1997], the ecological effects of the intensification of agriculture in the 60 s and 70 s of the last century were under public observation. It showed that intensification of agriculture led to dramatic changes in the production system, causing nutrient surplus, shortened crop rotation, and cleansing of agricultural landscapes [SRU1985].

A new paradigm takes place in agriculture with the shift from crop for food and fodder purposes to energy crop production for anaerobe digestion in biogas plants. Qualitative aspects important for the food and fodder production like protein content are replaced by the maximisation of dry matter mass yield per area unit. Generally every crop can be used as an energy crop. Solely plants with high contents of lignin and cellulose are not suitable, because these substances cannot be digested in biogas plants and lead to physical problems in the process. The further development of energy crop production depends on a couple of influencing factors. Most important will be market development in relation to politics in the fields of agriculture and energy. Retrogression in legal promotion of energy plants, would lead to a breakdown of the development of the recent past. Breeding of energy crops and herein the increase of dry matter yields per area unit will improve the economy of agricultural production [RODE ET AL.2005]. 
Effects on the diversity of species from the production of energy plants are hardly countable. Only certain dissertations deal with this subject. The majority of them concentrate on special aspects due to the variety of effected objects. For the production of biogas from energy plants, plants with high contents of fat, hydrocarbons and proteins are needed. Therefore mostly grass (first cut) and maize are produced as silages as inputs for biogas plants. Plants produced in extensive, nature conserving procedures (e.g. late cut grass) are therefore not as expedient due to their high content of lignin and cellulose as mentioned above.

The arable crop production takes into account the cultivation of the crops as well as further processing like drying of corn or silage of maize. The production process of arable crops, taken into account in this study, consists of the following stages:

> Ploughing: This is a soil cultivation method for initial cultivation of soil in preparation for sowing seed or planting. The main reason for ploughing is to turn over the upper layer of the soil. This may also incorporate the residue from the previous crop into the soil. Ploughing reduces the prevalence of weeds in the fields, and makes the soil more porous, easing later planting processes [WIKIPEDIA2006]. Some kind of traction force is needed for moving the plough through the soil. Today, tractors consuming fossil fuels are used to do this. The majority of total energy consumed in agricultural production processes is consumed in soil cultivation processes e.g. ploughing [VITLOX\&MICHOT1999].

$>$ Seedbed preparation and seeding: This is done to prepare the soil for sowing and germination of plant seeds. Due to the preparation, the soil heats up quicker and is finally broken up. In order to complete this task, state-of-the-art machinery is used, such as tractor driven seed drills combined with rollers, i.e. cultipackers. With regards to seeding, it is essential that constant and exact plant stocks are obtained, especially in the case of row crops. Thereby, the best possible results from crop production can be achieved [ZSCHEISCHLER1990].

Fertilisation: Organic and mineral fertilisers are used to improve crop growth. Plant productivity is limited by a lack of fertilising nutrients. Fertiliser application solves this problem. Mineral fertilisers are artificially produced using mineral and fossil resources. The production of mineral nitrogen is energy intensive, while the production of mineral phosphate consumes limited resources of phosphate rock. Organic fertilisers consist of organic and mineral substances, which are mostly waste from other processes like manure or compost. Even the waste from the biogas process, e.g. biogas manure, is considered an organic fertiliser. When using the Eco indicator '99 method, emissions to the soil must not be specially calculated when fertilisers are deliberately applied on the agricultural land, as the emissions are already calculated in the land use data. Emissions to the air and water must also be taken into account [GOEDKOOP\&SPRIENSMA2001]. Due to their strong influence on the overall ecological effects of biogas production, the emissions from organic fertilisers are explained in further detail later on in this study. 
$>$ Chemical plant protection: Plant protecting agents, i.e. pesticides, herbicides, and fungicides, are used to protect plants against biological influences reducing the plant's performance. They are easy to use, have a reliable effect, and are cheap [LANGE2005]. The high efficiency of these agents can cause problems to the environment and human health. They decrease biodiversity on a large scale, so that intensively managed fields have a diversity index close to sealed surfaces (cf. land-use in ecosystem quality, chapter 2.7.1). Human health can also be influenced, when parts of these agents leak into surface water and then to drinking water. Hardly any data exists for the assessment of upstream processes related with the production of pesticides. Only [GREEN1987] did an analysis of the energy consumption related to the pesticide production. Due to the small amount of material flow caused by pesticides in relation to the total amount of all material flows in the overall LCA, this field will not be analysed in detail. Analysis of the effects of pesticides in the impact category human health, done by [ARMAN2004], shows that this influence is around $1 \%$ of the overall effect in agricultural production systems. Therefore, there is no need to make a special effort in obtaining detailed data in this field. According to the Eco indicator '99 method, all kinds of chemical pest management that are directly applied to the soil must be counted as emissions to agricultural soil. Pesticides that will remain inside the agricultural area are not handled, as these effects are already included in the type of land use [GOEDKOOP\&SPRIENSMA2001].

$>$ Harvesting: This is done in three to four steps, i.e. cutting, chopping (silage), transport, cleaning, and storage. Combine-harvesters are used for cutting corn, which cut the ears and split corn and straw. Corn-choppers are used for maize silage, which cut and chop the plants. This part of harvesting is energy intensive, as can be seen below. Afterwards the harvest is put into storage, where it is stocked for the biogas plant. For the purpose of this study it is assumed that the transport is managed with agricultural vehicles. However, for long distance transports, both lorries and railway are used. Grains are cleaned from dust and afterwards stored in grain storage bins. Silages are compressed before storage to reduce the amount of oxygen in the stored goods. Afterwards the silage is sealed as hermetically as possible with foil.

$>$ Ensilage: Silage is fermented, high-moisture forage, which is fermented and stored in a storage silo, a process called ensilage. Silage must be made from plant material with a suitable moisture content, which ranges from about $55 \%$ to $70 \%$ depending on the construction of the storage structure and hence the degree of compression and the amount of water that will be lost during storage. Ensiling influences the quality of silage. The elimination of as much oxygen as possible by compression before covering the silage is especially important. Normally, this compression is done by tractors driven over the silage lying on the ground of the store. After a time of four to six weeks the fermentation process dies down and the silage can be used [WEGENER2005, EHRENGARD2005, WINKELMANN2005, FNR2004, ZSCHEISCHLER1990]. 
Some dissertations have been made on the effect of energy plant production on birds. Acres planted with fast growing energy crops like maize are not considered to be suitable habitats for most species, especially birds. Directly after sowing, some ground-nesting birds can colonise in maize fields. A growing cultivation of maize would lead to a further decrease in the diversity of birds living in fields. This aspect will get worse, especially if energy plants are produced in monoculture in large areas and field boundaries vanish. These field boundaries seem to be the only habitat where many bird species can live instead of the acres themselves [HÖTKER ET AL.2005]. Research on the causes for the decline of birds living in fields show, that intensification of agriculture, loss of landscape elements, habitat losses in meadows, and direct losses from agricultural activity are among the most important threats. The loss of the dietary basis through intensification of agriculture and the loss of nesting sites through the loss of landscape elements are the most tremendous threats to this. Industry, traffic and settlements have a lower effect [HÖTKER2004].

In this system under analysis the effects of crop rotation are not considered. As a simplification and related to [AUDSLEY ET AL.2003] it is assumed that single crops are part of an unspecific rotation forming a sustainable agricultural production system. Therefore no measurable influences from one single crop are expected to the soil or biodiversity. It is assumed that the specifications of the agricultural production system are not changed within the investigation time, and that the specifications are the same before and after the crop production. It has to be taken into account that the production of energy crops leads to regional changes in crop rotation [WILFERT ET AL.2004]. These can be broadening as well as narrowing of the rotation. The production of winter annual crops, probably energy crops, can herein help to reduce the negative effects of soil erosion and nutrient leaching. [AUDSLEY ET AL.2003] also stress that inventory data from agricultural production system vary strongly depending upon local conditions. The impact categories acidification, eutrophication, and photochemical oxidant formation (in this study summarized in the impact category respiratory effects) are related to regional influences.

In order to generate one functional unit, a certain amount of energy crops is needed, depending on the specific gas yield. The gas yield of energy crops is normally determined based on batch trials. As the quality of energy crops depends on a variety of influences e.g. climate and soil a bandwidth of gas yields from these trials can be found in literature. Additionally, the method of measurement influences the resulting gas yield. Around $80 \%$ of the potential biogas yield, gained from these batch tests, is realised in continuous processes, otherwise the retention time of the substrate in the biogas vessels would take too long. This fact is taken into account when calculating. Therefore average data, displayed in the table below, are used to calculate the amount of needed energy crops per functional unit. For the calculation of energy crop demand an electric energy conversion ratio of $36 \%$ from the energy content of the biogas is assumed. Most CHP plant producers state higher conversion ratios for their plants, but these values are related to natural gas as input. Biogas has lower energy content than natural gas meaning lower conversion ratios [ASUE2005]. Therefore $36 \%$ can be considered a suitable average conversion value for properly managed large gas engines. 
Table 2.2: Gas yields for different kinds of energy crops [HASSAN2003, HÄRDTLEIN2003, MÄHNERT ET AL.2002, FNR2004, KORFF ET AL.2005, FRITZ2006, LAURENZ2005]

\begin{tabular}{|l|r|r|r|r|r|r|}
\hline \multicolumn{1}{|c|}{ substrate } & $\begin{array}{c}\text { gas yield } \\
{\left[\mathbf{m}^{3} / \mathbf{M g}\right]}\end{array}$ & $\begin{array}{c}\mathbf{C H}_{4^{-}} \\
\text {content }\end{array}$ & $\begin{array}{c}\text { energy con- } \\
\text { tent [GJ/Mg] }\end{array}$ & $\begin{array}{l}\text { demand } \\
\text { [Mg/TJ] }\end{array}$ & $\begin{array}{c}\text { yield } \\
\text { [Mg/ha] }\end{array}$ & $\begin{array}{c}\text { area } \\
\text { [ha/TJ] }\end{array}$ \\
\hline silage maize & 190.00 & 0.52 & 3.55 & 783.37 & 45.00 & 17.41 \\
\hline silage grass & 185.00 & 0.54 & 3.59 & 774.74 & 25.00 & 30.99 \\
\hline silage rye & 195.00 & 0.55 & 3.85 & 721.65 & 23.00 & 31.38 \\
\hline forage beet & 98.00 & 0.54 & 1.90 & 1462.53 & 100.00 & 14.63 \\
\hline
\end{tabular}

Data calculated in the $\mathrm{LCl}$ for this unit process is based on various sources. All agricultural production processes are based on data from the Ecolnvent-Database adapted by sources given for each unit process [NEMECEK ET AL.2003, NEMECEK ET AL.2004]. All data sets are referenced to the functional unit. In the case of energy crops the following predication is made: the biogas needed comes entirely from the investigated energy crop. Mixtures of energy crops are only taken into account during the sensitivity analysis.

\section{Ecological effects of energy crop production}

The ecological assessment of energy crop production in arable production systems is affected by the current discussion between nature conservation and agriculture. All effects on the environment are therein referenced to the state-of-the-art arable production with narrow crop rotations and intensive production systems [RODE ET AL.2005]. The effects produced by this production are assessed within LCA in the impact category land-use (cf. chapter 2.7.1), and in LCl as occupation of arable or pasture. This occupation includes the following effects that harm soil quality:

$>$ soil compaction that interferes with soil functions and micro-organisms. It depends on soil quality, time and number of machines used as well as their weight and type of tyres,

$>$ soil erosion is caused by wind and precipitation depending on the kind of soil coverage and cultivation. Topography, crop rotation, and the special characteristics of the crops also influence erosion,

$>$ loss of landscape features and habitats in cultural landscape, and

$>$ decreases in biodiversity.

These aspects are taken into account in the following inventories of the different energy crops. The calculation of these very complex aspects can herein only be done in general terms, but will be given in detail to provide valid information regarding aspects of energy crop production for the biogas process.

\section{Maize silage}

Maize (Zea mays ssp. mays) is a cereal grain that was domesticated in Mesoamerica. The energy value of maize exceeds all other comparable concentrated and normal feedstuffs. Based on [PICKERT2004, FNR2004] the average yield in the year 2000 was around 45.0 Mg/ha silage maize and 12.0-13.0 Mg dry mass respectively. The Landwirtschaftskammer Weser-Ems presents average yields of $57.1 \mathrm{Mg} / \mathrm{ha}$ and $34 \%$ of dry mass in their trials 
from 2003-2005. Cultivation methods are fully developed and the conservation of silage maize is considered a safe and weather-proof method. Maize is the most important field forage plant as it is $60 \%$ of all field forage plants. In previous years, maize had a percentage of around $12-15 \%$ of the total cultivated area in Germany [BAYER2004, LWK WE2005]. Maize can be produced in monoculture. It needs high temperatures for germination and in its first phonological stage.

The ecological effects from the production of silage maize were assessed using the LCA method by [NEMECEK ET AL.2001]. This assessment accomplished in Switzerland, compared silage maize and grain maize production. The consumption of fossil fuels was detected as a main source of threat to the environment. It also conveyed that the application of fertilisers greatly affected the overall result. Environmental improvements can be realised by an optimisation of machine utilisation and the therefore resulted fuel savings. Additionally, the consideration of heavy metal contents in fertilisers and the reduction of ammonia emissions from environmental sound application technologies help to improve the ecological effects. Finally, nitrate leaching should be reduced with application technologies adapted to organic fertilisers, eligible soil cultivation methods, forward breeds, seasonal optimised nitrogen application, and election of adequate following plants in the crop rotation.

[FINKE ET AL.1999] state, that the effects on the environment from maize cultivation are based on plant specific and regional attributes. Maize is cultivated as a row crop that causes low rates of soil coverage especially in May and June when rainfall causes erosion. In most instances, maize is produced in areas with high stock levels, which respectively are disadvantageous to agriculture, causing additional problems. In the past, maize has partially been produced in crop rotation with maize (monoculture) and over-fertilized with manure due to high stock levels. Additional maize does not react with decrease in yield, if too high rates of nitrogen are applied, like in cases of a high stock rate-to-area ratio. All of this leads to a variety of negative effects connected to the cultivation of maize. Most of these effects can be reduced via optimised manure management including nutrient management and emissions by reducing slurry spreading. The vegetation of maize until autumn, which leads to an uptake of mineralised nitrogen from the soil, creates special positive effects. This reduces nitrate leaching reduced, above all in winter.

The production of maize is seen quite critical by ecologists due to the information presented above. Newer assessments, which object maize as an energy crop for biogas production, present different results. In a comparison with other energy crops, maize needs less water and minerals related to the energy output [TENTSCHER2004]. In regards to the future shortage of water and mineral resources in the future, this point constantly gains importance. The same source also states that maize has the highest area productivity of all energy crops. This result has an important influence on the question of land-use discussed in chapter 2.7.1. As an overall result, it is stated that maize "...lies in the number one position (of all considered crops), closely followed by triticale and rye" [TENTSCHER2004].

A production of $45.0 \mathrm{Mg} / \mathrm{ha}$ maize silage is assumed. Data taken into account for the production of 1.0 TJ electricity from silage maize are given in Table 2.3. As the LCl for maize silage 
consists of more than 500 data, only data with an impact $>1.0 \%$ to the total effect are listed below.

Table 2.3: $\mathrm{LCl}$ of silage maize for the generation of $1.0 \mathrm{TJ}$ electric energy

\begin{tabular}{|l|l|l|r|}
\hline \multicolumn{1}{|c|}{ substance } & compartment & \multicolumn{1}{c|}{ unit } & amount \\
\hline Carbon dioxide, in air & Raw & $\mathrm{Mg}$ & 378 \\
\hline Gas, natural, in ground & Raw & $\mathrm{m}^{3}$ & 1,340 \\
\hline Occupation, arable, non-irrigated & Raw & $\mathrm{m}^{2} \mathrm{a}$ & 53,600 \\
\hline Transformation from pasture and meadow & Raw & $\mathrm{m}^{2} \mathrm{a}$ & 339 \\
\hline Oil, crude, in ground & Raw & $\mathrm{Mg}$ & 2.66 \\
\hline Nitrogen oxides & Air & $\mathrm{kg}$ & 92.3 \\
\hline Particulates, $<2.5$ um & Air & $\mathrm{kg}$ & 11.7 \\
\hline Arsenic, ion & Water & $\mathrm{g}$ & 52.6 \\
\hline Cadmium & Water & $\mathrm{g}$ & 37.8 \\
\hline Chromium & Soil & $\mathrm{g}$ & 561 \\
\hline Nickel & Soil & $\mathrm{g}$ & 119 \\
\hline Zinc & Soil & $\mathrm{kg}$ & -1.71 \\
\hline
\end{tabular}

The first column lists the substances that are taken into account. Qualitative aspects e.g. use of soil are also listed as substances. It is objectively not correct to use the term 'substances', when talking about these qualitative aspects. However, it is caused by the software design and does not influence the results. It is noted that ecological benefits from the adsorption of carbon dioxide from fossil sources are taken into account in this calculation.

\section{Rye silage}

Rye (Secale cereale) is a grass grown extensively as a grain and forage crop. It is a member of the wheat family and is closely related to barley and wheat. It is highly tolerant of soil acidity and is more tolerant of dry and cool conditions than wheat, though it is not as tolerant of the cold as barley is. Fall rye used for silage is ready early in the season. This approach allows the producer to spread out the silage season, e.g. additional production of maize silage. If used for silage, the crop should be cut at the heading to early dough stage. The quality of fall rye for silage is comparable to other cereals. If rye is cut late for silage production the protein content decreases and the fibre content increases. This is important when using silage rye as an input to biogas plants (cf. chapter 2.6.1). Fall rye is a winter cereal and has the advantage of utilizing good spring moisture. The soil temperature in spring allows it to resume growth. This feature makes fall rye an attractive crop for silage on sandy soils or in drier areas [HARTMAN1999].

Within this study, rye is an example for other kinds of grain that can also be used in biogas plants. At the moment only silage rye is used as an input to biogas plants due to its arable and various economical advantages. The gas yields resulting from different silage grains are in the same dimension as from silage rye. Silage rye can be stored for several months like silage maize, with few quality losses [FNR2004].

A wide variety of crop yields for silage rye is given in literature, beginning with $16.0 \mathrm{Mg} / \mathrm{ha}$ up to $40.0 \mathrm{Mg} / \mathrm{ha}$ [FNR2004, LAURENZ2005]. As rye is normally produced on areas with reduced site productivity, rather low yields should be expected. This is especially the case if winter rye 
is produced, as due to early harvest low yields are expected. This early harvest is essential, if maize should follow in crop rotation.

Rye can be cultivated as a perennial plant meaning that rye disseminates itself. Therefore efforts in soil cultivation and sowing would be reduced. This can be an interesting approach to an alternative energy crop production with low inputs resulting in reduced effects to the environment [RODE ET AL.2005]. As there are no data available at the moment, this cannot be taken into account.

A production of $23.0 \mathrm{Mg} / \mathrm{ha}$ silage rye is assumed. Data taken into account for the production of $1.0 \mathrm{TJ}$ electricity from silage rye are given in Table 2.4. As the $\mathrm{LCl}$ for rye silage consists of more than 550 data, only data with an impact $>1.0 \%$ to the total effect are listed below.

Table 2.4: $\mathrm{LCl}$ of silage rye for the generation of $1.0 \mathrm{TJ}$ electric energy

\begin{tabular}{|l|l|l|r|}
\hline \multicolumn{1}{|c|}{ substance } & compartment & \multicolumn{1}{c|}{ unit } & amount \\
\hline Carbon dioxide, in air & Raw & $\mathrm{Mg}$ & 966 \\
\hline Gas, natural, in ground & Raw & $\mathrm{m}^{3}$ & 11,200 \\
\hline Occupation, arable, non-irrigated & Raw & $\mathrm{m}^{2} \mathrm{a}$ & 141,000 \\
\hline Occupation, industrial area, built up & Raw & $\mathrm{m}^{2} \mathrm{a}$ & 5,540 \\
\hline Oil, crude, in ground & Raw & $\mathrm{Mg}$ & 24.7 \\
\hline Ammonia & Air & $\mathrm{kg}$ & 788 \\
\hline Carbon dioxide, fossil & Air & $\mathrm{Mg}$ & 104 \\
\hline Dinitrogen monoxide & Air & $\mathrm{kg}$ & 390 \\
\hline Nitrogen oxides & Air & $\mathrm{kg}$ & 899 \\
\hline Particulates, $<2.5$ um & Air & $\mathrm{kg}$ & 101 \\
\hline Particulates, $>2.5$ um, and $<10 \mathrm{um}$ & Air & $\mathrm{kg}$ & 75.3 \\
\hline Arsenic, ion & Water & $\mathrm{g}$ & 365 \\
\hline Cadmium, ion & Water & $\mathrm{g}$ & 290 \\
\hline Cadmium & Soil & $\mathrm{g}$ & 85.6 \\
\hline Chromium & Soil & $\mathrm{kg}$ & 4.12 \\
\hline Zinc & Soil & $\mathrm{kg}$ & -17.3 \\
\hline
\end{tabular}

\section{Silage grass}

Grass (poaceae) generally denotes a monocotyledonous green plant characterized by slender leaves, called blades, which usually grow arching upwards from the ground. It has been cultivated as a food source for domesticated animals for up to 10,000 years. A wide variety of grasses is used nowadays in silage production e.g. orchard grass, perennial ryegrass, sudangrass [JOHNSON1998, HAHNSEN2002].

Theoretically grass should be cut up to 5 times per year for the production of silage. As the inputs to biogas plants should not contain too much wood content, only the first three cuts are normally used. Intensively produced grass has an input of 90 to $130 \mathrm{~kg} / \mathrm{ha}$ nitrogen fertilizers, extensive grass can be produced with much lower energy inputs [HANSEN2002]. Moreover grass is a perennial plant, disseminating itself like rye (see above). Compared to crops like maize, the production of grass only consumes fossil fuels, due to the lowered soil cultivation efforts.

Grass can also be quite a good input into biogas plants as maize. Like maize, silage grass has similar beneficial properties concerning harvest and storage. Crop yield per area unit is 
much lower, which means that grass is normally produced on low productivity areas. Grass from late cut nature conservation areas should not be used in biogas plants, due to its high content of lignin and cellulose [RODE ET AL.2005].

A production of $25.0 \mathrm{Mg} / \mathrm{ha}$ grass silage is taken into account. Data used for the production of 1.0 TJ electricity from silage grass are given in Table 2.5. As the LCl for grass silage consists of more than 550 data, only data with an impact $>1.0 \%$ to the total effect are listed below.

Table 2.5: $\mathrm{LCl}$ of silage grass for the generation of $1.0 \mathrm{TJ}$ electric energy

\begin{tabular}{|l|l|l|l|}
\hline substance & compartment & unit & amount \\
\hline Carbon dioxide, in air & Raw & $\mathrm{Mg}$ & 1,280 \\
\hline Gas, natural, in ground & Raw & $\mathrm{m}^{3}$ & 3,680 \\
\hline Occupation, pasture and meadow, intensive & Raw & $\mathrm{m}^{2} \mathrm{a}$ & 116,000 \\
\hline Oil, crude, in ground & Raw & $\mathrm{Mg}$ & 13 \\
\hline Ammonia & Air & $\mathrm{Mg}$ & 4.14 \\
\hline Dinitrogen monoxide & Air & $\mathrm{kg}$ & 312 \\
\hline Nitrogen oxides & Air & $\mathrm{kg}$ & 504 \\
\hline Particulates, $<2.5 \mathrm{um}$ & Air & $\mathrm{kg}$ & 59.1 \\
\hline Particulates, $>2.5 \mathrm{um}$, and $<10 \mathrm{um}$ & Air & $\mathrm{kg}$ & 40.2 \\
\hline
\end{tabular}

\section{Forage beets}

In comparison to the utilisation of the aerial parts of the plants e.g. maize, rye, and grass, the mostly sub terrestrial roots of the plant are used instead. Beets make high demands on soil quality and should only be produced in good soils with a high supply of nutrients. They are root crops and therefore require a great deal soil cultivation efforts. Nowadays, forage beets are produced on an area size $1 \%$ of the area of silage maize. They can be deemed unimportant as a crop for fodder production. Since the increase of maize silage production in the 1960s, the production of forage beet has declined [ERHARDT2005].

Beets are normally produced in a quadrennial crop rotation. The fact that beets are vulnerable to nematodes means that no onions, spinach, nor carrots should be produced in the crop rotation before them. Beets need from $100 \mathrm{~kg}$ up to $160 \mathrm{~kg}$ nitrogen, $300 \mathrm{~kg}$ potassium, and $90 \mathrm{~kg}$ phosphate fertilizers [STEFFEN2006].

The production of forage beets (chenopodiaceae) for the creation of biogas was first analysed by [HASSAN2003]. Forage beets could become an important energy crop for biogas production because of their high organic matter yield per hectare (cf. Table 2.2). They contain a high percentage of light degradable components and hardly any lignin and cellulose. Moreover, forage and sugar beets have optimal conditions for ensiling, so that they can be stored and used for the whole year. Forage beets have a low dry matter content which makes forage beets pumpable, a fact which can be used for fully automated biogas plants [HASSAN2003].

A production of $100.0 \mathrm{Mg} / \mathrm{ha}$ beet silage is assumed. Data taken into account for the production of 1.0 TJ electricity from forage beets are given in Table 2.6. As the $\mathrm{LCl}$ for beet silage consists of 572 data, only data with an impact $>1.0 \%$ to the total effect are listed below. 
Table 2.6: $\mathrm{LCl}$ of forage beets for the production of one functional unit

\begin{tabular}{|l|l|l|r|}
\hline \multicolumn{1}{|c|}{ substance } & compartment & \multicolumn{1}{c|}{ unit } & amount \\
\hline Carbon dioxide, in air & Raw & $\mathrm{Mg}$ & 586 \\
\hline Gas, natural, in ground & Raw & $\mathrm{m}^{3}$ & 944 \\
\hline Occupation, arable, non-irrigated & Raw & $\mathrm{m}^{2} \mathrm{a}$ & 58,700 \\
\hline Oil, crude, in ground & Raw & $\mathrm{Mg}$ & 4.28 \\
\hline Ammonia & Air & $\mathrm{kg}$ & 278 \\
\hline Carbon dioxide, fossil & Air & $\mathrm{kg}$ & 15.8 \\
\hline Dinitrogen monoxide & Air & $\mathrm{kg}$ & 83.8 \\
\hline Nitrogen oxides & Air & $\mathrm{kg}$ & 167 \\
\hline Particulates, $<2.5$ um & Air & $\mathrm{kg}$ & 19.3 \\
\hline Particulates, $>2.5$ um, and $<10$ um & Air & $\mathrm{kg}$ & 8.41 \\
\hline Sulfur dioxide & Air & $\mathrm{kg}$ & 29.8 \\
\hline Arsenic, ion & Water & $\mathrm{g}$ & 29.2 \\
\hline Cadmium, ion & Water & $\mathrm{g}$ & 37.1 \\
\hline Cadmium & Soil & $\mathrm{g}$ & -60 \\
\hline Copper & Soil & $\mathrm{kg}$ & -1.27 \\
\hline Metamitron & Soil & $\mathrm{kg}$ & 21.4 \\
\hline Zinc & Soil & $\mathrm{kg}$ & -1.03 \\
\hline
\end{tabular}

\subsubsection{Waste and manure}

Biodegradable waste from livestock and food production was a typical input to the biogas process some years ago. Due to the definitions of the [EEG2004] specially produced energy crops became more important as an input for biogas production. Therefore waste is now just used in some plants. In most cases these plants use biodegradable waste mixed with manure, but not energy crops.

Normally, waste that is used as input to other processes are not held responsible for any ecological effects caused by the production of their chief product, because all ecological effects have been taken into account with this product. Therefore, the LCl of waste that is used as an input is normally an empty data set

\section{Potato pulp}

Some of this waste is used as substitution for other products, for example potato pulp. Therefore potato pulp and its supplementing effects should be calculated in this assessment.

Potato pulp is a waste material from the production of potato starch; $240 \mathrm{~kg}$ of pulp is produced from $1.0 \mathrm{Mg}$ of potatoes [FNR2004]. This pulp can be used as fodder for dairy cows. It can also be used as an input to biogas plants, whereas potassium and chloride concentrations in the pulp, which could harm the biology of the biogas plants, have to be regarded. The nutrient content of potato pulp can be related to the nutrient content of grass silage.

Whereas grass silage contains $33,750 \mathrm{MJ}$ NEL/ha $(23.00 \mathrm{Mg} / \mathrm{ha})$, potato pulp has a nutrient value of 7.7 MJ NEL/kg (DM 13\%) [KTBL2002, SPIEKERS2005]. So $4.38 \mathrm{Mg}$ of potato pulp equals the nutrient content of 1.0 ha of grass silage, and $1.0 \mathrm{Mg}$ of potato pulp has the same nutrient content as 0.23 ha of grass silage. 
Potato pulp produces an average gas yield of $85 \mathrm{~m}^{3} / \mathrm{Mg}$ at $58 \% \mathrm{CH}_{4}$-content $(1.77 \mathrm{GJ} / \mathrm{Mg})$ [FNR2004]. To produce one functional unit $1,570 \mathrm{Mg}$ of pulp would be needed. In regard to the nutrient content, these $1,570 \mathrm{Mg}$ of pulp could substitute 361 ha of grass silage, whereas only 31 ha of grass silage are needed for the production of one functional unit. This shows that dairy cows can digest pulp with a higher efficiency than biogas plants. Therefore, pulp is more efficiently used as fodder supplement than as an input to biogas plants. For calculation in sensitivity analysis potato pulp will be charged with its nutrient value, which means with the amount of grass silage that has to be produced to replace pulp as fodder for dairy cows. A further explanation is that if 31 ha of grass silage are needed to produce one functional unit, $136 \mathrm{Mg}$ of pulp are charged with the $\mathrm{LCl}$ of these 31 ha of grass silage production.

\section{Manure from livestock husbandry}

With regards to manure, no inputs to the life cycle inventory are taken into account in the case of manure, as manure is a waste from livestock husbandry. Only the ecological efforts of manure transport are calculated. The emissions from storage and application of manure are considerd later, when calculating the emissions from biogas slurry (emission from biogas slurry, cf. chapter 2.4.4). The avoided emissions from manure will be calculated in this process.

Until changes were made in the Renewable-Sources-Act [EEG2004], manure was the main input to biogas plants [EDER\&SCHULZ2006]. Manure, from both cows and pigs, is the biological base of most biogas plants. Manure contains all bacteria and trace elements needed for the biogas process. Manure also buffers the biogas process chemically with its contended minerals. This is considered useful if too many metabolites disrupt the biogas process during the acidification phase. In the last years first plants have been put into operatoin doing biogas production without manure but just energy crops, e.g. the biogas plant in Obernjesa (Lower Saxony, Germany). But these plants have several difficulties in stabilising process biology [GEHRIG\&FRITZ2006]. The same problems are also described for plants, which are using high percentage of energy crops and a low percentage of manure [HEIDLER2006].

Manure can be mixed easily with different substrates. Especially energy crops with high dry matter contents get better pumpable when mixed with manure. Storage and handling of manure does not cause any problems. Manure can be added directly or indirectly via storage vessel to the biogas process without any further manipulation [FNR2004].

There is a huge potential of livestock husbandry manure that can be used in biogas plants (cf. Table 2.7). The increasing sizes of livestock farms and the intensification of environmental law, concerning the use of manure i.e. code of good agricultural practice, require alternatives to solely storage and application of manure. The utilisation in biogas plants and the therefore resulting storage of manure in covered vessels could be one possible solution to fulfil ecological requirements stated in the environmental law.

Livestock in Germany is mainly made up of pigs and cows. In 2003 there were around $10.6 \mathrm{~m}$ large cattle units (LCU) cows and $2.4 \mathrm{~m}$ LCU pigs. Within cattle husbandry most manure $(60 \%)$ derives from dairy farming. Manure from pig husbandry mainly originates from 
pig fattening (>70\%). In 2003 the total amount of farm manure from livestock husbandry in Germany was around $199 \mathrm{~m} \mathrm{Mg}$ [SCHWAB2004].

Table 2.7: Amount of farm manure in Germany, 1994-2003 [ScHWAB2004]

\begin{tabular}{|c|c|c|c|c|c|c|c|c|c|c|}
\hline \multirow[t]{2}{*}{ year } & \multicolumn{3}{|c|}{ manure [m Mg/y] } & \multicolumn{3}{|c|}{ solid manure [m Mg/y] } & \multicolumn{3}{|c|}{ liquid manure [m Mg/y] } & \multirow{2}{*}{$\begin{array}{c}\Sigma[\mathrm{m} \mathrm{Mg} / \mathrm{y}] \\
\Sigma\end{array}$} \\
\hline & cow & pig & $\Sigma$ & cow & pig & $\boldsymbol{\Sigma}$ & cow & pig & $\boldsymbol{\Sigma}$ & \\
\hline 1994 & 98,2 & 61,1 & 159,3 & 33,4 & 11,1 & 44,5 & 9,0 & 4,5 & 13,6 & 217,4 \\
\hline 1995 & 96,9 & 59,1 & 156,0 & 33,5 & 10,7 & 44,1 & 9,0 & 4,4 & 13,4 & 213,5 \\
\hline 1996 & 96,0 & 60,0 & 156,0 & 33,5 & 10,8 & 44,3 & 9,0 & 4,5 & 13,5 & 213,8 \\
\hline 1997 & 94,1 & 61,5 & 155,6 & 32,7 & 11,2 & 43,9 & 8,8 & 4,6 & 13,3 & 212,8 \\
\hline 1998 & 90,7 & 63,6 & 154,3 & 31,8 & $\overline{11,2}$ & 43,0 & 8,5 & 4,6 & 13,2 & 210,4 \\
\hline 1999 & 88,8 & 63,1 & 151,9 & 31,1 & 11,0 & 42,1 & 8,3 & 4,6 & 12,9 & 206,9 \\
\hline 2000 & 88,0 & 63,9 & 151,9 & 30,7 & $\overline{11,3}$ & 42,0 & 8,2 & 4,6 & 12,9 & 206,8 \\
\hline 2001 & 86,1 & 64,7 & 150,8 & 30,1 & 11,3 & 41,3 & 8,1 & 4,6 & 12,7 & 204,9 \\
\hline 2002 & 83,2 & 65,0 & 148,1 & 29,2 & 11,3 & 40,5 & 7,8 & 4,6 & 12,5 & 201,1 \\
\hline 2003 & 81,3 & 65,7 & 146,9 & 28,3 & 11,4 & 39,7 & 7,6 & 4,7 & 12,9 & 198,9 \\
\hline
\end{tabular}

Manure from cows produces an average gas yield of $25 \mathrm{~m}^{3} / \mathrm{Mg}$ with a $\mathrm{CH}_{4}$-content of around $60 \%$. Pig manure generates around $30 \mathrm{~m}^{3} / \mathrm{Mg}$ contenting $65 \%$ of $\mathrm{CH}_{4}$ [FNR2004, KTBL2005b]. With the amounts of manure given in Table 2.7 (year 2003) large amounts of biogas can be produced, as can be seen in Table 2.8 .

Table 2.8: Potential biogas production from manure in Germany, year 2003

\begin{tabular}{|l|r|r|r|r|r|}
\hline \multicolumn{1}{|c|}{ substrate } & $\begin{array}{c}\text { gas yield } \\
{\left[\mathbf{[ m}^{3} / \mathbf{M g}\right]}\end{array}$ & $\begin{array}{c}\mathrm{CH}_{4^{-}} \\
\text {content [\%] }\end{array}$ & $\begin{array}{c}\text { energy content } \\
\text { [GJ/Mg] }\end{array}$ & $\begin{array}{c}\text { amount } \\
\text { [Mg] }\end{array}$ & energy [TJ] \\
\hline cow manure & 25.00 & 60.0 & 0.54 & $81,300,000$ & 15,756 \\
\hline pig manure & 30.00 & 65.0 & 0.70 & $65,700,000$ & 16,553 \\
\hline
\end{tabular}

Relating this energy content to the energy that can be produced with maize, which is the most common energy crop for biogas production, this equals a total of 562,449 ha of silage maize. Compared to the total area under maize silage of $1,271,000$ ha, these are about $44 \%$ [DESTATIS2006b, DMK2006]. This shows that, even if the amount of energy crops produced for biogas production will further increase, manure will remain an important input to the biogas process in the future.

\subsubsection{Transport}

All transport of substances, related to the production of biogas, are taken into account, given that the transport of human beings, working on the biogas plant, are not calculated. Within this assessment only agricultural vehicles, i.e. tractors and trailers, will be used as the transport of inputs to and outputs from the biogas plant. As most energy crop transports to biogas plants are short distance transport, this kind of transport can be supposed within this LCl. All transport of biogas slurry is done with agricultural vehicles. Sometimes inputs to biogas plants are also transported using lorries, when waste with high energy contents are used e.g. from grease separators is used [HARTMANN2006].

Vehicles are not the only transport method used for inputs to the biogas plant; pipelines are also used to carry liquid substrates. However, this method is only used in the case of short transport distances and high transported volumes. This is seen in the case of wastes from 
the food industry, e.g. dairies or potato starch production. As these are considered as special cases in the field of biogas production, they will not be taken into account in this assessment.

Within this study, most transport processes data related to the production of biogas plants are based on the ecological assessment of the biogas plant in Lüchow (Germany). This assessment was done from 2003 to 2005 in order to evaluate the ecological effects from the production of biogas, especially from savings of transport processes due to biogas slurry treatment [HARTMANN2006]. These data are based on operating data from the plant using different kinds of input materials and biogas slurries. Herein load trips and no load trips are taken into account. In addition, methods used for estimating the influence of differing plant sizes on the transport efforts were developed and will be used within this assessment.

Regarding the object under investigation some assumptions have to be used based on the existing data set [cf. HARTMANN2006]. This data shows that around 1,000 ha of crops, mostly maize, were produced for a total sum of $75 \mathrm{TJ}$ electric energy. Manure was added to produce this energy, however a total of $68 \%$ of this energy results from the maize (cf. Table 2.2). This relation will be kept up for the different sensitivity analysis concerning plant size.The theoretical biogas plant used as a standard in this dissertation is dimensioned to a scale of 1.0 MW electric power and shall be operated for 7,800 full load hours per year. This leads to a total of $7,800 \mathrm{MWh} /$ year $(28.08 \mathrm{TJ}$ ) of produced electric energy and leads to equitation (3):

$$
\begin{aligned}
A_{1} & =\frac{A_{2} \times \text { annual energy production }_{1}}{\text { annual energy production }_{2}} \\
A_{28.08 \mathrm{TJ}} & =\frac{1,000 \mathrm{ha} 28.08 \mathrm{TJ}}{75.00 \mathrm{TJ}}=374.4 \mathrm{ha}
\end{aligned}
$$

An area under crops of 374.4 ha is needed to produce 28.08 functional units. The data of [HARTMANN2006] also shows that an average transport distance (atd) of $11.5 \mathrm{~km}$ was covered to deliver the yield from these 1,000 ha of energy crops to the biogas plant. Average transport distance describes the distance that has to be covered to transport $50 \%$ of all input or output flows to the biogas plant. This atd is the radius of a circular with $50 \%$ of the size of the circular area completely needed for the energy crop production. This atd of $11.5 \mathrm{~km}$ reflects a total area of 83,095 ha needed for the production of the energy crops $\left(2 \times 11.5 \mathrm{~km}^{2} \pi\right)$. Meaning that $1.203 \%$ of this total area was used for the production of energy crops.

By also assuming that $1.203 \%$ from the environmental area of the theoretical plant will be used to produce 374.4 ha of energy crops, an overall area of 31,111 ha $\left(311.1 \mathrm{~km}^{2}\right)$ will be called for. By taking into account the fact that the circular area (2) is growing by the factor $\mathrm{r}^{2}$, it is noted that the transported distances covered to feed a smaller plant is disproportional shrinking. For the theoretical biogas plant therefore an average transport distance according to equation (4) can consequently be assumed: 


$$
\begin{aligned}
\text { averagetransport dis } \tan c e & =\sqrt{\frac{\text { area under crops }}{2 \pi}} \\
\text { atd }_{28.08 T J} & =\sqrt{\frac{311.1 \mathrm{~km}^{2}}{2 \pi}}=7.03 \mathrm{~km}
\end{aligned}
$$

This means that if the area under crops is reduced to $37.4 \%$ as in this case, the atd is reduced to $61.1 \%$. It is thus noted that plant size has a non-linear influence on related transports and must therefore accurately be considered. This will be taken into account in the following sensitivity analysis.

Within the LCl of the module transport, certain aspects demand attention. Most obvious is the consumption of fossil resources as fuels and lubricants. The material and energy flows for the production of tractors, trailers, and sheds are included in the LCl. Transport vehicle and shed data will not be displayed below, as they are part of the database included in the LCA software [ECOINVENT2004]. The gaseous emissions from the tractors are also considered, whereas $\mathrm{CO}_{2^{-}}, \mathrm{CO}-, \mathrm{NO}_{x^{-}}$, and $\mathrm{HC}$-molecules are calculated. Furthermore, the landuse in the form of roads is considered. All of these aspects are taken into account basing on the unit [tkm], which equals the transport of one megagram [Mg] for one kilometre [km]. Example: a transport of $30 \mathrm{Mg}$ of energy crops for the distance of $7.03 \mathrm{~km}$ would lead to a transport effort of $210.9 \mathrm{tkm}$ in the LCl.

Certain aspects such as vibration and noise from transport will not be analysed. A first approach in considering these aspects was realised by [MüLLER-WENK2004]. This approach was developed for the assessment of road transport in Switzerland. No adapted or general data exists for the object under investigation and would have to be developed. This aspect will be neglected given that noise emissions have a minor influence on the ecological effects from road transport in rural areas.

\section{Land transformation}

Land transformation is the transformation of natural environment by housing, traffic, industrial and agricultural areas. In all cases, but agriculture, this leads to a sealing of soils, which is therefore lost from environment. Theses sealed areas can no longer fulfil their ecological functions as habitat, recycling, and retention of precipitation. This land transformation can lead to severe effects, especially in areas with a high population density. For example: Germany has a total area of $357,070 \mathrm{~km}^{2}$, from which $45,621 \mathrm{~km}^{2}(12.8 \%)$ are already sealed, $17.446 \mathrm{~km}^{2}$ for traffic areas [DESTATIS2005b]. Everyday an additional $1.15 \mathrm{~km}^{2}$ is sealed. This conveys the problem occurring in road transport related to traffic areas. Further on, increasing traffic areas lead to a growth in energy consumption, noise and gaseous emissions. The expansion of industrial real estates and housing areas in the outskirts of conurbations increase traffic plus material and energy intensive ways of production, building, housing and livestyle [DESTATIS2005a, EEA2002]. 


\section{Resource consumption}

In this study, transport resource consumption consists of fossil resources for fuels and mineral resources for the production of vehicles, sheds, and roads. Conventional diesel is calculated as fuel.

Due to the variety of influences on fuel consumption, e.g. driver, landscape, machinery general data are required in order to calculate the energy consumption from agricultural transport. These data are taken from [RINALDI\&STADLER2002, RINALDI ET AL.2005], who created a virtual tractor. This virtual tractor is made up from the data of 112 tractors, measured at different working levels. From these measurements, data on gaseous emissions and fuel consumption were collected. These data are combined with the framework of the LCA database, which leads to data used in this study for fuel consumed by agricultural transport, which are displayed in Table 2.9. These data are referred to a tractor with a power of $78 \mathrm{~kW}$ doing heavy transport duties.

Table 2.9: Fuel consumption of agricultural transport

\begin{tabular}{|c|c|c|}
\hline $\begin{array}{c}\text { tractor type } \\
\text { [kW] }\end{array}$ & \multicolumn{2}{|c|}{ fuel consumption } \\
{$[\mathbf{k g} / \mathbf{h}]$} & {$[\mathrm{l} / \mathbf{h}]$} \\
\hline $75-92$ & 12,70 & 15,30 \\
\hline
\end{tabular}

As transport efforts are calculated as [tkm] these time-referenced data have to be adapted. Therefore an average transport speed of $15 \mathrm{~km} / \mathrm{h}$ is assumed for these transports [HERMANN ET AL.2000]. As a result, an average of $1.02 \mathrm{l} / \mathrm{km}$ diesel fuel is consumed. With reference to the example above, a transport of $7.03 \mathrm{~km}$ would need a total of $7.17 \mathrm{I}$ of fuel, or $0.034 \mathrm{l} / \mathrm{tkm}$ $(0.0282 \mathrm{~kg} / \mathrm{tkm})$ accordingly.

Diesel from plant oil or plant oil itself is not taken into account as fuels. The effects of different fuels used for transport are not the object of this study and will therefore not be investigated. It is possible that fuels from renewable resources would lead to a decrease in fossil energy consumption which would be large enough to substantially influence the overall ecological effects of biogas production.

\section{Gaseous emissions}

The emissions from large diesel engines such as tractors, significantly contribute to the overall emission of particulates and nitrous oxides from traffic sector. The off-road sector greatly contributes to the emissions within this sector. Agricultural as well as silvicultural vehicles and machines produce around $50 \%$ of all diesel emissions from the off-road sector in Switzerland [RINALDI\&STADLER2002].

Data on gaseous emissions will be taken from the [ECOINVENT2002] database. Given that there is a large variety of gaseous emissions from combustion processes in engines, only the most important emission data from this source will be cross-checked. From an ecological point of view these are $\mathrm{HC}, \mathrm{NOx}, \mathrm{CO}$, and particulates. Particulates are not gaseous emissions, but are measured together with them in the same category. Derived from the regression model of [RINALDI\&STADLER2002, RINALDI\&GAILLARD1999], the emissions given in Table 2.10 are taken into account in $\mathrm{LCl}$. 
Table 2.10: Gaseous emissions from agricultural transport

\begin{tabular}{|c|c|c|c|}
\hline tractor type [kW] & $\mathbf{H C}[\mathbf{g} / \mathbf{h}]$ & $\mathbf{N O}_{\mathbf{x}}[\mathbf{g} / \mathbf{h}]$ & $\mathbf{C O}[\mathbf{g} / \mathbf{h}]$ \\
\hline $75-92$ & 23.8 & 275.7 & 45.9 \\
\hline
\end{tabular}

\section{Transport distances}

Data on transport efforts correlated with the biogas production process in industrial scale biogas plants are derived from the assessment of the biogas plant in Lüchow (Germany) [HARTMANN2006]. The data collection of the input and output mass flows and the therefore connected transport efforts are based on weighbridge protocols from this plant. These protocols were collected and analysed monthly in an MS ACCESS database (cf. Table 7.4). The first two rows illustrate the results of the protocols, whereas in the third row precipitation is calculated in the amounts brought into the biogas vessels. This rainwater is collected and pumped to the vessels in order to decrease the density of the substrate in the vessels. The amounts of water taken into account are shown in Table 7.5.

With the use of these data, the transport efforts for the biogas plant Lüchow were calculated in tkm as displayed in Table 7.4. For the purpose of this study the transportation in the period between September 2004 - October 2005 are relevant. During this time the inputs of the biogas plant were adapted to the regulations of the Renewable-Energies-Act giving special grants to the production and utilisation of energy crops [EEG2004]. As can be seen in Figure 7.4 transport efforts change due to the regulations of the Renewable-Energies-Act. From summer 2004, when the inputs of this plant were changed to the energy crop specifications of the Renewable-Energies-Act, the transported masses and distances were decreased in relation to the time between summers 2003 and 2004. This decrease was mainly caused by the increased utilisation of high-density energy crops, especially maize silage.

In order to gain an overview of the transport efforts, data of the Lüchow analyse were separated into transports with two loaded trips as well as one loaded and one deadhead trip. This was requisite due to the special effects of the biogas slurry treatment in this plant. This treatment produced solid and liquid organic manures, so that vehicles transporting silage to the plant were able to transport solid waste back to the farm. Conventional plants only produce liquid slurry, meaning that it is always slurry tankers that are needed to transport the biogas slurry back to the farms. For this reason in this study only one loaded trips with a deadhead will be taken into account in this study.

The input to the plant consists of a mixture of energy crops and manure, given in Table 2.11. This mixture will be the standard mixture used in the investigated theoretical biogas plant. The total amount of inputs needed for production of one functional unit is $1,030 \mathrm{Mg}$. Multiplying this mass of inputs with the average transport distance from equation (4) gives us the input transport efforts for one functional unit; $7,241 \mathrm{tkm}$.

Table 2.11: Standard input mixture used as reference input [Mg/TJ]

\begin{tabular}{|l|r|r|r|}
\hline \multicolumn{1}{|c|}{ substrate } & mixture [Mg] & mixture [\%] & Energy [TJ] \\
\hline maize silage & 610.0 & $59.2 \%$ & 0.779 \\
\hline grass silage & 30.0 & $2.9 \%$ & 0.039 \\
\hline rye silage & 60.0 & $5.8 \%$ & 0.083 \\
\hline
\end{tabular}




\begin{tabular}{|l|r|r|r|}
\hline forage beet & 60.0 & $5.8 \%$ & 0.041 \\
\hline cow manure & 150.0 & $14.6 \%$ & 0.029 \\
\hline pig manure & 120.0 & $11.7 \%$ & 0.030 \\
\hline total & 1030.0 & $100.0 \%$ & 1.001 \\
\hline
\end{tabular}

This input of $1,030 \mathrm{Mg} / \mathrm{TJ}$ results in an output of $945.54 \mathrm{Mg} / \mathrm{TJ}$. This mass reduction $(8.2 \%)$ is caused by the production of biogas $\left(\mathrm{CO}_{2}, \mathrm{CH}_{4}\right)$ from oxygen, hydrogen, and carbon of the inputs. From the study by [HARTMANN2006] it can be seen that the average transport distance of the output transport is slightly shorter than the input atd. Since there is no reason for that shorter atd, the same atd will be presumed for the output transport as for the input transport. In regard of equation (4) output transport efforts of 6,647 tkm will be applied in the LCl.

\section{LCl data}

In order to complete the calculation of the $\mathrm{LCl}$ the data set Transport, tractor and trailer/CH S from [ECOINVENT2002] was adapted to the emission and fuel consumption rates given above. Taking into account all ecological effects, as explained above, leads to a data set given in Table 2.12 for agricultural transport of energy crops. This data set is related to one functional unit including mass and energy flows connected to the objected transport process.

Table 2.12: LCl of agricultural transport of energy crops needed for $1.0 \mathrm{TJ}$ electric energy

\begin{tabular}{|l|l|l|r|}
\hline \multicolumn{1}{|c|}{ substance } & compartment & \multicolumn{1}{c|}{ unit } & amount \\
\hline Total of all compartments & & & \\
\hline Remaining substances & & & \\
\hline Aluminium, 24\% in bauxite, 11\% in crude ore, in ground & Raw & $\mathrm{kg}$ & 57.4 \\
\hline Gas, natural, in ground & Raw & $\mathrm{m}^{3}$ & 98.2 \\
\hline Nickel, 1.98\% in silicates, 1.04\% in crude ore, in ground & Raw & $\mathrm{kg}$ & 4.98 \\
\hline Occupation, forest, intensive, normal & Raw & $\mathrm{m}^{2} \mathrm{a}$ & 340 \\
\hline Occupation, urban, discontinuously built & Raw & $\mathrm{m}^{2} \mathrm{a}$ & 73 \\
\hline Oil, crude, in ground & Raw & $\mathrm{kg}$ & 279 \\
\hline Transformation, from pasture and meadow & Raw & $\mathrm{m}^{2}$ & 1.51 \\
\hline Transformation, to urban, discontinuously built & Raw & $\mathrm{dm}^{2}$ & 1.45 \\
\hline Carbon dioxide, fossil & Air & $\mathrm{Mg}$ & 1.94 \\
\hline Dioxins, measured as 2,3,7,8-tetrachlorodibenzo-p-dioxin & Air & $\mu \mathrm{g}$ & 1.56 \\
\hline Nitrogen oxides & Air & $\mathrm{kg}$ & 8.01 \\
\hline Particulates, $<2.5$ um & Air & $\mathrm{kg}$ & 2.2 \\
\hline Particulates, $>2.5$ um, and <10um & Air & $\mathrm{kg}$ & 1.94 \\
\hline Sulfur dioxide & Air & $\mathrm{kg}$ & 3.91 \\
\hline Arsenic, ion & Water & $\mathrm{g}$ & 4.14 \\
\hline Cadmium, ion & Water & $\mathrm{g}$ & 4.55 \\
\hline Zinc & Soil & $\mathrm{g}$ & 153 \\
\hline
\end{tabular}

Table 2.13 displays data of biogas slurry transport related to $1.0 \mathrm{TJ}$ of electric energy. This transport is done using a tractor and a slurry tanker (Volume $20.0 \mathrm{~m}^{3}$ ). All biogas slurry is brought to the farms delivering inputs to the biogas plant, where it is used as an organic fertilizer. 
Table 2.13: $\mathrm{LCl}$ of agricultural transport of biogas slurry resulting from $1.0 \mathrm{TJ}$ electric energy

\begin{tabular}{|l|l|l|r|}
\hline \multicolumn{1}{|c|}{ substance } & compartment & unit & amount \\
\hline Total of all compartments & & & \\
\hline Remaining substances & & & \\
\hline Aluminium, 24\% in bauxite, 11\% in crude ore, in ground & Raw & $\mathrm{kg}$ & 52.7 \\
\hline Gas, natural, in ground & Raw & $\mathrm{m}^{3}$ & 90.1 \\
\hline Nickel, $1.98 \%$ in silicates, 1.04\% in crude ore, in ground & Raw & $\mathrm{kg}$ & 4.57 \\
\hline Occupation, forest, intensive, normal & Raw & $\mathrm{m}^{2} \mathrm{a}$ & 312 \\
\hline Occupation, urban, discontinuously built & Raw & $\mathrm{m}^{2} \mathrm{a}$ & 62.7 \\
\hline Oil, crude, in ground & Raw & $\mathrm{kg}$ & 256 \\
\hline Transformation, from pasture and meadow & Raw & $\mathrm{m}^{2}$ & 1.38 \\
\hline Transformation, to urban, discontinuously built & Raw & $\mathrm{m}^{2}$ & 1.33 \\
\hline Carbon dioxide, fossil & Air & $\mathrm{Mg}$ & 1.79 \\
\hline Dioxins, measured as 2,3,7,8-tetrachlorodibenzo-p-dioxin & Air & $\mathrm{mg}$ & 1.43 \\
\hline Nitrogen oxides & Air & $\mathrm{kg}$ & 7.35 \\
\hline Particulates, $<2.5$ um & Air & $\mathrm{kg}$ & 2.02 \\
\hline Particulates, $>2.5$ um, and $<10$ um & Air & $\mathrm{kg}$ & 1.79 \\
\hline Sulfur dioxide & Air & $\mathrm{kg}$ & 3.59 \\
\hline Arsenic, ion & Water & $\mathrm{g}$ & 3.8 \\
\hline Cadmium, ion & Water & $\mathrm{g}$ & 4.18 \\
\hline Zinc & Soil & $\mathrm{g}$ & 140 \\
\hline
\end{tabular}

\subsubsection{Biogas plant}

The object under analysis is a fictional biogas plant based on existing plant data taken from [HARTMANN2006]. Data for each unit process were collected based on construction plans, bills of materials bought, information from suppliers, and technical textbooks. These data reflect the total amount of material inputs needed to build the biogas plant. In order to carry out the assessment, data per functional unit are needed. Therefore all materials from each unit were depreciated on a straight-line basis according to their expected useful life. The useful life was set at 20 years for buildings, vessels, and pipelines, 5-7 years for moveable parts of the hydraulic system e.g. pumps and cocks, and 5 years for the CHP plants. Comparable data for useful life are used in several feasibility studies [cf. SCHINDLER2004]. This depreciation was later divided by the number of functional units produced per year. As a result of this, data were generated for materials per unit process needed to produce one functional unit.

All units of the plant as the arrangement of the units comply with the state of the art of biogas plant technology. These data are adapted to the size and function of the object under analysis. The fictional biogas plant is determined by the following parameters:

$>$ management and technology building

$>$ weighbridge

$>$ renewable energy sources, according to the Renewable-Energies-Act, as inputs to the plant, mixture according to Table 2.11

$>$ storage vessel, mixing and storing inputs, stirrer included

$>$ heat exchanger, warming the inputs upstream the reactor 
$>$ hygienisation unit, reducing pathogens from manure and waste before the inputs enter the reactors

$>2$ upright standing reactors, one main reactor and one storage/gassing reactor, volume $2.500 \mathrm{~m}^{3}$, stirrers included, average hydraulic retention time: 50 days

$>$ gas purification facilities, biological trickling filter and activated charcoal trap

$>$ CHP engine, gas motor with $1.0 \mathrm{MW}_{\text {el }}$ output, electric conversion efficiency $\left(\eta_{\mathrm{el}}\right) 36 \%$

$>$ hydraulic systems

$>$ electric energy consumption from electric supply mains

$>$ gaseous emissions from the CHP engine

$>$ gaseous emissions from stored biogas slurry solids

\section{Management and technology building}

This building is made up of concrete, bricks, and corrugated sheet metal. In this building office, toilets, showers, as well as storages are situated. In an extension to this building hydraulic facilities are situated. Data of the $\mathrm{LCl}$ of this facility are given in Table 2.14.

Table 2.14: $\mathrm{LCl}$ of management and technology building for $1.0 \mathrm{TJ}$ electric energy

\begin{tabular}{|l|l|l|r|}
\hline \multicolumn{1}{|c|}{ substance } & compartment & unit & amount \\
\hline Coal, 18 MJ per kg, in ground & Raw & $\mathrm{kg}$ & 13.4 \\
\hline Gas, mine, off-gas, process, coal mining/kg & Raw & $\mathrm{g}$ & 114 \\
\hline Gas, natural, 35 MJ per m3, in ground & Raw & $\mathrm{I}$ & 327 \\
\hline Gas, natural, in ground & Raw & $\mathrm{I}$ & 134 \\
\hline Iron, in ground & Raw & $\mathrm{kg}$ & 13.5 \\
\hline Oil, crude, 42.6 MJ per kg, in ground & Raw & $\mathrm{kg}$ & 1.01 \\
\hline Oil, crude, in ground & Raw & $\mathrm{g}$ & 574 \\
\hline Tin ore, in ground & Raw & $\mathrm{kg}$ & 11.6 \\
\hline Transformation, from unknown & Raw & $\mathrm{cm}^{2}$ & 240 \\
\hline Transformation, to mineral extraction site & Raw & $\mathrm{cm}^{2}$ & 279 \\
\hline Carbon dioxide & Air & $\mathrm{kg}$ & 18.9 \\
\hline Carbon dioxide, fossil & Air & $\mathrm{kg}$ & 8.33 \\
\hline Nickel & Air & $\mathrm{mg}$ & 99.7 \\
\hline Nitrogen oxides & Air & $\mathrm{g}$ & 56 \\
\hline Particulates, $<10$ um (stationary) & Air & $\mathrm{g}$ & 2.57 \\
\hline Particulates, $<2.5$ um & Air & $\mathrm{g}$ & 9.61 \\
\hline Particulates, $>2.5$ um, and <10um & Air & $\mathrm{g}$ & 69.9 \\
\hline Sulfur oxides & Air & $\mathrm{g}$ & 57.3 \\
\hline Zinc & Air & $\mathrm{mg}$ & 334 \\
\hline Arsenic, ion & Water & $\mathrm{mg}$ & 45.8 \\
\hline
\end{tabular}

\section{Weighbridge}

This facility is a platform with a roadway for weighing vehicles. It is made up of reinforced concrete and steel. It is typically situated in the ground with the top at surface level. All material input and output flows are registered by this facility. Data of the $\mathrm{LCl}$ of this facility are given in Table 2.15. 
Table 2.15: $\mathrm{LCl}$ of the weighbridge for $1.0 \mathrm{TJ}$ electric energy

\begin{tabular}{|l|l|l|r|}
\hline \multicolumn{1}{|c|}{ substance } & compartment & \multicolumn{1}{c|}{ unit } & amount \\
\hline Coal, 18 MJ per kg, in ground & Raw & $\mathrm{kg}$ & 4.34 \\
\hline Gas, mine, off-gas, process, coal mining/kg & Raw & $\mathrm{g}$ & 37 \\
\hline Gas, natural, 35 MJ per m3, in ground & Raw & $\mathrm{I}$ & 107 \\
\hline Iron, in ground & Raw & $\mathrm{kg}$ & 4.41 \\
\hline Oil, crude, 42.6 MJ per kg, in ground & Raw & $\mathrm{g}$ & 326 \\
\hline Oil, crude, in ground & Raw & $\mathrm{g}$ & 191 \\
\hline Transformation, from unknown & Raw & $\mathrm{cm}^{2}$ & 94.6 \\
\hline Transformation, to mineral extraction site & Raw & $\mathrm{cm}^{2}$ & 77.7 \\
\hline Carbon dioxide & Air & $\mathrm{kg}$ & 6.1 \\
\hline Carbon dioxide, fossil & Air & $\mathrm{kg}$ & 3.51 \\
\hline Nickel & Air & $\mathrm{mg}$ & 32.2 \\
\hline Nitrogen oxides & Air & $\mathrm{g}$ & 18.5 \\
\hline Particulates, <2.5 um & Air & $\mathrm{g}$ & 4.12 \\
\hline Particulates, $>2.5$ um, and <10um & Air & $\mathrm{g}$ & 32.4 \\
\hline Sulfur oxides & Air & $\mathrm{g}$ & 18.5 \\
\hline Zinc & Air & $\mathrm{mg}$ & 109 \\
\hline Arsenic, ion & Water & $\mathrm{mg}$ & 14.7 \\
\hline
\end{tabular}

\section{Storage vessel}

This vessel is needed for the automation of plant operation. The inputs to the plant are collected in this vessel and homogenised. These homogenised inputs are pumped to the reactors at regular time intervals. Depending on the size of the vessel several days of plant operation can be done without refilling. It is therefore possible that no plant operator is needed to feed the plant at nighttime or at the weekend. The storage vessel is similar in construction as the reactor vessel. It is mainly made up from steel and concrete as well as two stirrers. Data of the LCl of this facility are given in Table 2.16.

Table 2.16: $\mathrm{LCl}$ of the storage vessel related to one functional unit

\begin{tabular}{|l|l|l|r|}
\hline \multicolumn{1}{|c|}{ substance } & compartment & unit & amount \\
\hline Coal, 18 MJ per kg, in ground & Raw & $\mathrm{kg}$ & 20.4 \\
\hline Gas, natural, 35 MJ per m3, in ground & Raw & $\mathrm{m}^{3}$ & 1.2 \\
\hline Gas, natural, in ground & Raw & $\mathrm{m}^{3}$ & 1.47 \\
\hline Nickel, 1.98\% in silicates, 1.04\% in crude ore, in ground & Raw & $\mathrm{g}$ & 89.7 \\
\hline Nickel, in ground & Raw & $\mathrm{g}$ & 237 \\
\hline Oil, crude, 42.6 MJ per kg, in ground & Raw & $\mathrm{kg}$ & 2.64 \\
\hline Oil, crude, in ground & Raw & $\mathrm{kg}$ & 1.51 \\
\hline Tin ore, in ground & Raw & $\mathrm{kg}$ & 185 \\
\hline Transformation, from unknown & Raw & $\mathrm{cm}^{2}$ & 334 \\
\hline Carbon dioxide & Air & $\mathrm{kg}$ & 37.5 \\
\hline Carbon dioxide, fossil & Air & $\mathrm{kg}$ & 19.6 \\
\hline Dioxins, measured as 2,3,7,8-tetrachlorodibenzo-p-dioxin & Air & $\mathrm{\mu g}$ & 77.4 \\
\hline Nickel & Air & $\mathrm{mg}$ & 221 \\
\hline Nitrogen oxides & Air & $\mathrm{g}$ & 136 \\
\hline Particulates, <10 um (stationary) & Air & $\mathrm{g}$ & 13.8 \\
\hline
\end{tabular}




\begin{tabular}{|l|l|l|r|}
\hline Particulates, $<2.5$ um & Air & g & 20.4 \\
\hline Particulates, $>2.5$ um, and < 10um & Air & g & 105 \\
\hline Sulfur oxides & Air & $\mathrm{g}$ & 715 \\
\hline Zinc & Air & $\mathrm{mg}$ & 572 \\
\hline Arsenic, ion & Water & $\mathrm{mg}$ & 182 \\
\hline Cadmium, ion & Water & $\mathrm{mg}$ & 87.9 \\
\hline
\end{tabular}

\section{Heat exchanger}

The biology of the reactors can be harmed by high temperature gradients. Cold input materials brought into the fermenter can cause this. Hence the input materials should be warmed up before they are fed to the reactors. Heat exchangers are devices made to transfer heat between two fluids, which are separated from each other by a solid wall. Several designs are possible, in our case a shell and tube heat exchanger made from high alloyed steel will be calculated. LCl data for this heat exchanger are given in Table 2.17.

Table 2.17: $\mathrm{LCl}$ of the heat exchanger device related to one functional unit

\begin{tabular}{|l|l|l|r|}
\hline \multicolumn{1}{|c|}{ substance } & compartment & unit & amount \\
\hline Gas, natural, in ground & Raw & $\mathrm{m}^{3}$ & 46.3 \\
\hline Nickel, in ground & Raw & $\mathrm{g}$ & 329 \\
\hline Oil, crude, 42.6 MJ per kg, in ground & Raw & $\mathrm{kg}$ & 2.36 \\
\hline Oil, crude, in ground & Raw & $\mathrm{kg}$ & 26 \\
\hline Carbon dioxide, fossil & Air & $\mathrm{kg}$ & 139 \\
\hline Nitrogen oxides & Air & $\mathrm{g}$ & 645 \\
\hline Particulates, <2.5 um & Air & $\mathrm{g}$ & 73.1 \\
\hline Particulates, > 2.5 um, and <10um & Air & $\mathrm{g}$ & 133 \\
\hline Sulfur dioxide & Air & $\mathrm{g}$ & 570 \\
\hline Sulfur oxides & Air & $\mathrm{g}$ & 910 \\
\hline
\end{tabular}

\section{Hygienisation unit}

Hygienisations are typically used, if an epidemic risk can emanate from a substance used as an input in biogas plants. These epidemic substances are listed in the animal by-products regulation [EC2002]. If only manure and energy crops are used as inputs, a hygienisation should not be required to prevent a spread of pathogens. In some cases, especially if manure from different farms is used in one biogas plant, hygienisation units are also installed. These units are batch vessels in which the substrate is heated up to $70{ }^{\circ} \mathrm{C}$ for at least one hour. Most pathogens can be reduced effectively using this method. With regards to the object under analysis a hygienisation unit will be calculated. Data collected for the $\mathrm{LCl}$ are provided below. 
Table 2.18: $\mathrm{LCl}$ of a hygienisation unit for one functional unit

\begin{tabular}{|l|l|l|r|}
\hline \multicolumn{1}{|c|}{ substance } & compartment & unit & amount \\
\hline Gas, natural, 35 MJ per m3, in ground & Raw & $\mathrm{I}$ & 959 \\
\hline Gas, natural, in ground & Raw & $\mathrm{I}$ & 341 \\
\hline Nickel, in ground & Raw & $\mathrm{g}$ & 350 \\
\hline Oil, crude, 42.6 MJ per kg, in ground & Raw & $\mathrm{kg}$ & 1.61 \\
\hline Oil, crude, in ground & Raw & $\mathrm{kg}$ & 1.07 \\
\hline Transformation, from unknown & Raw & $\mathrm{cm}^{2}$ & 464 \\
\hline Transformation, to mineral extraction site & Raw & $\mathrm{cm}^{2}$ & 382 \\
\hline Carbon dioxide & Air & $\mathrm{kg}$ & 16.5 \\
\hline Carbon dioxide, fossil & Air & $\mathrm{kg}$ & 18.9 \\
\hline Nickel & Air & $\mathrm{mg}$ & 141 \\
\hline Nitrogen oxides & Air & $\mathrm{g}$ & 80.9 \\
\hline Particulates, < 10 um (stationary) & Air & $\mathrm{g}$ & 9.35 \\
\hline Particulates, <2.5 um & Air & $\mathrm{g}$ & 21.8 \\
\hline Particulates, $>2.5$ um, and <10um & Air & $\mathrm{g}$ & 165 \\
\hline Sulfur oxides & Air & $\mathrm{g}$ & 929 \\
\hline Arsenic, ion & Water & $\mathrm{mg}$ & 39.5 \\
\hline & & &
\end{tabular}

\section{Reactors}

The reactor (or fermenter) is the heart of a biogas plant. In these vessels the anaerobic digestion of biomass and the resulting production of biogas take place. In most cases upright standing vessels are used as fermenters, but also horizontal fermenters are produced. Stirring and heating units are situated inside these vessels. Fermenters are either made of concrete or steel. In most cases more than one fermenter is used. These fermenters can be used in parallel form or sequentially. The sequential use of two fermenters is the most common used process at present time, whereas one vessel is used as the main reactor, the second one is a storage and gassing vessel. The size of the fermenter, the type and number of the stirrings, and the heating unit are reliant on the empirical value of the biogas plant planners, hence no general statement can be given.

Depending on the mass of inputs, and accordingly the desired average hydraulic retention time, the size of the fermenters can be dimensioned [GRONAUER ET AL.2003, KISSEL ET AL.2001, FNR2004]. For this assessment two upright steel fermenters (main and storage reactors) will be calculated. The vessels shall have a volume of $1,500 \mathrm{~m}^{3}$ (main) and 1,000 $\mathrm{m}^{3}$ (storage). Two central stirrings are situated in the main one and one submersible stirring is situated in the storage vessel. LCl data related to the reactors are given in Table 2.19 and Table 2.20. 
Table 2.19: LCI data of the main reactor for one functional unit

\begin{tabular}{|l|l|l|r|}
\hline \multicolumn{1}{|c|}{ substance } & compartment & unit & amount \\
\hline Coal, 18 MJ per kg, in ground & Raw & $\mathrm{kg}$ & 120 \\
\hline Gas, natural, 35 MJ per m3, in ground & Raw & $\mathrm{m}^{3}$ & 6.02 \\
\hline Gas, natural, in ground & Raw & $\mathrm{m}^{3}$ & 10.6 \\
\hline Nickel, 1.98\% in silicates, 1.04\% in crude ore, in ground & Raw & $\mathrm{g}$ & 533 \\
\hline Nickel, in ground & Raw & $\mathrm{kg}$ & 1.08 \\
\hline Oil, crude, 42.6 MJ per kg, in ground & Raw & $\mathrm{kg}$ & 13.5 \\
\hline Oil, crude, in ground & Raw & $\mathrm{kg}$ & 10.1 \\
\hline Tin ore, in ground & Raw & $\mathrm{Mg}$ & 1.1 \\
\hline Transformation, from unknown & Raw & $\mathrm{cm}^{2}$ & 52.3 \\
\hline Carbon dioxide & Air & $\mathrm{kg}$ & 208 \\
\hline Carbon dioxide, fossil & Air & $\mathrm{kg}$ & 118 \\
\hline Dioxins, measured as 2,3,7,8-tetrachlorodibenzo-p-dioxin & Air & $\mathrm{\mu g}$ & 427 \\
\hline Nickel & Air & $\mathrm{g}$ & 1.22 \\
\hline Nitrogen oxides & Air & $\mathrm{g}$ & 769 \\
\hline Particulates, $<10$ um (stationary) & Air & $\mathrm{g}$ & 56.9 \\
\hline Particulates, $<2.5$ um & Air & $\mathrm{g}$ & 117 \\
\hline Particulates, $>2.5$ um, and <10um & Air & $\mathrm{g}$ & 604 \\
\hline Sulfur dioxide & Air & $\mathrm{g}$ & 313 \\
\hline Sulfur oxides & Air & $\mathrm{kg}$ & 3.34 \\
\hline Zinc & Air & $\mathrm{g}$ & 3.42 \\
\hline Arsenic, ion & Water & $\mathrm{g}$ & 1.03 \\
\hline Cadmium, ion & Water & $\mathrm{g}$ & 490 \\
\hline
\end{tabular}

Table 2.20: $\mathrm{LCl}$ of the gassing reactor related to one functional unit

\begin{tabular}{|l|l|l|r|}
\hline \multicolumn{1}{|c|}{ substance } & compartment & unit & amount \\
\hline Coal, 18 MJ per kg, in ground & Raw & $\mathrm{kg}$ & 71.8 \\
\hline Gas, natural, 35 MJ per m3, in ground & Raw & $\mathrm{m}^{3}$ & 3.61 \\
\hline Gas, natural, in ground & Raw & $\mathrm{m}^{3}$ & 6.38 \\
\hline Nickel, 1.98\% in silicates, 1.04\% in crude ore, in ground & Raw & $\mathrm{g}$ & 320 \\
\hline Nickel, in ground & Raw & $\mathrm{kg}$ & 646 \\
\hline Oil, crude, 42.6 MJ per kg, in ground & Raw & $\mathrm{kg}$ & 8.12 \\
\hline Oil, crude, in ground & Raw & $\mathrm{kg}$ & 6.09 \\
\hline Tin ore, in ground & Raw & $\mathrm{kg}$ & 661 \\
\hline Transformation, from unknown & Raw & $\mathrm{dm}^{2}$ & 11.8 \\
\hline Carbon dioxide & Air & $\mathrm{kg}$ & 125 \\
\hline Carbon dioxide, fossil & Air & $\mathrm{kg}$ & 71.1 \\
\hline Dioxins, measured as 2,3,7,8-tetrachlorodibenzo-p-dioxin & Air & $\mu \mathrm{g}$ & 256 \\
\hline Nickel & Air & $\mathrm{mg}$ & 730 \\
\hline Nitrogen oxides & Air & $\mathrm{g}$ & 462 \\
\hline Particulates, <10 um (stationary) & Air & $\mathrm{g}$ & 34.1 \\
\hline Particulates, $<2.5$ um & Air & $\mathrm{g}$ & 70.5 \\
\hline Particulates, $>2.5$ um, and <10um & Air & $\mathrm{g}$ & 362 \\
\hline Sulfur dioxide & Air & $\mathrm{g}$ & 188 \\
\hline Sulfur oxides & Air & $\mathrm{kg}$ & 2 \\
\hline Zinc & Air & $\mathrm{g}$ & 2.05 \\
\hline Arsenic, ion & Water & $\mathrm{mg}$ & 620 \\
\hline Cadmium, ion & Water & $\mathrm{mg}$ & 291 \\
\hline
\end{tabular}




\section{Gas purification}

Biogas is mainly made up from $\mathrm{CH}_{4}$ and $\mathrm{CO}_{2}$, however trail gases are also included. Some of these trail gases, e.g. hydrogen sulphide, are harmful to the CHP plant and the exhaust system. Hence biogas must be purified before it can be used for electricity generation. A typical gas composition consists of: $52 \%$ methane, $43 \%$ carbon dioxide, $2 \%$ steam, $1.5 \%$ nitrogen, $1 \%$ oxygen, 2500 ppm hydrogen sulphide, 250 ppm ammonia, $50 \mathrm{mg} / \mathrm{m}^{3}$ dust [WEILAND2003, PRECHTL ET AL.2005].

The separation of steam is done in the gas-containing pipes. These are installed in the ground and thereby the biogas is cooled in these pipes until the steam is separated out. Therefore, no additional gas purification is needed for this trail component. In this assessment the gas purification installations are made up from a biological trickling filter and an activated charcoal trap. Data of these installations are given in Table 2.21.

Table 2.21: LCl date of the gas purification system for the generation of $1.0 \mathrm{TJ}$ electric energy

\begin{tabular}{|c|c|c|c|c|}
\hline substance & compartment & unit & amount & points \\
\hline Carbon dioxide, in air & Raw & $\mathrm{kg}$ & 81.6 & -0.335 \\
\hline Coal, $18 \mathrm{MJ}$ per kg, in ground & Raw & $\mathrm{kg}$ & 13.9 & 0.0771 \\
\hline Copper, in ground & Raw & $\mathrm{g}$ & 261 & 0.342 \\
\hline Gas, natural, $35 \mathrm{MJ}$ per $\mathrm{m} 3$, in ground & Raw & I & 812 & 0.152 \\
\hline Nickel, in ground & Raw & $\mathrm{g}$ & 152 & 0.129 \\
\hline Occupation, forest, intensive, normal & Raw & $m^{2} a$ & 204 & 1.75 \\
\hline Occupation, traffic area, road embankment & Raw & $m^{2} a$ & 1.99 & 0.131 \\
\hline Oil, crude, $42.6 \mathrm{MJ}$ per $\mathrm{kg}$, in ground & Raw & $\mathrm{kg}$ & 2.09 & 0.457 \\
\hline Oil, crude, in ground & Raw & $g$ & 389 & 0.0864 \\
\hline Carbon dioxide & Air & $\mathrm{kg}$ & 25.1 & 0.103 \\
\hline Carbon dioxide, biogenic & Air & $\mathrm{kg}$ & 19.6 & 0.0802 \\
\hline Methane, fossil & Air & $\mathrm{kg}$ & 1.4 & 0.121 \\
\hline Nickel & Air & $\mathrm{mg}$ & 151 & 0.0835 \\
\hline Nitrogen oxides & Air & g & 73.4 & 0.16 \\
\hline Particulates, $<10$ um (stationary) & Air & $g$ & 7.08 & 0.0518 \\
\hline Particulates, $<2.5$ um & Air & g & 20.1 & 0.279 \\
\hline Particulates, $>2.5 \mathrm{um}$, and $<10 \mathrm{um}$ & Air & $\mathrm{g}$ & 8.55 & 0.0626 \\
\hline Sulfur oxides & Air & $\mathrm{g}$ & 507 & 0.582 \\
\hline Zinc & Air & $\mathrm{g}$ & 338 & 0.0761 \\
\hline Arsenic, ion & Water & $\mathrm{mg}$ & 48 & 0.0617 \\
\hline
\end{tabular}

\section{CHP engine}

Combined heat and power plants, based on reciprocating gas engines, are typical engines for electricity generation in biogas plants with more than $500 \mathrm{~kW}$ electric power. In these engines biogas is burned in a combustion chamber, resulting in high pressure and heat. This energy is used to move the pistons and the rotor of the engine, which finally drives an electric generator.

A supercharged 16-cylinder CHP engine placed in a steel container running at a speed of $1,500 \mathrm{rpm}$ will be referenced to in this study. This engine can have an electric conversion efficiency of around $40 \%$ if fed with natural gas. When fed with biogas $\left(\mathrm{CH}_{4}\right.$-content $\left.52 \%\right)$, the conversion efficiency declines to $36 \%$. In addition to the materials used in the construc- 
tion of the CHP engine, the consumption of motor and lubricating oil is calculated. All data taken into account in this unit process are given in Table 2.22.

Table 2.22: $\mathrm{LCl}$ of the CHP plant for one functional unit

\begin{tabular}{|l|l|l|r|}
\hline \multicolumn{1}{|c|}{ substance } & compartment & \multicolumn{1}{c|}{ unit } & amount \\
\hline Coal, 18 MJ per kg, in ground & Raw & $\mathrm{kg}$ & 184 \\
\hline Gas, mine, off-gas, process, coal mining/kg & Raw & $\mathrm{kg}$ & 1.57 \\
\hline Gas, natural, 35 MJ per m3, in ground & Raw & $\mathrm{m}^{3}$ & 4.52 \\
\hline Gas, natural, in ground & Raw & $\mathrm{m}^{3}$ & 3.98 \\
\hline Iron, in ground & Raw & $\mathrm{kg}$ & 187 \\
\hline Oil, crude, 42.6 MJ per kg, in ground & Raw & $\mathrm{kg}$ & 13.8 \\
\hline Oil, crude, in ground & Raw & $\mathrm{kg}$ & 37.4 \\
\hline Carbon dioxide & Air & $\mathrm{kg}$ & 258 \\
\hline Lead & Air & $\mathrm{g}$ & 1.23 \\
\hline Nickel & Air & $\mathrm{g}$ & 1.38 \\
\hline Nitrogen oxides & Air & $\mathrm{g}$ & 500 \\
\hline Particulates, $<10$ um (stationary) & Air & $\mathrm{g}$ & 35.5 \\
\hline Sulfur oxides & Air & $\mathrm{g}$ & 785 \\
\hline Zinc & Air & $\mathrm{g}$ & 4.59 \\
\hline Arsenic, ion & Water & $\mathrm{mg}$ & 622 \\
\hline
\end{tabular}

\section{Hydraulic facilities}

The hydraulic system taken into account consists of eccentric screw pumps, cocks, valves, and sliders used for moving the biogas slurry from one vessel to the other. After the stirring units, the hydraulic system consumes most of the electric energy in the system under analysis. Data analysed within this system are given in Table 2.23.

Table 2.23: LCl of the hydraulic facilities for one functional unit

\begin{tabular}{|l|l|l|r|}
\hline \multicolumn{1}{|c|}{ substance } & compartment & \multicolumn{1}{c|}{ unit } & amount \\
\hline Coal, 18 MJ per kg, in ground & Raw & $\mathrm{kg}$ & 14.1 \\
\hline Gas, natural, 35 MJ per m3, in ground & Raw & $\mathrm{l}$ & 936 \\
\hline Nickel, in ground & Raw & $\mathrm{g}$ & 279 \\
\hline Oil, crude, 42.6 MJ per kg, in ground & Raw & $\mathrm{kg}$ & 2.97 \\
\hline Oil, crude, in ground & Raw & $\mathrm{g}$ & 248 \\
\hline Carbon dioxide & Air & $\mathrm{kg}$ & 29 \\
\hline Nickel & Air & $\mathrm{mg}$ & 197 \\
\hline Nitrogen oxides & Air & $\mathrm{g}$ & 55 \\
\hline Particulates, <10 um (stationary) & Air & $\mathrm{g}$ & 11.2 \\
\hline Sulfur oxides & Air & $\mathrm{g}$ & 832 \\
\hline Zinc & Air & $\mathrm{mg}$ & 215 \\
\hline Arsenic, ion & Water & $\mathrm{mg}$ & 49.8 \\
\hline
\end{tabular}

\section{Electric energy consumption}

The electric energy consumption of a biogas plant is influenced by a variety of factors. The stirrers and the CHP unit consume most energy whilst pumps, disintegrators, valves, and controlling units use just some energy. An average of $38 \%$ for stirrers, $26 \%$ for the CHP unit, $2 \%$ for pumping, and $8 \%$ for disintegration and solids introduction are consumed from the total electric energy needed [FNR2005]. 
The kinds of materials used as an input to the plant especially influence the energy consumption. High-density materials with high dry matter contents increase the effort of agitating the substrate in the vessels to avoid scum layers and dispel the gas from the substrate. In many cases the energy consumption of biogas plants is calculated with $4-6 \%$ of the total electric energy produced by the plant [cf. SCHINDLER2004]. Measurements made of an industrial scale biogas plant showed that $10-16 \%$ of the amount of electricity fed to the grid is used in the plant itself [HARTMANN2006]. Highest relative share of electricity was consumed when the plant was not operating at a full productivity level due to operating problems. When the plant was operating at a maximum productivity level, a share of $10 \%$ electricity from the grid was consumed per electric unit fed into the grid.

A consumption of $10 \%$ electric energy from the energy fed to the grid will be set for the system under investigation. The electricity taken into account is produced according to the data set electricity, medium voltage, production DE, at grid from the [ECOINVENT2002] data base. It takes into account transport losses and direct $\mathrm{SF}_{6}$-emissions. These data are based on the energy production of the year 2000; the share of renewable energy sources in this energy production is small compared to the today energy production. Data used are presented in Table 2.24.

Table 2.24: $\mathrm{LCl}$ of energy consumption related to one functional unit

\begin{tabular}{|l|l|l|r|}
\hline \multicolumn{1}{|c|}{ substance } & compartment & \multicolumn{1}{c|}{ unit } & amount \\
\hline Coal, hard, unspecified, in ground & Raw & $\mathrm{Mg}$ & 4.63 \\
\hline Gas, mine, off-gas, process, coal mining/m3 & Raw & $\mathrm{m}^{3}$ & 60.1 \\
\hline Gas, natural, in ground & Raw & $\mathrm{m}^{3}$ & 707 \\
\hline Oil, crude, in ground & Raw & $\mathrm{kg}$ & 175 \\
\hline Carbon dioxide, fossil & Air & $\mathrm{Mg}$ & 18.3 \\
\hline $\begin{array}{l}\text { Dioxins, measured as 2,3,7,8-tetrachlorodibenzo-p- } \\
\text { dioxin }\end{array}$ & Air & $\mathrm{mg}$ & 1.32 \\
\hline Nitrogen oxides & Air & $\mathrm{kg}$ & 17.1 \\
\hline Particulates, $<2.5$ um & Air & $\mathrm{kg}$ & 1.8 \\
\hline Particulates, $>2.5$ um, and $<10 \mathrm{um}$ & Air & $\mathrm{kg}$ & 2.51 \\
\hline Sulfur dioxide & Air & $\mathrm{kg}$ & 14.2 \\
\hline Arsenic, ion & Water & $\mathrm{g}$ & 11 \\
\hline
\end{tabular}

\section{Gaseous emissions of the CHP}

Like any other combustion, the energy conversion of biogas in a CHP plant leads to gaseous emissions to the environment. In general terms it can be said, that larger CHP plants emit less harmful gases per unit volume than smaller plants do [GRONAUER ET AL.2002]. To control the hazardous effects of these emissions, emission standards are set by authority for different kinds of emission sources. Regarding the object under investigation, emissions standards are given due to annex 1.2 row 2 of 4.BImSchV and chapter 5.4.1.4 TI Air [BIMSCHV2001, TI AIR2002]. 
Table 2.25: Emission standards for biogas fed CHP plants $<3.0 \mathrm{MW}_{\mathrm{el}}$

\begin{tabular}{|l|r|}
\hline \multicolumn{1}{|c|}{ emission } & \multicolumn{1}{c|}{ standard } \\
\hline carbon monoxide & $1.000 \mathrm{mg} / \mathrm{m}^{3}$ \\
\hline nitrogen oxides $\left(\mathrm{NO}_{\mathrm{x}}\right)$, given as laughing gas $\left(\mathrm{NO}_{2}\right)$ & $500 \mathrm{mg} / \mathrm{m}^{3}$ \\
\hline formaldehyde & $60 \mathrm{mg} / \mathrm{m}^{3}$ \\
\hline sulphurous oxide (state-of-the-art reduction) & - \\
\hline
\end{tabular}

In the case of sulphurous oxide no emission standards are provided, yet a reduction of this emission due to the state-of-the-art of flue gas cleaning is demanded. As these emission standards deal with maximum levels, data on real emissions are needed. Therefore, for the purpose of this assessment, data from a measurement of flue gas emissions done on a real existing biogas plant are taken into account. These data were collected under full load operation of the engine (90\% rated load). This measurement was done by [ÖKO-CONTROL2004]

Table 2.26: Emissions of 1.0 $\mathrm{MW}_{\mathrm{el}}$ biogas fuelled CHP plants

\begin{tabular}{|l|r|r|r|r|r|r|}
\hline & $\begin{array}{c}\text { power } \\
{\left[\mathbf{k W}_{\text {el }}\right]}\end{array}$ & $\begin{array}{c}\text { flue gas rate } \\
{\left[\mathrm{m}^{3} / \mathbf{h}\right]}\end{array}$ & $\begin{array}{c}\mathrm{CO} \\
{\left[\mathbf{m g} / \mathbf{m}^{3}\right]}\end{array}$ & $\begin{array}{c}\mathbf{N O}_{2} \\
{\left[\mathbf{m g}^{3} \mathbf{m}^{3}\right]}\end{array}$ & $\begin{array}{c}\mathbf{C O}_{2} \\
{\left[\mathbf{m g}^{3} \mathbf{m}^{3}\right]}\end{array}$ & $\begin{array}{c}\text { formaldehyde } \\
{\left[\mathbf{m g} / \mathbf{m}^{3}\right]}\end{array}$ \\
\hline CHP1 & 920 & 3,343 & 169 & 370 & 63,450 & 28.3 \\
\hline CHP2 & 945 & 3,364 & 581 & 376 & 63,800 & 31.6 \\
\hline
\end{tabular}

As can be seen from Table 2.26, these CHP units are able to meet all emission standards. Some CHP plants are equipped with oxidising converters, which should help to reduce the $\mathrm{CHP}$ unit emissions from biogas plants. Assessments on the performance of these converters showed, that most converters used in biogas plants are out of order [SKLORZ ET AL.2003]. This malfunction of the converters is caused by sulphurous oxide emissions in the flue gas, destroying the oxidizing layer in the converters. Although it must be said that most CHP units fulfil the emission standards given above. Data taken into account in the $\mathrm{LCl}$ for this influence are given in Table 2.27 .

Table 2.27: $\mathrm{LCl}$ of gaseous emission from the CHP related to one functional unit

\begin{tabular}{|l|l|l|r|}
\hline \multicolumn{1}{|c|}{ substance } & compartment & \multicolumn{1}{c|}{ unit } & amount \\
\hline Carbon dioxide, biogenic & Air & $\mathrm{Mg}$ & 61.8 \\
\hline Carbon monoxide, biogenic & Air & $\mathrm{kg}$ & 279 \\
\hline Formaldehyde & Air & $\mathrm{kg}$ & 28.3 \\
\hline Nitrogen oxides & Air & $\mathrm{kg}$ & 362 \\
\hline Particulates, $>2.5$ um, and $<10 \mathrm{um}$ & Air & $\mathrm{kg}$ & 2.92 \\
\hline Sulfur dioxide & Air & $\mathrm{kg}$ & 17.5 \\
\hline
\end{tabular}

\section{Emissions from biogas slurry solids}

In the fictional biogas plant used as a reference in all of the analysis, only liquid waste is generate, i.e. biogas slurry. As biogas plants grow larger, further treatments of the slurry e.g. separation, are seen as a possibility to reduce the transport efforts related to the biogas slurry application. This separation process leads to a solid and a liquid phase, which both can be used as organic fertilisers. As the liquid phase is stored in closed vessels, whereas the solid phase is stored in open heaps. For this reason, emissions from biogas slurry solids are taken into account in this assessment. 
While ammonia emission from manure have been analysed in several studies, only a few studies were already carried out on $\mathrm{NH}_{3}$ emissions from dung after application. These studies confirm the already known correlations between influencing factors and ammonia emissions stated for liquid systems. Although relative emissions from dung are comparable to manure, total emissions are lower due to the lower contents of ammonium in dung [DÖHLER ET AL.2002].

Dung is a source of greenhouse gases $(\mathrm{CH} 4, \mathrm{~N} 2 \mathrm{O}, \mathrm{NH} 3$ (indirect)) comparable to manure. Its dry matter content and therefore the oxygen infiltration rate into the stored dung cause a strong influence on the emission rates from dung. Oxygen increases nitrification and denitrification. In areas lacking in oxygen, e.g. in the core of dung piles, these two processes can cause $\mathrm{N} 2 \mathrm{O}$ generation and evaporation. Also $\mathrm{CH} 4$ is generated in these oxygen-deprived areas. NH3 emissions mostly occur at the beginning of storage in aerobe areas of the pile [CLEMENS ET AL.2002].

Non-publicised studies from [WOLTER2002 in CLEMENS ET AL.2002] show influences between composition as well as storage technique and emission rates from dung. These results are displayed in Figure 2.2.

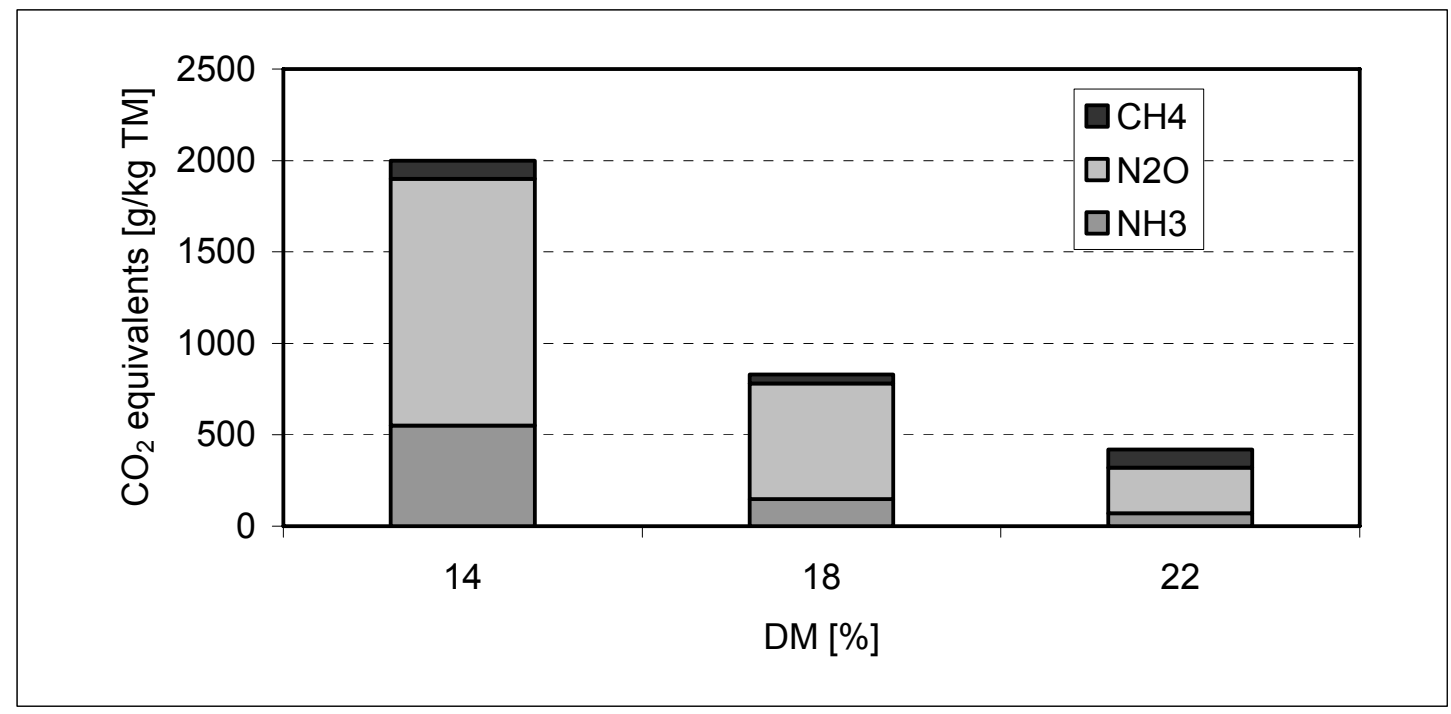

Figure 2.2: $\mathrm{CH}_{4}, \mathrm{~N}_{2} \mathrm{O}$, and $\mathrm{NH}_{3}$ emission rates of artificial pig dung stored at $25^{\circ} \mathrm{C}$ in $100 \mathrm{I}$ vessels [Wolter in Clemens et AL.2002]

From Figure 2.5 it can be seen that the dry matter content and so the oxygen infiltration into the stored dung has a strong influence on the overall emissions from dung. Typically $\mathrm{NH}_{3}$ emissions should increase with increasing oxygen content in the stored manure. It is assumed, that this artificial dung was produced using separation technology. If so, $\mathrm{NH}_{4}$, which is needed for $\mathrm{NH}_{3}$ generation, would be separated into the liquid phase and could not contribute to ammonia emissions. As this study has not been published, the method cannot be verified.

Seasonal effects also influence emission rates from stored manure. It is shown that $33 \%$ less $\mathrm{CO}_{2}$ equivalents are emitted in winter than in summer, whereas a higher share of $\mathrm{N}_{2} \mathrm{O}$ is emitted [AMON ET AL.2002]. It must be criticised that the double amount of manure was 
stored during the winter trials than in the summer trials [CLEMENS ET AL.2002]. As stated in chapter 2.6.5 $\left(\mathrm{N}_{2} \mathrm{O}\right.$ emissions) the emission rate of $\mathrm{N}_{2} \mathrm{O}$ is directly related to the amount of stored dung. Therefore the results of this study have been considered corrupted by these differences in stored manure. It can be concluded that most greenhouse gas emissions from stored dung are caused by $\mathrm{N}_{2} \mathrm{O}$ and $\mathrm{CH}_{4}$. The share of $\mathrm{NH}_{3}$ on the total emitted greenhouse gas rate is comparatively smaller.

\subsubsection{Application of biogas slurry}

In this first paragraph nitrate emissions to ground water are calculated. Following gaseous emissions from the application of biogas slurry will be explained in detail. Finally the results of field trials of different kinds of biogas slurry emissions will be presented.

According to [EDELMANN ET AL.2001] a remarkable part of all ecological effects related to the generation of electricity from biogas is caused by acidic emissions from applied biogas slurry. Therefore in this assessment, biogas slurry and its emissions related to the application are analysed in a great deal. Moreover, the emissions from cow and pig manure, applied without any further treatment, are analysed. When the manure is used for biogas production these emissions have to be regarded as avoided environmental effects, otherwise, this would lead to a double calculation of the emission from manure and biogas slurry. In addition, natural occurring emissions from the soil have to be investigated, when calculating broadcasting emissions [GEIER2000]. If not, the biogas slurry application would be charged with the ecological effects from these natural emissions. On the other hand [CLEMENS ET AL.2002, SCHUMACHER1999] state that fermented manure compared to untreated manure, leads to a reduction of greenhouse gas emissions.

Ecological positive effects are calculated for the nutrient content of the biogas slurry. This nutrient content is made up from the nutrients of the inputs. Manure and its nutrients are added to the process via the inputs. If the manure was not be used in the biogas production, it would be made use of as an organic fertiliser. Therefore these nutrients must not be calculated as part of the nutrients in the biogas slurry. The bio-chemical processes in the biogas plant lead to an increase of ammonium related to the overall nitrogen content. This improves the nutrient value of the biogas slurry in regard to untreated manure. Altogether, the nutrient credit is made up from the nutrient content of the inputs, increased by bio-chemical changes minus the original nutrient content of the manure used as input.

\section{Nitrate leaching}

If adapted rates of fertilisers are applied to the soil during the vegetation period, hardly any nitrate emissions to ground water occur. Almost all nitrate in the ground is consumed by plants. Nitrate leaching is therefore a problem of over fertilisation or application of fertilisers out of the vegetation period. Nitrate leaching depends on the following parameters: nitrogen balance of the soil, field capacity in the rooting zone, and drainage water rate [BRENTRUP2000]. 
As stated in the chapter 2.7.1, the agricultural system under investigation is seen as a sustainable one. This means that there is just little nitrogen overplus, in this case $10.0 \mathrm{~kg} / \mathrm{a}^{*} \mathrm{ha}$. In order to calculate the field capacity, high soil texture and high rooting zone are taken into account, resulting in $160 \mathrm{~mm}$ of field capacity in effective rooting zone. The rate of drainage water is set to $380 \mathrm{~mm} / \mathrm{a}$. This means that the exchange frequency is higher than 1 and therefore all overflow nitrate in the ground is leached. All data for this assumption are based on [BRENTRUP2000]. This assumption leads to a $\mathrm{NO}_{3}$ leaching rate of $10.0 \mathrm{~kg} / \mathrm{ha}{ }^{*} \mathrm{a}$.

\section{Gaseous emissions from manure}

In this section qualitative and quantitative formations of gaseous emissions from manure and biogas slurry are theoretically described. Additionally, a comparison is made between the emissions from untreated and treated biogas slurry as well as manure. The results of this assessment are taken into account for LCl data within this LCA study.

Within the overall scope of this dissertation the emissions from the application of biogas slurry are part of the input production and also the waste disposal scenario. Due to their strong impact on the overall ecological effects of biogas production, they are analysed in detail. In this first assessment of the ecological effects from biogas production around $50 \%$ of the overall effect depends on ammonia emissions. This strong impact, stated by [EDELMANN ET AL.2001], shows remarkable uncertainties for the emission rates of $\mathrm{NH}_{3}, \mathrm{~N}_{2} \mathrm{O}$, and $\mathrm{CH}_{4}$, which are depending on on-site effects of the application process.

Nitrogen emissions from on-field unit processes contribute considerably to the ecological effects of agricultural production systems. Herein, it is quite difficult to obtain data on exact rates of water- and airborne emissions, owing to the strong influences of soil, climate, and farming method. Measurements are investment intensive in terms of time and money and could only represent results depending on the specific conditions. Therefore average potential emission rates adjusted to the system under investigation should be used for LCAs [BRENTRUP2000]. Further on in this chapter calculation methods for the most important $\mathrm{N}$ emissions will be presented. If none of the general data are applicable, data from special studies will be used, i.e. the emissions from biogas slurry with and without treatment after application to the soil. These special data are compared to theoretical emission rates assumed by existing models for gaseous emissions from manure application.

\section{$\mathrm{CH}_{4}$ emissions}

Methane $\left(\mathrm{CH}_{4}\right)$ is the most important green house gas emitted from stored manure. The amount of $\mathrm{CH}_{4}$, which can be generated from stored manure, is thereby depending on the anaerobic degradable biomass brought into the storage [CLEMENS ET AL.2000]. Methane is generated, when organic matter and methane generating bacteria are placed in an anaerobic environment. This happens for example when manure is stored in large vessels. Solely in the top layer of the stored manure oxygen remains, while oxygen lacks in deeper layers. The methane from this process is released into the atmosphere, where it contributes to the green- 
house effect. The covering of storage vessels, as in the case of the fermenters from biogas plants, helps to prevent these emissions.

The influences of manure treatment methods on greenhouse gas emissions from applied manure were studied by [AMON ET AL.2002]. This study provided first indications that both fermentation and separation lead to reduced methane emissions. It is assumed, that the reduction is related to the reduction of organic carbon compounds by biological and mechanical treatment. The biological influence is part of the standard scenario of this LCA. The influence of the separation process will be taken into account in a sensitivity analysis. The results of the study from [AMON ET AL.2002] are given below.

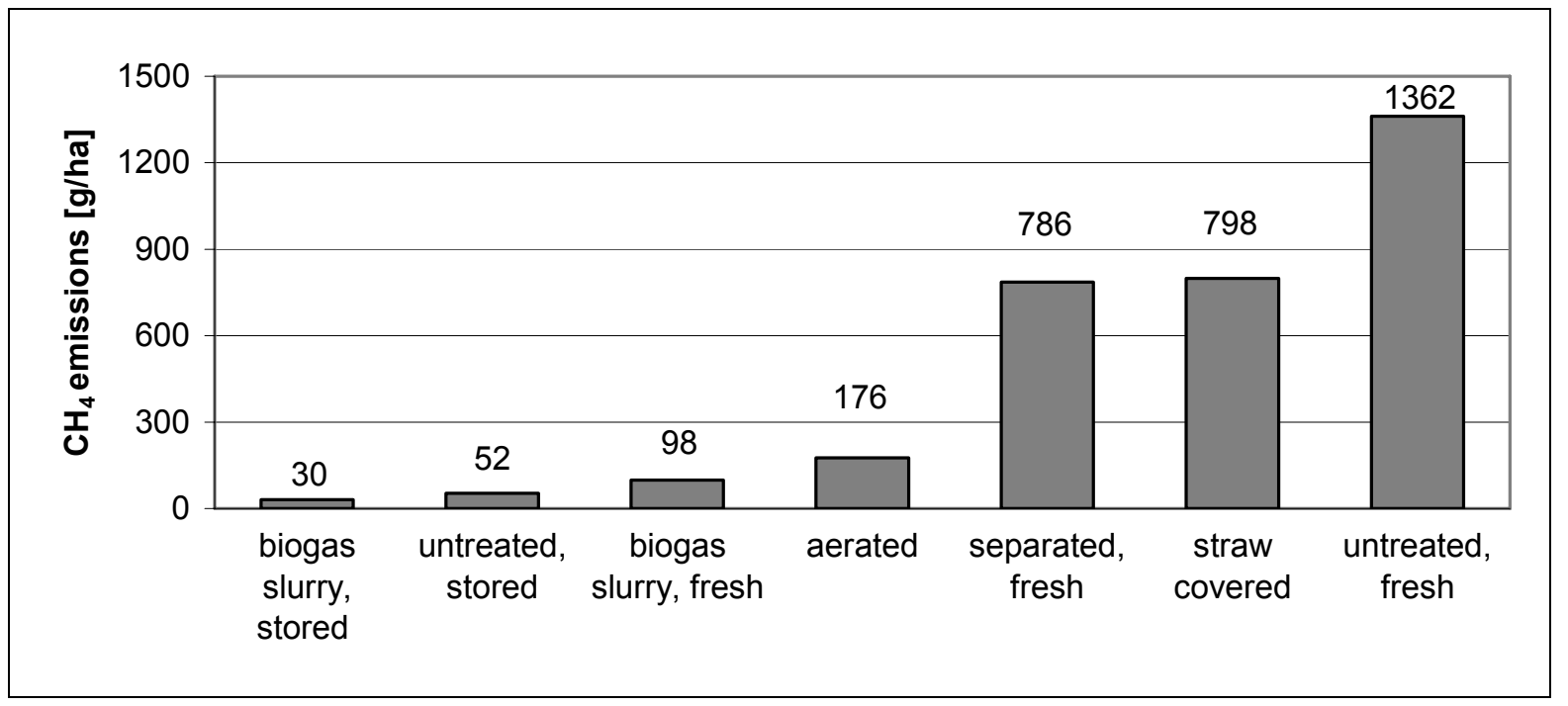

Figure 2.3: $\mathrm{CH}_{4}$ emissions after application of differently treated manure [AMON ET AL.2002]

Explanation: untreated means not separated; fresh describes substrate that was tested without delay; stored describes substrate that was stored for a time of 6 months in open vessels before testing

Clear differences in the emission rates of the differently treated manures can be seen. The highest levels of emissions are caused by untreated, fresh manure. Separation and fermentation show a strong influence on the emission rate after application. Moreover storing reduces the emissions after application; it has to be taken into account that these avoided emissions occur, but in the time of storing. Hence, storing helps to reduce the $\mathrm{CH}_{4}$ emissions only if manure is stored in gas-tight vessels e.g. biogas plants. However separation also leads to an emission reduction of $42 \%$ in comparison to the untreated, fresh manure.

\section{$\mathrm{N}_{2} \mathrm{O}$ emissions}

Throughout the world, the majority of laughing gas $\left(\mathrm{N}_{2} \mathrm{O}\right)$ is emitted from the soil. Laughing gas is both produced and consumed in the soil. The cultivation of arable land, especially nitrogen fertilisation and therefore increased $\mathrm{N}$-conversion, causes an increase of $\mathrm{N}_{2} \mathrm{O}$ emissions. Therefore arable land is seen as the most import source of soil emissions [FLESSA ET AL.1998]. According to [ISERMANN1994] 81\% of all $\mathrm{N}_{2} \mathrm{O}$ emissions derive from agriculture.

Incomplete nitrification $\left(\mathrm{NH}_{4}{ }^{+} \rightarrow \mathrm{NO}_{3}{ }^{-}\right)$as well as incomplete denitrification $\left(\mathrm{NO}_{3}{ }^{-} \rightarrow \mathrm{N}_{2}\right)$ can cause laughing gas emissions. Normally, just small amounts of $\mathrm{N}_{2} \mathrm{O}$ are generated due to nitrification. Low $\mathrm{pH}$ values can increase the nitrification based $\mathrm{N}_{2} \mathrm{O}$ generation process. 
Oxygen lacks, $\mathrm{NO}_{3}{ }^{-}$concentration, and the content of easy to disintegrate organic compounds increase the denitrification based $\mathrm{N}_{2} \mathrm{O}$ generation process [AID2003]. A sketch of $\mathrm{N}_{2} \mathrm{O}$ generation in soils is given in Figure 2.4.

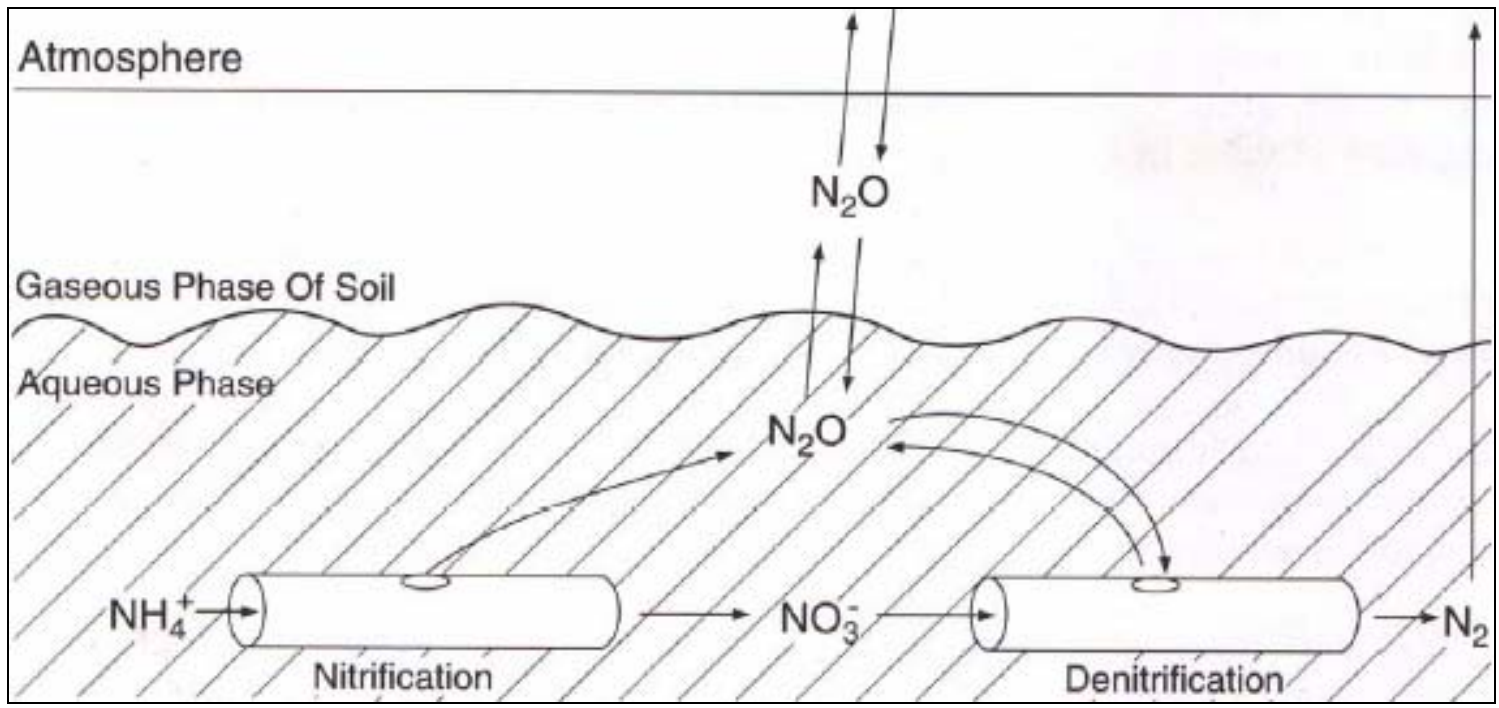

Figure 2.4: Nitrification and denitrification based $\mathrm{N}_{2} \mathrm{O}$ generation and bonding in Soils [LEICK2003]

Analogue to the generation process of $\mathrm{CH}_{4}$ from manure and dung, $\mathrm{N}_{2} \mathrm{O}$ generation depends on the available amount of upstream substances that can be converted into laughing gas. The generation of $\mathrm{N}_{2} \mathrm{O}$ is caused by microbes in anaerobic conditions. Furthermore chemical processes of $\mathrm{N}_{2} \mathrm{O}$ generation can occur in soils [CLEMENS ET AL.2000].

Effects on the $\mathrm{N}_{2} \mathrm{O}$ emission rates after manure application were analysed by [AMON ET AL.2002]. Different kinds of manure treatment, e.g. separation and fermentation, were investigated, showing decreased emission rates for both fermented manure and separated manure. The results of this analysis are given in Figure 2.5:

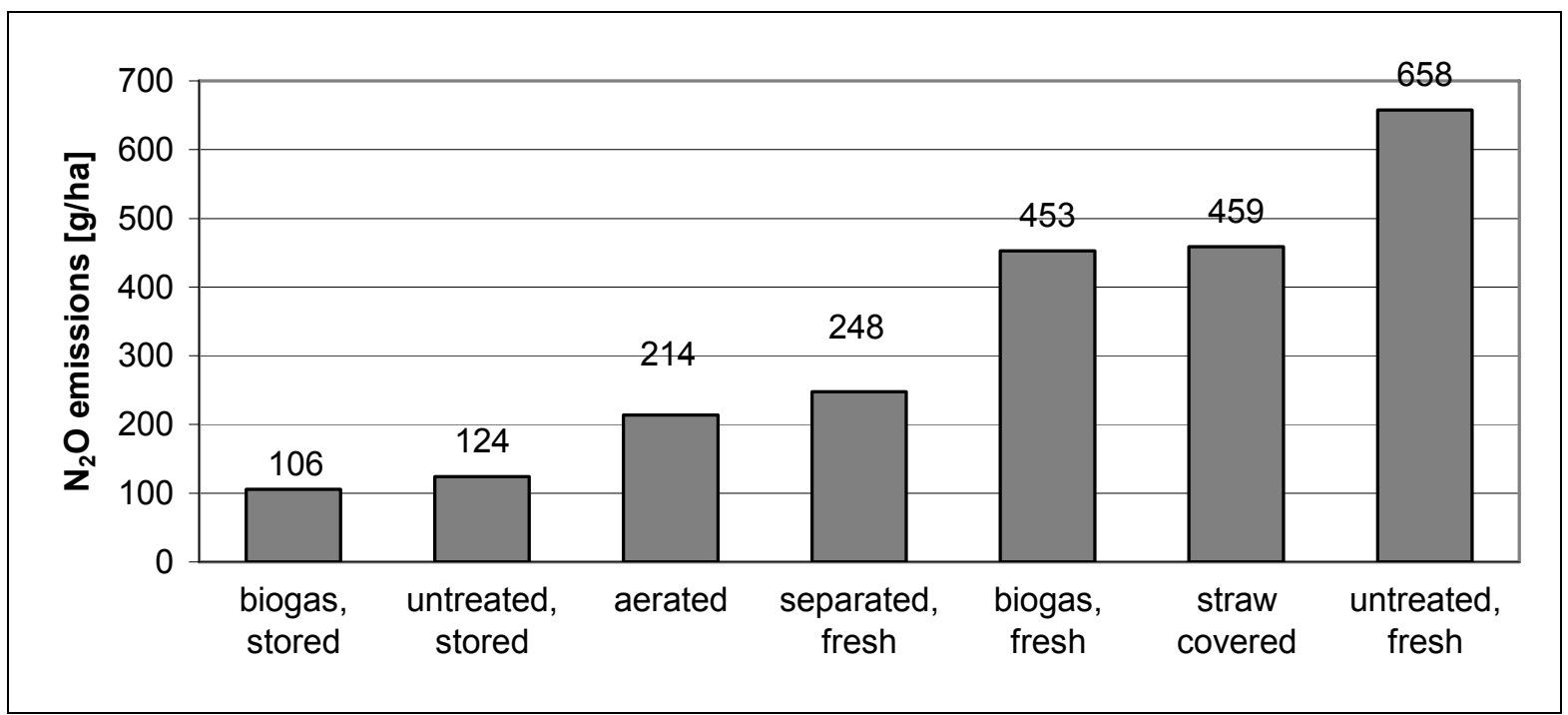

Figure 2.5: $\mathrm{N}_{2} \mathrm{O}$ emissions after application of differently treated manure [AMON ET AL.2002]

Explanation: untreated means not separated; fresh describes substrate that was tested without delay; stored describes substrate that was stored for a time of 6 months in open vessels before testing 
The strong influence of time on the emission rates can be seen from Figure 2.5. The longer the manure was stored, the lower the emission rates after application became. This time effect is caused by the fact that the $\mathrm{N}_{2} \mathrm{O}$ evaporates whilst storing. So, the total emission rate is not reduced but postponed. Storing manure in covered vessels, e.g. biogas plants, can contain these emissions. Also the separation, aeration, and fermentation shown lead to reduced $\mathrm{N}_{2} \mathrm{O}$ emission rates.

Analysis of [FLESSA ET AL.1998] showed that the $\mathrm{N}_{2} \mathrm{O}$ emissions are mainly caused by nitrate concentration in the soil. Nitrogen fertiliser application is shown to have a minor influence on the emission rate. Adapted fertiliser application is therefore seen as a practicable way of reducing nutrient losses.

$\mathrm{N}_{2} \mathrm{O}$ is not only generated directly from microbes, but also indirect generation in the soil via ammonia $\left(\mathrm{NH}_{3}\right)$ is possible. Depending on the amount of ammonia and some chemical effects, $1-10 \% \mathrm{~N}_{2} \mathrm{O}$, related to the mass of $\mathrm{NH}_{3}$, is generated. To estimate the $\mathrm{N}_{2} \mathrm{O}$ emissions in this study the approach of [BOUWMAN1995 in BRENTRUP2000] adapted to the $\mathrm{NH}_{3}$ emission rate will be applied. It states that $1.25 \%$ of applied $\mathrm{N}$ [kg N/ha] are emitted as $\mathrm{N}_{2} \mathrm{O}$ emission [kg N $\mathrm{N}_{2} \mathrm{O} / \mathrm{ha}$ ]. Herein, the applied amount of nitrogen shall be reduced by the earlier occurring $\mathrm{NH}_{3}$ emissions. The calculation of $\mathrm{NH}_{3}$ emissions is explained later on in this chapter.

The majority of indirect $\mathrm{N}_{2} \mathrm{O}$ emissions caused by the application of manure and biogas slurry are probably caused by $\mathrm{NH}_{3}$ in the atmosphere. These $\mathrm{NH}_{3}$ emissions are evaporated to the atmosphere, where they are converted to $\mathrm{NH}_{4}{ }^{+}$. This $\mathrm{NH}_{4}{ }^{+}$is bonded to particulates in the air and brought back into the soil via evaporation. Incomplete nitrification processes of $\mathrm{NH}_{4}^{+}$in the soil lead to $\mathrm{N}_{2} \mathrm{O}$ emissions. Depending on this coherency about 1-2 \% of $\mathrm{NH}_{3}$ emitted from manure application is converted to $\mathrm{N}_{2} \mathrm{O}$ [SCHÖN ET AL.1993, BMLF2003].

$\begin{aligned} \mathrm{NH}_{3} \stackrel{\text { atmosphere }}{\longrightarrow} & \mathrm{NH}_{4}^{+} \text {(particulate bond) } \\ & \downarrow \text { precipitation and transport to soil } \\ & \downarrow \text { incomplete denitrification } \\ & \mathrm{N}_{2} \mathrm{O}\end{aligned}$

Figure 2.6: $\mathrm{N}_{2} \mathrm{O}$ generation of $\mathrm{NH}_{3}$ emissions from agriculture [SCHÖN ET AL.1993]

Extrapolations on the share of indirect $\mathrm{N}_{2} \mathrm{O}$ emission from the total amount of $\mathrm{N}_{2} \mathrm{O}$ emissions can be made [SCHÖN ET AL.1993]. An average emission rate of $2.0 \mathrm{~kg} \mathrm{~N} / \mathrm{O} / \mathrm{ha} / \mathrm{a}$ from arable soils leads to a total emission of $24 \mathrm{Gg} \mathrm{N}_{2} \mathrm{O} / \mathrm{a}$ from soils in Germany. Handling and storage of manure lead to an indirect emission of $11 \mathrm{Gg} \mathrm{N} \mathrm{N}_{2} \mathrm{O} / \mathrm{a}$. Therefore a total amount of $35 \mathrm{Gg} \mathrm{N}_{2} \mathrm{O} / \mathrm{a}$ is emitted, whereas indirect emissions cause a share of $31.4 \%$.

This rough calculation clarifies, that a reduction of ammonia emissions also causes relevant reductions to indirect laughing gas emissions. Especially separation and fermentation of manure can fundamentally influence this reduction. 


\section{$\mathrm{NH}_{3}$ emissions}

Application of farm manure, including biogas slurry, can lead to nitrogen losses due to gaseous emission of $\mathrm{NH}_{3}$ that can contain an amount close to $90 \%$ of $\mathrm{NH}_{4}-\mathrm{N}$ included [HORLACHER\&MARSCHNEr in WULF ET AL.2002]. Nitrogen compounds excreted with dung and urine denote the quality and quantity of ammonia emissions. Enzymes (urease) disintegrate these nitrogen compounds resulting in the production of ammonia. Cows' and pigs' urine make up the biggest percentage of evaporated ammonia in Germany. [AID2003].

According to first analysis of ecological effects related to the electricity generation via biogas in agricultural biogas plants, large percentages of the overall effect are caused by nitrate emissions. These emissions are caused by evaporation from manure following application. For this reason $\mathrm{NH}_{3}$ emissions are analysed in more detail than other sources of ecological effects in this assessment.

Ammonia emission rates from liquid systems are influenced by a variety of chemical and physical factors. The most efficient influences are substrate characteristics, application technology, and weather. Generation and evaporation of ammonia from livestock husbandry are based on urea excreted. From this excreted urea, ammonia is generated in three steps: (1) ammonia generation through enzymatic urea decomposition (ammonification), (2) dissociation equilibrium of ammonium and dissolved ammonia, and (3) ammonia evaporation via mass transfer from liquid system to the air [HARTUNGG2002]. Ammonification will not be included, as it is not included in the scope of this study. Consequently, only dissociation equilibrium and mass transfer will be assessed.

Influencing factors of the ammonia evaporation from liquid systems and a model of this evaporation process are given below. According to [GRONAUER1993] the evaporation of $\mathrm{NH}_{3}$ from liquid systems depends on several chemical reactions, which can be displayed as equilibrium of $\mathrm{NH}_{3}-\mathrm{N}$ and $\mathrm{NH}_{4}-\mathrm{N}$ concentrations (cf. equation (5)).

$$
C_{N_{4}^{+}(s .)} \leftrightarrow C_{N_{4}^{+}(l .)} \leftrightarrow C_{N H_{3(l .)}} \leftrightarrow C_{N H_{3(g .)}}
$$

According to equation (5) $\mathrm{NH}_{3}$ evaporation depends on concentration changes and equilibrium shifts of $\mathrm{NH}_{4}{ }^{+} \mathrm{N}$ and $\mathrm{NH}_{3}-\mathrm{N}$ in the liquid system. The intensity of $\mathrm{NH}_{3}$ evaporation is determined by the partial pressure of $\mathrm{NH}_{3}$ between the liquid and the gaseous system above liquid system.

It is stated by [AID2003] that the dissolution equilibrium of ammonium and dissolved ammonia in fresh and fermented manure is additionally influenced by the $\mathrm{pH}$ value and temperature in the liquid system. In the case of manure, ammonium has an important influence on the ammonia evaporation rate [HÜTHER1999]. The same source also states a positive correlation of evaporation rate and temperature as well as $\mathrm{pH}$ value (cf. equation (6)).

$$
\mathrm{NH}_{3}+\mathrm{H}_{2} \mathrm{O} \stackrel{\mathrm{pH}, \mathrm{T}}{\longrightarrow} \mathrm{NH}_{4}^{+}+\mathrm{OH}^{-}
$$


This means that increasing concentrations of ammonium in organic manure lead to higher evaporation rates. Moreover, it must be taken into account that when manure is applied to field, also airflow velocity shows a positive correlated influence on the ammonia evaporation rate from manure [AID2003]. A model of the overall influences on $\mathrm{NH}_{3}$ evaporation, based on [GRONAUER1993], is given in Figure 2.7.

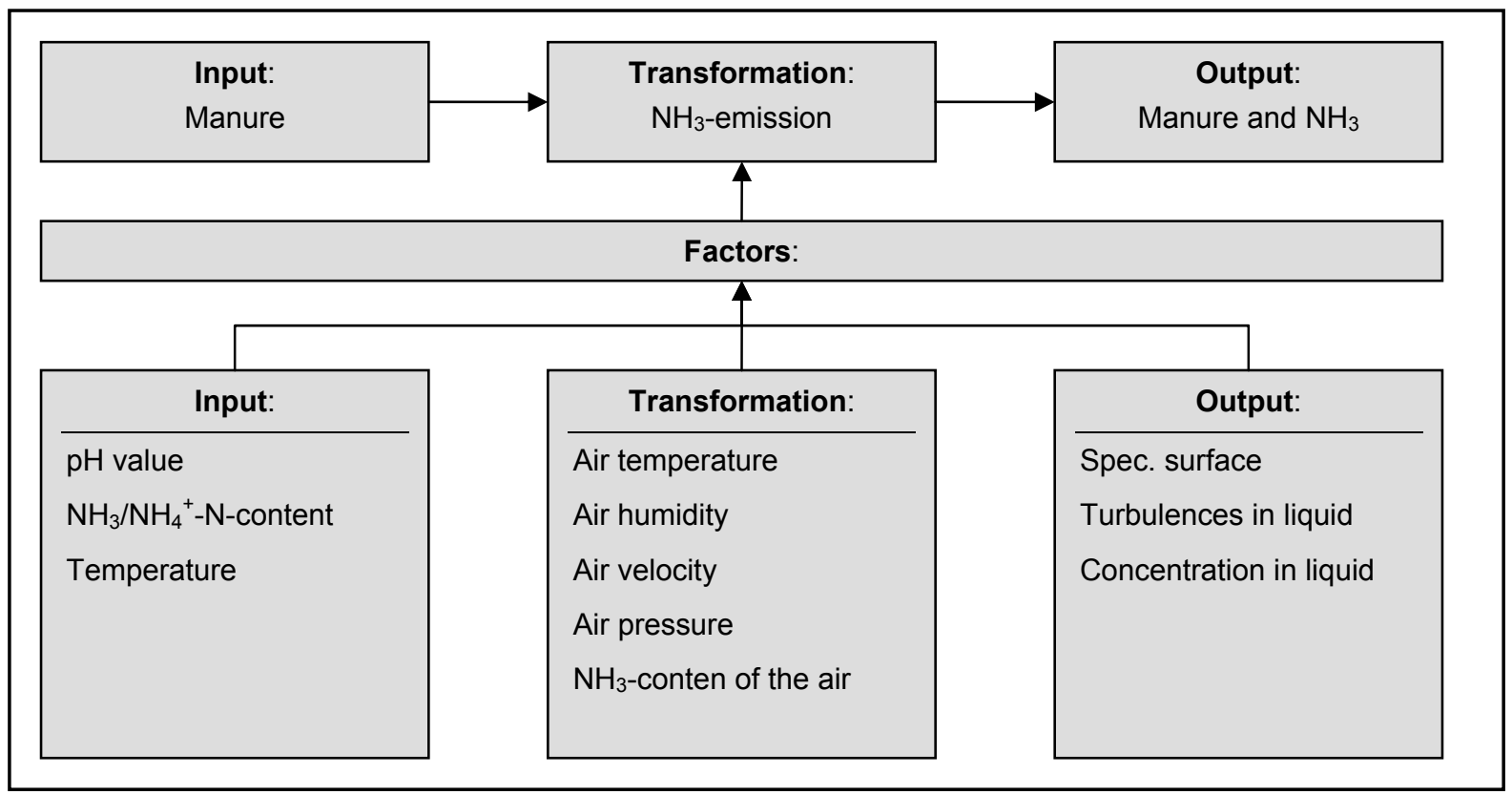

Figure 2.7: Model of $\mathrm{NH}_{3}$ evaporation from liquid systems

The $\mathrm{NH}_{3}-\mathrm{N}$ content of manure, as input to the process, influences the evaporation rate in correlation with the $\mathrm{pH}$ value. Both variables influence the $\mathrm{NH}_{3}$ concentration and therefore indirectly the gas pressure in the liquid system. Direct influence on the evaporation rate is caused by air and liquid temperature. The $\mathrm{NH}_{3}$ concentration gradient in the atmosphere above the emitting surface (spec. surface) is determined by air velocity and partial pressure of $\mathrm{NH}_{3}$ in the air. The relation between specific surface and the liquid volume makes up the emission rate/volume relation. The system under investigation is assumed to be a static system, in which a $\mathrm{NH}_{3}$ concentration gradient is developed. This gradient causes a declining concentration at the emitting surface. If turbulences in the liquid occur, e.g. scum layer destruction via stirring, the $\mathrm{NH}_{3}$ evaporation rate is increased.

Effects on the emission rates of $\mathrm{NH}_{3}$ after application of treated manure were analysed by [AMON ET AL.2002]. Several treatment methods were tried. The study gave indications on increasing ammonia emission rates due to the fermentation of manure, and declining emission rates for separated and stored manure. The results of this study are presented in Figure 2.8 . 


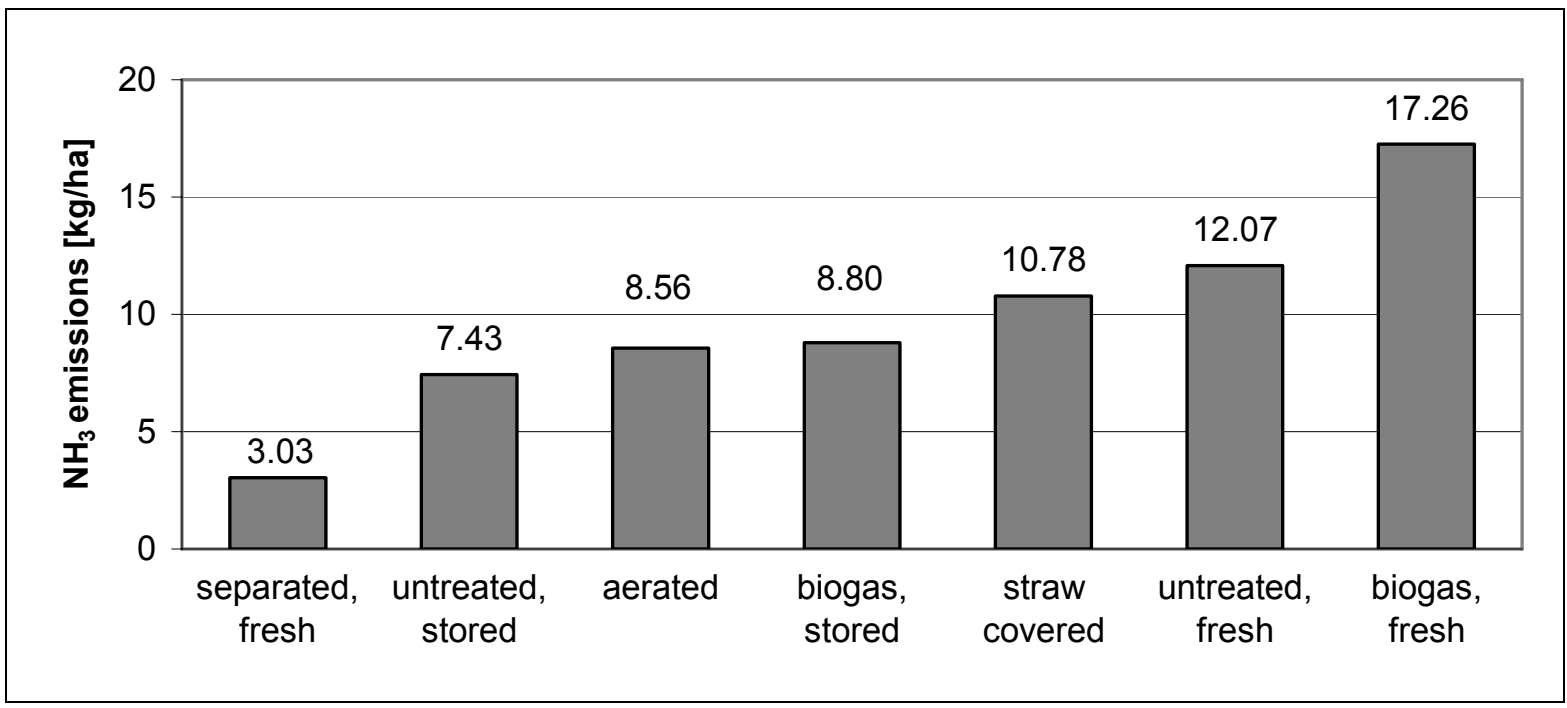

Figure 2.8: $\mathrm{NH}_{3}$ emission after application of differently treated manure [AMON ET AL.2002]

Explanation: untreated means not separated; fresh describes substrate that was tested without delay; stored describes substrate that was stored for a time of 6 months in open vessels before testing

In Figure 2.8 it can be seen that most ammonia from all treatments is emitted from fermented manure. This is caused by the increase in $\mathrm{pH}$ value due to the fermentation process (cf. equation (6)). All treatments considering stored manure emitted less $\mathrm{NH}_{3}$ than the untreated, fresh sample. This is caused by the fact, that the evaporation takes place during storing as in the cases of $\mathrm{CH}_{4}$ and $\mathrm{N}_{2} \mathrm{O}$. Therefore storing is no adequate method to reduce $\mathrm{NH}_{3}$ emissions, except in the case of covered stores.

Large reductions can be made by the separation of manure. Separation leads to a concentration of ammonia in the liquid phase, just small quantities are kept back in the solid phase. [KAUPENJOHANN\&VANDRĖ1998] show that $97.4 \%$ of $\mathrm{NH}_{4}-\mathrm{N}$ from cattle manure is situated in the liquid phase after separation (untreated manure $1.54 \mathrm{~g} \mathrm{NH}_{4}-\mathrm{N} / \mathrm{kg}$, liquid phase $1.50 \mathrm{~g}$ $\mathrm{NH}_{4}-\mathrm{N} / \mathrm{kg}$ ). This liquid phase, and with it most of the $\mathrm{NH}_{4}$ from manure, infiltrates faster in the soil than manure does due to its lower viscosity. $\mathrm{NH}_{4}$ is needed as a precursor for the production of $\mathrm{NH}_{3}$ after application of manure. As previously stated, air velocity, air temperature, and soil temperature have strong influences on the emission rates of $\mathrm{NH}_{3}$. Given that the ammonium goes into the soil quickly, all these influences are decreased or set to zero in comparison to the application of untreated manure. Therefore the $\mathrm{NH}_{3}$ emission rates of separated manure are lower than the rates of untreated manure.

Based on [HORLACHER\&MARSCHNER1990 in BRENTRUP2000] a method for estimating ammonia emissions from cattle slurry is adapted to be used in the calculation of emissions from biogas slurry. This method takes into account average air temperature, infiltration rate, time between application and incorporation, and precipitation or incorporation after rainfall. The method used is based on the following cattle slurry data from [HORLACHER\&MARSCHNER1990] and has been adapted to measured data for biogas slurry. 
Table 2.28: Dry matter, $\mathrm{N}$ and $\mathrm{NH}_{4}-\mathrm{N}$ content of different organic fertilizers

\begin{tabular}{|l|c|c|c|c|}
\hline Fertilizer & Dry matter [\%] & $\mathbf{N}[\mathbf{k g} / \mathbf{M g}]$ & $\mathbf{N H}_{\mathbf{4}} \mathbf{- N}[\mathbf{k g} / \mathbf{M g}]$ & $\mathbf{N H}_{\mathbf{4}}-\mathbf{N}[\%$ of $\mathbf{~}]$ \\
\hline Cattle slurry & 8.0 & 4.0 & 2.2 & 55 \\
\hline Biogas slurry & 5.0 & 3.9 & 2.4 & 62 \\
\hline
\end{tabular}

For the infiltration rate in this study, an average data set is used. The infiltration rate is seen as high, this means prepared or loose soil and slurry has low dry matter content. The influence of temperature on infiltration is also based on a value of $10-15^{\circ} \mathrm{C}$ soil temperature. This leads to steady ammonia losses of $40 \%$ of the applied $\mathrm{NH}_{4}-\mathrm{N}$ caused by these two factors. Additionally, the influence of time between application and incorporation is set to a loss of $15.0 \%$ of the applied $\mathrm{NH}_{4}-\mathrm{N}$ (1h time factor, temperature $10-15^{\circ} \mathrm{C}$ ). The influence of precipitation is not calculated due to the short time between application and incorporation. After incorporation, an additional of $2.0 \%$ of applied $\mathrm{NH}_{4}-\mathrm{N}$ is calculated as an emission [BRENTRUP2000]. This leads to an overall $\mathrm{NH}_{3}$ emission factor of $8.0 \%$ of applied $\mathrm{NH}_{4}-\mathrm{N}$ for cattle slurry. Due to the higher $\mathrm{pH}$ value of biogas slurry, this emission factor is adapted to $14.0 \%$ for standard biogas slurry.

Furthermore, the ammonia losses from the application of mineral fertilizers should be stated. Based on [ECETOC1994 in BRENTRUP2000] emission rates of $1.0 \%$ of applied $\mathrm{NH}_{4}-\mathrm{N}$ will be taken into account for data in LCl.

A comparison of the measured data from [AMON ET AL.2002] and data based on calculations according to [BRENTRUP2002] highlights the differences. For this comparison data from Figure 2.8 for biogas, fresh $\left(1.726 \mathrm{mg} / \mathrm{m}^{2}\right)$ and untreated, fresh $\left(1.207 \mathrm{mg} / \mathrm{m}^{2}\right)$ and calculated data for biogas, fresh $\left(1.400 \mathrm{mg} / \mathrm{m}^{2}\right)$ and untreated, fresh $\left(0.704 \mathrm{mg} / \mathrm{m}^{2}\right)$ are taken into account. Higher values (biogas, fresh 23.3\%; untreated, fresh $71.4 \%$ ) for both untreated cattle manure and biogas slurry results from [AMON ET AL.2002]. This comparison underlines the problems when taking into account the $\mathrm{NH}_{3}$ emissions.

\section{Application influences}

Application of biogas slurry can be carried out using the same machines as used in the application of manure, as both substrates have similar physical characteristics [TSCHEPE\&KROHMER2003]. It is stated by [WULF ET AL.2002] that the application method has a strong influence on the emission results, especially $\mathrm{NH}_{3}$ emissions. Trail hose application will be considered as a standard method in this analysis. Broadcast application will be taken into account within one sensitivity analysis.

The effects of application technology on the greenhouse gas emission rate from manure and biogas slurry were analysed by [WULF ET AL.2002]. The standard-comparison-method according to [KAUPENJOHANN\&VANDRÈ1998] was used in this study. The hypothesis that biogas slurry emits more greenhouse gases, due to its higher content of $\mathrm{NH}_{4}$ and higher $\mathrm{pH}$ value, compared to manure could not be proven. These expected physical aspects compensated higher emissions due to the chemical characteristics of biogas slurry, i.e. lower viscosity of biogas slurry causing better infiltration to the soil. 
$\mathrm{NH}_{3}$ emissions mostly occur from organic manure that is spread on top of the soil or plants. Therefore incorporation or infiltration of manure and biogas slurry after application influences the gaseous emissions from these substrates. Continuous gaseous emissions are produced between the specific surface of the emitting substrate and the surrounding gaseous atmosphere. Measurable rates of $\mathrm{NH}_{3}$ are emitted within minutes after application. Taking this fact into account, it must be noted that the $\mathrm{pH}$ value of applied manure and biogas slurry increases by one unit within 30 minutes after application through which the $\mathrm{NH}_{3}$ emission rates are further increased. After infiltration into the soil, absorbent materials in the ground, e.g. clay and humus, bind the ammonium of the organic fertilizer. By doing this, the content of precursors of the $\mathrm{NH}_{3}$ generation is reduced (cf. equation (6)). There are just small quantities of sorpt ammonium that go into solution and can therefore feed the ammonia production [DÖHLER ET AL.2002].

Studies on the influence of application methods on $\mathrm{NH}_{3}$ emissions from untreated and fresh manure were made by [VANDRĖ1997]. The results of this study are given in Figure 2.9.

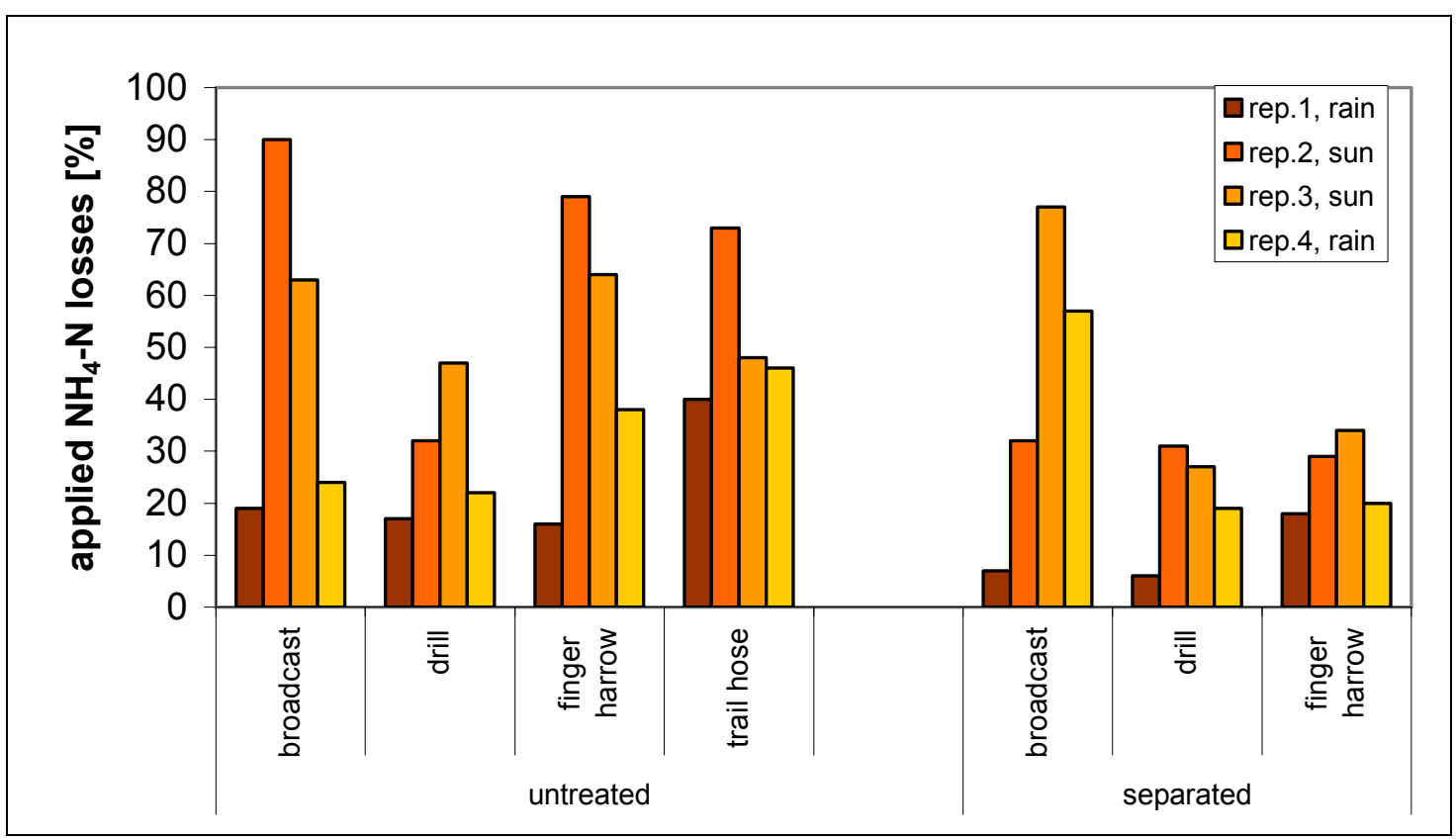

Figure 2.9: $\quad \mathrm{NH}_{3}$ losses after application of untreated and separated manure concerning different incorporation methods

As can be seen from the figure above, untreated as well as separated manure emit less $\mathrm{NH}_{3}$, when applied during rainy weather. Furthermore, separated manure emits less $\mathrm{NH}_{3}$ than untreated manure, as shown before. Drill application shows less emission than any other method. From a theoretical point of view it, it is not feasible that trail hose application causes more emissions than finger harrow or broadcast applications.

An assessment of the standard comparison method (SC method) using separated manure showed gaseous ammonia losses of about $7 \%$ of applied nitrogen within one hour after application. To summarise, $0.2 \mathrm{~g} / \mathrm{m}^{2}$ nitrogen were lost after application of $2.67-3.01 \mathrm{~g} / \mathrm{m}^{2}$ nitrogen, these are $0.65-0.74 \%$ of applied nitrogen [KAUPENJOHANN\&VANDRĖ1998]. This illustrates that almost all $\mathrm{NH}_{3}$ losses occur directly after application. This result is in agreement with the prediction of $6 \%$ nitrogen losses basing on [HORLACHER\&MARSCHNER1990]. In 
addition [WULFF ET AL.2002] state that around $90 \%$ of all $\mathrm{NH}_{3}$ emissions occur within 12 hours after application. The same sources states that the ammonia emission rate is on the background level of $\mathrm{NH}_{3}$ emissions from the soil within four days after application. Therefore, after application, a fast incorporation of organic fertilisers is necessary. The standard scenario of this assessment will assume immediate incorporation after a thorough application of biogas manure.

\section{Biogas slurry emissions from an energy crop/manure mixture}

In this chapter it is proven that there are several influences on the emissions from biogas slurry. It is also noted that there are widely differing emission rates from the various studies. Furthermore all of these studies are based on manure; there are no data on emissions from biogas slurry derived from high contents of energy crops. Therefore field trials were made with biogas slurry from an existing biogas plant. This biogas slurry is derived from inputs according to the input mixture given in Table 2.11, which is used as standard mixture for this assessment. Different treatments of this biogas slurry were investigated: (1) untreated biogas slurry, (2) solid phase from separated biogas slurry, and (3) liquid phase from separated biogas slurry. The nutrient content of these different substrates was analysed by the Federal Agricultural Research Centre (FAL, (D) Braunschweig). The results of this analysis are given in Table 2.29.

Table 2.29: Nutrient contents of substrates derived from biogas slurry [WEILAND2004]

\begin{tabular}{|l|c|c|c|}
\hline substrate nutrient & $\mathbf{N}_{\text {tot }} / \mathbf{N H}_{\mathbf{4}}$ [g/kg] & $\mathbf{P O}_{4}-\mathbf{P}$ [g/kg] & DM/oDM [\%] \\
\hline untreated biogas slurry & $3,9 / 2,4$ & 0,8 & $5,0 / 3,8$ \\
\hline separated solids & $5,8 / 2,7$ & $2,0-4,5$ & $22,0 / 20,5$ \\
\hline separated liquid & $3,4 / 2,3$ & 0,6 & $4,2 / 2,3$ \\
\hline
\end{tabular}

The assessment was done in the form of a totally randomised field trial with four replications. It was done on a sandy clay loam field in Lenglern (Germany, South Lower Saxony). Before this assessment was carried out, spring wheat had been cultivated in this field; stubbles were incorporated using a grubber. 16 parcels were created in a quadratic arrangement. 


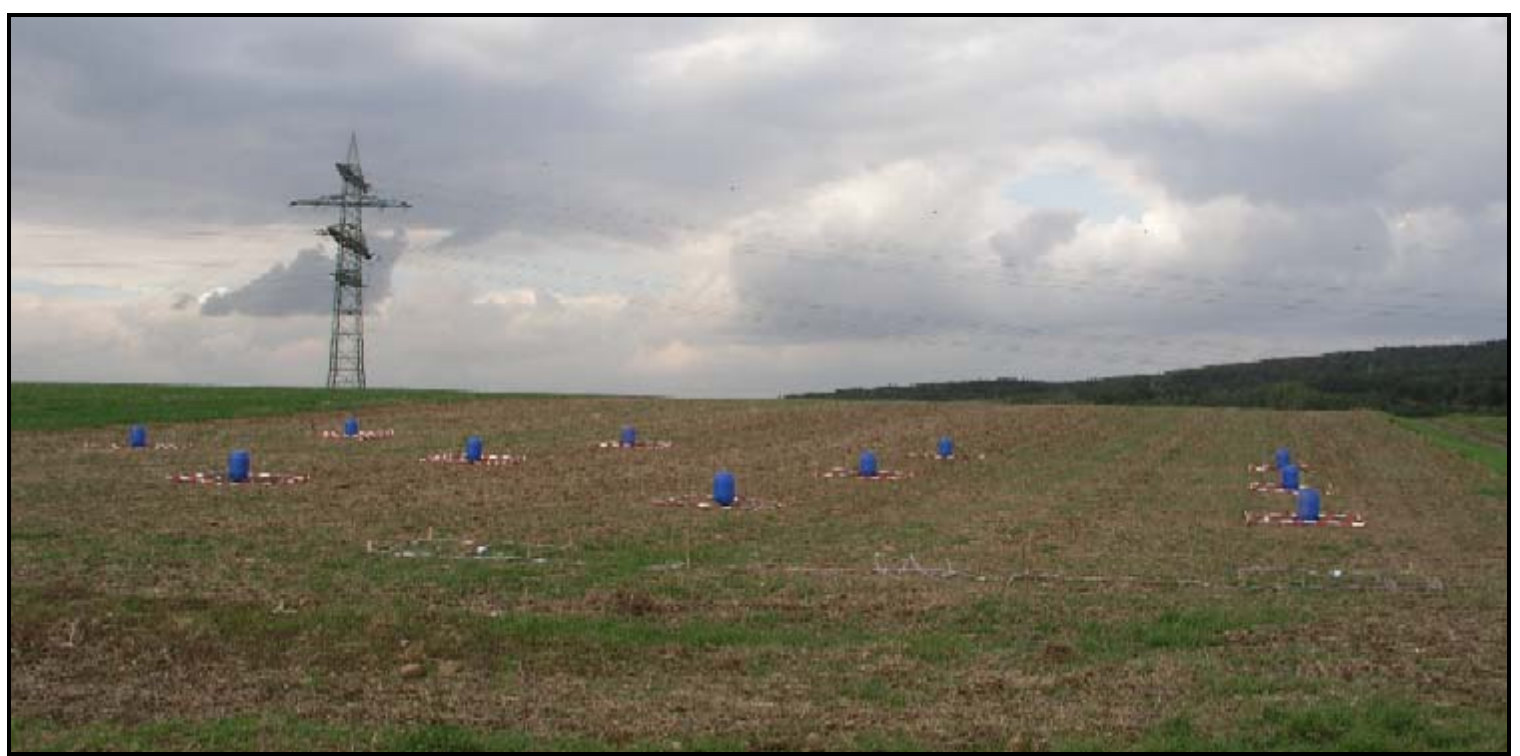

Figure 2.10: Field trial on emissions from biogas slurry substrates

Four parcels per treatment, two parcels testing the background emissions, and two parcels for the standard emission rates of $\mathrm{NH}_{3}$ according to the $\mathrm{SC}$ method were arranged. The parcels for the $\mathrm{NH}_{3}$ standard emission rates were placed upwind, so they were not influenced by the emissions of the applied manure. The arrangement of the field trial and the arrangement plot are displayed in Figure 2.10 and Figure 2.11.

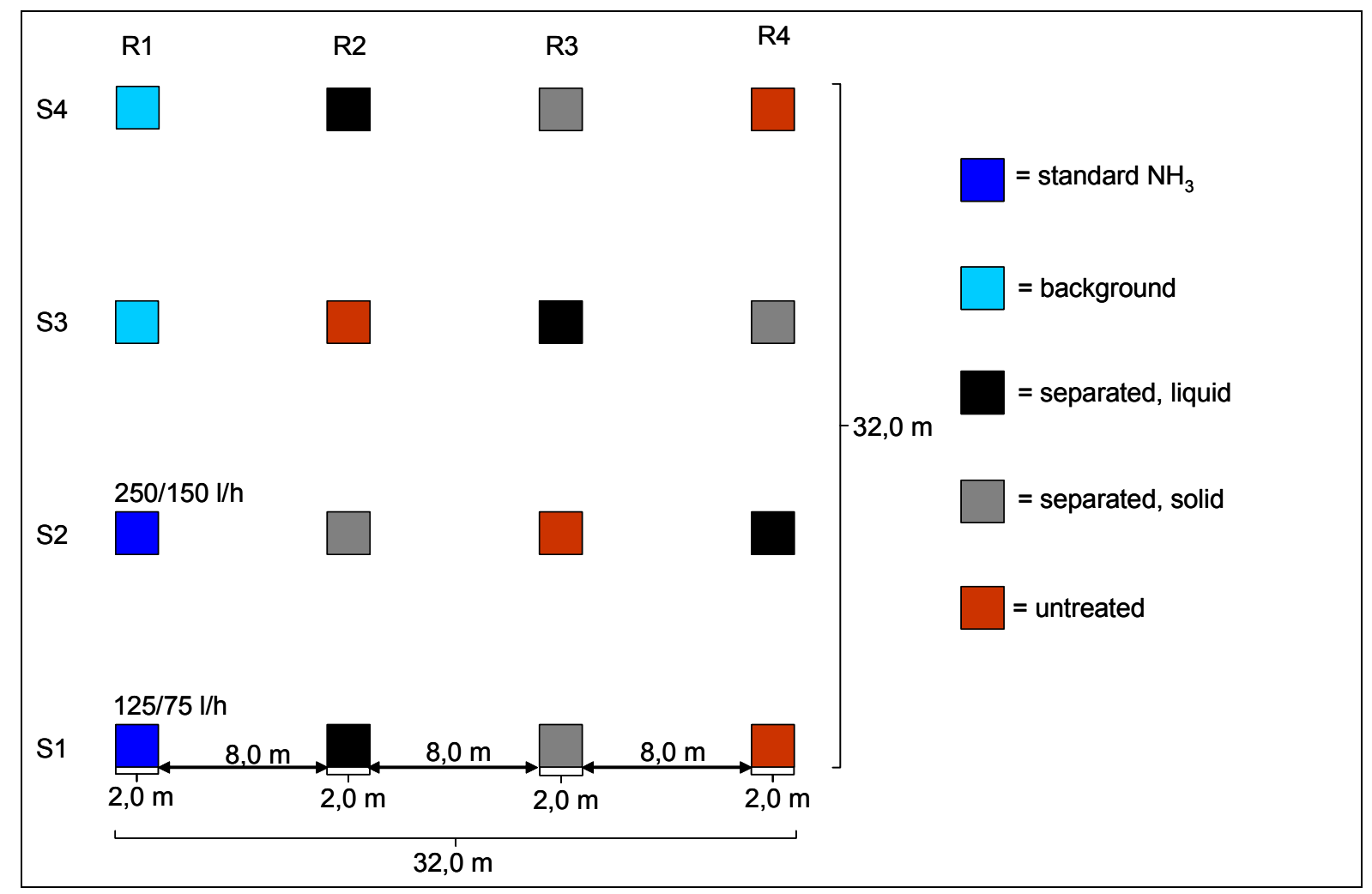

Figure 2.11: Arrangement plot of the field trial on emissions from biogas slurry substrates 
The parcels were quadratic and had a side length of $2.0 \mathrm{~m}\left(4.0 \mathrm{~m}^{2}\right)$. The distance between the parcels was set at $8.0 \mathrm{~m}$. These wide distances between the single parcels were elected to reduce the possibility of the results being influenced by emissions from neighbouring parcels. $30 \mathrm{~m}^{3} / \mathrm{ha}\left(3.0 \mathrm{l} / \mathrm{m}^{2}\right)$ of untreated manure, $30 \mathrm{~m}^{3} / \mathrm{ha}\left(3.0 \mathrm{l} / \mathrm{m}^{2}\right)$ of separated liquid, and $3.0 \mathrm{~kg} / \mathrm{m}^{2}$ of separated solids respectively were applied. Due to the comparable $\mathrm{NH}_{4}$ contents of the different substrates, no further differentiation of the applied masses according to the $\mathrm{NH}_{4}$ content was made.

Manure and separated liquid were applied close to the soil with trail hoses; separated solids were applied with a shovel. After application, all applied substrates were incorporated directly using a grubber. This application method was selected as it was fitting to the code of good agricultural practice.

Samples were taken every 6 hours during a period of 48 hours after application. All gaseous emissions from this trial were analysed taking into account $\mathrm{NH}_{3}, \mathrm{CH}_{4}$, and $\mathrm{N}_{2} \mathrm{O}$. Ammonia emissions $\left(\mathrm{NH}_{3}\right)$ were bound in passive collecting systems as described by [VANDRĖ\&KAUPENJOHANN1997] filled with 0.1molar sulphuric acid. The nitrogen share from this liquid was extracted using steam distillation (Fa. Gerhardt, Vapodest 20). Finally the extracted amount of nitrogen was determined with photo-optic analysis (Dr. Lange, XION 500).

Methane and laughing gas emissions were collected in $50 \mathrm{I}$ hoods. Thereto the concentrations of the gases under the hood were sampled every 15 minutes, four times per sampling date. Increase and the emission rates were calculated from this the concentration. The collected samples were gas chromatic determined in the laboratory of the Institute of Geography (University of Goettingen) Department of Landscape Ecology.

As seen in Figure 2.9 temperature and precipitation have a significant influence on applied manure emissions rates. Therefore air temperature was recorded for each sampling date. As there was no rainfall during the trial no data on the amount of precipitation were collected.

As emanate from Figure $2.12 \mathrm{CH}_{4}$ emission rate differences between the treatments are apparent. Most $\mathrm{CH}_{4}$ is emitted directly after application from untreated biogas slurry. This emission rate declines by time and could no longer be measured after $36 \mathrm{~h}$. After application the emissions could not be measured from solid and liquid phase of the separated biogas slurry. Some emissions could be measured 24 hours after application, when the temperature had reached its highest level. $\mathrm{CH}_{4}$ emissions are not analysed as background level. No more emissions from all treatments could be measured 36 hours after application. 


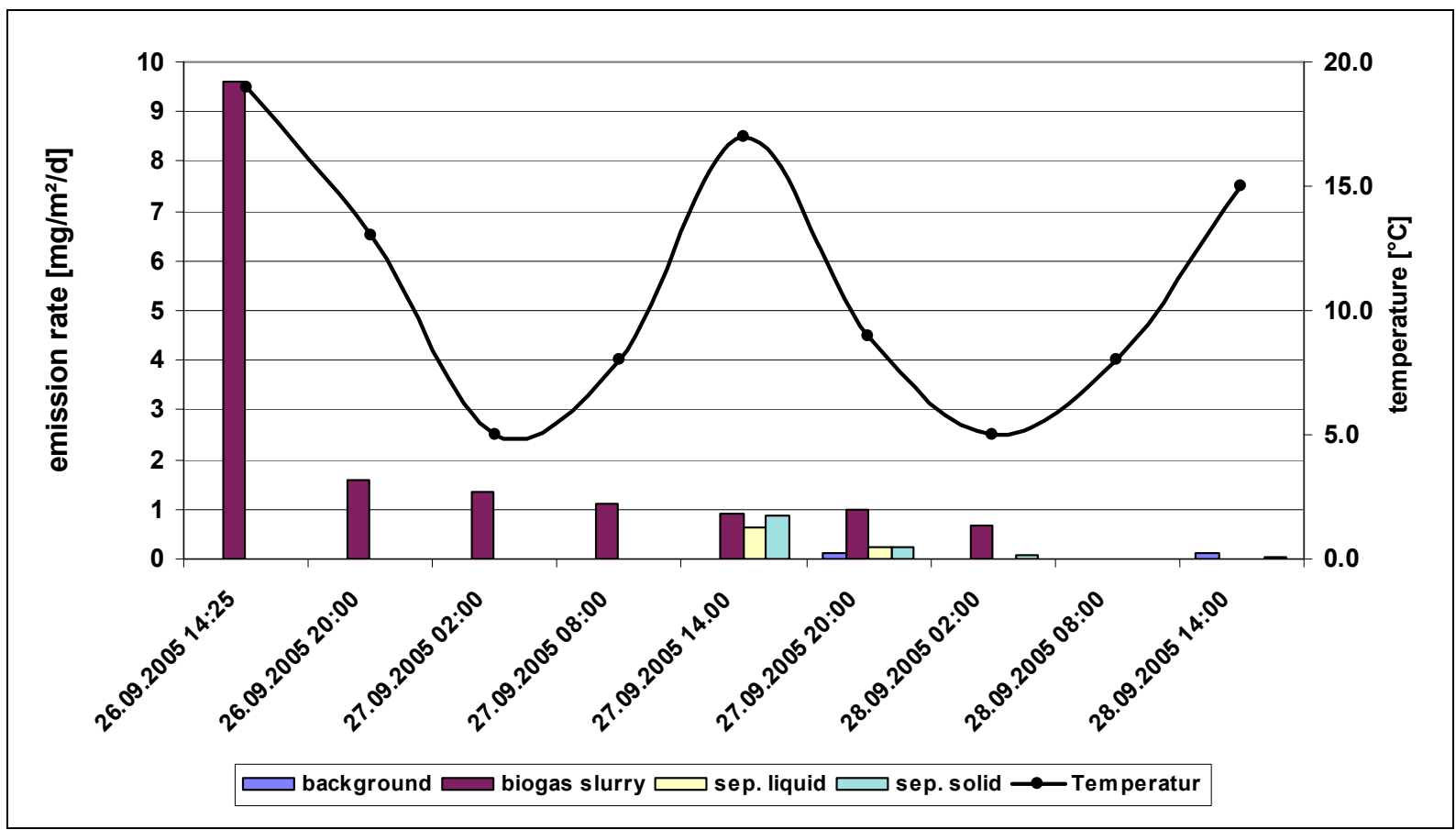

Figure 2.12: $\mathrm{CH}_{4}$ emissions after application of differently treated biogas slurry

As can be seen in Figure 2.13 hardly any laughing gas emissions can be measured directly after application. The emission rates of untreated biogas slurry and the liquid phase of the separated biogas slurry increase after six hours. Within a period of 42 hours these emission rates decline slowly, but do not reach the background emission level until the end of the trial. The emission rate of the solid phase of the separated manure does not significantly exceed the level of the background emission at any time. These results can be explained in two different ways. On the one hand the $\mathrm{NH}_{4}$ content is the base of $\mathrm{N}_{2} \mathrm{O}$ emissions as stated above. As untreated biogas slurry and the liquid phase of separated biogas manure normally have higher shares of $\mathrm{NH}_{4}-\mathrm{N}$ compared to separated solids from biogas slurry, these higher emission rates can be expected. On the other hand laughing gas is generated in anaerobe atmosphere. The solids left from the separation process do not infiltrate into the soil and instead remain in the upper soil, where oxygen is available. Therefore hardly any $\mathrm{N}_{2} \mathrm{O}$ is generated from the solid fraction. Temperature influences on the emission rate could not be recognised, so therefore no temperature data are given in this figure. 


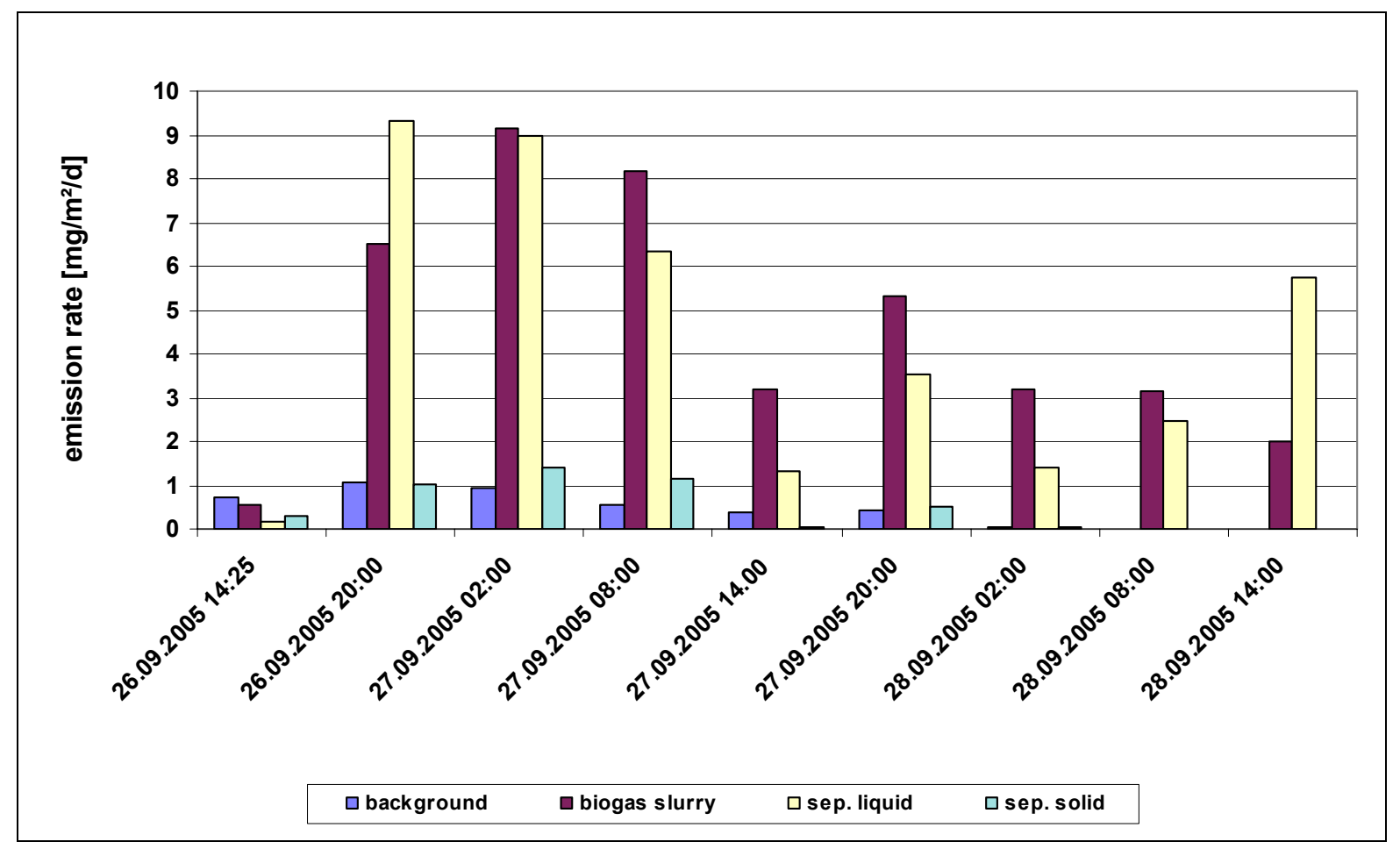

Figure 2.13: $\mathrm{N}_{2} \mathrm{O}$ emissions after application of differently treated biogas slurry

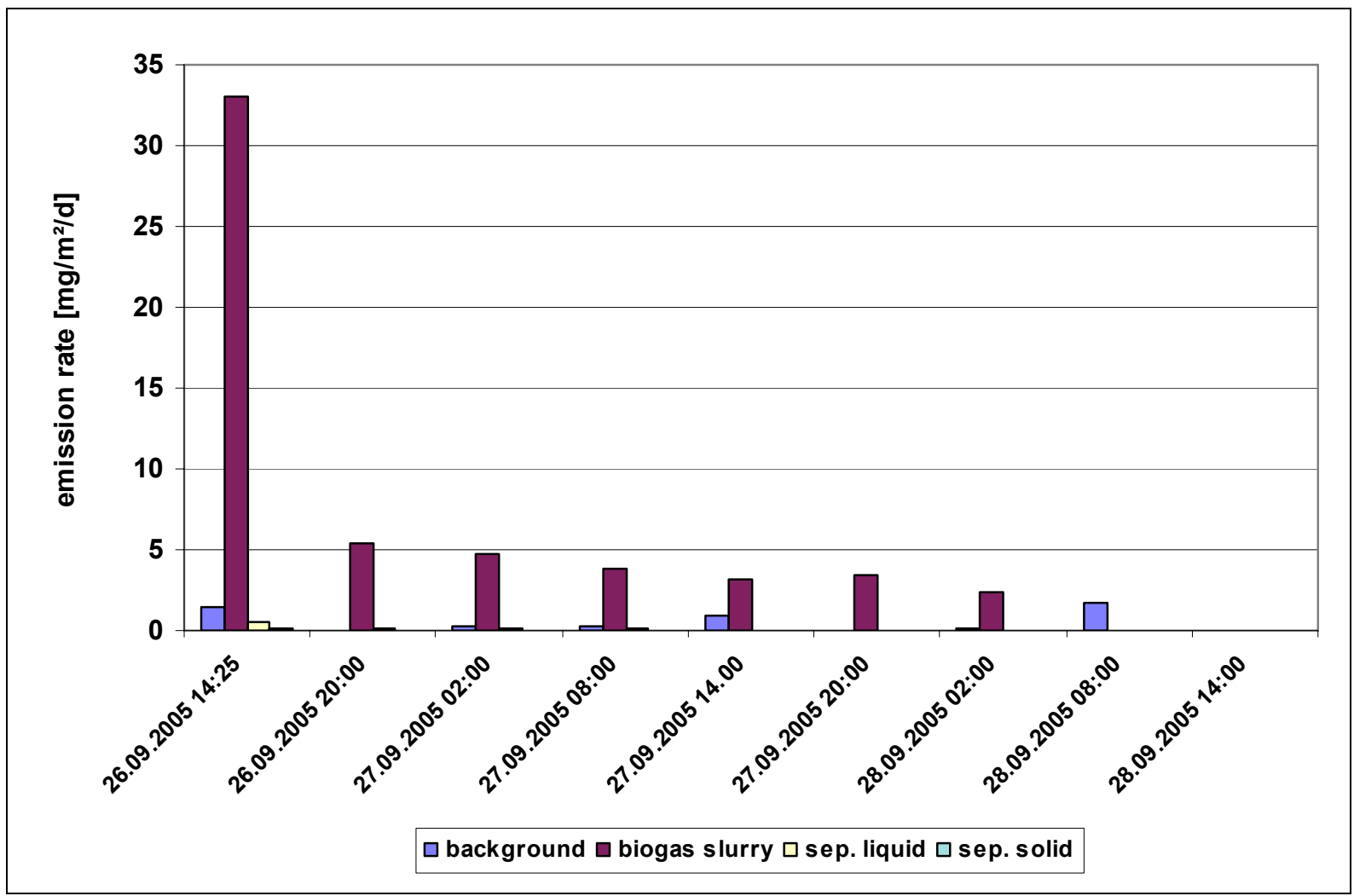

Figure 2.14: $\mathrm{NH}_{3}$ emissions after application of differently treated biogas slurry 
The $\mathrm{NH}_{3}$ emission rates, given in Figure 2.14, greatly differ between the several treatments. As stated in the studies mentioned previously, a $\mathrm{NH}_{3}$ emission rate of $33 \mathrm{mg} / \mathrm{m}^{2} / \mathrm{d}$ from biogas slurry occurs directly after application. This emission rate declines to less than $6 \mathrm{mg} / \mathrm{m}^{2} / \mathrm{d}$ in the following six hours. 42 hours after application no $\mathrm{NH}_{3}$ emissions exceeding background level can be measured. Both phases resulting from the separation process do not emit $\mathrm{NH}_{3}$ in levels above the background emission rate.

Integrating the results of the emission rates of each sample date leads to a $48 \mathrm{~h}$ emission for each treatment. To integrate the single samples the emission rates per sample date are considered to be the same for a period of six hours. These six hour emission rates are summed up, resulting in a $48 \mathrm{~h}$ emission level. The results of these calculations are shown in the following figures.

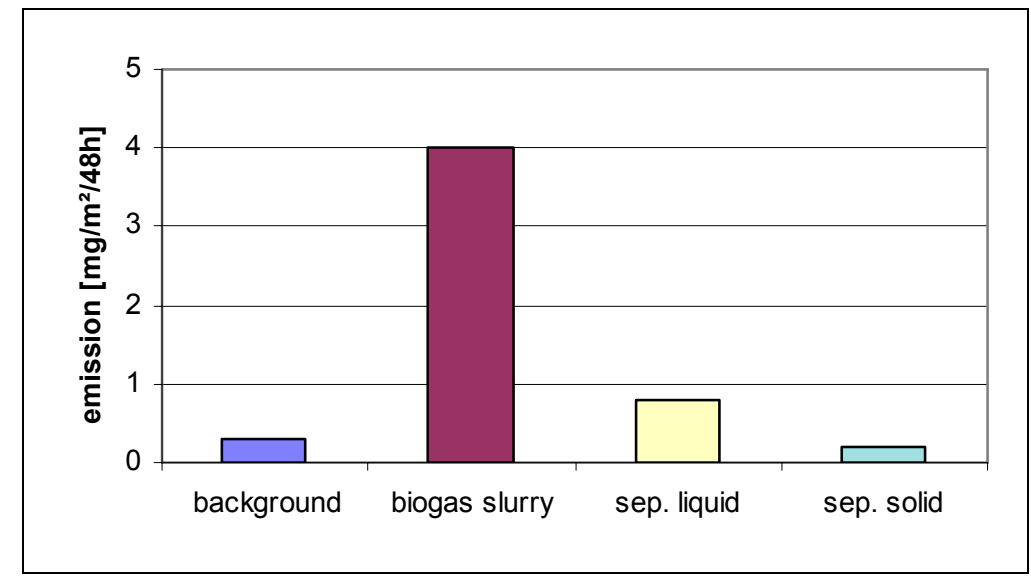

Figure 2.15: $\mathrm{CH}_{4}$ emissions within 48 hours

Most methane emissions were released from the untreated biogas slurry, as seen in Figure 2.15. A sum of $4.0099 \mathrm{mg} / \mathrm{m}^{2} / 48 \mathrm{~h}$ was emitted from this treatment. Background emissions occurred on a level of $0.3057 \mathrm{mg} / \mathrm{m}^{2} / 48 \mathrm{~h}$. The liquid fraction of the separated manure emitted $0.7993 \mathrm{mg} / \mathrm{m}^{2} / 48 \mathrm{~h}$, while the solid fraction emitted $0.1828 \mathrm{mg} / \mathrm{m}^{2} / 48 \mathrm{~h}$. Based on a theoretical assumption, it is apparent that most emissions occur from biogas slurry. It is also clear that only a few emissions occur from the solid fraction, as this treatment does not infiltrate deeply into the soil and stays in aerobe areas, where $\mathrm{CH}_{4}$ is not generated. The emission level from the liquid fraction cannot be explained. It is assumed that enough organic-fixed carbon was reserved in the liquid phase and infiltrated into anaerobe layers of the soil, where methane was generated. 


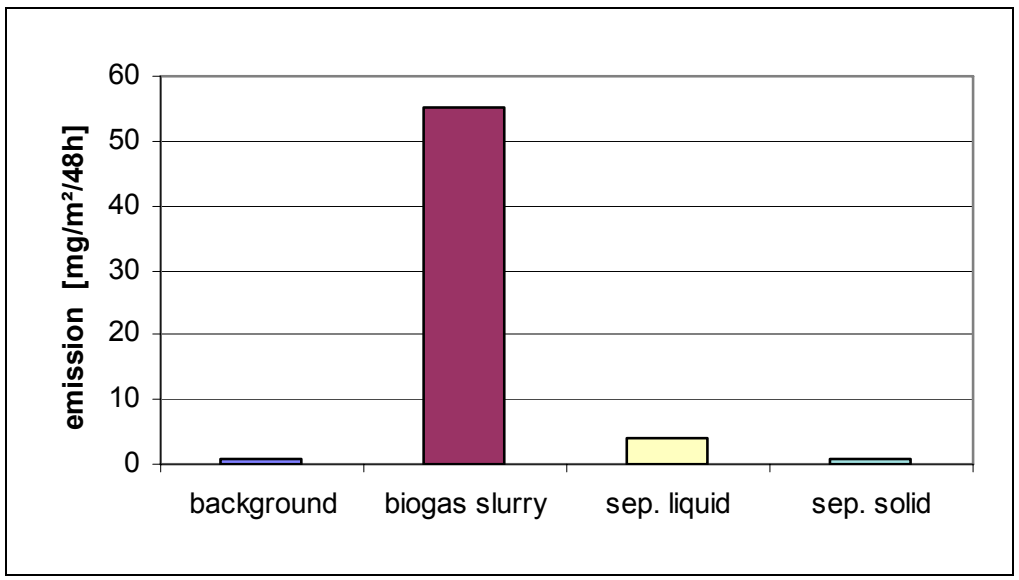

Figure 2.16: $\mathrm{NH}_{3}$ emissions within 48 hours

Hardly any $\mathrm{NH}_{3}$ emissions could be measured from the background level; $1.0 \mathrm{mg} / \mathrm{m}^{2} / 48 \mathrm{~h}$ of gaseous $\mathrm{NH}_{3}$ were detected. As assumed from theory, high emissions were caused by the applied biogas slurry. Around $55.16 \mathrm{mg} / \mathrm{m}^{2} / 48 \mathrm{~h}$ occurred, which can be explained from the $\mathrm{NH}_{4}-\mathrm{N}$ content and the low infiltration rate of the treatment. In comparison to the untreated biogas slurry, a small amount of emissions occurred from the separated liquid fraction. An emission level of $3.89 \mathrm{mg} / \mathrm{m}^{2} / 48 \mathrm{~h}$ was reached. This quite low emission level could be explained by the higher infiltration rate of the liquid phase compared to the untreated biogas slurry. The separated solid phase emitted $0.89 \mathrm{mg} / \mathrm{m}^{2} / 48 \mathrm{~h}$. Therefore, this emission is considered to be at the level of the background emission, which can be explained by the low $\mathrm{NH}_{4}-\mathrm{N}$ content in the solid phase. It could have been shown that separation of biogas slurry leads to a total reduction of $\mathrm{NH}_{3}$ emissions from biogas slurry.

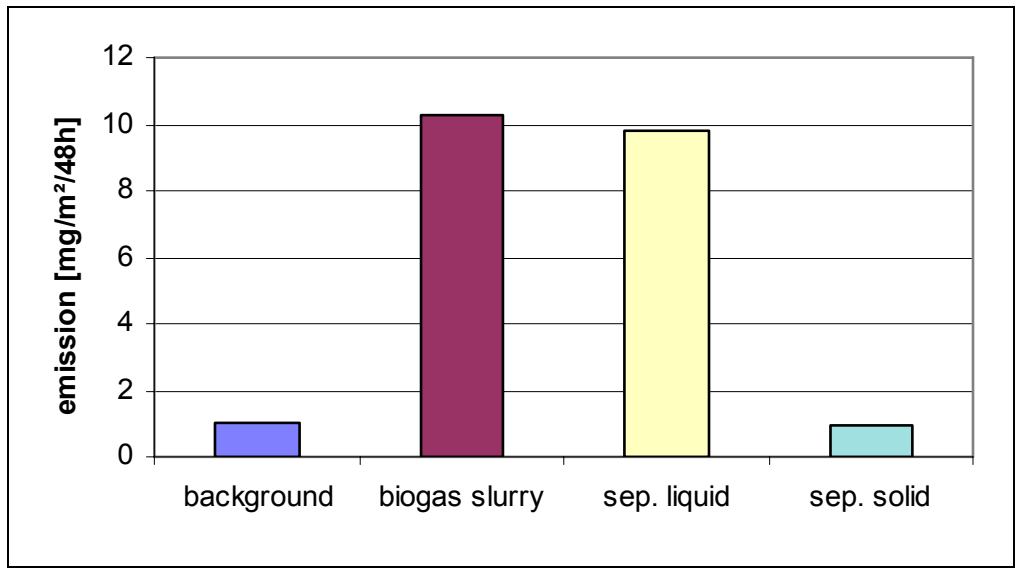

Figure 2.17: $\mathrm{N}_{2} \mathrm{O}$ emissions within 48 hours

An emission level of $10.3 \mathrm{mg} / \mathrm{m}^{2} / 48 \mathrm{~h}$ was created from applied biogas slurry. Nearly the same emission level $\left(9.8 \mathrm{mg} / \mathrm{m}^{2} / 48 \mathrm{~h}\right)$ was caused by the applied liquid phase from the separated manure. Hardly any $\mathrm{N}_{2} \mathrm{O}$ emissions $\left(0.96 \mathrm{mg} / \mathrm{m}^{2} / 48 \mathrm{~h}\right)$ were emitted from the solid phase of the separation. This was at the same level as the background emissions, causing an emission level of $1.0 \mathrm{mg} / \mathrm{m}^{2} / 48 \mathrm{~h}$. These results confirm the assumptions that can be made from literature. The high content of $\mathrm{NH}_{4}-\mathrm{N}$ and the high infiltration rate of the separated liquid phase of the biogas slurry causes this emission level, which is comparable to the emission 
level of the biogas slurry. This means, that no effective $\mathrm{N}_{2} \mathrm{O}$ emission reduction can be achieved by biogas slurry separation.

The gained results for untreated biogas slurry equals the emission rates stated by [AMON ET AL.2002] for $\mathrm{N}_{2} \mathrm{O}$ and $\mathrm{CH}_{4}$ from stored manure. This source states $\mathrm{N}_{2} \mathrm{O}$ emission rates of $106 \mathrm{~g} / \mathrm{ha}$, while the self-done analysis resulted in $103 \mathrm{~g} / \mathrm{ha}$. Besides, a $\mathrm{CH}_{4}$ emission rate of $30 \mathrm{~g} / \mathrm{ha}$ is stated from this source, while the self-done analysis resulted in $40.1 \mathrm{~g} / \mathrm{ha}$. There are wide differences between the results from [AMON ET AL.2002] and the self-done analysis for the $\mathrm{NH}_{3}$ emission rates from biogas slurry. This source records an emission level of 8,800 $\mathrm{g} / \mathrm{ha}$, while $551.6 \mathrm{~g} / \mathrm{ha}$ of $\mathrm{NH}_{3}$ emissions were analysed in this self-done study. This wide difference can be explained by the use of the application and incorporation methods, which form part of good agricultural practice, in the self-done analysis. As explained above, the majority of $\mathrm{NH}_{3}$ emissions are caused by careless application, e.g. broadcasting, and no incorporation after application. This can lead to $\mathrm{NH}_{3}$ emissions of $90 \%$ of all applied $\mathrm{NH}_{4}-\mathrm{N}$, while application according to good agricultural practice can reduce these emissions to less than $10 \%$ of applied $\mathrm{NH}_{4}-\mathrm{N}$.

On completing the analysis, the emission rates for $\mathrm{NH}_{3}$ were checked due to the low level of $\mathrm{NH}_{3}$ emissions from the separated liquid phase. In doing this, an additional influence was found that had not been noticed before. The manure and the separated fractions are from a real existing biogas plant. In this plant, the biogas slurry is separated and afterwards the liquid phase of the separation is concentrated by evaporation. To avoid evolution of gaseous $\mathrm{CO}_{2}$ while evaporation, sulphuric acid is added to reduce the $\mathrm{pH}$ value of the liquid. This $\mathrm{pH}$ value reduction leads to a decline in $\mathrm{NH}_{3}$ emissions, as the generation of $\mathrm{NH}_{3}$ from $\mathrm{NH}_{4}$ is influenced by the $\mathrm{pH}$ value (cf. equation (6)). In general terms, a reduction of the $\mathrm{pH}$ value by factor 1 leads to a $\mathrm{NH}_{3}$ emission reduction by factor 10 . Given that the quantity of sulphuric acid added is not known, no information can be provided regarding the impact this influence had on the overall effect.

This will be taken into account in the sensitivity analysis concerning the influence of biogas slurry separation on the ecological overall effect. It will be assumed that sulphuric acid is added to the liquid phase reducing the $\mathrm{pH}$ value by a factor of 1 .

Table 2.30 presents data (net emissions from biogas slurry) taken into account for the $\mathrm{LCl}$. These data are made up from the emissions related to the application of biogas slurry and avoided emissions from manure, which is used as an input to the biogas production, according to Table 2.11. These data are related to one functional unit. These two factors lead to the net emissions, which have to be calculated within LCl. It is noted, that a net amount of around $8.15 \mathrm{~kg}$ of $\mathrm{NH}_{3}$ is emitted from slurry application. In addition, emissions of $4.53 \mathrm{~kg}$ of $\mathrm{CH}_{4}$ and $0.50 \mathrm{~kg}$ of $\mathrm{N}_{2} \mathrm{O}$ are avoided due to the fermentation and storage process of the manure within the biogas production. 
Table 2.30: Emissions from biogas slurry cleared by avoided emissions from manure used as input

\begin{tabular}{|l|c|c|c|}
\hline emissions & $\begin{array}{c}\text { biogas slurry } \\
\mathbf{9 4 5 . 5}[\mathrm{Mg} / \mathrm{TJ}]\end{array}$ & $\begin{array}{c}\text { share of manure } \\
\mathbf{1 7 8 . 5}[\mathrm{Mg} / \mathrm{TJ}]\end{array}$ & $\begin{array}{c}\text { net emissions from } \\
\text { biogas slurry }\end{array}$ \\
\hline $\mathrm{NH}_{3}$ & $17,384 \mathrm{~g} / \mathrm{TJ}$ & $2,963 \mathrm{~g} / \mathrm{TJ}$ & $14,421 \mathrm{~g} / \mathrm{TJ}$ \\
\hline $\mathrm{CH}_{4}$ & $1,264 \mathrm{~g} / \mathrm{TJ}$ & $5,334 \mathrm{~g} / \mathrm{TJ}$ & $-4,070 \mathrm{~g} / \mathrm{TJ}$ \\
\hline $\mathrm{N}_{2} \mathrm{O}$ & $3,245 \mathrm{~g} / \mathrm{TJ}$ & $2,577 \mathrm{~g} / \mathrm{TJ}$ & $668 \mathrm{~g} / \mathrm{TJ}$ \\
\hline
\end{tabular}

Explanation: Data on the share of manure are taken from [AMON ET AL.2002] as presented above. Due to the differences in the $\mathrm{NH}_{3}$ emission levels described above, data on the $\mathrm{NH}_{3}$ emissions from manure are taken from the same source but reduced to $6.26 \%$. This reduction equals the relation between the emission level measured by [AMON ET AL.2002] and the self analysed emissions from $\mathrm{NH}_{3}$ from biogas slurry.

\section{Odorant emissions}

A variety of odorous substances from manure are reduced via fermentation. The smell of the odour is altered and is subsequently deemed less unpleasant by many people [WILFERT ET AL.2004]. Degradation of high-molecular organic compounds and the clearing of sulphurous compounds while fermenting cause this reduction. It is not possible to provide data on the reduction potential of this environmental effect due to the complicated nature of determining odour concentrations by olfactometry. Therefore this effect will not be assessed in this LCA study.

\section{Reduction of germs}

Bacteria and viruses can be reduced or inactivated through the fermentation process. Also the germination capacity of pest seeds can be reduced through the fermentation process. This results in biogas slurry having more hygienic advantages compared to untreated manure when applied. Biogas slurry from six biogas plants was analysed for their hygienic aspects [JäKEL\&MAU1999]. A safe reduction of germs could not be proven. All samples exceeded the tolerable amount of total coliform bacteria, faecal coliform bacteria, and faecal streptococcus. No ecological savings will therefore be calculated in the LCl.

\section{LCl data}

Resulting from this chapter data shown in Table 2.31 are taken into account for the assessment of the application of the biogas slurry. In this table the applicated amount of biogas slurry, the transport efforts per slurry scenario, the substituted amounts of artificial fertilisers, and the emissions from the applied fertilisers are given.

Three different biogas slurry application scenarios are taken into account. Scenario (1) is the standard scenario. In this scenario conventional biogas slurry is applied according to good agricultural practice standard. In scenario (2) the application of conventional slurry with a broadcaster without an additional incorporation process is simulated. Scenario (3) considers the application of treated biogas slurry. This special scenario is explained in chapter 2.7.5.

The application data are resulting from the measurements and calculations given in Table 2.11. The transport efforts base on these data combined with the result of equation (4). The gaseous emissions of the different biogas slurries are based on the results of the field trials of this chapter. The emission of the below good agricultural practice application scenario are 
taken from [AMON ET AL.2002]. The nutrients content of cow and pig manure is derived from literature data [FNR2004]. The emissions from the application of the biogas slurry are neglected.

The substitution of $\mathrm{NH}_{4}-\mathrm{NH}_{3}$ is made up from $100 \%$ of the $\mathrm{NH}_{4}-\mathrm{N}$ content of the biogas slurry and $50 \%$ of the remaining nitrogen $\left(\mathrm{N}_{\text {tot }}-\mathrm{NH}_{4}\right)$, reduced by the gaseouse nitrogen emissions. The $\mathrm{P}_{2} \mathrm{O}_{5}$ content of the slurry is taken into account by $100 \%$.

The nutrient content of the manure is substracted from the nutrient content of the biogas slurry. This is done, because the manure would be used as organic fertiliser, if it would not be used as input to the biogas plant. So, a fertiliser is brought into a process, which produces fertiliser. Counting the effects of this input fertiliser would cause double counting.

Table 2.31: LCI data for biogas slurry application scenarios

\begin{tabular}{|c|c|c|c|c|c|c|c|}
\hline Scenario & $\begin{array}{l}\text { Appli- } \\
\text { cation } \\
{\left[\mathrm{m}^{3}\right]}\end{array}$ & $\begin{array}{c}\text { Transport } \\
\text { [tkm] }\end{array}$ & $\begin{array}{l}\text { Substitu- } \\
\text { ted } \mathrm{NH}_{4^{-}} \\
\mathrm{NH}_{3}[\mathrm{~kg}]\end{array}$ & $\begin{array}{c}\text { Substitu- } \\
\text { ted } \mathrm{P}_{2} \mathrm{O}_{5} \\
{[\mathrm{~kg}]}\end{array}$ & $\begin{array}{l}\mathrm{CH}_{4} \text { emis- } \\
\text { sions [g] }\end{array}$ & $\begin{array}{c}\mathrm{NH}_{3} \text { emis- } \\
\text { sions [g] }\end{array}$ & $\begin{array}{c}\mathrm{N}_{2} \mathrm{O} \text { emis- } \\
\text { sions [g] }\end{array}$ \\
\hline $\begin{array}{l}1.0 \mathrm{MW} \text {, } \\
\text { standard }\end{array}$ & 945.50 & 6,647 & $2,978.33$ & 756.40 & $1,263.79$ & $17,384.62$ & $3,246.19$ \\
\hline $\begin{array}{l}\text { 1.0 MW, } \\
\text { non-gap }\end{array}$ & 945.50 & 6,647 & 936.05 & 756.40 & $3,082.33$ & $543,977.35$ & $14,277.05$ \\
\hline $\begin{array}{l}1.0 \mathrm{MW}, \\
\text { sep. solid }\end{array}$ & 162.06 & 1,139 & 688.75 & 526.69 & 10.14 & 48.08 & 43.22 \\
\hline $\begin{array}{l}1.0 \mathrm{MW}, \\
\text { sep. liquid }\end{array}$ & 185.81 & 1,306 & 529.57 & 111.49 & 49.51 & 240.95 & 59.46 \\
\hline $\begin{array}{l}1.0 \mathrm{MW} \\
\text { liq.+sol. mix }\end{array}$ & 347.87 & 2,446 & $1,218.32$ & 638.18 & 59.65 & 289.03 & 102.68 \\
\hline cow manure & 150.0 & & 504.0 & 180.0 & & & \\
\hline pig manure & 120.0 & & 630.0 & 240.0 & & & \\
\hline$\Sigma$ manure & 270.0 & & $1,134.0$ & 420.0 & & & \\
\hline
\end{tabular}

Regarding the nutrient contents of the mixed solid and liquid fraction of the separated manure compared to the standard scenario show some differences. Around 2,760 kg of nitrogen and $118 \mathrm{~kg}$ of phosphate are lost in the mixed treated biogas slurry. These losses cannot be explained by chemistry. Therefore an error in measurement is assumed. For the nutrient content of the mixed separated biogas slurry the same data will be assumed as for the standard biogas slurry. 


\subsection{Life cycle impact assessment}

Within the impact assessment of a LCA, this being a life-cycle-impact-assessment study, the results of the $\mathrm{LCl}$ are described and evaluated, i.e. inventory data are categorised into potential effects on the environment and are also classified into impact categories. General information on the ecological effects, instead of the actual real effects occurring in the environment are given as a result of the impact assessment step. It is generally not possible to give information on the real occurring effects due to limitations in area and time relationship and also due to the absolute amount of produced functional units related to the LCA. When classifying LCl data, it has to be noted that only one data should be classified within one impact category. If this one data can be listed in different impact categories, allocation rules must be defined in the goal and scope definition [UBA1999, CEN200A].

According to ISO 14040 and 14042, life-cycle-impact-assessment (LCIA) is essentially meant to improve the understanding of the results of the inventory phase [GOEDKOOP\&SPRIENSMA2001]. It is shown in [HOFSTETTER1999] that LCIA has to deal with three scientific knowledge fields and reasoning, which are called spheres. These are:

$>$ Technosphere, which is the description of the life cycle, the emissions from processes, the allocation procedures based on causal relations.

$>$ Ecosphere, which symbolises changes, which probably damage the inflicted environment.

$>$ Valuesphere, which means the assessment of the perceived seriousness of such changes/damages, as well as the management of modelling choices that are made in techno- and ecosphere.

Data collected in techno- and ecosphere can be measured, calculated or estimated. All of these data are based on technical and natural science and could therefore be regarded as reliable facts. The assessment of the valuesphere is based in the world of social science. In order to calculate ecosphere processes, natural science based methods are used. From a natural science point of view, the findings of ecological effects due to a product life cycle are therefore deemed reliable. The following valuation procedure is used to establish how serious these changes really are. Definitions, conclusions and all other aspects, which influence the results of the LCA, must be regarded as undependable facts. It is important to understand, that unlike in the other two spheres, there is no "single truth" in valuesphere. All of these three spheres are needed to provide understandable and comparable results within a LCA study.

The Eco indicator '99 approach (El'99, explained in detail in chapter 2.8) uses these three spheres in the following way. In step 1, the model of the life cycle is defined in the technosphere. It effects the inventory table. In step 2, the inventory table is linked with the three damage categories of the El'99 when modelling the ecosphere. Finally, in the last step, valuesphere modelling is used to weight the three endpoints to a single indicator, and to model 
the value choices in the ecosphere [GOEDKOOP\&SPRIENSMA2001]. The core concept of the El'99 method can be seen in Figure 2.18.

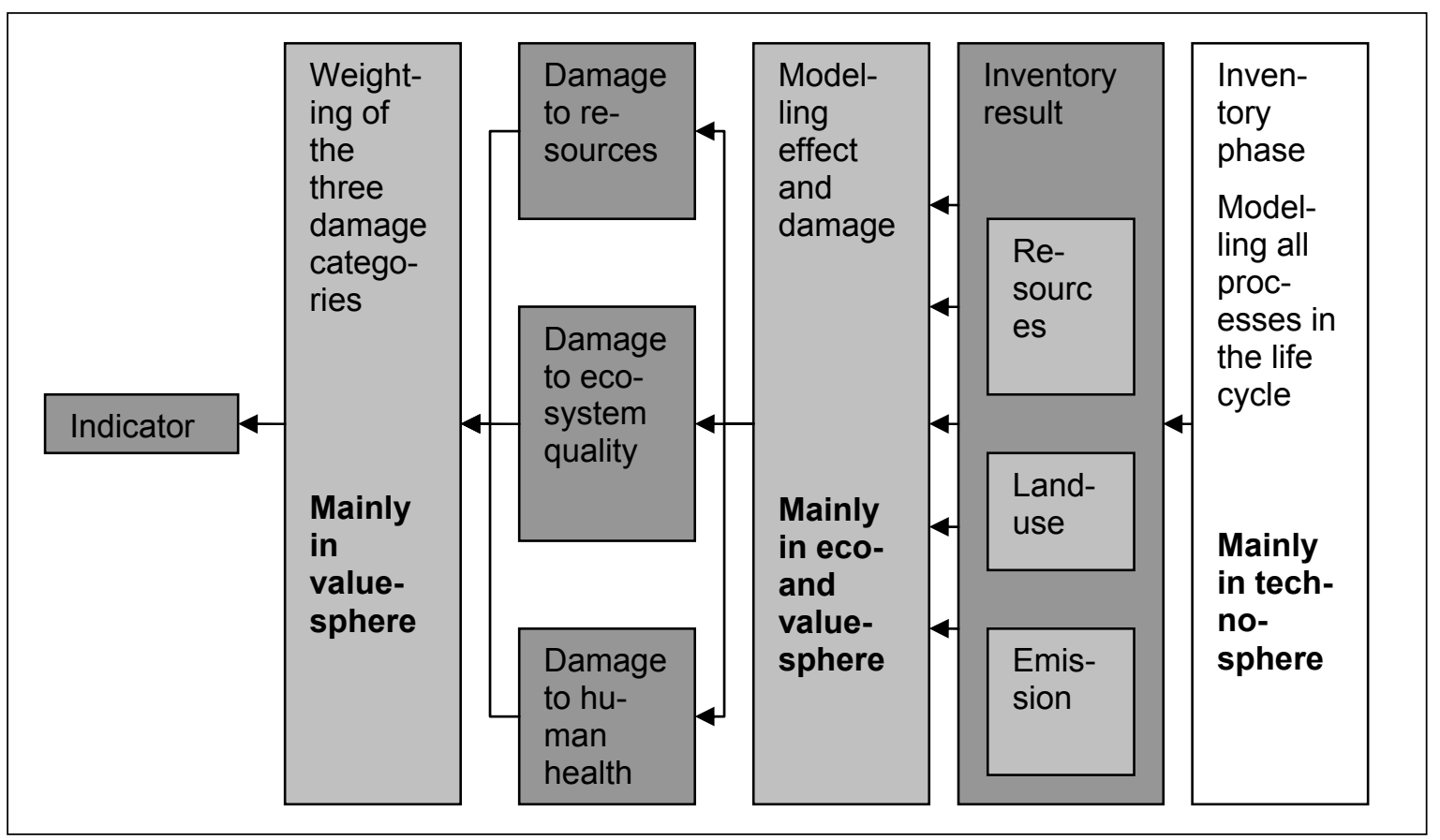

Figure 2.18: Core concept of El'99 [GOEDKOOP\&SPRIENSMA2001]

\subsubsection{Impact Categories}

According to ISO 14042 impact categories are categories, which represent important threats to the environment in which $\mathrm{LCl}$ results can be classified [CEN2000a]. Summed up more than 20 impact categories are used for utilisation in LCIA. Every LCA can include further or new categories, so the total number and kind of impact categories cannot be given. Normally just a few of all impact categories are used within a single LCA. For each LCA a special set of impact categories can be defined, representing the system under investigation and its threats to the environment. The following categories are ones most often used:

$>$ mineral resources

$>$ fossil resources

$>$ land use

$>$ water use

$>$ waste

$>$ human-/ecotoxicity

$>$ acidification

$>$ green house effect

$>$ ozone depletion

$>$ eutrophication
$>$ photochemical oxidants

$>$ noise and odour

$>$ waste heat

$>$ ionising radiation

$>$ biodiversity

$>$ soil function 
These frequently used impact categories can be added to special categories for special LCA objectives. According to [GEIER2000] these could be e.g. traffic accidents or incidents with nuclear material, electro magnetic radiation or any other kind of annoyance like light. Separate sections of the object under investigation can have main focuses on special impact categories. In the case of the agricultural production system, cultivating energy crops for the biogas plant, the impact categories shown in Table 2.32 are relevant [HAAS ET AL.2000].

Table 2.32: Impact categories and indicators of agricultural production systems

\begin{tabular}{|c|c|c|}
\hline \multicolumn{2}{|c|}{ impact categories } & indicators \\
\hline \multirow{2}{*}{ resources } & fossil & consumption of primary energy sources \\
\hline & mineral & consumption of K- and P- fertilizers \\
\hline \multicolumn{2}{|l|}{ green house effect } & $\begin{array}{l}\mathrm{CO}_{2^{-}}, \mathrm{CH}_{4^{-}} \text {and } \mathrm{N}_{2} \mathrm{O} \text {-emissions }\left(\mathrm{CO}_{2^{-}}\right. \\
\text {equivalents) }\end{array}$ \\
\hline \multirow{2}{*}{ soil function, land use } & rye, grass & $\mathrm{NH}_{3^{-}}, \mathrm{NO}_{x^{-}}, \mathrm{SO}_{2}$-emissions, $\mathrm{N}$ - and P-surplus \\
\hline & maize, forage beets & $\left(\mathrm{SO}_{2}\right.$ - and $\mathrm{PO}_{4}$-equivalents), hemeroby scale \\
\hline \multirow{2}{*}{ water quality } & $\begin{array}{l}\text { ground water (ni- } \\
\text { trate leaching) }\end{array}$ & $\mathrm{N}$-fertilisation, nitrogen balance, nitrate leaching \\
\hline & $\begin{array}{l}\text { surface water } \\
\text { (P-over-fertilisation) }\end{array}$ & P-fertilisation, P-balance \\
\hline \multicolumn{2}{|l|}{ human-/ecotoxicity } & $\begin{array}{l}\text { utilisation of herbicides and antibiotics, nitrate } \\
\text { leaching, } \mathrm{NH}_{3} \text {-emissions }\end{array}$ \\
\hline
\end{tabular}

The transport module can be described with the impact categories and indicators given in Table 2.33. These categories and their indicators are considered as the most relevant impacts by [BORKEN ET AL.1999]. The assumptions are mainly based on the standard impact category list of DIN-NAGUS, so that most impact categories are the same as in the module agricultural production system.

Table 2.33: Impact categories and indicators in the transport module [BORKEN ET AL.1999]

\begin{tabular}{|l|l|}
\hline \multicolumn{1}{|c|}{ impact categories } & \multicolumn{1}{c|}{ indicators } \\
\hline resources & consumption of primary energy sources \\
\hline land use & covered land, hemeroby scale \\
\hline green house effect & $\mathrm{CO}_{2}, \mathrm{CH}_{4}$ - and $\mathrm{N}_{2} \mathrm{O}$-emissions $\left(\mathrm{CO}_{2}\right.$-equivalents $)$ \\
\hline ozone depletion & $\mathrm{CFC}$ emissions $(\mathrm{ODP}$-equivalents $)$ \\
\hline acidification & $\mathrm{SO}_{2}, \mathrm{NO}, \mathrm{NO}_{2}, \mathrm{HCl}, \mathrm{NH}_{3}\left(\mathrm{SO}_{2}\right.$-equivalents $)$ \\
\hline eutrophication & $\mathrm{NO}_{x}, \mathrm{NH}_{4}, \mathrm{PO}_{4}{ }^{3-}\left(\mathrm{PO}_{4}\right.$-equivalents $)$ \\
\hline human-/ecotoxicity & particulates, cancerogens, dioxins \\
\hline photochemical smog & $\mathrm{O}_{3}$, polyacrylonitrile close to the ground \\
\hline noise & $\mathrm{dB}$, time, and distance \\
\hline
\end{tabular}

Up until now, the impact categories of the module biogas plant were only described by [EDELMANN ET AL.2001]. The whole range of impact categories of the Eco indicator '95 method was thereby used. These categories are mainly based on the standard impact category list of DIN-NAGUS. Therefore, the impact categories used to describe the biogas plant are quite similar to the categories already mentioned above and are given in Table 2.34. 
Table 2.34: Impact categories in the module biogas plant [EDELMANN ET AL.2001]

\begin{tabular}{|c|c|c|}
\hline \multicolumn{2}{|c|}{ impact category } & indicator \\
\hline \multirow{2}{*}{ resources } & fossil & consumption of primary energy sources \\
\hline & mineral & consumption of $\mathrm{K}$ - and $\mathrm{P}$ - fertilizers \\
\hline \multicolumn{2}{|l|}{ land use } & covered land, hemeroby scale \\
\hline \multicolumn{2}{|c|}{ green house effect } & $\mathrm{CO}_{2^{-}}, \mathrm{CH}_{4^{-}}$and $\mathrm{N}_{2} \mathrm{O}$-emissions ( $\mathrm{CO}_{2}$-equivalents) \\
\hline \multicolumn{2}{|c|}{ ozone depletion } & CFC emissions (ODP-equivalents) \\
\hline \multirow{2}{*}{\multicolumn{2}{|c|}{$\begin{array}{l}\text { acidification } \\
\text { eutrophication }\end{array}$}} & $\mathrm{SO}_{2}, \mathrm{NO}, \mathrm{NO}_{2}, \mathrm{HCl}, \mathrm{NH}_{3}\left(\mathrm{SO}_{2}\right.$-equivalents) \\
\hline & & $\mathrm{NO}_{\mathrm{x}}, \mathrm{NH}_{4}, \mathrm{PO}_{4}^{3-}\left(\mathrm{PO}_{4}\right.$-equivalents $)$ \\
\hline \multicolumn{2}{|c|}{ ionising radiation } & Bq, radioactive substances \\
\hline \multicolumn{2}{|c|}{ respiratory org./inorg } & SPM, VOCs, adapted to DALY \\
\hline \multicolumn{2}{|c|}{ cancerogens } & adapted to DALY \\
\hline
\end{tabular}

In this study, the Eco indicator '99 method is used for assessing the results of the life cycle inventory phase. This method aggregates the above represented damage categories to three safeguard subjects: Human Health, Ecosystem Quality, and Resources (also see chapter 2.8.1). The single damage categories will be shown as follows grouped by safeguard subjects. Explanations are given about impact categories, their contents, and the way of data is collected in order to make the classification process of the $\mathrm{LCl}$ results intelligible. The definitions of the different impact categories are not consistent through different LCAs. In the following chapters the definitions of [PATYK\&REINHARDT1997, UBA1999] will be used.

\section{Human Health}

Human Health is defined by the World Health Organisation (WHO) as "a state of complete physical, mental, and social well being, and not merely the absence of disease or infirmity. (This) ... includes both the direct pathochemical effects of chemicals, radiation and some biological agents, and the effects on health and well-being of the broad physical, psychological, social and aesthetic environment, which includes housing, urban development, land-use and transport" [WHO1946, GOEDKOOP\&SPRIENSMA2001].

This definition is considered too broad for the use in LCA studies. In LCA studies unhealthy conditions at workplaces, homes, traffic accidents, drinking, and smoking are not taken into account. In addition to these, natural disasters, climate, micro-organisms, and volcanic eruptions are also not calculated. For the purpose of this LCA, in which the El'99 method is applied, the definition of Human Health of WHO is altered in the following way: "Human Health (is)... the absence of premature death, sickness or irritations caused by emissions from industrial and agricultural processes to air, water and soil" [GOEDKOOP\&SPRIENSMA2001]. This definition takes into account the number of individuals affected, the length of time humans suffer or the lifetime lost to premature death, and the severity of the health problem.

The number of Disability-Adjusted Life Years (DALY), counting the number of fallen ill due to disability and premature death is used as an indicator to express human health. Thereby the time lived with disabilities is counted as Years Lived Disabled (YLD) and combined with the time lost due to premature mortality i.e. Years Life Lost (YLL). 
Carcinogenic substances, these are hard to assess, as the causal link between a substance considered as carcinogenic and the resulting effect is almost impossible to prove. Risk assessments are done by the International Agency of Cancer Research, which leads to a ranking scheme for different substances. This ranking scheme is used together with the Unit-Risk model of the WHO to estimate the cancer risk. The Unit-Risk concept is used to estimate of the dose response relationship [WHO1987]. A major problem when estimating the cancer risk is based on the fate analysis, which is regarding the exposure of carcinogenic substances to air, water, and food.

- Respiratory effects, on humans are caused by several inorganic substances and dust: Particulate matter $\mathrm{PM}_{10}$ and $\mathrm{PM}_{2,5}$, Nitrate and sulphate, $\mathrm{SO}_{3}, \mathrm{O}_{3}, \mathrm{CO}$, and $\mathrm{NO}_{\mathrm{x}}$. These substances are caused by the following primary emissions or pollutants: $\mathrm{PM}_{10}, \mathrm{PM}_{2,5}$, TSP (total suspended particulate), $\mathrm{NO}_{\mathrm{x}}, \mathrm{NH}_{3}, \mathrm{CO}, \mathrm{VOCs}$, and $\mathrm{SO}_{\mathrm{x}}$. An epidemiological approach is used for the damage analysis of these emissions by [HOFSTETTER1999] due to its large body of literature and its use already in several external studies.

$>$ Climate change, also called greenhouse effect, is caused by the emission of climate changing gases to the atmosphere. The main problem in assessing the harm done by this damage category is the time scale. Today, just a small number of the effects are caused by climate change and the influence of greenhouse gases cannot be completely proven. Nevertheless, it is expected that there will be tremendous effects in the coming decades and centuries. Although, a great amount of uncertainties exist about the modelling of climate change effects. Due to these uncertainties only certain direct and indirect effects are taken into account, which are certain enough to be calculated. These are: exposure to thermal extremes causing altered rates of illnesses and death, changes in range and activity of vectors and parasites, sea-level rise causing population displacement, damage to infrastructure, and also an increased risk of infectious disease and psychological disorders. In addition, positive effects created by climate change are counted in the El'99 approach, which is different to most other models. These positive effects are considered to have an effect of $3.0-4.3 \%$ of the negative effects as calculated in the Hierarchist version of the El'99 approach [GOEDKOOP\&SPRIENSMA2001]. The effects, which are not considered, are diseases except vascular diseases due to heat waves, other vector borne diseases except malaria, schistosomiasis, dengue, effects of malnutrition and hunger, increased impacts of pollutants at higher temperatures, and civil strife.

$>$ Ionising radiation, is caused by the release of radioactive materials into the environment. Especially in the nuclear fuel cycle, in phosphate rock extraction, in coal powered plants and with the extraction of liquid and gaseous fossil fuels air- and waterborne radionuclides are released to the environment. These emissions are taken into account by this calculation. As a result of these emissions, carcinogenic and hereditary effects are counted by the number of cases related to the exposure and the number of DALYs per case. Not calculated are possible large accidental releases, because it is impossible to calculate them in a scientifically reliable way. Health damages due to occupational exposure are also not taken into account. Within the Hierarchist assessing perspective, a time horizon of 100,000 years is calculated and no weighting regarding the age of the affected person is done. 
Ozone layer depletion: has been increasing in importance during the last years as the thickness of the ozone layer is now at its lowest point since the first measurements in the year 1970. The depletion of the ozone layer is caused by the emission of chlorine and bromine compounds, which have a long atmospheric residence time, therby increasing the UV radiation level on earth especially in the Arctic Spring (22\% increase) and Antarctic Spring (130\% increase) [GOEDKOOP\&SPRIENSMA2001]. UV radiation can also cause beneficial effects, e.g. formation of Vitamin D as well as adverse effects to human health, e.g. sunburn, skin ageing, and snow blindness. The most important adverse effects are the danger of skin cancer and cataracts. Skin cancer, especially squamous cell carcinomas and melanoma skin carcinomas, causes most DALYs due to early death, while cataracts cause $3 / 4$ of all DALYs per percentage of ozone layer decrease.

Within the impact category Human Health only the effects of some carcinogenic heavy metals are calculated, while other heavy metals are not taken into account. In older assessment methods, such as the Eco indicator '95, lead emissions were recorded. This was because at this time lead emissions from fuels were considered an important environmental problem. Nowadays, lead is not used in fuels and heavy metal emissions from industrial processes have been significantly reduced. Noise is not taken into account, as the calculation of this impact category is already considered not valid. [MÜLLER-WENK2004] tried to include the effects of road noise on Human Health in LCA. The inclusion of this category will probably be possible in the future when more data on noise effects and different noise emission scenarios are available. This is a serious point as experts regard noise as important as other impact categories taken into account for the assessment of Human Health [HOLLANDER ET AL.1999].

\section{Resources}

Within this category only non-renewable resources, i.e. fossil and mineral resources, will be taken into account. Products from agri- or silviculture are not calculated. The consumption of resources leads to a decrease in the resources' quality. The resources' quality is a unit of measurement for the efforts that have to be made to exploit resources. This means that in future it will become more complicated and therefore more energy intensive to exploit resources, given that easier to exploit resources are already consumed. The increasing consumption of resources, leading to a decrease of resources quality, will lead to the fact that economic factors, and environmental burdens associated with mining low grade ores will become the real problem of resources depletion [LOMBORG2001].

In order to obtain an overview of the time span of consumable resources, it is imperative to know the amount of existing resources. However, it is quite complicated to assess the stock size of the existing resources deposits, as new deposits are found everyday. Herein the efforts mankind is willing to make to obtain these resources have to be taken into account. These efforts are the most limiting factor for the amount of resources that can be used by mankind. Or in other words "... not the quantity of the resource is the limiting factor, but the quality" [GOEDKOOP\&SPRIENSMA2001]. 
It is first imperative that a calculation is made of the effort made to carry out the explorations of resources. Afterwards, the decrease of resources quality is an indicator for the consumable resources by mankind and will therefore be used in the Eco indicator '99 methodology.

$>$ Fossil fuels, i.e. oil, gas, and coal and the belonging subcategories are included in this damage category. These subcategories are important for the calculation of the quality of resources, as they include unconventional deposits, e.g. tar sands for oil or gas from coalbeds. The efforts made in exploiting these resources increases step by step, if one reservoir is fully exploited and resources with a lower quality have to be exploited. So mankind will just start to exploit unconventional resources in a larger scale, when all conventional resources are depleted. Between these steps the efforts of exploitation are relatively constant. As shown in the next paragraphs the calculated reach of conventional fossil fuels, leads to the result that there will be no conventional resources left by a consumption rate of five times the consume until the year 1990 [MÜLLER-WENK1998b]. This leads to the conclusion, that within a relatively short period of time more unconventional resources will be exploited and the surplus energy herein will increase.

$>$ Mineral resources, describes the decrease of mineral resources quality caused by the exploitation of these resources. The quantity of resources existing worldwide and their distribution is not really known. In order to estimate the existing amount of resources, a lognormal distribution is widely assumed, which can be carried out with a mathematical function. From this lognormal distribution the decline of the actual consumption rate, which represents the marginal effect of present extractions, can be calculated [cf. DEFFEYES1964 in GoEdKOOP\&SPRIENSMA2001, ChAPMAN\&ROBERTS1983]. This method can be used to get information for the calculation of all minerals taken into account in LCA. In [CHAPMAN\&ROBERTS1983] it ist stated that just as the ores are decreasing, the energy requirements for exploration are decreasing, too. This parallel decrease is caused by technological improvements and will continue for more than 100 times the amount of most metals that are already explored.

To calculate resources quality today and in the future the method of surplus energy can be used [MÜLLER-WENK1998b]. Surplus energy is herein defined as: "Difference between the energy needed to extract a resource now and at some point in the future". The surplus energy is calculated by the multiplication of the total amount of resources that have been extracted by mankind before $1990(\mathrm{Q})$, and the number of times this amount has been extracted $(N)$. The choice of $N$ is arbitrary, [MüLLER-WENK1998b] uses $N=5$ and $N=10^{28}$. This means that the absolute values of the surplus energy calculation have no real meaning but they are a relative measure for the damage that is caused by the depletion of fossil and mineral resources. Thus, surplus energy is just a characterisation method, while the choice of $\mathrm{N}$ is used as a reference. 


\section{Ecosystem Quality}

Quality of an ecosystem is hard to define and even harder to measure. Clear indicators, like in the case of human health, are missing. These leads to the fact that it is unclear which indicators should generally be taken into account. For this study three impact categories influence the safeguard subject ecosystem quality: land-use, ecotoxicity, and acidification/eutrophication and will therefore be calculated.

$>$ Ecotoxicity, this damage category describes the impacts on the ecosystem due to toxic substances that are emitted to air, water, agricultural soil, industrial soil and water, as well as pore water of agricultural, industrial and natural soils. Herein ecosystem includes all kinds of plants and animals naturally living in the area under investigation. For calculating the damage to Ecosystem Quality an elaboration of the ITOX-concept of [HAMERS ET AL.1996] providing an algorithm to calculate the toxic stress on ecosystems, denoted as a potentially affected fraction (PAF) of species, is used in the El'99 method. The value of PAF indicates the fraction of naturally occurring organisms exposed to concentrations higher or equal to the laboratory NOEC (no observable effect level). When analysing the damaging effect of a substance it is assumed that there is an average background concentration for all substances in Europe. This means that the slope of one single substance PAF curve is not relevant, but the slope of the overall PAF curve, based on a mixture of substances, must be determined to assess the marginal damage caused by an emission. This overall PAF curve is constructed by standardising the concentrations of individual substances into units of average toxicity of the total mixture (hazard units). The marginal increase in hazard units can be calculated from the marginal increase in a substances concentration. This procedure is repeated for all substances, finally the damages in $\mathrm{PAF} \times \mathrm{m}^{2} \times \mathrm{a}$ are calculated, resulting in the total damage in Europe [GOEDKOOP\&SPRIENSMA2001].

$>$ Acidification/Eutrophication, the damage category describes the effects caused by deposits of inorganic substances such as sulphates, nitrates and phosphates. These deposits mainly occur in air and water. The primary effect is the change in nutrient level and acidity in the soil. Furthermore, wetlands and swamps are taken into account as long as they are classified as natural areas. Direct emissions to rivers and lakes are not calculated, as they do not present a problem in Central Europe unlike Scandinavia. Changes in the nutrient and acidity levels do not always lead to damages in ecosystems, given that every species has its special optima. Thus, changes in nutrient and acidity levels will lead to changes in the species population, which could cause either an increase or decrease in the number of species. To find out, if a shift is harming an ecosystem, one must choose between desired and less desired species populations in the ecosystem under investigation. A special list of typical species for over 40 ecosystems in Europe has been developed by [BAL ET AL.1995 cited in GOEDKOOP\&SPRIENSMA2001]. In the Eco indicator ' 99 method this analysis has been done for a wide variety of ecosystems, so that a wide range of data can be used. It must be noted that only changes in natural areas are calculated, while changes in agricultural soils due to acidity and eutrophication are mainly based on fertilizer and acidity regulating agents applied by farmers and therefore not calculated. 
Land use, questions if terrestrial surfaces are needed for a given anthropogenic process, this is often called land use. The term land use describes that a land surface is occupied for a certain process during a certain length of time, without being used up. The environmentally relevant properties may be changed or not by this occupation. In Europe, the influence of this damage category causes far more defects in ecosystems than the majority of the other categories [MÜLLER-WENK1998a]. Different sources stress problems with assessing land use, especially in agricultural production systems. The main problem is the question of how to measure the quality of soils and assess the damage caused by the object under investigation to this impact category [GEIER2000, ARMAN2004].

Due to the iterative character of LCA, some assessments have been repeated. With regards to the object under investigation, first studies showed the eminent influence of energy crop production on the total ecological effects of electricity production from biogas. The impact category land use has a high impact on the production of energy plants and therefore on the whole system under investigation. For this reason, the assessment of the land use category was repeated and carried out in more detail. Therefore this impact category and the data collection method are presented in great deal compared to the other categories within this safeguard subject.

The impact category land use describes the environmental impacts of occupying, reshaping and managing land for human purposes within the life-cycle-assessment methodology. Land use can thereby either be the long-term use of land (e.g. for arable farming) or a change in the type of land use (e.g. from natural to urban area). Land use leads to a degradation in the naturalness of the area utilised. In this respect the naturalness of any area can be defined as an area of land not actually influenced by humans and the remaining naturalness of land under use. To determine the remaining naturalness of land under use, this study suggests applying the Hemeroby concept [BRENTRUP ET.AL2002].

The effects of land use are not cogently related to simply local areas but can also harm surrounding regions. Furthermore, when calculating the effects of the land-use category, land occupation and land transformation must be differentiated. For example, the production of crops on arable land that has already been used for a long period of time could not be held responsible for land transformation. However, it is responsible for preventing the area from returning to its natural condition, and is therefore harming the ecosystem. One of the main threats to the environment within the land use category is the decline of biodiversity. Other effects from land use, e.g. soil quality or landscape, will not be taken into account in this study, but could be important to more specialised studies. The effects from land use on the diversity of species in a special region can be presented as below, in equation (7) according to [GOEDKOOP\&SPRIENSMA2001].

$$
P D F=\frac{S_{\text {reference }}-S_{\text {use }}}{S_{\text {reference }}}
$$

PDF = Potentially Disappeared Fraction of vascular plants

$\mathrm{S}_{\text {reference }}=$ Species diversity on the reference area type

$\mathrm{S}_{\text {use }} \quad=$ Species diversity on the converted or occupied area

[KÖLLNER2000] collected a wide variety of data from which he produced an overview of the influence of land use types on the PDF value. Therefore he took into account an area under use related to a mixed broad-leafed forest as a reference unit. Only data from [KöLLNER2000] 
which takes into account the land use types occurring in this LCA study are represented in the following table. It must be noted that in the original work of [KöLLNER2000] 'In a' values were used, whilst cited in [GOEDKOOP\&SPRIENSMA2001] and in this LCA ' $a$ ' is used instead of the log-transformed value.

Table 2.35: PDF values for local effects of land-use [KöLLNER2000 cited in GOEDKOOP\&SPRIENSMA2001]

\begin{tabular}{|l|c|c|r|r|}
\hline \multicolumn{1}{|c|}{ Land use type } & $\mathbf{n}$ & $\mathbf{a}$ & correction & PDF $_{\text {natural } \rightarrow \text { use }}$ \\
\hline Conventional arable & 16 & 12.2 & 2.0 & 0.91 \\
\hline Industrial area & 29 & 81.5 & 1.0 & 0.70 \\
\hline
\end{tabular}

The resulting damage to Ecosystem Quality is then calculated by multiplying the PDF value by the appropriate area and time span (cf. equation (8)).

$$
E Q=P D F \times \text { area } \times \text { time }(8) \quad E Q=\text { Ecosystem Quality }
$$

Separate data for species, area, and time period should be taken into account for each kind of land use and affected area. In this study only land occupation is calculated, due to the fact that all crops are produced on existing arable land. The following values are used.

Table 2.36: Parameters determining land use types

\begin{tabular}{|l|l|l|l|l|}
\hline Type & S $_{\text {reference }}$ & S $_{\text {use }}$ & Area size A & Time period t \\
\hline Occup. local & Natural state & S on new land use type & Occupied area & Occup.time \\
\hline Occup. regional & Natural state & Smaller natural area & Natural area & Occup. time \\
\hline
\end{tabular}

Also the species area relationship has to be calculated. This relationship is expressed by equation (9).

$$
\begin{aligned}
& S=a \times A^{b} \text { (9) } \quad \begin{array}{l}
\mathrm{S}=\text { species diversity } \\
\mathrm{a}=\text { species richness factor, usually between } 20 \text { and } 2000
\end{array} \\
& A=\text { Area (in hectare) } \\
& \mathrm{b}=\text { species accumulation factor, usually between } 0.2 \text { and } 0.5
\end{aligned}
$$

The species area relationship implies that arable used land in a natural area as a local effect will decrease species diversity due to the lower species richness factor of arable land in comparison to natural land. Additionally a decrease in species will occur as a regional effect, given that the size of the natural area is reduced. The calculation of the land-use effects is based on empirical data, such as observations of species numbers in different types of landcover instead of extrapolations of laboratory data and computer models. With regards to the object under investigation, no object related effects are measured however existing data are used to calculate the effects of a special kind of land use.

Within this damage category, double-counting is a serious problem, as the effects of other damage categories, which influence the species in a certain area, cannot be separated from the land-use influences. In order to try and avoid, as far as possible, double-counting, the following rules should be followed. 1. fertilisers that are directly applied on agricultural soil should not be counted as an emission. 2. fertilisers that leach into ground water should be taken into account. 3. pesticides applied on the agricultural soil should be included as an emission to the soil.

Within a life-cycle-assessment study, direct impacts, relating to land use, such as nitrate leaching or diffuse emissions from soil to air, are accounted for in different impact categories. These emissions are part of the $\mathrm{LCl}$ and would be considered in different impact categories 
other than land use during the life-cycle-impact-assessment (LCIA). The impact category land use comprises exclusively of those environmental consequences that impact the environment due to the land use itself, for instance through the reduction of landscape elements, the planting of monocultures or artificial vegetation, or the sealing of surfaces [BRENTRUP ET AL.2002]. These consequences also contribute to the biodiversity (see below Hemeroby) of an area.

Land use can be expressed in terms of the size of an area used for a specific product or process for a certain time, e.g. in $\mathrm{m}^{2}$ xa per product unit [HEIJUNGS ET AL.1992]. However, this neglects the fact that different types of land use have different impacts on the environment [MÜLLER-WENK1998A]. Therefore, a measure is required to approximate the degree of environmental damages due to different land use types. [HEIJUNGS ET AL.1997] state that it is impossible to scientifically validate the land use category. The same source also states that the characterisation methods used for land use are a great deal less objective and scientific in nature than those used for most output-related impact categories.

A number of efforts were also made to characterise and to measure the effects of land use, in LCA studies. According to [BRENTRUP ET AL.2002] the assumption is made that the more the natural setting is preserved, the better it is for the environment. This means, that any land use that degrades the naturalness of an area is suggested as an environmental problem. Not only the conversion of natural land to land under use, but also the continuous utilisation of land, which prevents the area of returning to a more natural state, is seen as a degradation of the nature of the land.

\section{Hemeroby and alternative land use scenarios}

From an ecological point of view, biodiversity means the variety of species within a habitat. Herein, habitat could also just be part of an ecosystem e.g. soil. The variety of species is always seen in correlation to a base value. This base value is related to a single habitat. The number of species and the relative frequency of occurrence are counted in order to calculate the biodiversity of a habitat. Diversity is calculated using diversity indices, derived from the theory of probability. In this process, it has to be taken into account, that a system containing a huge number of species can equally have a small diversity, if most of the individuals are from the same species [REMMERT1992].

Biodiversity is a value that is nearly impossible to measure by counting the numbers of species and the number of individuals of each species. This is due to the fact that there are too many species and the fact that it is impossible to find all individuals within an open system. Therefore, a different system, the Hemeroby concept has been chosen to assess biodiversity in this study. The word Hemeroby is made up from the Greek word hémeros (tarned, cultivated) and bíos (live) and was first mentioned by the botanist [JALAS1955]. Hemeroby names the human influence on the naturalness of an eco system. From this, the human influence on eco systems can be classified in hemeroby levels, evaluating human impacts that prevent the system from developing towards a natural endpoint situation. This natural endpoint situation describes the reference to which any modified situation is compared [KOWARIK1999]. This hemeroby level of an area describes the intensity of land use and can 
therefore be used to typify different kinds of land use and their diversity of species. Calculations of land use within life-cycle-assessment studies can be made using these levels.

In this assessment, hemeroby intergrades between eleven classes of human influence on land use in a descriptive, qualitative way. The human influence is counted in a reciprocal system, wherein 0.0 symbolises a system without any human influence, while 1.0 symbolises a system without any flora and fauna due to human influence [KOWARIK1999]. These categories take into account the different kinds of vegetation, land use, and typical ecosystems. Also the use intensity and characterisation factors (naturalness degradation potentials, NDP) are taken into account. In regard of Table 7.3 extensive used arable land has a NDP value of 0.7 and intensive arable of 0.8 .

The naturalness of an area can be regarded as the amount of land, which is not affected by humans and the remaining naturalness of land that is currently being used [BRENTRUP ET AL.2002]. Within the area under investigation, namely central Europe, there is hardly any area that is not anthropogenic influenced [KORNECK\&SUKOPP1988]. Almost the entire land in Europe is more or less influenced by human activity. Even ecosystems, which are in some regions under protection due to their high environmental value, like in heathland or lowproductive permanent pastures are a result of and therefore dependent on specific forms of human land use [BRENTRUP ET AL.2002]. This means, hardly any area within Europe, would be considered as natural, as a result of human influence during hundreds of years, which has changed the natural scenery, animal and plant life.

It is also important to take into account, that every region has its own kind of naturalness. Animal and plant life is not the same in every part of the world or just in Europe. For this reason a model of biogeographic regions of Europe of comparable biodiversities is suggested [BRENTRUP ET AL.2002]. This should help to make land use applicable within LCAs or sensitivity analysis if one LCA refers to different regions. 


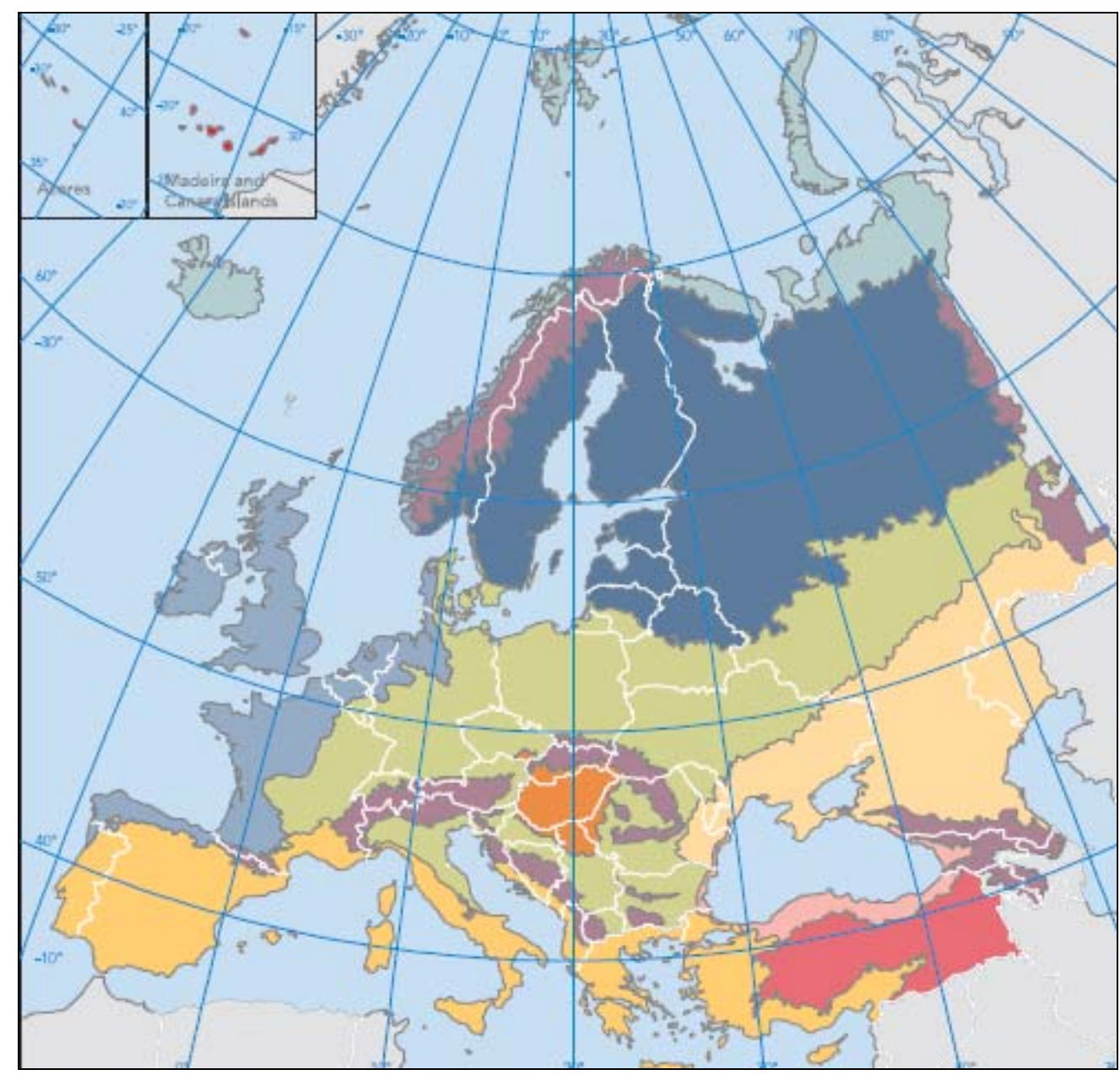

Figure 2.19: Biogeographic regions of Europe [EEA2003]

As can be seen from Figure 2.19 the object under investigation is situated in the continental (olive-coloured) and the Atlantic (light blue) region. The most important threats to biodiversity in these two regions are the high degree of habitat fragmentation by transport, urban infrastructure, and intensive agriculture. Special ecological threats are caused in the Atlantic region by eutrophication of the sea and invasive alien species, which would not be taken into account, due to their negligible importance to this study. Industry and mining, atmospheric pollution and intensive use of rivers are special problems of the continental region, that will not be taken into account within the aspects of land use but will be dealt with in other impact categories of the LCA [cf. EEA2003].

As a part of the hemeroby concept the diversity of vascular plants can be viewed as an indicator for ecosystem damage [JACKOWIAK1998, SUKOPP\&LANGER1996]. This method is more or less a supplying process to the hemeroby concept and is normally used in combination with other indicators. The counting of the diversity of vascular plants is used, because counting all species in an area under investigation is hardly impossible. The studies of [JACKOWIAK1998, SUKOPP\&LANGER1996] show that there is a reasonable correlation between this indicator and the full species diversity. 
Vascular plants can be used as an indicator for biodiversity, as they are a species that represents the diversity damage situation in an adequate way and are also practical (1), they are a large group within Europe's total species (2), and have a key position in the terrestrial ecosystem, as they are the main transmitter of solar energy into ecosystems, so therefore it can be said that the fate of all species is related to vascular plants (3) [MÜLLER-WENK1998A].

\section{Base value for naturalness}

With regards to the evaluation of the naturalness of an investigated system a reference value is needed, which states the situation of nature without any human influence. All directly or indirectly measured values for the assessment of the naturalness of the investigated object are related to this base value. In order to come up with a definition of this reference value, two different kinds of methods are used: historical and current based. Historical used systems are based on the vegetation that could be found before any human influence occurred in the investigated area. For Central Europe this goes back up to 10,000 years before first settlements were established.

Current based systems use the potential natural vegetation (PNV) as base value. PNV symbolises the vegetation that will be established within the investigated area, if all human influence is ceased. So, PNV symbolises the actual diversity potential of the area under investigation. The hemeroby concept used in this study is based on PNV, measuring the human influence on the investigated system [KOWARIK1999]. In consideration of [KOWARIK1999] land use effects have to be benchmarked with a natural endpoint situation of the system under investigation.

Furthermore, [WEGENER SLEESWIJK ET AL.1996] propose to overlook history of land use and concentrate on the actual land use instead of the transition (see below). [RÜHS2001] stresses that the naturalness of a system is defined by its possibility to develop freely and undisturbed, not by its primitive state. Therefore he suggests using "potential natural vegetation" (PNV), which means the possible stable endpoint stage of a biological system (climax), as a reference system for estimating the influence on biodiversity. For the system under investigation this would be a deciduous/mixed forest [ARLT\&EGGERS1997] or oligo- to mesohemerobic situations as a reference system, if we were to take an ahemerob situation as PNV. This benchmark would cause an impact category land contribution of more than $70 \%$ to the overall ecological effects of the electricity production from biogas.

The above source also emphasises that an ahemerob level does not always need to be the stable endpoint situation of a biological system. Especially in cultural landscapes, the PNV can be seen as a meso- or euhemerob system. This represents an influence through the use of land that is $30-70 \%$ lower than taking an ahemerob level as a reference system. According to this source the decision about the reference system should be made according to rareness and occurrence of special species within the system under investigation.

In comparison to this [BECKER1997] states, that there has been human influence on landscape and biodiversity within the last 15,000 years in Europe. This means, that there has not been any natural endpoint situation of European biodiversity during this time period. Up until two thousand years ago the majority of Europe was covered with forests. 
From this time on up until now nature was created by human forestry and agriculture. To conserve this kind of nature, human influence is needed. In consideration of the hemeroby concept our present kind of nature, meaning from 1850 until today, has a level of mesohemerobic to a-euhemerobic (NDP 0.3-0.7).

\section{Agriculture's influence on nature and biodiversity}

The state-of-the-art agricultural system, which is the technological basement for the production of energy crops today, has an important influence on the ecological effects of the electricity generation from biogas. [BECKER1997] states, that "the pre-industrial agricultural (...) use had also negative environmental effects, but the diversity of sites and species was increased. The more intensive agricultural use in the industrial era with increasing yields of crops has led to a decline of species in the past". The same source also stresses that there was and always will be a conflict between the production of food and the preservation of biological diversity. The same will also be correct for the production of energy crops.

An agricultural eco-system is a system under use. On the one hand it consists of wild growing plants and wildlife and on the other hand it is made up from crops and productive livestock. The pre-industrial agriculture was a combination of consumption (e.g. meadow) and production (arable) processes. Meadow, forestry, and other processes led to a reduction in nutrients and soil destruction on non arable used areas. These different kinds of land use led to an increase in the variety of land types and biodiversity. Agriculture involuntarily increased biodiversity, e.g. through a shortage of nutrients in low quality soils [HEYER\&CHRISTEN2005]. These human landscape changes led to an increase in biodiversity from 1800 to 1850 , when the largest biodiversity was reached.

Agriculture, beside forestry and the depletion of habitats, is seen as one of the most import causes for the reduction in biodiversity. The kind of agriculture influences the diversity on a wide range. Conventionally managed arable land leads to biggest diversity reductions followed by integrated, extensive and ecological management systems, as can be seen in the following figure [changed from KTBL2005a].

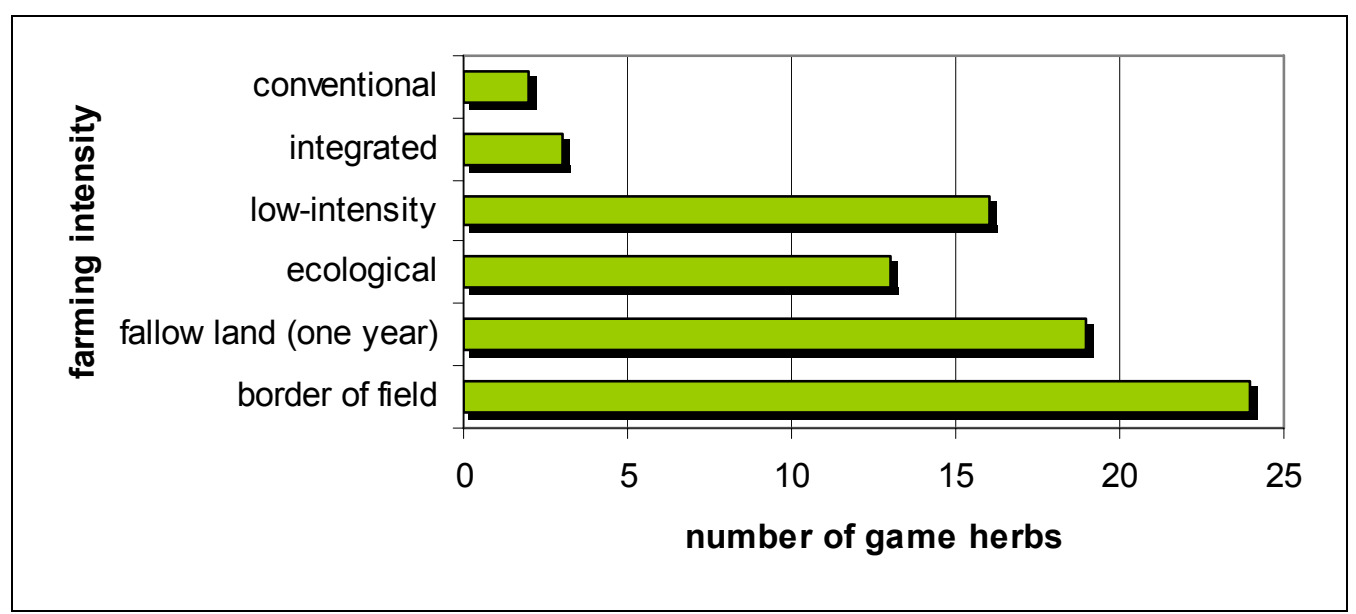

Figure 2.20: Relation of farming intensity and number of game herbs 
It was essential to concentrate natural mass and energy flows on the crops to increase yields. Three factors: plant breeding (1) for higher potential yields, adapted fertilisation (2) for reduction of site-related limitations, and plant protection (3) for elimination of competing plants led to this goal, known as the intensification of agriculture [HEYER\&CHRISTEN2005]. The intensification of agriculture, including the normalisation of different area factors, intensification of soil cultivation, the abandoning of three-field rotation, usage of mineral fertilizers and the starting of chemical plant protection led to a decrease of biodiversity. The number of wild plants and animals was mostly decreased within the last fifty years, due to the fact that only functional plants (crops) were fostered.

On the other hand, it has to be taken into account, that agriculture and silviculture do not harm plants and animals just because $53.0 \%$ of the area in Germany is dedicated to these two production systems [DESTATITS2005a, DESTATIS2006a]. They are producing goods for general public. The intensification of agriculture allowed people in Europe not to die of starvation during the last 150 years except in times of war.

In contrast to the proposition of the other authors [KRETSCHMER ET AL.1997] declare that the state of the art agricultural use of land mostly leads to a decrease but also can lead to an increase of biodiversity. The same source also stresses, that biodiversity does not give adequate information on ecological sound agricultural systems. This is because biodiversity does not differ between indigenous and invasive plants. This endorses the point of [RÜHS2001] stating that large areas in Europe will be kept as cultural landscape. The same source goes on to stress that at the same time, more differentiation and regionally adapted intensities are needed to preserve and generate open area biotopes.

\section{Cumulative Energy Demand}

The cumulative energy demand can be defined as follows: " The ...(CED) states the entire demand, valued as primary energy, which arises in connection with the production, use and disposal of an economic good (...) or which may be attributed respectively to it in a causal relation [VDI1997]. This energy demand represents the sum of the ...(CEDs) for the production $\left(K E A_{H}\right)$, for the use $\left(K E A_{N}\right)$, and for the disposal $\left(K E A_{E}\right)$ of these partial sums which preliminary and parallel stages are..." given in equation (10).

$$
K E A=K E A_{H}+K E A_{N}+K E A_{E}(10)
$$

Thereby the CED describes both the sum of the cumulative process energy demand and of the cumulative non-energy demand. The process energy demand therefore includes all final energies for heat, power, light and other useful electricity. The non-energy demand is the sum of the energy content of all energy carriers used for non-energy purposes and the inherent energy of working materials [VDI1997].

The analysis of the energy flows is not an original part of LCA due to ISO 14040. However it can be considered as one possible important characteristic value of an ecological assessment of a system under analysis [VDI1997]. For the purpose of this study, the analysis of the cumulative energy demand (CED) will be done according to the VDI standard 4600, to pro- 
vide an overview of the relation between energy produced and energy consumed in the biogas production [VDI1997]. The system boundaries set in the LCA study will be used again. The cumulative energy demand can be given, aggregated or disaggregated into primary energy sources, depending on the goal of the study. This allows, with respect to energy criteria, the evaluation and comparison of products and services. The CED data form a base from which energy saving potentials of the object under analysis can be analised [VDI1997].

In order to carry out the CED assessment, different kinds of energy form and energy conversion have to be calculated. Natural occurring energy sources are regarded as primary energy as long as they are deposited and have not been subjected to any conversion. Primary energies include natural gas, fossil fuel ores, solar radiation, wind and hydro power. The mining and transport of primary energies cause energy losses, meaning that they are converted into secondary energy e.g. crude oil after exploration. The final transport stage to the consumer and the energy demand of the energy sector also causes energy losses that reduce secondary energy to final energy or end-point energy, which can be used by the consumer. Energy losses are calculated at the place of the consumers, which finally leads to the useful energy [MOERSCHNER2000, VDI1997].

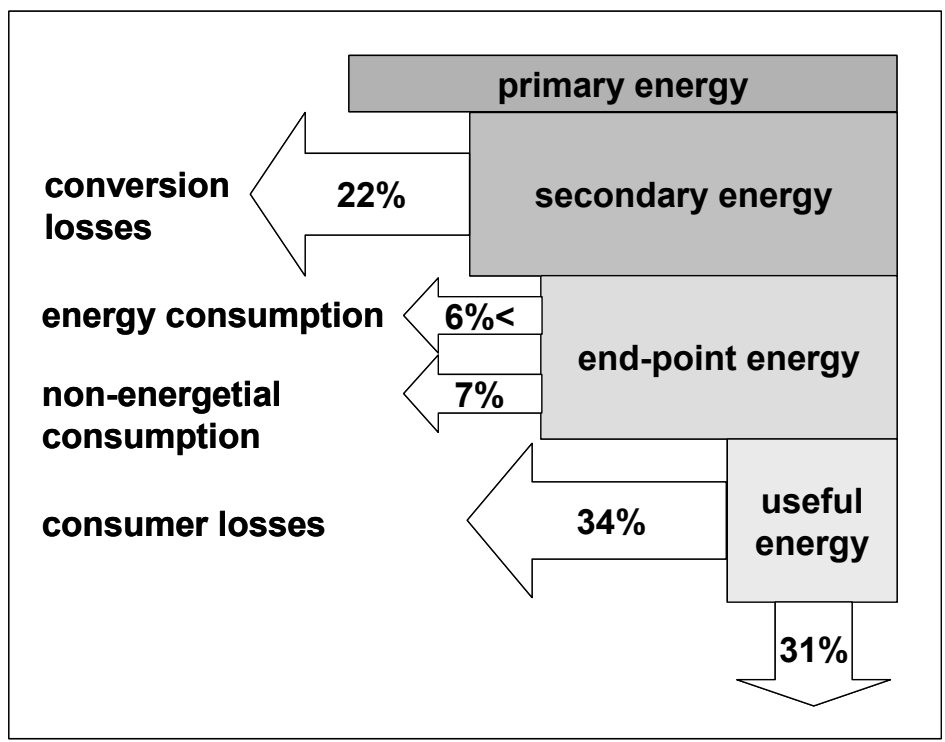

Figure 2.21: Schematic energy flow in Germany (1990) [MOERSCHNER2000]

Within this analysis two production systems, the industrial and the agricultural production system, have to be considered. The CED assessment for the industrial process can be done based on the LCA inventory analysis data. These data are combined with the databases of the SimaPro software, meaning that a thorough and detailed analysis is made of the energy efforts.

The CED assessment of the agricultural production system is more complicated. [MOERSCHNER2000] investigated energy inputs to agricultural production systems and at the same time developed adapted assessment methods for this kind of production system. $\mathrm{He}$ states that most energy utilised in agricultural production systems is brought into this system in an indirect form, i.e. chemical bond. This same source also states that this indirect kind of energy use from upstream processes is reliable for approximately $2 / 3$ of all energy efforts in 
agricultural production systems. This dissertation gives a first methodological device for the assessment of energy inventories of agriculture and is therefore used as a data and methods base for the data collection in the agricultural system under analysis [MOERSCHNER2000]. First methodological approaches for the calculation of direct and indirect energy consumption in agricultural production systems were also shown by [MOERSCHNER\&GEROWITT1999].

The above source also plants an interesting question regarding the assessment of biological energy sources such as biomass as an input for biogas production systems. This question is based on the fact that energy contents are calculated on the lower heating value (net caloric value) content of an energy source. The lower heating value takes into account the water content of an energy source, lowering the value for higher water contents. This method is correct, if energy sources are used in combustion processes. If these biological energy sources are used in other conversion processes such as biogas production, the water content does not or if so, just slightly influence conversion system's energy yield. Therefore, assessment methods based on the lower heating value concept could lead to wrong results when used in agricultural based production system, as in the case of this study.

One of the first studies carried out on the CED of energy crops related to the energy output were done by [TENTSCHER2004]. He states that more energy can be generated from crops, than it is used for their production. There are differences in the CED/output energy relation of factor three between the single energy crops. Maize produces 23 times, more than 20 times are produced by rye and triticale. Seven times more energy is produced by hemp, lucerne and grass silage than is needed for their production.

For assessing all different kinds of energy forms in this study the Cumulative Energy Demand V1.1 database software included in SimaPro will be used. This database software is based on the method of Ecoinvent V1.01 and expanded on by PRé Consultants for energy resources available in the SimaPro databases [FRISCHKNECHT\&JUNGBLUTH.2003]. This software also allows the assessment of the energy sources by the following groups as demanded by [FRITSCHE ET AL.1999]:

$>$ Non renewable, fossil

$>$ Non renewable, nuclear

$>$ Renewable, wind, solar, geothermal
$>$ Renewable, water

$>$ Renewable, biomass

\subsubsection{Life cycle impact category indicator}

Impact categories are related to category indicators, which are used as a base unit within each category. Within LCA these indicators are called impact category indicators. Examples of these indicators are given in Table 2.32 - Table 2.34. From these examples, it can be concluded that impacts of one category can possess different units. It is impossible to summarise these different impacts due to the fact that they are based on different units.

Information regarding the quantity of an impact from one impact category of the object under analysis can only be given, when a characterisation within each impact category is done. Using characterisation factors within the characterisation makes the single impacts of one category comparable with each other. If the impacts of one category are comparable to each 
other, they can be summed up, leading to a numerical indicator result for each impact category.

An example of this can be seen in Table 2.37, where a list of characterisation factors for the impact category ozone layer depletion as used in this assessment is given. In the table, all substances taken into account in this impact category and their share on the effect of this category compared to other impacts is given. All substances are related to the common unit $\mathrm{DALY} / \mathrm{kg}$. Each substance is calculated by its factor, showing its contribution to the overall effect. All results are expressed in the unit of the impact category.

Table 2.37: Characterisation factors of the impact category ozone layer depletion used in this study based on the EI ' 99 method

\begin{tabular}{|l|l|r|c|}
\hline \multicolumn{1}{|c|}{ compartment } & \multicolumn{1}{|c|}{ substance } & \multicolumn{1}{c|}{ factor } & unit \\
\hline Air & Ethane, 1-chloro-1,1-difluoro-, HCFC-142 & $5.26 \mathrm{E}-05$ & $\mathrm{DALY} / \mathrm{kg}$ \\
\hline Air & Ethane, 1,1-dichloro-1-fluoro-, HCFC-141b & 0.000105 & $\mathrm{DALY} / \mathrm{kg}$ \\
\hline Air & Ethane, 1,1,1-trichloro-, HCFC-140 & 0.000126 & $\mathrm{DALY} / \mathrm{kg}$ \\
\hline Air & Ethane, 1,1,1-trifluoro-2,2-chlorobromo-, Halon 2311 & 0.000147 & $\mathrm{DALY} / \mathrm{kg}$ \\
\hline Air & Ethane, 1,1,1,2-tetrafluoro-2-bromo-, Halon 2401 & 0.000263 & $\mathrm{DALY} / \mathrm{kg}$ \\
\hline Air & Ethane, 1,1,2-trichloro-1,2,2-trifluoro-, CFC-113 & 0.000948 & $\mathrm{DALY} / \mathrm{kg}$ \\
\hline Air & Ethane, 1,2-dibromotetrafluoro-, Halon 2402 & 0.00737 & $\mathrm{DALY} / \mathrm{kg}$ \\
\hline Air & Ethane, 1,2-dichloro-1,1,2,2-tetrafluoro-, CFC-114 & 0.000895 & $\mathrm{DALY} / \mathrm{kg}$ \\
\hline Air & Ethane, 2-chloro-1,1,1,2-tetrafluoro-, HCFC-124 & $3.16 \mathrm{E}-05$ & $\mathrm{DALY} / \mathrm{kg}$ \\
\hline Air & Ethane, 2,2-dichloro-1,1,1-trifluoro-, HCFC-123 & $1.47 \mathrm{E}-05$ & $\mathrm{DALY} / \mathrm{kg}$ \\
\hline Air & Ethane, chloropentafluoro-, CFC-115 & 0.000421 & $\mathrm{DALY} / \mathrm{kg}$ \\
\hline Air & Methane, bromo-, Halon 1001 & 0.000674 & $\mathrm{DALY} / \mathrm{kg}$ \\
\hline Air & Methane, bromochlorodifluoro-, Halon 1211 & 0.00537 & $\mathrm{DALY} / \mathrm{kg}$ \\
\hline Air & Methane, bromodifluoro-, Halon 1201 & 0.00147 & $\mathrm{DALY} / \mathrm{kg}$ \\
\hline Air & Methane, bromotrifluoro-, Halon 1301 & 0.0126 & $\mathrm{DALY} / \mathrm{kg}$ \\
\hline Air & Methane, chlorodifluoro-, HCFC-22 & $4.21 \mathrm{E}-05$ & $\mathrm{DALY} / \mathrm{kg}$ \\
\hline Air & Methane, chlorotrifluoro-, CFC-13 & 0.00105 & $\mathrm{DALY} / \mathrm{kg}$ \\
\hline Air & Methane, dibromodifluoro-, Halon 1202 & 0.00132 & $\mathrm{DALY} / \mathrm{kg}$ \\
\hline Air & Methane, dichlorodifluoro-, CFC-12 & 0.000863 & $\mathrm{DALY} / \mathrm{kg}$ \\
\hline Air & Methane, dichlorofluoro-, HCFC-21 & 0.000042 & $\mathrm{DALY} / \mathrm{kg}$ \\
\hline Air & Methane, monochloro-, R-40 & $2.11 \mathrm{E}-05$ & $\mathrm{DALY} / \mathrm{kg}$ \\
\hline Air & Methane, tetrachloro-, CFC-10 & 0.00126 & $\mathrm{DALY} / \mathrm{kg}$ \\
\hline Air & Methane, trichlorofluoro-, CFC-11 & 0.00105 & $\mathrm{DALY} / \mathrm{kg}$ \\
\hline Air & Propane, 1,3-dichloro-1,1,2,2,3-pentafluoro-, HCFC-225cb & $2.11 \mathrm{E}-05$ & $\mathrm{DALY} / \mathrm{kg}$ \\
\hline Air & Propane, 3,3-dichloro-1,1,1,2,2-pentafluoro-, HCFC-225ca & $2.11 \mathrm{E}-05$ & $\mathrm{DALY} / \mathrm{kg}$ \\
\hline
\end{tabular}

\subsubsection{Assessment via damage-oriented methods}

In a Life Cycle Impact Assessment (LCIA), two methods are essentially used to describe the environmental threats, these being, problem-oriented methods (mid points) and damageoriented methods (end points). In the problem-oriented approaches, flows are classified into environmental impacts to which they contribute. Themes covered in most Life Cycle Assessment (LCA) studies are: Greenhouse effect (or climate change), Natural resource depletion, Stratospheric ozone depletion, Acidification, Photochemical ozone creation, Eutrophication, Human toxicity and Aquatic toxicity. These methods aim at simplifying the complexity of hundreds of flows into a few environmental areas of interest. The EDIP or CML 2000 methods are examples of problem-oriented methods. 
The damage-oriented methods, in comparison to distance to target approaches, also start by classifying a system's flow into various environmental impacts. However, each environmental impact's damage is categorised into human health, ecosystem health or resources damage. These used distance to target methods do not sufficiently express the gravity of an environmental problem, meaning that additional weighting factors are needed [GOEDKOOP\&SPRIENSMA2001] For example, acidification - often related to acid rain - could harm ecosystems, but could also damage buildings and monuments. In essence, this method aims to answer the question: Why should we worry about climate change or ozone depletion? Eco indicator '99 is an example of a damage-oriented method.

When possible, problem-oriented methodologies are based on internationally and scientifically accepted approaches. However certain categories, such as human toxicity or aquatic toxicity, are currently under development, require careful evaluation when used and therefore remain difficult to categorise. Even more difficulties of scientific relevance are made up from damage-oriented methods, hence careful evaluation is necessary [SIB2006].

The weighting of impact categories is the most controversial step in LCIA, as it usually proves difficult to give representative values to environmental problems. Therefore the topdown approach is designed around the weighting procedure. The rest of the procedure is set up to accommodate the best weighting procedure. This starting point has some important consequences for the methodology, e.g. the number of environmental problems is limited to just three (human health, ecosystem health, resources). Furthermore the environmental problems are defined at their endpoint levels. Definitions of the endpoint levels are easier to understand than the abstract definitions of impact categories. As a consequence, the definition of the impact categories is no longer done individually.

In contrast to this, the modelling of impact categories in bottom-up approaches is more simple, but the weighting problem is virtually impossible to solve. In this case the ability of topdown approaches to separate the most important issues from less important issues is a systematic advantage. By using these approaches it becomes clear which effects are important and which are not.

\subsubsection{Normalisation and weighting}

ISO 14042 declares normalisation and weighting as optional elements of the inventory analysis. They are made to assess damage caused by the object under investigation. In contrast to these optional elements, the elements choice of impact categories, indicators, characterisation, category endpoints, and the associated LCl results are mandatory [CEN200a]. This is because normalisation, weighting, and also ranking are not sound from a natural scientific point of view. Therefore the weighting step is not allowed in comparative studies that are disclosed to the public.

The aim of the normalisation of indicator results is to gain a better understanding of the relative values of each indicator result of the system under analysis. Calculating the magnitudes of indicator results relative to reference information (normalisation) can be useful in gaining 
knowledge of the relative significance of the indicator results and is a mandatory step before weighting can be done.

The term, normalisation means that indicator results are related to selected reference values. The normalisation of the indicator results leads to factors without unit, which reflect the relative share of the calculated damages to a special reference. The reference values in the chosen El ' 99 method are normalisation values for Europe taken from [BLONK ET AL.1997]. This means, all impact category results caused by one functional unit of the system under analysis are related to the value of the same impact category for the whole of Europe. In the following table the normalisation values for Europe are given for the Hierarchist assessment method El'99 $(\mathrm{H})$.

Table 2.38: Normalisation values for Europe [BLONK ET AL.1997 in GoEDKOOP\&SPRIENSMA2001]

\begin{tabular}{|c|c|c|c|c|c|c|}
\hline Factor & Air & Water & $\begin{array}{c}\text { Industrial } \\
\text { soil }\end{array}$ & $\begin{array}{l}\text { Agricul- } \\
\text { tural soil }\end{array}$ & Total & $\begin{array}{l}\text { Per in- } \\
\text { habitant }\end{array}$ \\
\hline Carciongenic effects & $1.99 \mathrm{E}+0,5$ & $3.10 \mathrm{E}+05$ & $1.83 \mathrm{E}+05$ & $6.77 \mathrm{E}+04$ & $7.60 \mathrm{E}+05$ & 2.00E-03 \\
\hline Respiratory inorganic & $4.05 \mathrm{E}+06$ & & & & $4.05 \mathrm{E}+06$ & 1.07E-02 \\
\hline Respiratory organic & $2.60 \mathrm{E}+04$ & & & & $2.60 \mathrm{E}+04$ & 6.84E-05 \\
\hline Climate Change & $9.08 \mathrm{E}+05$ & & & & $9.08 \mathrm{E}+05$ & $2.39 \mathrm{E}-03$ \\
\hline Radiation & $1.01 \mathrm{E}+03$ & $9.84 \mathrm{E}+01$ & & & $1.02 \mathrm{E}+04$ & 2.68E-05 \\
\hline Ozone depletion & $8.32 \mathrm{E}+04$ & & & & $8.32 \mathrm{E}+04$ & $2.19 \mathrm{E}-04$ \\
\hline $\begin{array}{l}\text { Total Human Health } \\
\text { [DALY/a] }\end{array}$ & $5.27 \mathrm{E}+06$ & $3.10 \mathrm{E}+05$ & 1.83E+05 & $6.77 \mathrm{E}+04$ & $5.84 \mathrm{E}+06$ & 1.54E-02 \\
\hline Ecotoxicity [PAFm²a/a] & $7.02 \mathrm{E}+11$ & $7.87 \mathrm{E}+09$ & $2.37 \mathrm{E}+12$ & $4.32 \mathrm{E}+08$ & $3.08 \mathrm{E}+12$ & $8.11 \mathrm{E}+03$ \\
\hline Ecotoxicity [PDFm²a/a] & $7.02 \mathrm{E}+10$ & $7.87 \mathrm{E}+08$ & $2.37 \mathrm{E}+11$ & $4.32 \mathrm{E}+07$ & $3.08 \mathrm{E}+11$ & $8.11 \mathrm{E}+02$ \\
\hline Acidification/eutrophication & $1.43 \mathrm{E}+11$ & & & & $1.43 \mathrm{E}+11$ & $3.75 E+02$ \\
\hline Land-use & $1.50 \mathrm{E}+12$ & & & & $1.50 \mathrm{E}+12$ & $3.95 E+03$ \\
\hline $\begin{array}{l}\text { Total Ecosystem Quality } \\
\text { [PDFmª/a] }\end{array}$ & $1.71 \mathrm{E}+12$ & 7.87E+08 & $2.37 E+11$ & $4.32 \mathrm{E}+07$ & $1.95 \mathrm{E}+12$ & $5.13 E+03$ \\
\hline Minerals & & & & & $5.61 \mathrm{E}+10$ & $1.48 \mathrm{E}+02$ \\
\hline Fossil & & & & & $3.14 \mathrm{E}+12$ & $8.26 \mathrm{E}+03$ \\
\hline Total Resources [MJ/a] & & & & & $3.20 \mathrm{E}+12$ & $8.41 E+03$ \\
\hline
\end{tabular}

After normalisation the factors calculated from the indicator results can be weighted. Therefore the Eco indicator '99 approach is used. Due to the influence of the weighting method on the results of LCA studies, this method is explained in detail in chapter 2.8. An overall comparison factor is created, which helps to compare the investigated systems, by using a standardised method in relation to study-independent weighting factors to single out one alternative from all systems under investigation. These weighting factors are given in Table 2.39. These are just standard weighting factors; other methods can use different weighting factors to compare the different damage categories.

Table 2.39: Weighting factors of El '99 (H) used in this assessment

\begin{tabular}{|l|r|}
\hline \multicolumn{1}{|c|}{ damage category } & \multicolumn{1}{c|}{ weighting } \\
\hline Human Health & 400 \\
\hline Ecosystem Quality & 400 \\
\hline Resources & 200 \\
\hline
\end{tabular}

Weighting is an absolutely normative step and the used weighting factors are by definition normative and can therefore neither be true nor false. The only criterion is, if the normalisation factors are correctly reflecting the view of the appropriate stakeholders. For this purpose the stakeholder group has to be defined in detail and represented in the methodology used, 
and the method has to be used in a consistent and social science sound procedure [GOEDKOOP\&SPRIENSMA2001]. Furthermore, [BRENTRUP2003] stresses the importance of combining natural science and subjective values under social consensus when using weighting methods. Due to this normative character of the weighting procedure ISO14042 states that weighting "shall not be used for comparative assertions disclosed to public" [CEN2000a]. To prevent the production of false results in this study, only data that are dealt with using natural science based methods should be used for comparisons

The utilisation of weighting methods aids in making the different results of the impact categories comparable and highlights the one best alternative out of all investigated systems. If these standardised weighting methods are not used, each LCA user will use his individual weighting approach, which could prove problematic [BRENTRUP2003]. This leads to incomprehensible impact assessment results. The above source states that the use of weighting methods strengthens the LCA user when "...interpret(ing) complex environmental data sets on a more transparent and documented basis". [BISCHOFF1994 in BRENTRUP2003] observes that environmental factors will never solely be comparable by an evaluation and aggregation of different environmental effects based on a pure (natural) scientific basis. Values and societal preferences will always be included in the impact category results assessment. Thus, weighting results can be viewed as a voluntary step added to the normalised results of the LCA study.

The LCA done in this study is a comparative LCA, which places the ecological effects related to different technologies in the field of biogas production side by side. This study is made accessible to the public as a PhD. thesis and should therefore not use weighting. As mentioned previously, weighting is a useful tool in making the results of $\mathrm{LCl}$ and the impact assessment comparable on a common methodological base between varieties of studies. The results of the LCA are presented in different levels of detail in order to incorporate the possibilities of the weighting step without impairing the requirements of ISO14042. This means all results e.g. inventory data, impact assessment indicators, and normalisation values are accessible to the reader. Thereby, the reader can reconstruct the natural science based data and its manipulation through the weighting procedure.

The weighting assessment methods for the El'99 method were developed based on a panel approach, done by [METTIER in GOEDKOOP\&SPRIENSMA2001]. This weighting method has the advantage that it takes into account only three damage categories, which is different to other methods. It was therefore easier for the panel to complete the questionnaire and help to develop this method. Once the questionnaires were answered and the panel's opinions of the importance of the three damage categories were given, three groups of perspectives based on cultural perspectives could be formulated. These being, Individualists,

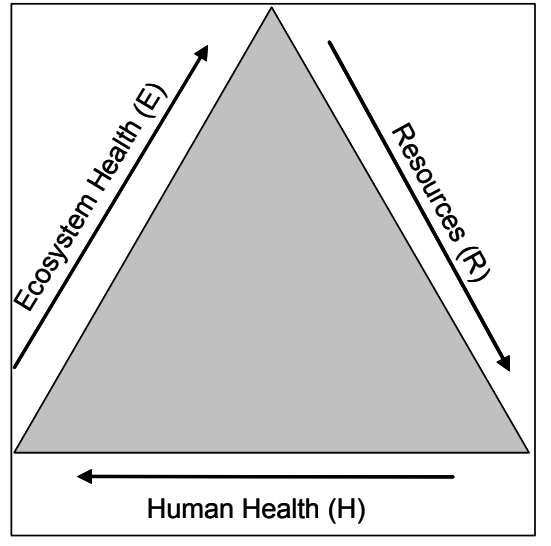

Figure 2.22: Weighting triangel Egalitarians, and Hierarchists, from which it can be concluded that the Hierarchist has the most balanced view of the three damage categories which is conveyed in the following table 
(also see chapter 2.8.2). The Hierarchist model has been chosen as the standard weighting method in this study. It is noted that only 29 of the original 82 questionnaire respondents were described as adhering to a perspective and correspondingly grouped.

Table 2.40: Estimate of rounded weighting factors [METTIER in GOEDKOOP\&SPRIENSMA2001]

\begin{tabular}{|l|r|r|r|r|}
\hline & Average & Individualist (n=10) & Egalitarian (n=14) & Hierarchist (n=5) \\
\hline Ecosystem Quality & $40 \%$ & $25 \%$ & $50 \%$ & $40 \%$ \\
\hline Human Health & $40 \%$ & $55 \%$ & $30 \%$ & $30 \%$ \\
\hline Resources & $20 \%$ & $20 \%$ & $20 \%$ & $30 \%$ \\
\hline
\end{tabular}

The combination of the calculated normalisation figures and the weighting factors makes it possible to show the contribution of the impact categories to the three safeguard subject of the El '99 Hierachist assessment method. Therefore the normalisation values given in Table 2.38 and the weighting process of the Hierarchist model are used. This leads to the results given in Figure 2.23.

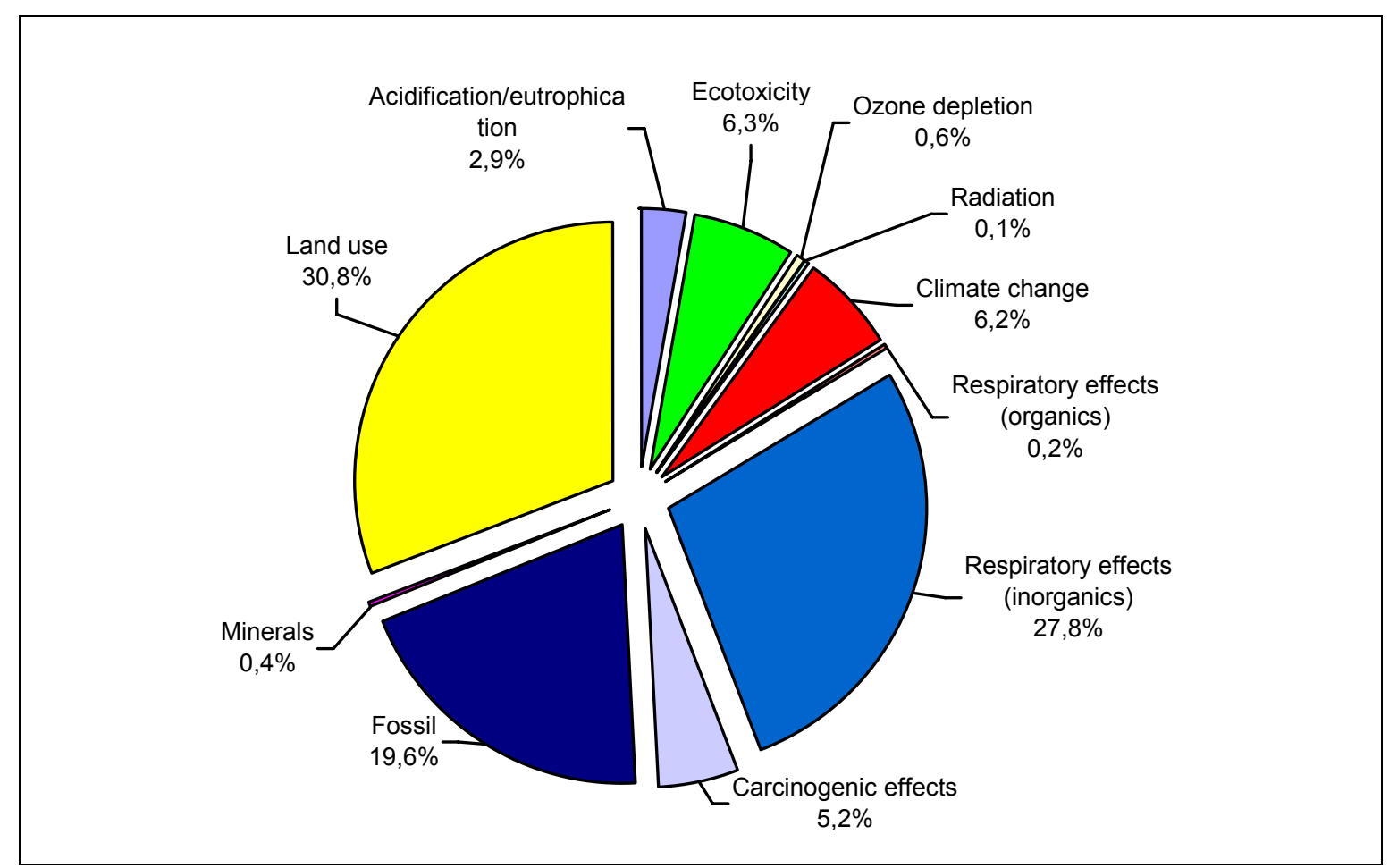

Figure 2.23: Relative contribution of the impact categories to the European damage [GOEDKOOP\&SPRIENSMA2001]

From this figure some conclusion can be drawn. First of all to be noted, is that the damage categories land use, respiratory effects (inorganics), and the consumption of fossil resources are seen as the most important impact categories. Other impact categories like ionising radiation and ozone depletion have only a subordinate importance in the El '99 (H) assessment. Ecotoxicity and acidification/eutrophication seem rather unimportant in relation to the strong influence of the land use category.

Once again, it should be stressed, that the El ' 99 method is probably considered the most modern and complicated method for the normalisation and weighting of indicator results. Nevertheless, it is simply a weighting method. Other methods could lead to different results. This method is a helpful tool to illustrate the rather abstract results of the characterisation 
step and also aids in understanding the results of this work. If any comparative statements are to be drawn from data of this work, it should be noted that the results of the El '99 method should not be used. Instead, only the data up to the characterisation/normalisation step should be drawn upon. All the proceeding results are based on social science and are therefore not natural science sound.

\subsubsection{Sensitivity analysis}

Sensitivity analysis is a method to check the impact a single unit process or module has on the overall environmental effects from the system under analysis. By doing this, all data from the object under analysis except one unit process or module are kept stable (ceteris paribus). The data of this one process or module are then changed and their influence on the overall effect is analysed. Comparing the overall effect caused by this sensitivity analysis compared to the initial situation shows the influence of the analysed module or unit process on the overall effect [CEN1998].

Several sensitivity analyses will be carried out during the assessment of ecological effects of electricity generation from industrial scale biogas plants. The utilisation of waste heat for heating processes will be taken into account. Technology changes in CHP processes, e.g. fuel cells, will also be considered. Higher yields of energy crops per unit area due to breeding achievements will be also be included. There will be an analysis of change in the kind of used inputs, with a special focus on the utilisation of biodegradable waste. Scale changes of the plant and related processes will be done. Finally, the influence of the method used for assessing the impact category land use will be investigated within a single sensitivity analysis.

\section{Use of waste heat}

CHP processes generate electricity and heat, which can both be used in different ways. As the electricity can be fed to the grid and thus is independent from the place of utilisation, thermal energy can hardly be transported in any way. Thermal energy can be transported (only in a short range) providing that there is a local heat grid. Furthermore, the heat from the $\mathrm{CHP}$ unit $\left(90^{\circ} \mathrm{C}\right)$ is reduced by conversion and transport losses, so that only a temperature of around $65^{\circ} \mathrm{C}$ at the place of utilisation can be used. This means, that the heat from CHP units can be used in a very limited number of applications, e.g. heating of houses or lowtemperature drying.

The fictional CHP unit under investigation has an electric output of $1.0 \mathrm{MW}$, from which a thermal output of 1.1 MW is assumed [HAASE2005, ASUE2005]. Based on the assumption that the CHP engine is operated for 7,800 full load hours per year, a thermal output of $8,580 \mathrm{MWh} / \mathrm{a}$ can be calculated. An internal consumption including losses of $15 \%$ for heating of the plant is assumed, resulting in 7,293 MWh available thermal energy [HEIDLER2002, FNR2004]. As most heat is needed in the winter months, for both heating of the biogas plant and other processes, it is assumed that $25 \%$ of this total thermal heat $(1,823 \mathrm{MWh})$ can be used to replace other resources. By taking into account losses of $5 \%$ for conversion and 
transport processes, 1,732 MWh/a (61.7 MWh/functional unit) of thermal heat from other resources can be saved.

$\mathrm{LCl}$ data for the assessment of the thermal heat grid needed to distribute this heat is taken from the data set Infra distribution heat large WW $U$ [ECOINVENT2002]. It is assumed that the heat is used to replace natural gas as an energy source in household heating systems. The energy shall be distributed to 237 households with a total load level of $2,84 \mathrm{MW}$ (12 kW/household). The replaced heating processes in these households are represented by the data set Heat boiler lowNOx condensing <100kW $U$ [EcoINVENT2002]. Data for this facility are given in Table 2.41. Attention should be paid to the negative algebraic signs before the accounted data. This negative sign symbolises ecological credits from this process.

Table 2.41: Replaced heatings from $61.7 \mathrm{MWh}$ fed to a heat grid.

\begin{tabular}{|l|l|l|r|}
\hline \multicolumn{1}{|c|}{ substance } & compartment & \multicolumn{1}{r|}{ unit } & amount \\
\hline Gas, natural, 35 MJ per m3, in ground & Raw & $\mathrm{m}^{3}$ & $-7,110$ \\
\hline Oil, crude, 42.6 MJ per kg, in ground & Raw & $\mathrm{kg}$ & -232 \\
\hline Carbon dioxide & Air & $\mathrm{kg}$ & $-14,400$ \\
\hline Nitrogen oxides & Air & $\mathrm{kg}$ & -10.5 \\
\hline
\end{tabular}

\section{CHP technology change, fuel cell}

The use of gas engines is the most advanced method of electricity generation from biogas. New developments are discussed but have not been put into use yet. One of these new methods is the fuel cell technology. Fuel cells are electrochemical energy conversion devices designed for continuous replenishment of the reactants consumed. These reactants used to produce electricity are an external kind of fuel e.g. biogas and oxygen. Fuel cells are not constrained by the maximum Carnot cycle efficiency as combustion engines are, due to the fact that they do not operate with a thermal cycle. Consequently, they can have very high efficiencies in converting chemical energy to electrical energy. Normally, a fuel cell converts the chemical energy of its fuel into electricity with an efficiency of about 47\%-50\% [RÜHLE2005, HUPPMANN2006]. This higher conversion rate of $47 \%$ related to $36 \%$ of conventional gas engines leads to a reduction of $23.4 \%$ of energy crops and transport efforts used as inputs to the process. 


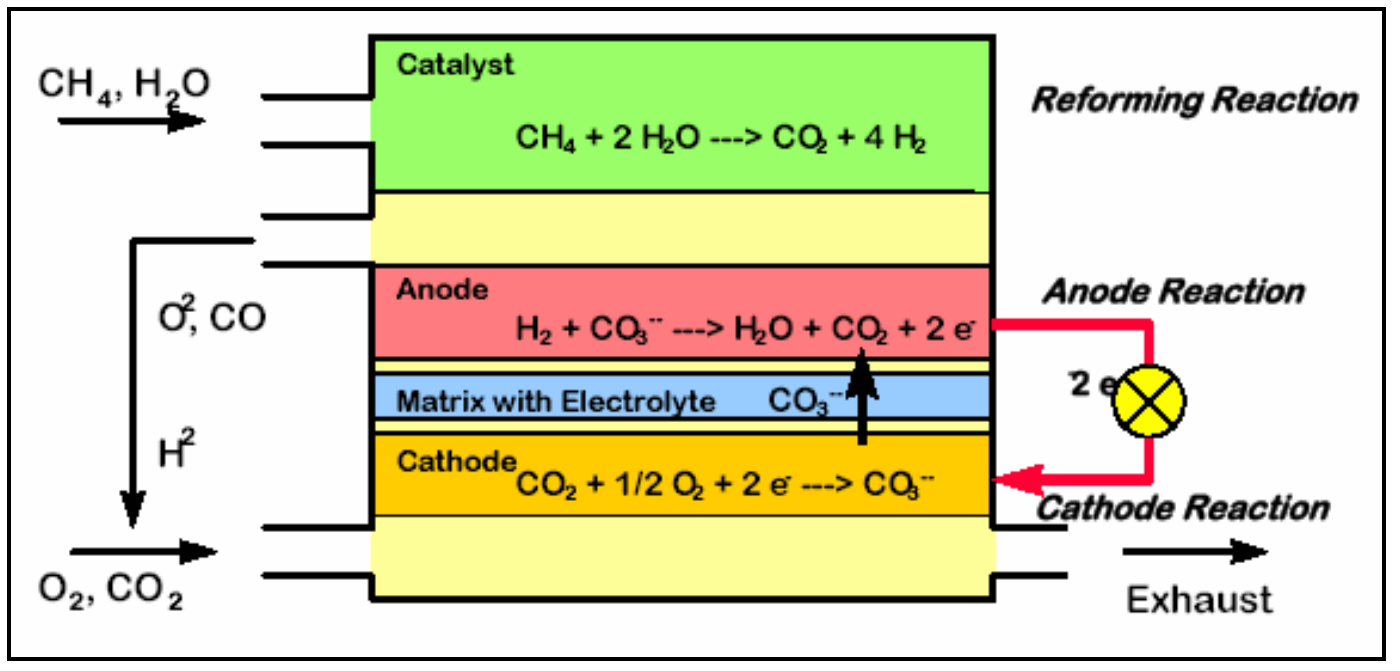

Figure 2.24: Scheme of a molten carbonate fuel cell (MCFC) [BERGER2006]

The utilisation of fuel cells for electricity generation from biogas is presented with several problems. Biogas consists of methane and carbon dioxide as well as several trail gases. These trail gases can destroy the fuel cell within a short period of time. These harmful trail gases are: $\mathrm{H}_{2} \mathrm{~S}$, steam, $\mathrm{NH}_{3}, \mathrm{COS}$, siloxane, $\mathrm{Cl}, \mathrm{F}$, and dust. Also $\mathrm{CO}_{2}$ and $\mathrm{CO}$ can be harmful in low-temperature fuel cells, therefore only high-temperature fuel cells, especially Molten Carbonate Fuel Cells (MCFC), will be taken into account in this sensitivity analysis. Before fuel cells can be used for generation of electricity from biogas, the biogas has to be purified from these trail gases [OTT\&TAMM2003, SCHNELL2003, SCHNEIDER ET AL.2003].

A detailed assessment of the technology needed to purify biogas from a biogas plant using energy crops was done by [PINGEL2006]. This assessment shows that standard technology is sufficient to purify biogas from too high loads of trail gases. According to [PINGEL2006] a biological trickling filter, removing dust and most $\mathrm{SO}_{2}$, followed by a conventional gas drying, and an activated charcoal trap are sufficient methods to remove harmful trail gases. The LCI data of activated charcoal consumption of the biogas plant in the standard scenario are increased by a factor of three. This high amount of activated charcoal prevents any trail gases from passing the charcoal trap. This is the same method as it is used at the biogas plant in Leonberg (Germany), which is the first industrial scale experimental plant using fuel cells in combination with biogas plants [BMU2006].

The durability of hot module fuel cells is currently limited to around 20,000 full load hours [GEITMANN2002]. In the future, this will be probably increased to 40,000 full load hours [HUPPMANN2006]. Therefore, in this analysis, the fuel cell is estimated at having a life time of three years.

After considering the higher conversion rate of the fuel cell, the rate of gaseous emissions from fuel cells also proves to be of great interest. Given that, an open flame is not generated in fuel cells; no gaseous emissions related to burning are generated. This reduced emission level compared to other conversion technologies is shown in Figure 2.25. 


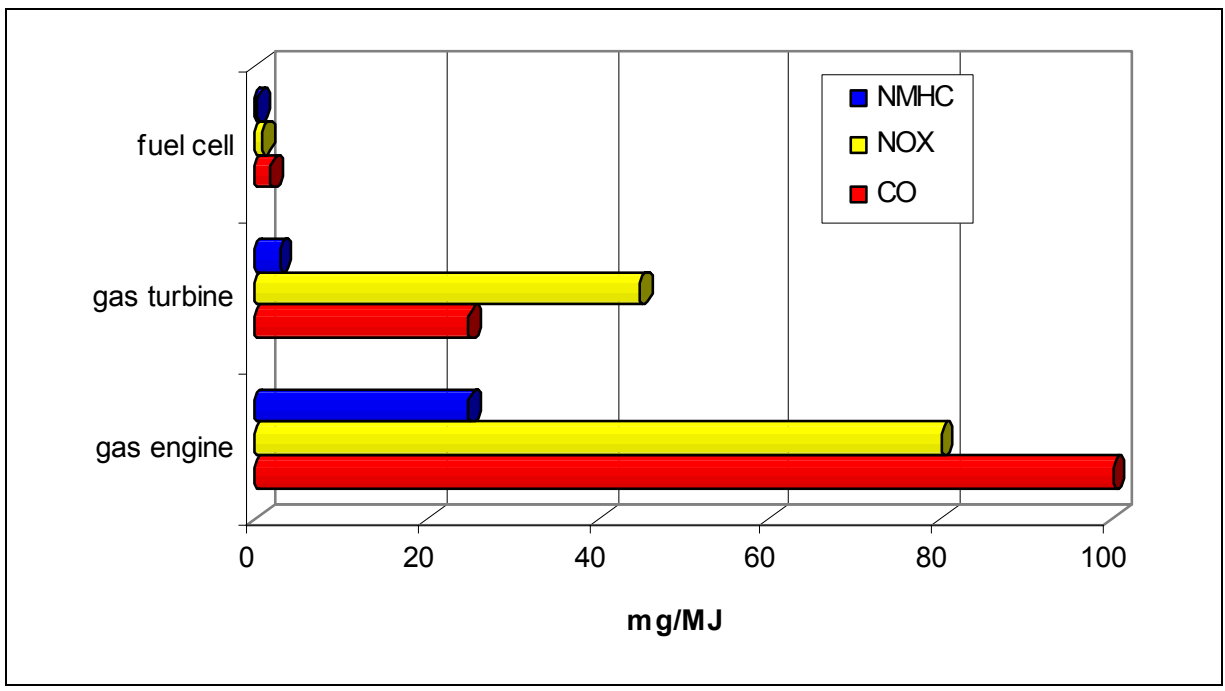

Figure 2.25: Emissions from fuel cells compared to gas turbine and gas engine

Unlike in conventional CHP plants, the catalytic substances in fuel cells have to be taken into account. Platinum is used in low temperature fuel cells. Due to the high temperatures in MCFCs, nickel can be used instead of platinum; ecological and economical efforts are therefore reduced [BERGER2006]. Catalytic substances are not consumed in processes, but their performance can be impeded. Therefore a consumption of these catalytic substances will be considered. The additional charcoal needed for gas purification is taken into account in the data set of the MCFC fuel cell. Data collected for the production of a $1.0 \mathrm{MW}_{\mathrm{el}}$ fuel cell and also the emissions from this fuel cell are given in Table 2.42 and Table 2.43.

Table 2.42: $\mathrm{LCl}$ of a MCFC fuel cell of $1.0 \mathrm{MWel}$ power related to one functional unit

\begin{tabular}{|c|c|c|c|}
\hline substance & compartment & unit & amount \\
\hline Coal, $18 \mathrm{MJ}$ per kg, in ground & Raw & $\mathrm{kg}$ & 187 \\
\hline Gas, mine, off-gas, process, coal mining $/ \mathrm{kg}$ & Raw & $\mathrm{kg}$ & 1.59 \\
\hline Gas, natural, $35 \mathrm{MJ}$ per $\mathrm{m} 3$, in ground & Raw & $\mathrm{m}^{3}$ & 5.15 \\
\hline Iron, in ground & Raw & $\mathrm{kg}$ & 187 \\
\hline Land use II-III & Raw & $m^{2} a$ & 6.22 \\
\hline Land use II-IV & Raw & $m^{2} a$ & 4.2 \\
\hline $\begin{array}{l}\text { Nickel, } 1.13 \% \text { in sulfide, } \mathrm{Ni} 0.76 \% \text { and } \mathrm{Cu} \\
0.76 \% \text { in crude ore, in ground } \\
\end{array}$ & Raw & g & 832 \\
\hline Oil, crude, $42.6 \mathrm{MJ}$ per $\mathrm{kg}$, in ground & Raw & $\mathrm{kg}$ & 15.6 \\
\hline Oil, crude, in ground & Raw & $\mathrm{kg}$ & 1.12 \\
\hline Cadmium & Air & $\mathrm{mg}$ & 63.2 \\
\hline Carbon dioxide & Air & $\mathrm{kg}$ & -273 \\
\hline Lead & Air & $g$ & 1.25 \\
\hline Nickel & Air & $g$ & 1.64 \\
\hline Nitrogen oxides & Air & $g$ & 542 \\
\hline Particulates, < 10 um (stationary) & Air & $g$ & 44.6 \\
\hline Particulates, $<2.5$ um & Air & g & 19.5 \\
\hline Particulates, $>2.5 \mathrm{um}$, and $<10 \mathrm{um}$ & Air & $g$ & 50.4 \\
\hline Sulfur dioxide & Air & $g$ & 920 \\
\hline Sulfur oxides & Air & $g$ & 876 \\
\hline Zinc & Air & $g$ & 4.64 \\
\hline Arsenic, ion & Water & $\mathrm{mg}$ & 625 \\
\hline
\end{tabular}


Table 2.43: Emissions from a $1.0 \mathrm{MW}_{\mathrm{el}}$ fuel cell related to one functional unit

\begin{tabular}{|l|l|l|r|}
\hline \multicolumn{1}{|c|}{ substance } & compartment & \multicolumn{1}{c|}{ unit } & amount \\
\hline Carbon dioxide, biogenic & Air & ton & 47.3 \\
\hline Carbon monoxide, biogenic & Air & $\mathrm{kg}$ & 5.58 \\
\hline Formaldehyde & Air & $\mathrm{g}$ & 565 \\
\hline Nitrogen oxides & Air & $\mathrm{kg}$ & 4.52 \\
\hline
\end{tabular}

\section{Increasing yields from energy crops}

In the last years, there has been increased discussion regarding energy crops, which are especially breeded for high yields of dry matter content per unit area. Different companies have dedicated their research to high yield maize hybrids, as maize is viewed as the energy crop, which has the highest potential out of all the other energy crops [SCHMIDT2006].

In the standard calculation (cf. chapter 2.6.1) maize yields of $45.0 \mathrm{Mg} / \mathrm{ha}$ absolute yield or 15.0 MG/ha dry matter are expected. New breedings are expected to achieve yields of 45.0 - 54.0 Mg DM/ha [SCHMIDT2006]. Tests from the year 2005 showed that commercial varieties from southern parts of Europe could also generate yields of $21.0-25.0 \mathrm{Mg} \mathrm{DM} / \mathrm{ha}$ in North West Germany [GRÖBLINGHOFF2006].

It must be pointed out that all of these results are considered the best possible ones. That means, they were measured on soils of high quality and with sufficient water supply. A lack of water can reduce maize yields tremendously. In the case of the sensitivity analysis, it is therefore estimated that an increase from $15.0 \mathrm{Mg} / \mathrm{ha}$ to $30.0 \mathrm{Mg} / \mathrm{ha}$ will take place within the next five years. This leads to a $50 \%$ reduction in land use and a $30 \%$ reduction in fertiliser and plant protection agents. There is no significant reduction in transport efforts, as the mass of transported energy crops is not changed. This leads to the LCl data given in Table 2.44.

Table 2.44: $\mathrm{LCl}$ of high yield maize related to one functional unit

\begin{tabular}{|l|l|l|r|}
\hline \multicolumn{1}{|c|}{ substance } & compartment & \multicolumn{1}{c|}{ unit } & amount \\
\hline Carbon dioxide, in air & Raw & $\mathrm{Mg}$ & 378 \\
\hline Gas, natural, in ground & Raw & $\mathrm{m}^{3}$ & 1110 \\
\hline Occupation, arable, non-irrigated & Raw & $\mathrm{m}^{2} \mathrm{a}$ & 27,500 \\
\hline Oil, crude, in ground & Raw & $\mathrm{Mg}$ & 2.18 \\
\hline Transformation, from pasture and meadow & Raw & $\mathrm{m}^{2}$ & 339 \\
\hline Carbon dioxide, fossil & Raw & $\mathrm{Mg}$ & 9.72 \\
\hline Nitrogen oxides & Air & $\mathrm{kg}$ & 75.1 \\
\hline Particulates, <2.5 um & Air & $\mathrm{kg}$ & 9.56 \\
\hline Particulates, $>2.5$ um, and <10um & Air & $\mathrm{kg}$ & 8.34 \\
\hline Sulfur dioxide & Air & $\mathrm{kg}$ & 32.4 \\
\hline Arsenic, ion & Water & $\mathrm{g}$ & 43.9 \\
\hline Cadmium, ion & Water & $\mathrm{g}$ & 31.2 \\
\hline Cadmium & Soil & $\mathrm{g}$ & 14.4 \\
\hline Chromium & Soil & $\mathrm{g}$ & 283 \\
\hline Nickel & Soil & $\mathrm{g}$ & 60 \\
\hline Zinc & Soil & $\mathrm{g}$ & -743 \\
\hline
\end{tabular}




\section{Input substrate changes}

This assessment considers mainly energy crops as defined by the Renewable-EnergySources-Act as inputs to the biogas process. As said in the introduction, many more substrates exist that can be used as input to the biogas process. Nearly every biodegradable substance can be used, in a limited way. Toxic organic materials or materials that contain toxic substances cannot be used in biogas plants. Mycotoxins from fusarium are an exception. They are generally toxic to methane bacteria in biogas plants, but small amounts of mycotoxins are tolerated, as shown by [FRAUZ ET AL.2005]. So, crops that are charged with mycotoxins can be used as inputs to biogas plants without disrupting the biogas process.

Additional substrates other than toxin charged energy crops can also be used as input to biogas plants. Until the last revision of the Renewable-Energy-Sorces-Act organic waste materials from the food-processing industry were typical inputs for the biogas production. This waste is made up of e.g. pomace, pulp, slop, and expired food. A short list of waste from the food industry and its possible gas yields is given below [FNR2004]:

Table 2.45: Energy content of waste from the food industry

\begin{tabular}{|l|r|r|r|r|}
\hline \multicolumn{1}{|c|}{ substrate } & $\begin{array}{c}\text { gas yield } \\
\left.\text { [ } \mathbf{m}^{3} / \mathbf{M g}\right]\end{array}$ & $\mathbf{C H}_{4}$-content & $\begin{array}{c}\text { energy con- } \\
\text { tent [GJ/Mg] }\end{array}$ & \multicolumn{1}{c|}{$\begin{array}{c}\text { demand } \\
\text { [Mg/TJ] }\end{array}$} \\
\hline fruit pomace & $250-280, \varnothing 265$ & $65-70 \%, \varnothing 67 \%$ & 6.37 & 435.92 \\
\hline potatoe pulp & $80-90, \varnothing 85$ & $52-65 \%, \varnothing 57 \%$ & 1.74 & 1597.46 \\
\hline corn slop & $30-50, \varnothing 40$ & $58-65 \%, \varnothing 61 \%$ & 0.88 & 3172.01 \\
\hline expired food & $50-480, \varnothing 265$ & $45-61 \%, \varnothing 53 \%$ & 5.04 & 551.06 \\
\hline
\end{tabular}

If waste is used as input in other processes, it is taken into account without any ecological burden. This means that no LCl data from upstream processes are calculated for the utilisation of waste, when they are used as inputs of the biogas process. Only transport efforts will be considered, which are needed to transport the different waste materials to the biogas plant. For this, an average transport distance of $10 \mathrm{~km}$ is assumed. For calculation purposes a mixture of the waste types presented above is used. A conversion rate of $36 \%$ is calculated.

Table 2.46: Mixture of waste materials for the production of one functional unit

\begin{tabular}{|l|r|r|}
\hline \multicolumn{1}{|c|}{ substrate } & mass [Mg] & share [TJ] \\
\hline fruit pomace & 100 & 0.229 \\
\hline potatoe pulp & 280 & 0.175 \\
\hline corn slop & 110 & 0.035 \\
\hline expired food & 260 & 0.472 \\
\hline cow manure & 200 & 0.039 \\
\hline pig manure & 200 & 0.050 \\
\hline
\end{tabular}

From this input mass $(1,150 \mathrm{Mg} / \mathrm{TJ})$ a mass of outputs of $1,056 \mathrm{Mg} / \mathrm{TJ}$ is assumed. Data of the $\mathrm{LCl}$ of these transports are given in Table 2.47. 
Table 2.47: LCl of input transports of waste for one functional unit

\begin{tabular}{|l|l|l|r|r|}
\hline \multicolumn{1}{|c|}{ substance } & compartment & \multicolumn{1}{c|}{ unit } & \multicolumn{1}{c|}{$\begin{array}{c}\text { input } \\
\text { amount }\end{array}$} & $\begin{array}{c}\text { output } \\
\text { amount }\end{array}$ \\
\hline Aluminium, 24\% in bauxite, 11\% in crude ore, in ground & Raw & kg & 91.2 & 83.7 \\
\hline Gas, natural, in ground & Raw & $\mathrm{m}^{3}$ & 156 & 143 \\
\hline $\begin{array}{l}\text { Nickel, 1.98\% in silicates, 1.04\% in crude ore, in } \\
\text { ground }\end{array}$ & Raw & $\mathrm{kg}$ & 7.91 & 7.27 \\
\hline Occupation, forest, intensive, normal & Raw & $\mathrm{m}^{2} \mathrm{a}$ & 539 & 495 \\
\hline Occupation, urban, discontinuously built & Raw & $\mathrm{m}^{2} \mathrm{a}$ & 116 & 106 \\
\hline Oil, crude, in ground & Raw & $\mathrm{kg}$ & 443 & 406 \\
\hline Transformation, from pasture and meadow & Raw & $\mathrm{m}^{2} \mathrm{a}$ & 2.39 & 2.2 \\
\hline Transformation, to urban, discontinuously built & Raw & $\mathrm{m}^{2}$ & 2.31 & 2.12 \\
\hline Carbon dioxide, fossil & Air & $\mathrm{Mg}$ & 3.09 & 2.84 \\
\hline $\begin{array}{l}\text { Dioxins, measured as 2,3,7,8-tetrachlorodibenzo-p- } \\
\text { dioxin }\end{array}$ & Air & $\mathrm{mg}$ & 2.47 & 2.27 \\
\hline Nitrogen oxides & Air & $\mathrm{kg}$ & 12.7 & 11.7 \\
\hline Particulates, <2.5 um & Air & $\mathrm{kg}$ & 3.5 & 3.21 \\
\hline Particulates, $>2.5$ um, and <10um & Air & $\mathrm{kg}$ & 3.09 & 2.84 \\
\hline Sulfur dioxide & Air & $\mathrm{kg}$ & 6.21 & 5.7 \\
\hline Arsenic, ion & Water & $\mathrm{g}$ & 6.58 & 6.04 \\
\hline Cadmium, ion & Water & $\mathrm{g}$ & 7.23 & 6.64 \\
\hline Zinc & Soil & $\mathrm{g}$ & 242 & 223 \\
\hline
\end{tabular}

\section{Up-scaling of the plant}

The size of the biogas plant is set to $1.0 \mathrm{MW}_{\mathrm{el}}$ power as a base value. In this sensitivity analysis the size of the plant will be set to $2.0 \mathrm{MW}_{\text {el }}$ power. Therefore a second fermenter with the same volume $\left(1,500 \mathrm{~m}^{3}\right)$ is added. The storage vessel is enlarged to a volume of $2,000 \mathrm{~m}^{3}$. A second CHP engine of the same size will be taken into account. The amount of every other component in the biogas plant is doubled.

When the electric output is doubled, the total consumption of electric energy from the grid will be increased by $80 \%$. The energy consumption of the CHP plants and the pumps will increase at the same rate as the size of the plant. The energy consumption of the stirrers is assumed to increase by just $50 \%$.

Not only will the number of inputs double, but the area under cultivation will also double in size. This increase of area under cultivation leads to a subproportional increase of transport efforts, as explained in chapter 2.6.3. From equation (4) the average transport distance for a $2.0 \mathrm{MW}_{\mathrm{el}}$ power biogas plant is derived, as shown in equation (11).

$\operatorname{atd}_{56.16 T J}=\sqrt{\frac{622.2 \mathrm{~km}^{2}}{2 \pi}}=9.95 \mathrm{~km}$

Taking into account the mass flows of Table 2.11, inputs of $1,030 \mathrm{Mg} / \mathrm{TJ}$ and outputs of $945.5 \mathrm{Mg} / \mathrm{TJ}$ are related to the production of one functional unit. Multiplied by the atd $\mathrm{ab6.16 \textrm {TJ }}$ from equation (11) transport efforts of 10,249 tkm (input) and 9,408 tkm (output) can be correlated to the production of one functional unit in a $2.0 \mathrm{MW}_{\mathrm{el}}$ power biogas plant. 
The influence of the up-scale effect on the LCl data will be represented by the change in both electric energy consumption and transport efforts. These data are given below in Table 2.48.

Table 2.48: $\mathrm{LCl}$ of transport efforts of a $2.0 \mathrm{MW}_{\mathrm{el}}$ biogas plant related to one functional unit

\begin{tabular}{|l|l|l|r|r|}
\hline \multicolumn{1}{|c|}{ substance } & compartment & unit & \multicolumn{1}{c|}{$\begin{array}{c}\text { int } \\
\text { amount }\end{array}$} & $\begin{array}{c}\text { output } \\
\text { amount }\end{array}$ \\
\hline Aluminium, 24\% in bauxite, 11\% in crude ore, in ground & Raw & $\mathrm{kg}$ & 81.3 & 74.6 \\
\hline Gas, natural, in ground & Raw & $\mathrm{m}^{3}$ & 139 & 128 \\
\hline $\begin{array}{l}\text { Nickel, 1.98\% in silicates, 1.04\% in crude ore, in } \\
\text { ground }\end{array}$ & Raw & $\mathrm{kg}$ & 7.05 & 6.47 \\
\hline Occupation, forest, intensive, normal & Raw & $\mathrm{m}^{2} \mathrm{a}$ & 481 & 441 \\
\hline Occupation, urban, discontinuously built & Raw & $\mathrm{m}^{2} \mathrm{a}$ & 103 & 94.8 \\
\hline Oil, crude, in ground & Raw & $\mathrm{kg}^{2}$ & 394 & 362 \\
\hline Transformation, from pasture and meadow & Raw & $\mathrm{m}^{2}$ & 2.13 & 1.96 \\
\hline Transformation, to urban, discontinuously built & Raw & $\mathrm{m}^{2}$ & 2.06 & 1.89 \\
\hline Carbon dioxide, fossil & Air & $\mathrm{Mg}$ & 2.75 & 2.53 \\
\hline $\begin{array}{l}\text { Dioxins, measured as 2,3,7,8-tetrachlorodibenzo-p- } \\
\text { dioxin }\end{array}$ & Air & $\mathrm{mg}$ & 2.2 & 2.02 \\
\hline Nitrogen oxides & Air & $\mathrm{kg}$ & 11.3 & 10.4 \\
\hline Particulates, $<2.5$ um & Air & $\mathrm{kg}$ & 3.12 & 2.86 \\
\hline Particulates, $>2.5$ um, and <10um & Air & $\mathrm{kg}$ & 2.75 & 2.53 \\
\hline Sulfur dioxide & Air & $\mathrm{kg}$ & 5.53 & 5.08 \\
\hline Arsenic, ion & Water & $\mathrm{g}$ & 5.87 & 5.39 \\
\hline Cadmium, ion & Water & $\mathrm{g}$ & 6.44 & 5.91 \\
\hline Zinc & Soil & $\mathrm{g}$ & 216 & 198 \\
\hline
\end{tabular}

\section{Weighting of the impact category land use}

As shown in the impact category land use, by choosing an alternative strategy to the current type of land use, there is a strong influence evident in the development of the land use category as well as the final result of the LCA. This is why in the assessment of land, two sensitivities are tested. The sensitivities vary from (1) the potential natural vegetation in the standard scenario as given in chapter 2.7.1, to (2) extensive integrated agricultural production i.e. $\alpha$-euhemerobic, to (3) no alternative scenario, which means no land occupation is regarded.

Scenario (1) is described in chapter 2.7.1 as the standard scenario of this LCA study. The $\mathrm{LCl}$ data results from this scenario are given in chapter 2.6.1 (Table 2.3-Table 2.5). The land use intensity of $70 \%-80 \%$ (Hemeroby level $\mathrm{H} 7-\mathrm{H} 8$ ) is responsible for the effects on the environment from the type of arable land use.

Scenario (2) takes into account extensive arable crop production as a reference system; instead of the potential natural vegetation used in scenario (1). This scenario is based on the statement of [BECKER2004] that highest biodiversity can be reached when agricultural production changes from intensive to extensive production. Extensive arable crop production systems have a low input of fertilisers and chemical or mechanical plant protection. Until the year 1850, extensive crop production was the most common type of crop production. The development of mineral fertilizers and pest control chemicals ensured that agriculture changed from extensive to intensive production in most parts of Europe. 
Extensive production systems lead to a species increase compared to intensive production systems by factor four (Figure 2.20). Extensive production systems have lower yields than comparable intensive production systems and therefore need more area under cultivation per crop unit. In this situation only silage maize will be considered, as maize is the most important energy crop for biogas production.

Comparisons between integrated intensive and extensive maize production were made by [TSCHACHTLI ET AL.2004]. This study of extensive production systems involves the use of $39 \%$ less nitrogen fertiliser and $82 \%$ less plant protection chemicals. Therefore the data gathered does not fully reflect the state of agriculture in the year 1850. A decrease in productivity per unit area of $25 \%$ compared to the intensive production system is taken into consideration. A use intensity of $45 \%$ (Hemeroby level $\mathrm{H} 4-\mathrm{H} 5$ ) is assumed. This data and the data set Silage maize organic, at farm/ $\mathrm{CH} \cup$ from the Ecoinvent database are considered in the LCl of scenario (2) [ECOINVENT2004].

The data calculation of results from the study of land used for silage maize production, illustrates the difference of $0.055 \mathrm{~m}^{2} \mathrm{a} / \mathrm{kg}$ land used through the extensive production system, in comparison to $0.066 \mathrm{~m}^{2} \mathrm{a} / \mathrm{kg}$ of land occupied by the intensive production system. The occupation rate $0.055 \mathrm{~m}^{2} \mathrm{a} / \mathrm{kg}$ of the extensive production system will be considered as a refrence unit for the assessment of land occupation, instead of the pnv value taken into account in scenario (1). Therefore only $0.011 \mathrm{~m}^{2} \mathrm{a} / \mathrm{kg}\left(0.066 \mathrm{~m}^{2} \mathrm{a} / \mathrm{kg}-0.055 \mathrm{~m}^{2} \mathrm{a} / \mathrm{kg}\right)$ are taken into account for the land use of silage maize production. Data for this $\mathrm{LCl}$ are given in Table 2.49.

Table 2.49: LCI data of silage maize for one functional unit, considering an extensive production system as reference unit for land use

\begin{tabular}{|l|l|l|r|}
\hline \multicolumn{1}{|c|}{ substance } & compartment & unit & amount \\
\hline Carbon dioxide, in air & Raw & $\mathrm{Mg}$ & 378 \\
\hline Gas, natural, in ground & Raw & $\mathrm{m}^{3}$ & 1,340 \\
\hline Nickel, $1.98 \%$ in silicates, 1.04\% in crude ore, in ground & Raw & $\mathrm{kg}$ & 30.3 \\
\hline Occupation, arable, non-irrigated & Raw & $\mathrm{m}^{2} \mathrm{a}$ & 10,100 \\
\hline Oil, crude, in ground & Raw & $\mathrm{Mg}$ & 2.66 \\
\hline Transformation, from pasture and meadow & Raw & $\mathrm{m}^{2} \mathrm{a}$ & 339 \\
\hline Carbon dioxide, fossil & Air & $\mathrm{Mg}$ & 11.8 \\
\hline Nitrogen oxides & Air & $\mathrm{kg}$ & 92.3 \\
\hline Particulates, $<2.5$ um & Air & $\mathrm{kg}$ & 11.7 \\
\hline Particulates, $>2.5$ um, and $<10 \mathrm{um}$ & Air & $\mathrm{kg}$ & 9.82 \\
\hline Sulfur dioxide & Air & $\mathrm{kg}$ & 38.8 \\
\hline Arsenic, ion & Water & $\mathrm{g}$ & 52.6 \\
\hline Cadmium, ion & Water & $\mathrm{g}$ & 37.8 \\
\hline Cadmium & Soil & $\mathrm{g}$ & 27.8 \\
\hline Chromium & Soil & $\mathrm{g}$ & 561 \\
\hline Nickel & Soil & $\mathrm{g}$ & 119 \\
\hline Zinc & Soil & $\mathrm{kg}$ & -1.71 \\
\hline
\end{tabular}

Scenario (3) is drawn from the assumption that no data for transformation and occupation should be taken into account, if existing arable area is used for the crop production. [MÜLLERWENK1998a] explains that the damaging impact to nature per unit area $\left[\mathrm{m}^{2 *} \mathrm{a}\right]$ varies depending on the type of land use. In addition to this, he gives the following example: "If an already existing crop-field of $10,000 \mathrm{~m}^{2}$ is occupied during 1 year for growing potatoes, the damage 
to nature is apparently smaller than if a rare biotope of $10,000 \mathrm{~m}^{2}$ is transformed into a cropfield for growing potatoes during one year". He also states, that there is no need to change the type of land used, if the area under investigation is used in the same way as it was previously. This confirms the point made beforehand, that only the ecological effects from the change of an alternative crop to energy crops (especially maize) should be taken into account when assessing the life-cycle-inventory, not the natural endpoint-situation [KOWARIK1999] or the time of highest biodiversity as stated by [BECKER1997]. This argument is also supported by [HEIJUNGS ET AL.1992], who also takes into account the type of land use before and after the change in utilisation. In this particular LCA study, the majority of the influence on the overall results from the impact category land use is caused by the natural input occupation, arable, non-irrigated. This input is part of the Ecoinvent data base, which also takes into account the occupation of arable area, not the transformation of this area.

When presenting the first results of this thesis to experts in the field of biogas production, some experts hold the view that the impact category land use should not include the occupation of the area under cultivation (discussion enclosed to the speech given by [HARTMANN\&NELLES2006]). This view is taken from the assumption that there would be crop production on the area taken into account even if there would be no production of energy crops. This means, if there was no biogas plant and no energy crop production for the biogas plant, there would nevertheless be crop production, occupying arable areas. Therefore, if no energy crops are produced, no general ecological savings can be achieved. However, from a methodological viewpoint, it must be stated that any other crop production would be allocated this land occupation. So this argument is not completely correct. It is correct to say that the same number of unit areas will be used even if not used for the production of energy crops. Yet there will be land occupied by this different type of crop production and therefore the land use will be calculated with this production process. Therefore the occupation of land has to be taken into account.

To check the influence of the data set occupation, arable, non-irrigated on the total effect of energy crop production this third scenario will be calculated. In scenario (3) only the production of silage maize is calculated without the influence from occupation of arable area. The silage maize production includes the data set maize seed IP, at regional storehouse/CHU. This data set includes land occupation. Therefore, in scenario (3), land occupation is observed, although no reference or link is made to the silage maize production process. Data taken into account for this $\mathrm{LCl}$ are given in Table 2.50 .

Table 2.50: $\mathrm{LCl}$ of silage maize production for one functional unit, without calc. land occupation

\begin{tabular}{|l|l|l|r|}
\hline \multicolumn{1}{|c|}{ substance } & compartment & \multicolumn{1}{c|}{ unit } & amount \\
\hline Carbon dioxide, in air & Raw & $\mathrm{Mg}$ & 378 \\
\hline Gas, natural, in ground & Raw & $\mathrm{m}^{3}$ & 1,340 \\
\hline Nickel, $1.98 \%$ in silicates, 1.04\% in crude ore, in ground & Raw & $\mathrm{kg}$ & 30.3 \\
\hline Occupation, arable, non-irrigated & Raw & $\mathrm{m}^{2} \mathrm{a}$ & 1,400 \\
\hline Oil, crude, in ground & Raw & $\mathrm{Mg}$ & 2.66 \\
\hline Transformation, from pasture and meadow & Raw & $\mathrm{m}^{2} \mathrm{a}$ & 339 \\
\hline Carbon dioxide, fossil & Air & $\mathrm{Mg}$ & 11.8 \\
\hline Dinitrogen monoxide & Air & $\mathrm{kg}$ & 10.7 \\
\hline Dioxins, measured as 2,3,7,8-tetrachlorodibenzo-p-dioxin & Air & $\mathrm{mg}$ & 5.34 \\
\hline \hline
\end{tabular}

$$
-105-
$$




\begin{tabular}{|l|l|l|r|}
\hline Nitrogen oxides & Air & $\mathrm{kg}$ & 92.3 \\
\hline Particulates, $<2.5$ um & Air & $\mathrm{kg}$ & 11.7 \\
\hline Particulates, $>2.5$ um, and <10um & Air & $\mathrm{kg}$ & 9.82 \\
\hline Sulfur dioxide & Air & $\mathrm{kg}$ & 38.8 \\
\hline Arsenic, ion & Water & $\mathrm{g}$ & 52.6 \\
\hline Cadmium, ion & Water & $\mathrm{g}$ & 37.8 \\
\hline Cadmium & Soil & $\mathrm{g}$ & 27.8 \\
\hline Chromium & Soil & $\mathrm{g}$ & 561 \\
\hline Nickel & Soil & $\mathrm{g}$ & 119 \\
\hline Zinc & Soil & $\mathrm{kg}$ & -1.71 \\
\hline
\end{tabular}

\section{Biogas slurry treatment}

Biogas slurry treatment is sometimes created in order to reduce the transport efforts. Particularly in industrial scale biogas plants this can be an alternative to the essential transport efforts related to the distribution of biogas slurry. The first step of biogas slurry treatment is made by solid-liquid-separation, the second step being evaporation of the water from the liquid phase. Waste heat from the CHP process is used for the evaporation of the water. The evaporated water gets recovered and is used in the biogas fermenters for dilution of the substrate.

This method is effective for the reduction of substrates that are taken to the fields after the treatment. Biogas slurry with a dry matter content of $6 \%$ can be separated in the solid phase $(28 \% \mathrm{DM})$ and the liquid phase $(828.6 \mathrm{~kg})$. The evaporation leads to a concentration of the liquid phase by factor 4 [HEIDLER2002]. This leads to a total reduction of the biogas slurry to $37.9 \%$ of the initial value (cf. equation (1)). The transport efforts related to the biogas slurry are also reduced to $37.9 \%$ of the initial value.

The fictional biogas plant causes $945.5 \mathrm{Mg} / \mathrm{TJ}$ of biogas slurry. This would be reduced to $359.0 \mathrm{Mg}$ slurry after treatment. A screw press is used for the separation process, and a plate heat exchanger is used for evaporation. Also sulphuric acid is added to this process $(1 / 1000)$ to avoid gassing of $\mathrm{CO}_{2}$ in the evaporation process. An energy consumption of $0.2 \mathrm{kWh} / \mathrm{m}^{3}$ of biogas slurry is calculated [HARTMANN2006]. All of this data is related to one functional unit in the following data set given in Table 2.51.

Table 2.51: LCl of installations and consumptions for biogas slurry treatment related to one functional unit

\begin{tabular}{|l|l|l|r|}
\hline \multicolumn{1}{|c|}{ substance } & compartment & \multicolumn{1}{c|}{ unit } & amount \\
\hline Gas, natural, 35 MJ per m3, in ground & Raw & $\mathrm{m}^{3}$ & 61.4 \\
\hline Oil, crude, 42.6 MJ per kg, in ground & Raw & $\mathrm{kg}$ & 23.8 \\
\hline Nickel, in ground & Raw & $\mathrm{kg}$ & 3.03 \\
\hline Gas, natural, in ground & Raw & $\mathrm{m}^{3}$ & 10.3 \\
\hline Oil, crude, in ground & Raw & $\mathrm{kg}$ & 5.9 \\
\hline Land use II-III & Raw & $\mathrm{m}^{2} \mathrm{a}$ & 12.9 \\
\hline Sulfur oxides & Air & $\mathrm{kg}$ & 13.8 \\
\hline Nitrogen oxides & Air & $\mathrm{g}$ & 852 \\
\hline Carbon dioxide & Air & $\mathrm{kg}$ & 356 \\
\hline Particulates, <10 um (stationary) & Air & $\mathrm{g}$ & 112 \\
\hline Nickel & Air & $\mathrm{g}$ & 1.34 \\
\hline Carbon dioxide, fossil & Air & $\mathrm{kg}$ & 154 \\
\hline
\end{tabular}




\subsection{Eco indicator ' 99}

For this thesis the Eco indicator ' 99 method is used as weighting method. Developed by PRé Consultants (Netherlands) with the help of various scientists from Switzerland and the National Institute of Public Health and the Environment (RIVM) of the Netherlands, Eco indicator ' 99 is seen as the most reliable method available. It represents the state-of-the-art in LCA methodology and application [GOEDKOOP\&SPRIENSMA2001]. It is a method for weighting the results gained from the normalisation of the $\mathrm{LCl}$ data. In addition it considers the results of the LCl phase which are complex and do not posses one single unit, which can be used as an indicator of the environmental effects of the product. In order to calculate such single scores a methodology is needed. In this instance weighting methods, like the Eco indicator ' 99 , are used. They use scientific methods to make the results of the LCI phase comparable with each other.

The Eco indicator '99 (El '99) method is a damage function based approach for weighting $\mathrm{LCI}$ results within the LCIA phase. Damage function based means the relation between the impact and the damage to human health or to the ecosystem (cf. chapter 2.7.3). Within LCIA the weighting of data from the $\mathrm{LCl}$ is the most complicated and controversial step. Therefore El '99 was developed top-down with the weighting step as starting point, instead of bottom-up like other methods. The configuration of the El '99 assessment method is given in Figure 2.27. From here, damage models for the impact categories have been developed, considering that the number of subjects should be as small as possible and easy to explain.

This resulted in the following three types of safeguard subjects (endpoints):

$>$ Human Health; means that all human beings in present and future should be free of illnesses, disabilities or premature death caused by environmentally transmitted effects,

$>$ Ecosystem Quality; wants to avoid disruptive changes of non-human population or their geographical distribution, and

$>$ Resources; means that the natural supply of non-living material, which is essential to human society, should be available for future generations.

\subsubsection{Damage categories and normalisation}

The damage category Human Health includes effects related to climate change, e.g. infectious diseases, cardiovascular and respiratory diseases. Effects from ionising radiation are considered as cancer risks. Cancer and eye damages are also deemed possible due to ozone layer depletion. Additional respiratory diseases and cancer due to toxic chemicals in air, drinking water and food are counted. These different types of damages to Human Health are weighted for being comparative by using DALY values (disability adjusted life years).

The damage category Ecosystem Quality collects all data concerning effects to the ecosystem, if it is possible. It may not be possible due to the fact that ecosystems are complex and it is hardly possible to determine all damages inflicted upon them. Good ecosystem quality is a condition in which the flows are not noticeably disrupted by anthropogenic activities. Spe- 
cies diversity is used as an indicator for the quality of an ecosystem; although there are other potential indicators for assessing ecosystem quality e.g. free biomass production. Damage to an ecosystem is expressed as a percentage of species that are threatened or that disappear during a certain time in a specific area. Here it has to be distinguished between the complete and irreversible extinction of species and the reversible or irreversible disappearance of stress on a species during a certain area and time. Within Ecosystem Quality the damage categories ecotoxicity, expressed as potentially affected fraction (PAF), land use, expressed as potentially disappeared fraction (PDF) multiplied by area and time (PDF $\left.\times m^{2} \times a\right)$, and acidification/eutrophication, expressed in PDF, are used for assessment. Both parameters are combined to the common unit PDF $\times m^{2} \times a$. Therefore the PAF value is divided by 10 . The result corresponds to the PDF unit (PDF $=\mathrm{PAF} / 10)$. Further information to this calculation is given in [GOEDKOOP\&SPRIENSMA2001].

The damage category Resources deals with mineral resources and fossil fuels. Agricultural and silvicultural biotic resources, in addition to mined resources like sand or gravel are covered by the category land use und are not considered in the category resources. It is clear that the deposits of the measured resources are limited. However, the volume of these deposits is not clear. Therefore not the quantity of these resources is considered, but their qualitative structure. [GOEDKOOP\&SPRIENSMA2001] explain that the unit of the damage category resources is surplus energy [MJ/kg extracted material]. Surplus energy describes the increase of energy needed per $\mathrm{kg}$ extracted material, when mankind has extracted an amount of this material, which is n-times the cumulative extracted material of the time period from the beginning of extraction until 1990. In the El ' 99 method $n$ is as five. As the surplus energy is dependent on the choice of $n$, the absolute value of the surplus energy has no absolute meaning.

To make the three introduced damage categories comparable their different units must be adapted. A normalisation step is used to single out the units from the damage categories. In order to carry out normalisation the European normalisation values given in Table 2.52 from the LCA database are used [SIMAPRO2006]. The damage categories, not the impact categories, are normalised on an European level. This European level represents the damage caused by 1 European per year.

Table 2.52: Normalisation-Weighting set Europe EI 99 H/A

\begin{tabular}{|l|r|}
\hline \multicolumn{1}{|c|}{ safeguard subject } & normalisation value \\
\hline Human Health & 65.1 \\
\hline Ecosystem Quality & 0.000195 \\
\hline Resources & 0.000119 \\
\hline
\end{tabular}

Usually the normalisation step is done after the characterisation of data. In accordance with ISO 14042 the El'99 method combines normalisation and weighting. 


\subsubsection{Uncertainties}

The results of the three weighting categories are finally combined using a further weighting step (Table 2.39), This weighting step is based on the cultural theory of [HOFSTETTER1999] related on [THOMPSON ET AL.1990]. There is some uncertainty to this weighting step and all preceding steps. Where uncertain calculation methods like the squared geometric standard deviation $\left(\sigma_{\mathrm{g}}{ }^{2}\right)$ could be used for vague data, no such methods are available for the modelling of the LCA methods and weighting steps.

For this reason, other methods like the cultural theory must be used. This theory represents five different value systems, demonstrating the way of life of the individuals of each group. The assumption is made that people could be assigned to these groups by their relation to an external grid and the influence of the group on the individual. The following figure gives an overview of the mentioned groups.

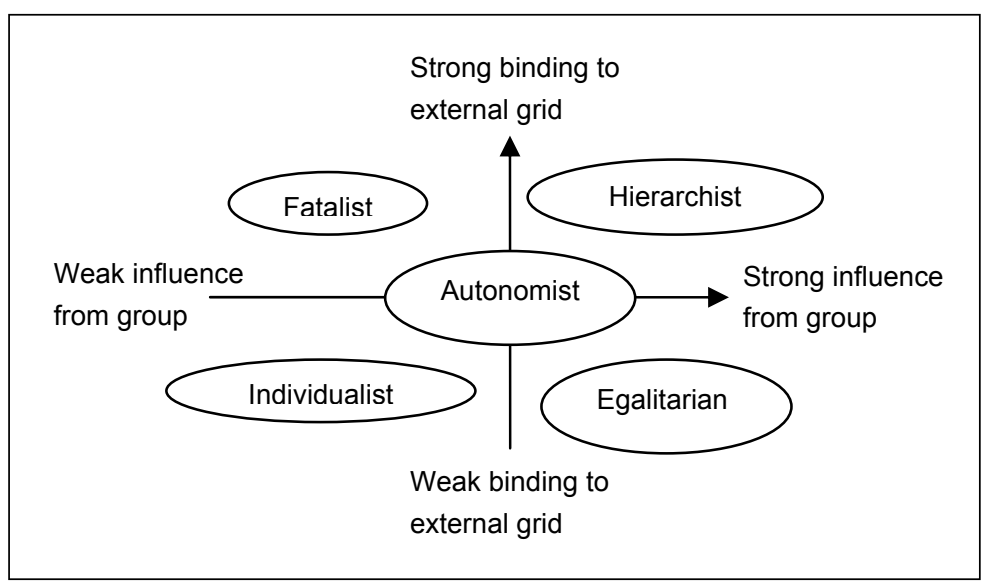

Figure 2.26: Five archetypes grid-group dependency of the Cultural Theory

The Cultural Theory is used in risk perception studies, where it is able to explain people's attitudes. It helps to predict basic attitudes and assumptions the individuals of each group make. In this LCA study only the Hierarchist group will be used. The modelling choices that have to be made to normalise the three damage categories are based on this Hierarchist value system. The Hierarchist group has a strong link to its group and the external grid. People from this group are controlling other people and are controlled by people. This kind of hierarchy leads to stable conditions within the group. This Hierarchist group is similar to our social environment. Hierarchists predict due to evidences and have a perception of time that is balanced between short and long term distinction. Resources are viewed as limited commodities that can be managed and must be increased, whereas actual needs are not managed by Hierarchists. The Hierarchist is risk-accepting, regulates nature, has a restrictive behaviour toward humans and is tolerant in their perception of nature [GOEDKOOP\&SPRIENSMA2001]. Therefore, only facts are considered that have political and scientific support and which are sufficiently recognised. For example, the IPCC models for the effects of climate effective gases are viewed as reliable, even if changes to the future climate due to climate effective gases are not totally proven. 


\subsubsection{Annotations}

The El '99 method is based on a specific definition of the environment. "A set of biological, physical and chemical parameters influenced by man, that are conditions to the functioning of man and nature. These conditions include human health, ecosystem quality and sufficient supply of resources [Goedkoop\&Spriensma2001]". Other definitions of environment are not totally covered in this method and have to be adapted. These different definitions include the assessment of human welfare and the preservation of cultural heritages.

The calculated results of the damage models are marginal results; they therefore reflect the increases of the damage of one functional unit, which are added to the actual damage level. This means that the damage of one additional functional unit equals the slope of the damage function, regardless if the function is linear or not.

In the following figure the procedures and (intermediate) results of a LCIA according to El '99 are displayed. A distinction is therefore made between intermediate results (white boxes) and procedures (grey boxes).

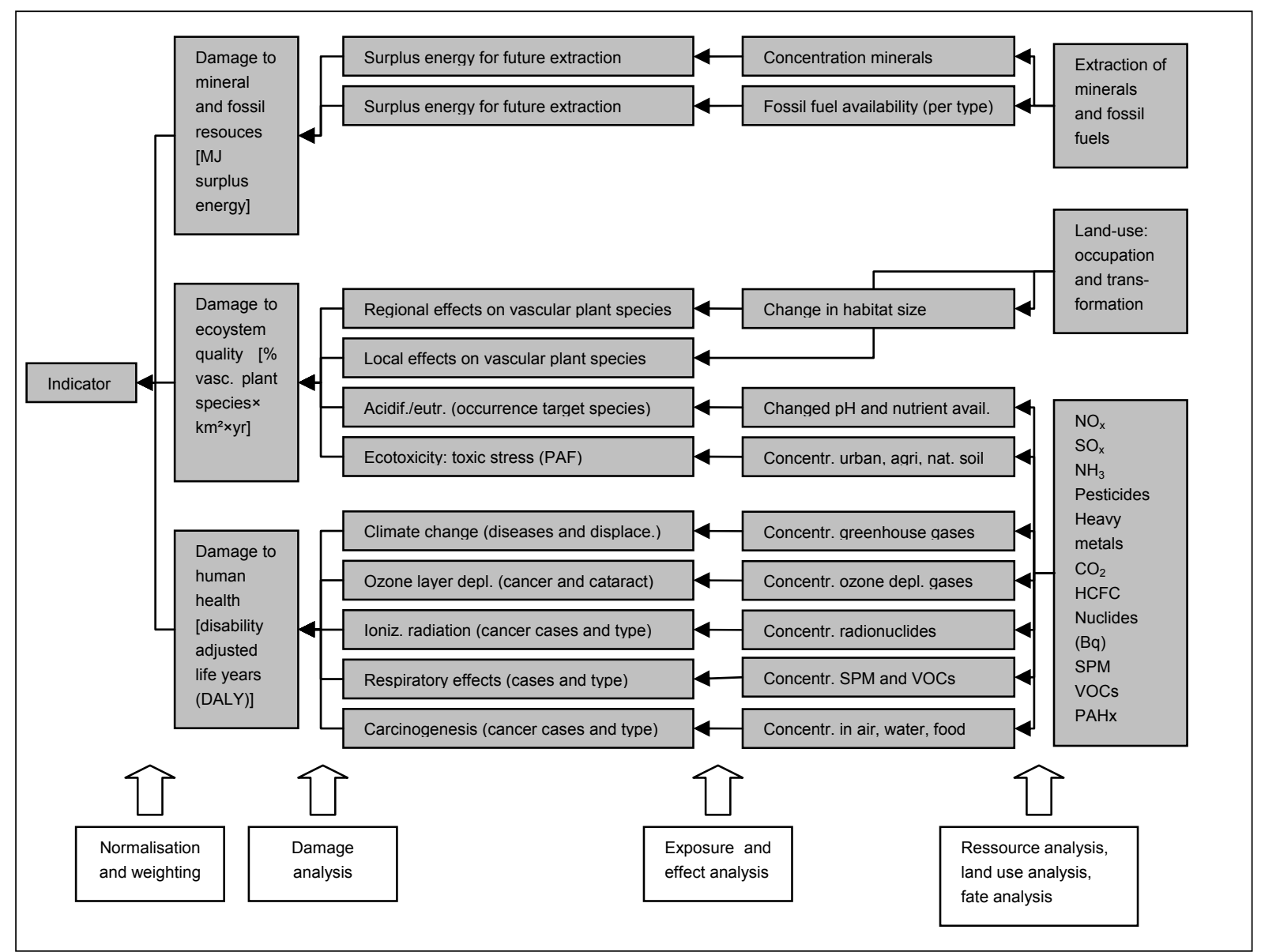

Figure 2.27: General representation of the El'99 methodology according to [GOEDKOOP\&SPRIENSMA2001]

A limiting assumption of this method is that most emissions, land use and all subsequent damages occur in Europe. Damages, which are exceeding this limit are damages to resources, damages related to climate change, ozone layer depletion, air emissions of persistent carcinogenic substances, inorganic air pollutants that have a long-range dispersion, and 
some radioactive substances. The damage that is calculated is not the actual damage, but is instead marginal damage.

The Eco Indicator '99 method is similiar to the ISO 14042 standard, but has some differences. The three optional elements, normalisation, grouping and weighting are carried out closely to the ISO standard. The most important difference is that the proposal to define the normalisation value on different temporal and spatial scales is not followed. 


\subsection{SimaPro}

SimaPro (ㅁystem for Integrated Environmental Assessment of Products) is a software tool to collect, analyse and monitor the environmental performance of products and services. In using this software, complex life cycles are modelled and analysed in a systematic and clear way, following the ISO 14040 series recommendations. All the data included in this LCA study is collected, stored, and processed using SimaPro (version 7.0.0).

This software is configured according to the ISO 14040 method. The ISO 14040 is herein divided into several steps: goal and scope, inventory, impact assessment, and interpretation. Due to the iterative character of LCA, every step can be altered at any given time, while the influence of these changes is immediately calculated for all related data sets.

Several data bases are included in this software from which general data can be taken for LCA studies. For example, from these data bases, $\mathrm{LCl}$ data relating to $1.0 \mathrm{~kg}$ of reinforced concrete can be taken for the production of biogas plant foundations. This saves time and assures that comparable LCl data are taken for different LCA studies. Thereby the results of different LCAs can be compared in depth. Data bases included in SimaPro 7.0.0 are:

$>$ Ecoinvent v1.2

$>$ ETH-ESU 96

$>$ BUWAL 250

$>$ Dutch Input Output database

$>$ US Input Output database

$>$ Danish Input Output database

$>$ LCA food

$>$ Industry data

$>$ IDEMAT 2001

$>$ Franklin US LCI database

$>$ Dutch Concrete database

$>$ IVAM

$>$ FEFCO

$>$ EuP database for Energy using Products

In addition, several assessment methods are included in SimaPro. From these, two methods are used in the assessment of the electricity generation from biogas produced in industrialscale biogas plants:

$>$ Eco Indicator '99 V2.1

$>$ Cumulative Energy Demand V1.1

All data bases and assessment methods described above are used in this LCA study. All results presented in chapter 3 are calculated using the SimaPro software. 


\section{Results}

In this chapter the weighted results (Eco indicater '99 normalisation and weighting) of this life-cycle-assessment are given. The results are given for each module, i.e. inputs, transport, biogas plant, and slurry application, and for the whole life cycle of the electricity generation from biogas produced in industrial scale biogas plants. All results are given in EI '99 points (points). Comparisons between the single sensitivity analyses can be made from the El '99 based results.

All data given, especially percentages, are related to the total ecological effect of the process under analysis. The total ecological effects always represent $100 \%$ of all effects. If there are ecological threats and savings, the sum of the single ecological effects of positive or negative effects can exceed $100 \%$.

\subsection{Energy crops}

Below, a list of the process contribution of single unit processes from the different energy crops under investigation is given. To compare the ecological effects created by the production of these different energy crops, the contribution of each unit process per energy crop is given as points, calculated using the Eco indicator '99 Hierarchist method (cf. chapter 2.8). All data given in the tables below are related to the production of one functional unit.

As can be seen from Table 3.1 the production of maize silage for the generation of one functional unit causes effects of 6,090 points. Most important of all influences are the influences of the land use (occupation, arable, non-irrigated) with an overall effect contribution of $79.0 \%$. In addition, the consumption of fossil resources contributes $14.0 \%$ to the overall effect. This consumption is caused by the production of mineral nitrogen fertilizers (natural gas) and the fuel consumed by maize choppers and tillage, especially ploughing. The production of maize leads to a reduction of heavy metals in the soil, e.g. zinc. The consumption of carbon dioxide for the biomass production is also taken into account contributing to $-25.5 \%$ of the overall result.

Table 3.1: Weighted Effects (EI '99H) of maize silage production

\begin{tabular}{|l|l|r|}
\hline \multicolumn{1}{|c|}{ substance } & compartment & points \\
\hline Total of all compartments & & 6,090 \\
\hline Remaining substances & & 355 \\
\hline Carbon dioxide, in air & Raw & $-1,550$ \\
\hline Gas, natural, in ground & Raw & 260 \\
\hline Occupation, arable, non-irrigated & Raw & 4,810 \\
\hline Transformation from pasture and meadow & Raw & -809 \\
\hline Oil, crude, in ground & Raw & 590 \\
\hline Nitrogen oxides & Air & 201 \\
\hline Particulates, <2.5 um & Air & 163 \\
\hline Arsenic, ion & Water & 67.6 \\
\hline Cadmium & Water & 1,180 \\
\hline Chromium & Soil & 185 \\
\hline Nickel & Soil & 67.8 \\
\hline Zinc & Soil & -398 \\
\hline
\end{tabular}


As shown in Table 3.2 the production of grass silage for the generation of one functional unit causes effects of 23,400 points. The adsorption of carbon dioxide from the air contributes to $-22.8 \%$ of the effects from grass silage production. Most important ifluences are the influences of the land use (occupation, arable, non-irrigated) with a contribution of $44.5 \%$ to the overall effect. Ammonia emissions from the meadows contribute to $51.7 \%$ of the overall effect. These emissions are caused by the application of organic fertiliser, which is not incorporated after application. $15.6 \%$ of the overall effects are caused by the consumption of fossil ressources for fertilizer generation and fuels. The adsorption of cadmium from the soil in the grass contributes to $-11.3 \%$.

Table 3.2: Weighted Effects (EI '99H) of silage grass production

\begin{tabular}{|l|l|r|}
\hline \multicolumn{1}{|c|}{ substance } & compartment & points \\
\hline Total of all compartments & & 23,400 \\
\hline Remaining substances & & 1,340 \\
\hline Carbon dioxide, in air & Raw & $-5,250$ \\
\hline Gas, natural, in ground & Raw & 715 \\
\hline Occupation, pasture and meadow, intensive & Raw & 10,200 \\
\hline Oil, crude, in ground & Raw & 2,880 \\
\hline Ammonia & Air & 11,900 \\
\hline Dinitrogen monoxide & Air & 420 \\
\hline Nitrogen oxides & Air & 1,100 \\
\hline Particulates, <2.5 um & Air & 819 \\
\hline Particulates, $>2.5$ um, and <10um & Air & 294 \\
\hline Cadmium & Soil & $-2,610$ \\
\hline Zinc & Soil & 1,190 \\
\hline
\end{tabular}

As can be seen from Table 3.3 the production of rye silage for the generation of one functional unit causes effects of 27,500 points. The adsorption of carbon dioxide from the air contributes to $-14.4 \%$ of the rye silage production effects. The adsorption of zinc from the soil into the plants contributes to $-14.7 \%$ of the ecological effects. $46 \%$ of all threats to the environment in this production system are caused by land use. Fossil resources for the production of mineral fertilisers and fuel make a contribution of $27.9 \%$ to the overall effects. cadmium emissions to the soil cause a share of $13.2 \%$ of the overall effects.

Table 3.3: Weighted Effects (EI ' $99 \mathrm{H}$ ) of rye silage production

\begin{tabular}{|l|l|r|}
\hline \multicolumn{1}{|c|}{ substance } & compartment & points \\
\hline Total of all compartments & & 27,500 \\
\hline Remaining substances & & 1,210 \\
\hline Carbon dioxide, in air & Raw & $-3,960$ \\
\hline Gas, natural, in ground & Raw & 2,170 \\
\hline Occupation, arable, non-irrigated & Raw & 12,600 \\
\hline Occupation, industrial area, built up & Raw & 497 \\
\hline Oil, crude, in ground & Raw & 5,480 \\
\hline Transformation from pasture and meadow, intensive & Raw & $-11,300$ \\
\hline Ammonia & Air & 2260 \\
\hline Carbon dioxide, fossil & Air & 428 \\
\hline Dinitrogen monoxide & Air & 526 \\
\hline Nitrogen oxides & Air & 1960 \\
\hline Particulates, $<2.5$ um & Air & 1400 \\
\hline Particulates, $>2.5$ um, and $<10$ um & Air & 551 \\
\hline
\end{tabular}




\begin{tabular}{|l|l|r|}
\hline Arsenic, ion & Water & 468 \\
\hline Cadmium, ion & Water & 415 \\
\hline Cadmium & Soil & 3,620 \\
\hline Chromium & Soil & 1,360 \\
\hline Zinc & Soil & $-4,030$ \\
\hline
\end{tabular}

The production of silage from forage beets causes ecological effects with a total number of $11,400 \mathrm{El}$ ' 99 points. A share of $-21.2 \%$ of this effect is caused by the adsorption of carbon dioxide from the air. The occupation of arable area contributes to a positive share of $114 \%$ of the overall effects. The consumption of fossil resources for fuels and fertiliser production causes $12.0 \%$ of the ecological effects. The adsorption of cadmium from the soil leads to a reduction in the ecological effects of $-22.3 \%$.

Table 3.4: Weighted Effects (EI '99H) of silage from forage beet production

\begin{tabular}{|l|l|r|}
\hline \multicolumn{1}{|c|}{ substance } & compartment & points \\
\hline Total of all compartments & & 3,120 \\
\hline Remaining substances & & 189 \\
\hline Carbon dioxide, in air & Raw & $-2,410$ \\
\hline Gas, natural, in ground & Raw & 183 \\
\hline Occupation, arable, non-irrigated & Raw & 5,260 \\
\hline Oil, crude, in ground & Raw & 951 \\
\hline Ammonia & Air & 793 \\
\hline Carbon dioxide, fossil & Air & 64.8 \\
\hline Dinitrogen monoxide & Air & 112 \\
\hline Nitrogen oxides & Air & 364 \\
\hline Particulates, $<2.5$ um & Air & 268 \\
\hline Particulates, $>2.5$ um, and $<10$ um & Air & 61.6 \\
\hline Sulfur dioxide & Air & 34.2 \\
\hline Arsenic, ion & Water & 37.5 \\
\hline Cadmium, ion & Water & 53 \\
\hline Cadmium & Soil & $-2,540$ \\
\hline Copper & Soil & -148 \\
\hline Metamitron & Soil & 77.7 \\
\hline Zinc & Soil & -241 \\
\hline
\end{tabular}

Most biogas plants are not fed with just one substrate (mono fermenter). A mixture of energy crops and manure is typically used as input. For the purpose of this study a mixture described in Table 2.11 is assumed. This mixture results in a total of 8,380 El '99 points. Carbon dioxide adsorption has a share of $-21.9 \%$. The adsorption of zinc from the soil contributes to $-7.2 \%$. The occupation of arable land contributes to $63.5 \%$ of the total ecological effect. The consumption of fossil resources for the production of fuels and mineral fertilisers has a share of $17.8 \%$. Cadmium entries to the soil cause $12.1 \%$ of all ecological damages. Ammonia emissions have a share of $8.3 \%$ of all ecological effects. 
Table 3.5: Weighted Effects (EI '99H) from the standard input mixture

\begin{tabular}{|l|l|r|}
\hline \multicolumn{1}{|c|}{ substance } & compartment & points \\
\hline Total of all compartments & & 8,380 \\
\hline Remaining substances & & 529 \\
\hline Carbon dioxide, in air & Raw & $-1,840$ \\
\hline Gas, natural, in ground & Raw & 423 \\
\hline Occupation, arable, non-irrigated & Raw & 5,330 \\
\hline Occupation, pasture and meadow, intensive & Raw & 397 \\
\hline Oil, crude, in ground & Raw & 1,070 \\
\hline Transformation, from pasture and meadow & Raw & -640 \\
\hline Transformation, from pasture and meadow, intensive & Raw & -969 \\
\hline Ammonia & Air & 696 \\
\hline Carbon dioxide, fossil & Air & 84.5 \\
\hline Nitrogen oxides & Air & 379 \\
\hline Particulates, $<2.5$ um & Air & 287 \\
\hline Particulates, $>2.5$ um, and $<10$ um & Air & 116 \\
\hline Arsenic, ion & Water & 97.7 \\
\hline Cadmium, ion & Water & 85.7 \\
\hline Cadmium & Soil & 1,010 \\
\hline Chromium & Soil & 259 \\
\hline Zinc & Soil & -607 \\
\hline
\end{tabular}

Described in the sensitivity analysis (chapter 2.7.5), the assumption is made that special energy maize hybrid can improve ecological and economical aspects of the biogas production. It is assumed that this hybrid will yield $30.0 \mathrm{Mg} / \mathrm{ha}$ dry matter. The production would cause overall ecological effects of 2,970 El '99 points. Carbon dioxide adsorption has a share of $-52.2 \%$. The occupation of arable land contributes to $83.0 \%$ of the total ecological effect. The consumption of fossil resources for the production of fuels and mineral fertilisers has a share of $23.6 \%$. Cadmium entries to the soil cause $20.5 \%$ of all ecological damages.

Table 3.6: Weighted Effects (El '99H) of high yield silage maize

\begin{tabular}{|l|l|r|}
\hline \multicolumn{1}{|c|}{ substance } & compartment & points \\
\hline Total of all compartments & & 2,970 \\
\hline Remaining substances & & 171 \\
\hline Carbon dioxide, in air & Raw & $-1,550$ \\
\hline Gas, natural, in ground & Raw & 216 \\
\hline Occupation, arable, non-irrigated & Raw & 2,470 \\
\hline Oil, crude, in ground & Raw & 483 \\
\hline Transformation, from pasture and meadow & Raw & -809 \\
\hline Carbon dioxide, fossil & Raw & 39.9 \\
\hline Nitrogen oxides & Air & 164 \\
\hline Particulates, <2.5 um & Air & 132 \\
\hline Particulates, > 2.5 um, and <10um & Air & 61 \\
\hline Sulfur dioxide & Air & 37.2 \\
\hline Arsenic, ion & Water & 56.4 \\
\hline Cadmium, ion & Water & 44.5 \\
\hline Cadmium & Soil & 609 \\
\hline Chromium & Soil & 93.5 \\
\hline Nickel & Soil & 34.3 \\
\hline Zinc & Soil & -173 \\
\hline
\end{tabular}




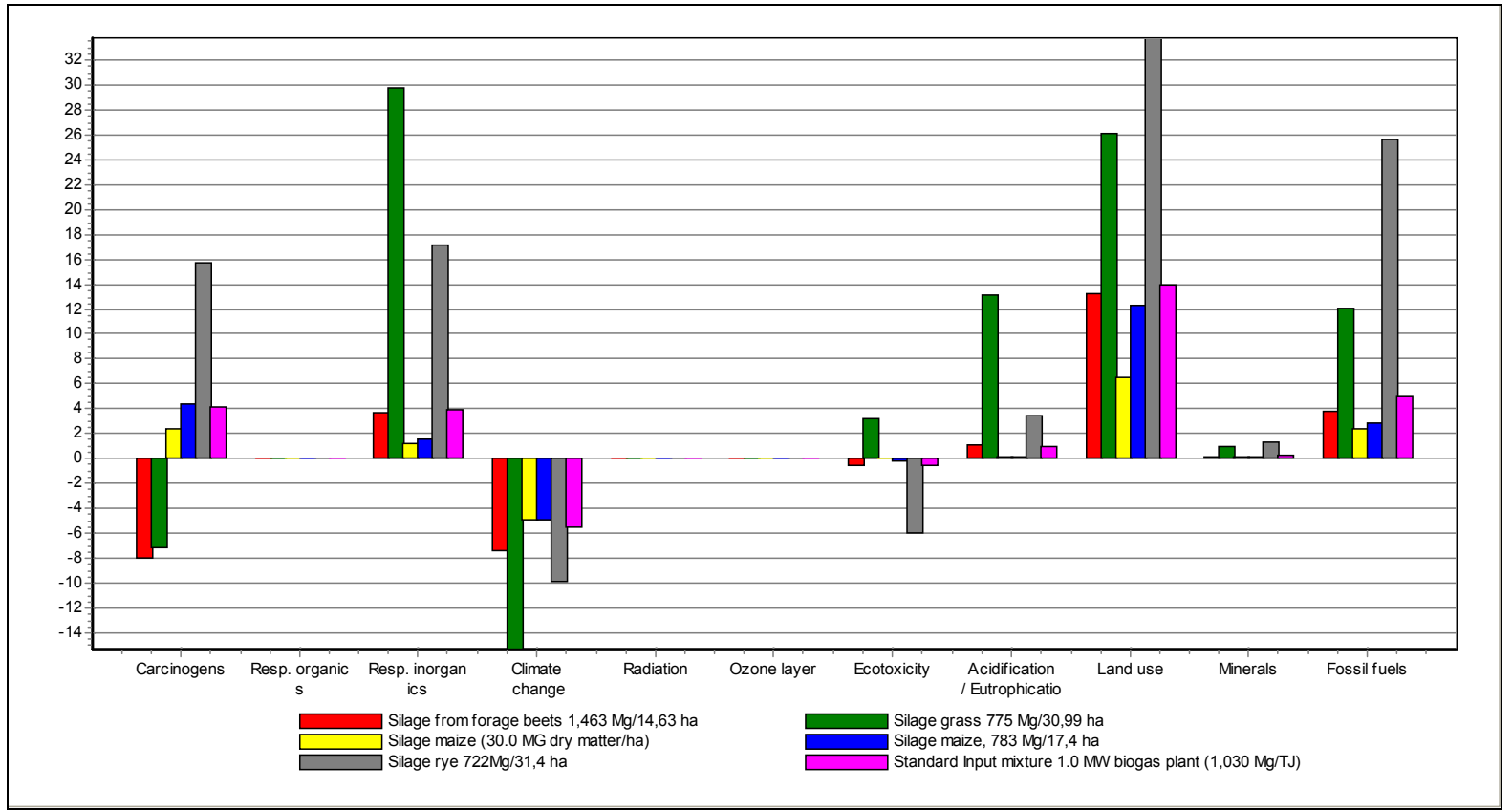

Figure 3.1: Comparison of the ecological effects (normalised values) from energy crops used as input per functional unit

In Figure 3.1 a comparison of the normalised values per impact category of the different energy crops is given. It can be seen that subtle influence on the impact categories respiratory organics, radiation, and ozone layer is caused by the energy crop production. Differences can be seen at the emission of carcinogenic substances. Rye production causes most effects in this impact category. The emission of respiratory inorganics is highest for the production of silage grass. This is related to nitrogen emissions from this system, as nitrogen fertilisers cannot be incorporated after application. Highest adoption of climate effective gasese is caused by the maize production, as this system produces most biomass. It can also be seen that the production systems with high yield levels per area consume at least fossil fuels and occupy at least land. Generally it can be said from these data that high yield per area level production system cause at least ecological effects per functional unit.

Figure 3.2 shows a graphical comparison of the ecological effects from the production of the different energy crops used in the biogas plant under analysis. Bars (1), (2), (3), and (5) represent the ecological effects per input substrate, bar (6) shows the ecological effects from the mixture of substrates as they should be used as input in the fictional biogas plant. Additional, the ecological effects from the production of high yield energy maize, as described in chapter 2.7.5, are given in bar (4). 


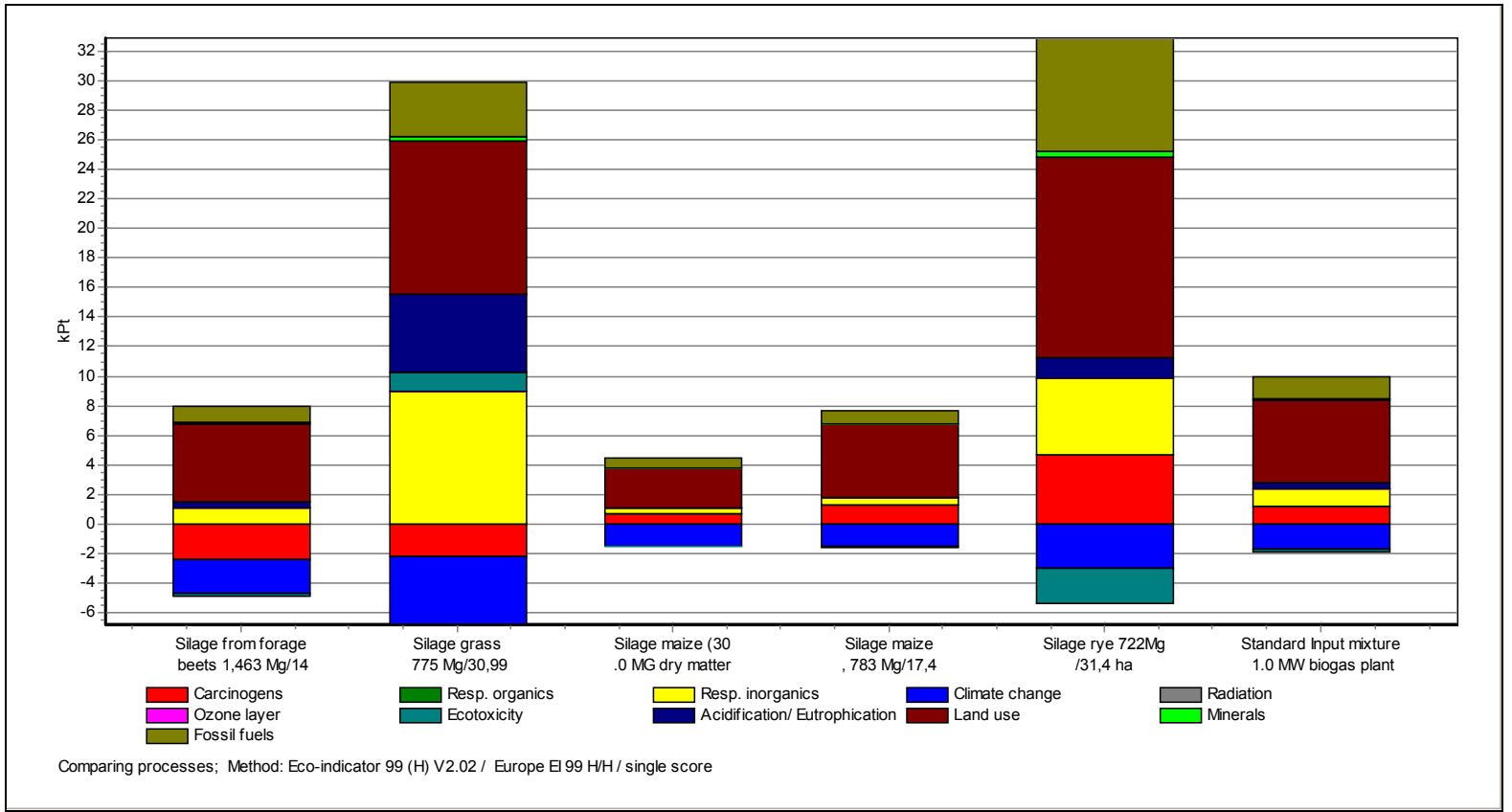

Figure 3.2: Comparison of the total ecological effects from different energy crops and the standard input mixture used in this LCA

From Figure 3.2, it is evident that the high yield maize (30.0 Mg DM/ha) causes the least ecological effects (2,970 El '99 points). The production of silage maize (15.0 Mg DM/ha), in keeping with good agricultural practice, effects 6,090 El '99 points. This difference between the high yield and the conventional maize is caused by the $100 \%$ higher yield per unit area of the high yield maize compared to the conventional maize. Soil cultivation efforts are halved; essential plant protection chemicals are also reduced.

Most of the effects of forage beet production are caused by the land use impact category. The production of beets is a very intensive arable production system; especially the harvest of the beets in autumn causes heavy impacts on the soil. Positive effects from forage beets are caused by the adsorption of $\mathrm{CO}_{2}$ and the reduction of carcinogens. The production of silage from forage beets related to one functional unit causes total ecological effects of 3,120 El '99 points.

The standard input substrate causes a total ecological effect of 8,380 El '99 points. This increased effect, compared to maize, is caused by the mixture of different energy crops. These energy crops e.g. forage beets, grass, and rye are causing much higher ecological effects than maize, due to their higher emissions of respiratory inorganics and increased land use.

The production of silage grass and silage rye causes comparatively higher effects. For the production of one functional unit of silage grass 23,400 El '99 points and for silage rye $27,500 \mathrm{El}$ ' 99 points are affected. The majority of these total effects are caused by the impact categories land use, respiratory inorganics and fossil fuels. They are all related to the yield per area ratio of grass and rye. This yield per area ratio is much lower but the yield area ratio of maize or forage beets. Therefore more unit areas are needed for the production of one functional unit in these two systems. The occupation of land for crop production, the con- 
sumption of fossil resources for soil cultivation and harvest, and the emission of particles from the exhaust of tractors and combine harvesters are all related to the yield per area ratio.

It is noted that energy crops with high yield per area levels cause less ecological effects per functional unit, compared to energy crops with low yield per area levels. The ecological effects from the energy crop production are most effectively reduced by the production of crops with high yield per area levels, if a definite amount of crops is needed. This use of crops with a high yield per unit area level should not cause that the same area under cultivation is used to produce more crops.

\subsection{Weighting of the impact category land use}

The weighted effects from the sensitivity analysis of the land use impact category are presented below. A comparison is made of the ecological effects of intensive maize production from conventional hybrid, as well as the consideration of an extensive production system as a reference system in the category land use. In a third sensitivity no direct effects from land use are considered. These three scenarios are given in Table 3.1 (standard scenario), Table 3.7 (scenario (2)), and Table 3.8 (scenario (3)). The consideration of an extensive production system as a reference system in the land use impact category leads to an impact reduction of $83.3 \%$ in this sector. The total effects of all sections are thereby reduced to 2,180 points (standard scenario 6,090 points). Adsorption of carbon dioxide from the air has a share of $-71.0 \%$, the adsorption of zinc from the soil has a share of $-18.2 \%$. Most of the negative ecological effects are caused by the entry of cadmium into the soil (54.0\%), occupation of land (41.5\%), consumption of fossil resources $(38.9 \%)$, the emission of nitrogen oxides to the air $(9.2 \%)$ and entry of chromium to the soil $(8.5 \%)$ in this case.

Table 3.7: Weighted effects (EI '99H) of the silage maize production, using an extensive production system as reference system for land use effects

\begin{tabular}{|l|l|r|}
\hline \multicolumn{1}{|c|}{ substance } & compartment & points \\
\hline Total of all compartments & & 2,180 \\
\hline Remaining substances & & 183 \\
\hline Carbon dioxide, in air & Raw & $-1,550$ \\
\hline Gas, natural, in ground & Raw & 260 \\
\hline Nickel, 1.98\% in silicates, 1.04\% in crude ore, in ground & Raw & 25.7 \\
\hline Occupation, arable, non-irrigated & Raw & 906 \\
\hline Oil, crude, in ground & Raw & 590 \\
\hline Transformation, from pasture and meadow & Raw & -809 \\
\hline Carbon dioxide, fossil & Air & 48.3 \\
\hline Nitrogen oxides & Air & 201 \\
\hline Particulates, $<2.5$ um & Air & 163 \\
\hline Particulates, $>2.5$ um, and $<10 u m$ & Air & 71.9 \\
\hline Sulfur dioxide & Air & 44.6 \\
\hline Arsenic, ion & Water & 67.6 \\
\hline Cadmium, ion & Water & 54 \\
\hline Cadmium & Soil & 1,180 \\
\hline Chromium & Soil & 185 \\
\hline Nickel & Soil & 67.8 \\
\hline Zinc & Soil & -398 \\
\hline
\end{tabular}


The third scenario does not take into account ecological effects from direct land use. This means no occupation of arable area is considered as land use for the process of silage maize production. However, the occupation of arable area is taken into account for the maize seed production and other up stream processes. The weighting method of scenario (3) leads to total ecological effects of 1,400 El '99 points. The adsorption of $\mathrm{CO}_{2}$ from the air leads to $-111 \%$ of the total ecological effect and the adsorption of zinc from the soil leads to $-28.3 \%$ of ecological effects. The entry of cadmium to the soil causes $84.0 \%$ and the consumption of fossil resources give a total of $60.6 \%$ of all ecological effects. $\mathrm{NO}_{\mathrm{x}}$ emissions to the air have a share of $14.3 \%$, particulate emissions cause $11.6 \%$, and chromium emissions to the soil cause $13.2 \%$ of all ecological effects.

From this list, it can be seen that, when land use is not considered, the release of heavy metals to soil cause the most ecological effects $(97.2 \%)$ of the silage maize production. Furthermore, the consumption of fossil resources becomes more important $(60.6 \%)$ from an ecological point of view. Emissions to the air have a total share of roughly $30 \%$ of the total ecological effects.

Table 3.8: Weighted effects (EI ' $99 \mathrm{H})$ of the silage maize production, considering no land use impacts

\begin{tabular}{|l|l|r|}
\hline \multicolumn{1}{|c|}{ substance } & compartment & points \\
\hline Total of all compartments & & 1,400 \\
\hline Remaining substances & & 149 \\
\hline Carbon dioxide, in air & Raw & $-1,550$ \\
\hline Gas, natural, in ground & Raw & 260 \\
\hline Nickel, 1.98\% in silicates, 1.04\% in crude ore, in ground & Raw & 25.7 \\
\hline Occupation, arable, non-irrigated & Raw & 126 \\
\hline Oil, crude, in ground & Raw & 590 \\
\hline Transformation, from pasture and meadow & Raw & -809 \\
\hline Carbon dioxide, fossil & Air & 48.3 \\
\hline Dinitrogen monoxide & Air & 14.5 \\
\hline Dioxins, measured as 2,3,7,8-tetrachlorodibenzo-p-dioxin & Air & 18.7 \\
\hline Nitrogen oxides & Air & 201 \\
\hline Particulates, $<2.5$ um & Air & 163 \\
\hline Particulates, $>2.5$ um, and <10um & Air & 71.9 \\
\hline Sulfur dioxide & Air & 44.6 \\
\hline Arsenic, ion & Water & 67.6 \\
\hline Cadmium, ion & Water & 54 \\
\hline Cadmium & Soil & 1,180 \\
\hline Chromium & Soil & 185 \\
\hline Nickel & Soil & 67.8 \\
\hline Zinc & Soil & -398 \\
\hline & & \\
\hline
\end{tabular}

The effects of weighting of the impact category land use are displayed in Figure 3.3. Here, the results of the characterisation of the $\mathrm{LCl}$ data of the three scenarios are given. As can be seen, the levels of all impact categories are the same except the land use impact category.

In this impact category scenario (1) symbolises the maximum level of land use impacts. Scenario (2) considers an extensive production system as a reference unit and has a share of $22 \%$ of the impacts of scenario (1). Scenario (3) considers no direct land use impacts and causes $5 \%$ maximum impact level in this category. 


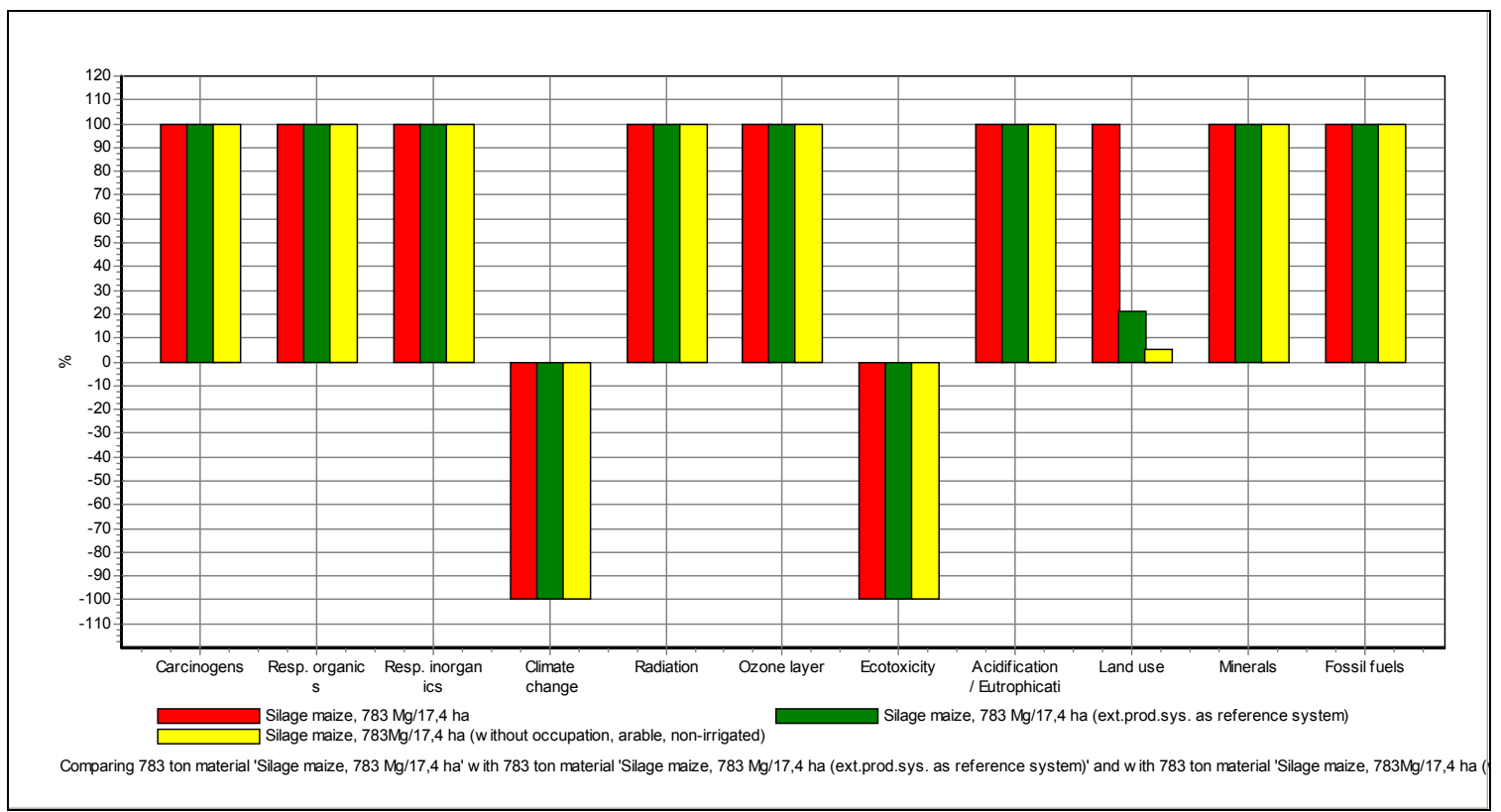

Figure 3.3: Characterisation of the $\mathrm{LCl}$ data of the three sensitivity analysis considering the influence of the impact category land use

The results from the different weighting methods and their influence on the overall effects of the maize silage production can also be taken from Figure 3.4. The bar on the left hand side shows the total effects and the effects per impact category for standard scenario (1). The central bar shows the effects, if an extensive production system is used as a reference system for land use effects. The bar on the right hand side shows the results of when direct land use for the production of silage maize is not considered. It can be seen, that no other impact categories but land use are influenced from the changes in weighting in this category. All effects on the overall results are caused by the land use impact category weighting method.

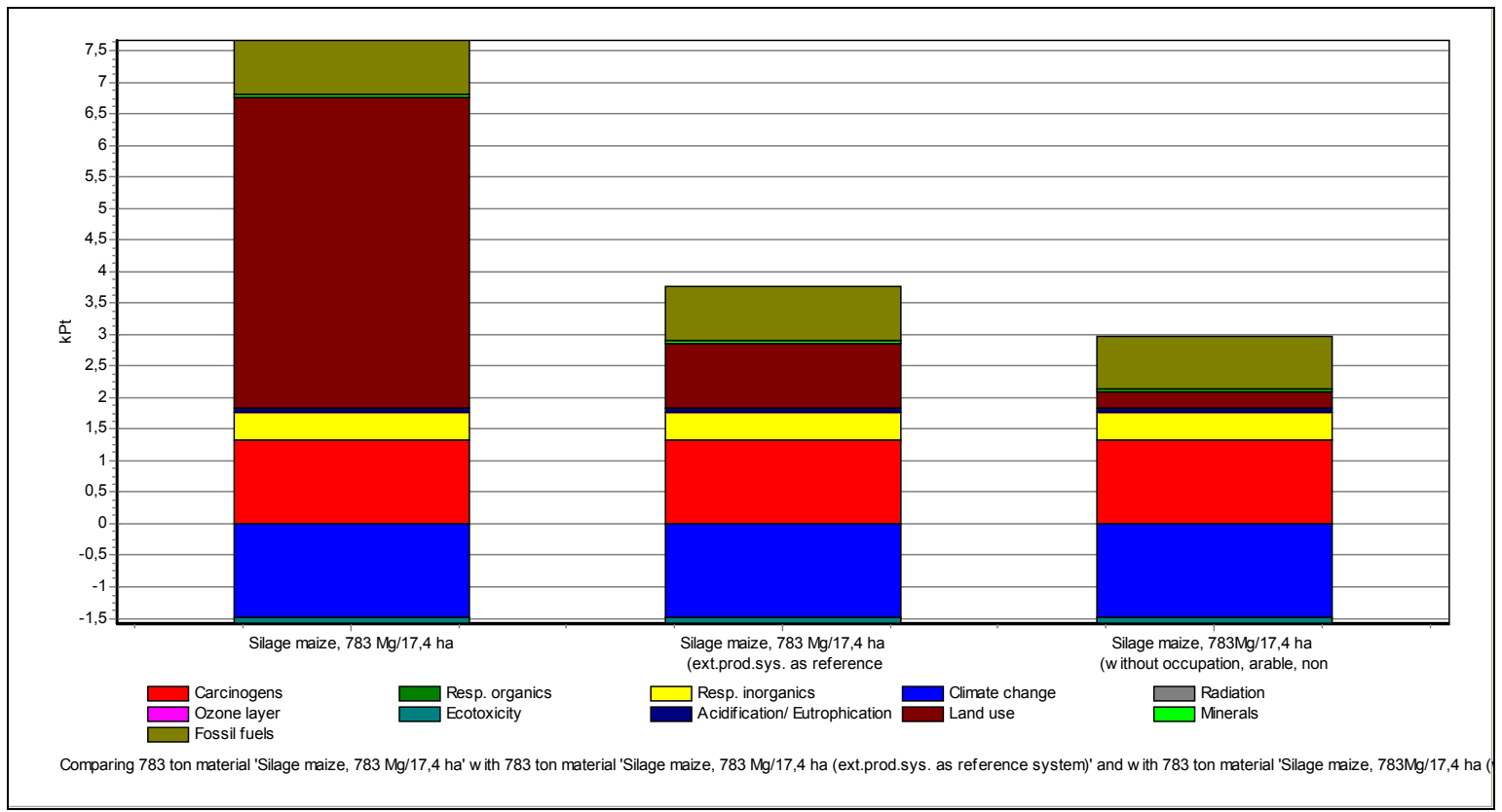

Figure 3.4: Comparison of the weighting methods influence on the total ecological effects

First bar represents the effects from the maize production standard scenario (Table 2.3), second bar represents the effects of maize production considering an extensive production system as reference system for land use (Table 2.49), and the third bar represents the LCl data of scenario (3) from the land use sensitivity analysis taking into account no direct land use effects. 


\subsection{Transport}

This chapter considers the ecological effects of the transport efforts related to the input and output flows of the biogas plant. All data on the transport efforts are based on the data set Transport, tractor and trailer (energy crops). This data set is derived from the data set Transport, tractor and trailer/CH S of the Ecoinvent data base [ECOINVENT2004]. All influences on the results therefore depend on the influence of the inputs' composition, the size of the biogas plant, or the mass reduction of the biogas slurry.

The standard scenario of this assessment considers an input substrate mixture as shown in Table 2.11. The average transport distance for this plant size and input substrate mixture is calculated in equation (4). Combining the average transport distance and the mass of the input substrates leads to transport efforts of $7,241 \mathrm{tkm}$. The same calculation, which considers the masses on the output side of the biogas process, leads to transport efforts of $6,647 \mathrm{~km}$ for the biogas slurry. The total ecological effects from these transports are given in Table 3.9.

The transport of the input substrates causes weighted ecological effects of $242 \mathrm{El}$ ' $99(\mathrm{H})$ points; the transport of the biogas slurry back to the fields causes $222 \mathrm{El}$ ' $99(\mathrm{H})$ points. From this result list it can be seen that $25.6 \%$ of all ecological effects are caused by the consumption of fossil resources for fuels and another $12.6 \%$ of fossil resources for the production of the transport vehicles. Emissions of zinc to the soil cause $14.7 \%$ of all effects to the environment. $34.5 \%$ of all ecological effects are caused by emissions to the air, whereas particulates have a share of $18.5 \%$ and nitrogen oxides $7.2 \% . \mathrm{CO}_{2}$ has a share of $3.3 \%$ of all ecological effects and therefore has comparatively small influence on the overall results.

Table 3.9: Weighted effects (EI '99H) of the agricultural transport of input and output substrates of a $1.0 \mathrm{MW}_{\mathrm{el}}$ biogas plant, considering energy crops as input substrates

\begin{tabular}{|l|l|r|r|}
\hline \multicolumn{1}{|c|}{ substance } & compartment & $\begin{array}{r}\text { input } \\
\text { (points) }\end{array}$ & $\begin{array}{c}\text { output } \\
\text { (points) }\end{array}$ \\
\hline Total of all compartments & & 242 & 222 \\
\hline Remaining substances & & 16 & 14.7 \\
\hline Aluminium, 24\% in bauxite, 11\% in crude ore, in ground & Raw & 4.88 & 4.48 \\
\hline Gas, natural, in ground & Raw & 19.1 & 17.5 \\
\hline Nickel, 1.98\% in silicates, 1.04\% in crude ore, in ground & Raw & 4.23 & 3.88 \\
\hline Occupation, forest, intensive, normal & Raw & 2.91 & 2.68 \\
\hline Occupation, urban, discontinuously built & Raw & 5.47 & 5.02 \\
\hline Oil, crude, in ground & Raw & 61.9 & 56.8 \\
\hline Transformation, from pasture and meadow & Raw & -3.6 & -3.3 \\
\hline Transformation, to urban, discontinuously built & Raw & 3.26 & 2.99 \\
\hline Carbon dioxide, fossil & Air & 7.98 & 7.32 \\
\hline Dioxins, measured as 2,3,7,8-tetrachlorodibenzo-p-dioxin & Air & 5.46 & 5.01 \\
\hline Nitrogen oxides & Air & 17.4 & 16 \\
\hline Particulates, <2.5 um & Air & 30.5 & 28 \\
\hline Particulates, $>2.5$ um, and <10um & Air & 14.2 & 13.1 \\
\hline Sulfur dioxide & Air & 4.49 & 4.12 \\
\hline Arsenic, ion & Water & 5.32 & 4.89 \\
\hline Cadmium, ion & Water & 6.5 & 5.97 \\
\hline Zinc & Soil & 35.5 & 32.5 \\
\hline \hline
\end{tabular}


The consideration of organic waste from the food processing industry as input for the standard biogas plant leads to ecological effects from the transport module. No other ecological effects, e.g. from the production of these waste, are considered with this input substrate. An average transport distance of $10.0 \mathrm{~km}$ is assumed. This results in transport efforts of 7,950 tkm for the input substrates and 7,298 tkm for the output substrates.

The same data set (Transport, tractor and trailer (energy crops)) as was used for the assessment of the transport effects caused by the energy crops is used in the assessment of the ecological effects of the waste transport. Thus, the share of single impacts remains the same, only the absolute values per impact and of all effects change. Therefore, that only the total effects will be given. The transport of the biodegradable waste to the biogas plant causes $384 \mathrm{El}$ '99 points and the transport of the resulting biogas slurry causes $352 \mathrm{El}$ '99 points.When compared to the energy crop scenario, $58.7 \%$ more ecological effects are caused by the transport of waste.

The up-scaling of the biogas plant also causes an increase in the average transport distance. This is considered in the up-scaling sensitivity analysis. As given in equation (11) this upscale of $100 \%$ related to the standard scenario causes an increase of the average transport distance of $41.5 \%$ (9.95 km related to $7.03 \mathrm{~km})$. In this scenario, the same data set used in assessing the ecological effects from agricultural transport is once again used. Therefore, meaning only the transport efforts are changed. Transport efforts of 10,249 tkm for the input substrates and 9,408 tkm for the output substrates are assumed. Total ecological effects of $342 \mathrm{El}$ '99 points for the input substrate transport and $314 \mathrm{EI}$ '99 points for the biogas slurry transport per functional unit are caused.

The sensitivity analysis of biogas slurry treatment considers the effects this process has on the related transport efforts. The initial amount of slurry $(945.5 \mathrm{Mg} / \mathrm{TJ})$ is reduced to $359.0 \mathrm{Mg} / \mathrm{TJ}$. In doing this, transport effort savings of $4,123 \mathrm{tkm}(586.5 \mathrm{Mg} 7.03 \mathrm{~km})$ are achieved. The effects from the construction and the operation of the treatment facility are also taken into account.

Table 3.10: Weighted effects (EI ' $99 \mathrm{H}$ ) of biogas slurry treatment facility related to one functional unit

\begin{tabular}{|l|l|r|}
\hline \multicolumn{1}{|c|}{ substance } & compartment & points \\
\hline Total of all compartments & & 48.8 \\
\hline Remaining substances & & 4.2 \\
\hline Gas, natural, 35 MJ per m3, in ground & Raw & 11.5 \\
\hline Oil, crude, 42.6 MJ per kg, in ground & Raw & 5.21 \\
\hline Nickel, in ground & Raw & 2.57 \\
\hline Gas, natural, in ground & Raw & 2.06 \\
\hline Oil, crude, in ground & Raw & 1.31 \\
\hline Land use II-III & Raw & 0.514 \\
\hline Sulfur oxides & Air & 15.9 \\
\hline Nitrogen oxides & Air & 1.86 \\
\hline Carbon dioxide & Air & 1.46 \\
\hline Particulates, < 10 um (stationary) & Air & 0.822 \\
\hline Nickel & Air & 0.746 \\
\hline Carbon dioxide, fossil & Air & 0.632 \\
\hline
\end{tabular}


Table 3.11: Weighted effects (EI ' $99 \mathrm{H}$ ) of the reduction of transport efforts due to the biogas slurry treatment

\begin{tabular}{|l|l|r|}
\hline \multicolumn{1}{|c|}{ substance } & compartment & points \\
\hline Total of all compartments & & -138 \\
\hline Remaining substances & & -9.12 \\
\hline Aluminium, 24\% in bauxite, 11\% in crude ore, in ground & Raw & -2.78 \\
\hline Gas, natural, in ground & Raw & -10.9 \\
\hline Nickel, 1.98\% in silicates, 1.04\% in crude ore, in ground & Raw & -2.41 \\
\hline Occupation, forest, intensive, normal & Raw & -1.66 \\
\hline Occupation, urban, discontinuously built & Raw & -3.11 \\
\hline Oil, crude, in ground & Raw & -35.2 \\
\hline Transformation, from arable, non-irrigated & Raw & 3.05 \\
\hline Transformation, from pasture and meadow & Raw & 2.05 \\
\hline Transformation, to arable, non-irrigated & Raw & -3.05 \\
\hline Transformation, to urban, discontinuously built & Raw & -1.86 \\
\hline Carbon dioxide, fossil & Air & -4.54 \\
\hline Dioxins, measured as 2,3,7,8-tetrachlorodibenzo-p-dioxin & Air & -3.11 \\
\hline Nitrogen oxides & Air & -9.94 \\
\hline Particulates, <2.5 um & Air & -17.4 \\
\hline Particulates, > 2.5 um, and <10um & Air & -8.11 \\
\hline Sulfur dioxide & Air & -2.55 \\
\hline Arsenic, ion & Water & -3.03 \\
\hline Cadmium, ion & Water & -3.7 \\
\hline Zinc & Soil & -20.2 \\
\hline
\end{tabular}

In Table 3.10 - Table 3.11 the total sum of the ecological effects from the installation of the biogas slurry treatment facility, its operation efforts, and the transport savings are given. The biogas slurry treatment facility causes $48.8 \mathrm{El}$ ' 99 points per functional unit; at the same time $138 \mathrm{El}$ ' 99 points are saved by avoiding certain transports. On a whole, $89.2 \mathrm{El}$ ' 99 points/TJ can be saved in a $1.0 \mathrm{MW}_{\mathrm{el}}$ biogas plant by using biogas slurry treatment.

This saving depends heavily on the substrate mixture and the average transport distance. If a large number of substrates with a low energy density are used as inputs, the mass of outputs increases. This leads to an increase in transport efforts needed to dispose biogas slurry. In this case, compared to the given example, biogas slurry treatment can increase transport efforts savings.

As shown in equation (11) biogas plants with a higher installed electric power have larger average transport distances in comparison to smaller plants (cf. equation (4)). Biogas slurry treatment therefore makes more ecological cutbacks in larger plants than in the smaller ones. Considering equation (11) a $2.0 \mathrm{MW}_{\mathrm{el}}$ biogas plant with the same input substrate mixture as the standard biogas plant creates an atd value of $9.95 \mathrm{~km}$. When multiplied by the saved mass of biogas slurry/TJ $(586.5 \mathrm{Mg} / \mathrm{TJ})$ a transport effort reduction of $5,835.7 \mathrm{tkm} / \mathrm{TJ}$ is achieved. According to Table 3.11 ecological effects of $-195 \mathrm{El}$ ' 99 points from saved transport efforts and ecological effects from the installation of the treatment facility would cause a total of $146.6 \mathrm{El}$ '99 points/TJ if biogas slurry treatment technology is used. 


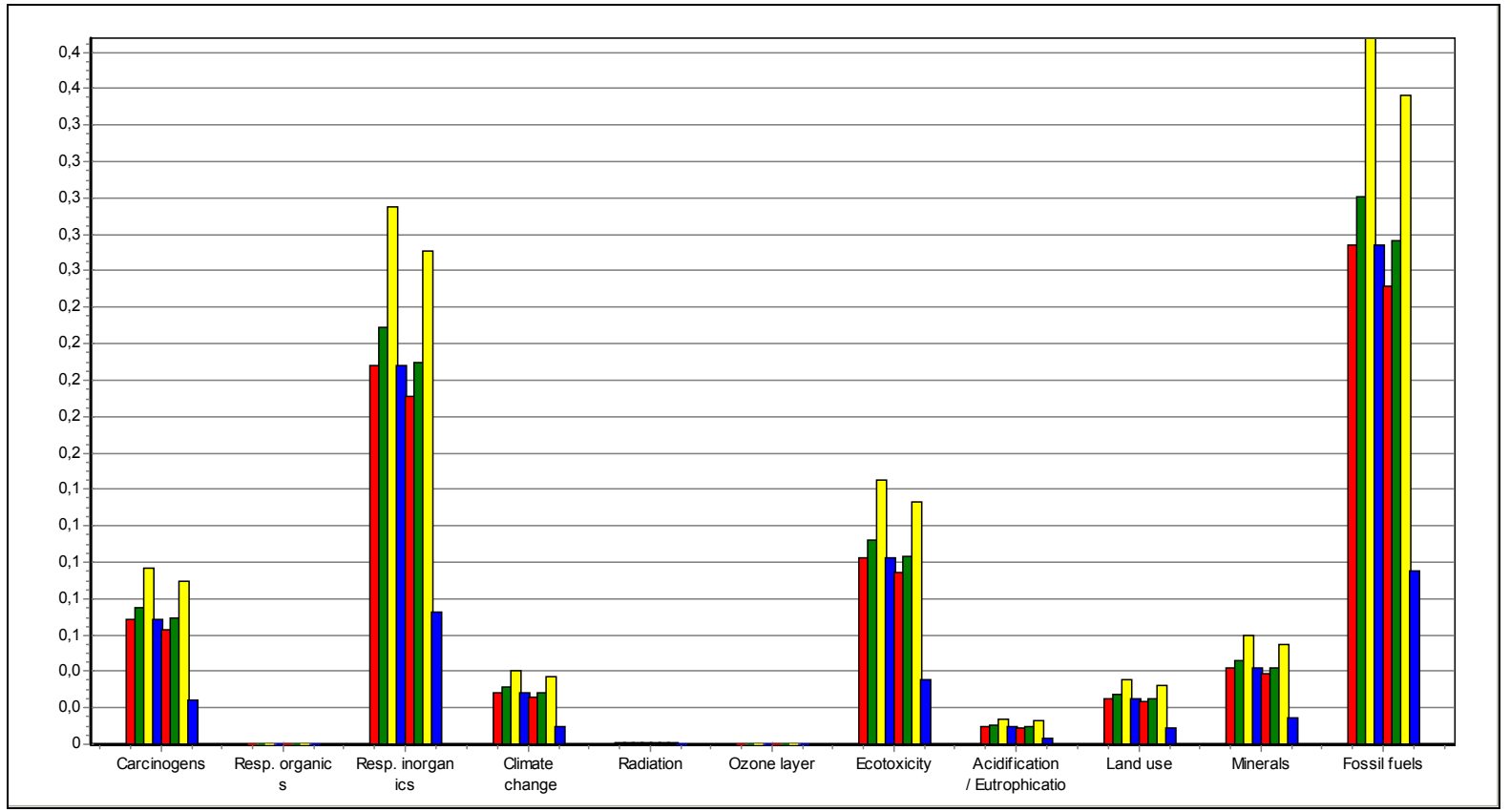

Figure 3.5: Comparison of the normalised values of the transport scenarios

All results are categorised by impact categories. Each scenario is symbolised by one color, where the left hand side bar of the same color represents the ecological effects from the input and the right hand side bar from the output of each scenario. Scenarios: red, standard; green, waste input; yellow, up-scaling; blue, biogas slurry treatment

Figure 3.5 represents a comparison between the normalised values of the different transport scenarios. Small differences occur between the standard scenario and the waste input scenario. As explained above, the up-scaling scenario creates $41.5 \%$ higher results in all impact categories. The biogas slurry treatment scenario causes fewer impacts per category than any other scenario. This is important, especially in the impact categories fossil fuels, exotoxicity, and respiratory inorganics, which are rated as important categories due to their strong influence in the normalisation step. 


\subsection{Biogas plant}

This chapter considers the weighted results of the ecological effects from the building and operation of the biogas plant. All mass and energy flows are taken into account regarding data from chapter 2.4.3. Data from sensitivity analyses are considered if they belong to this module. For the purpose of this assessment, all installations are considered together as one plant. The consumption of energy crops, manure, or waste materials is not considered in this chapter.

The total ecological effects and the share of each impact category per unit process are given in Figure 3.6. The technical installations in the biogas plant cause ecological effects of $98.4 \mathrm{El}$ ' $99 \mathrm{H}$ points. The majority of this total effect is caused by the installations with a high content of steel or premium steel, e.g. CHP plant, fermenter, and spiral-plate heat exchanger.

Consumption of fossil fuels $(41.1 \%)$ and the emission of respiratory inorganics $(29.9 \%)$ are the impacts which have the highest influence on the overall result. Both impact categories are related to the production of steel and concrete. Natural gas and mineral oil are consumed for the production of these two materials; in addition nitrogen oxides and particulates are emitted from the burning of these energy resources.

The consumption of mineral resources has a share of $9.3 \%$, the emission of carcinogens a $5.9 \%$ share, and the emission of ecotoxic substances a $5.3 \%$ share of the overall ecological effects. Climate changing emissions contribute to $4.1 \%$ to the overall effects. Mineral resources are consumed for the production of steel, concrete, limestone. The carcinogenic and ecotoxic emissions are related mainly to the burning of fossil fuels for the generation of building materials but also a small share is related to the emission of particulates from the production of concrete. The climate changing emissions are also related to the burning of fossil resources, especially to the emission of $\mathrm{CO}_{2}$.

As shown below, the total ecological effect (138 El ' $99 \mathrm{H})$ from the installations of the biogas plant is small in comparison to the ecological effect from the consumption of electric energy from the grid and the emissions of the CHP plant. Therefore no sensitivity analysis is carried out on the biogas plant installations. No suggestions for improvements can be given, as typical biogas plants only use the minimum amount of installations. 


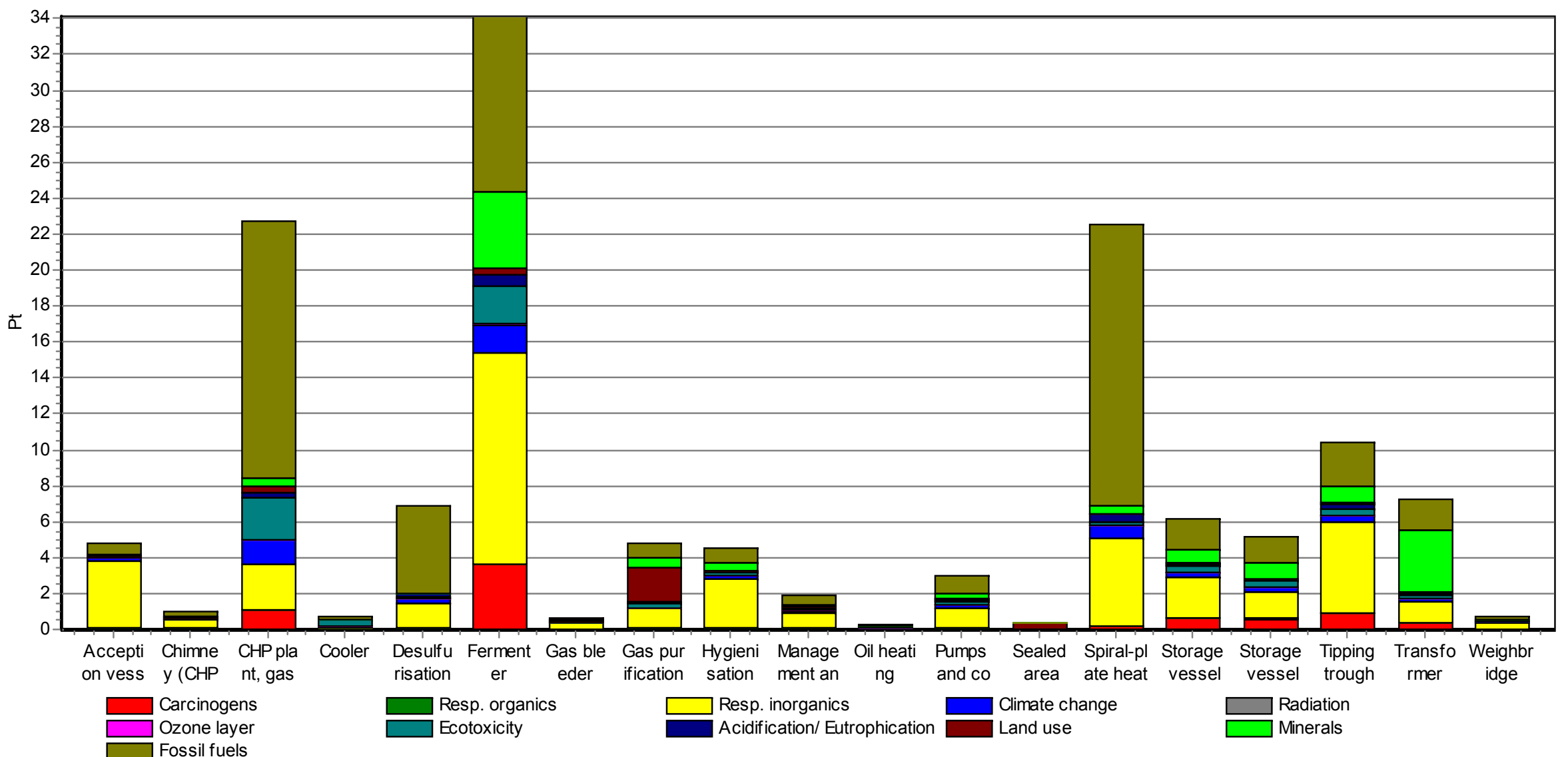

Analysing $1 \mathrm{p}$ assembly 'Biogas plant $1.0 \mathrm{MW}$ (standard scenario)'; Method: Eco-indicator $99(\mathrm{H}) \mathrm{V} 2.02$ / Europe E $99 \mathrm{H} / \mathrm{H} /$ single score

\section{Figure 3.6: Comparison of the weighted ecological effects (EI ' $99 \mathrm{H})$ of the assemblies of the biogas plant}

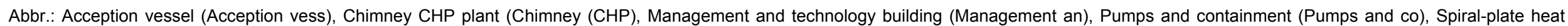
exchanger (Spiral-plate heat), Storage vessel and 2. fermenter (Storage vessel 2) 
The consumption of electric energy is mainly made up from the energy demand of the stirrers and the CHP plant (cf. chapter 2.6.4). The electricity consumption of the object under investigation is considered to be $10 \%$ of the generated electricity of the biogas plant. This means $0.1 \mathrm{TJ}$ per functional unit $(1.0 \mathrm{TJ})$ are taken into account. Data used in the assessment of the electricity consumption are taken from the data set medium voltage, production DE, at grid from the [ECOINVENT2002] data base.

Weighted ecological effects with a total sum of $436 \mathrm{El}$ ' $99 \mathrm{H}$ points are caused by the consumption of medium voltage electricity from the grid. The consumption of fossil resources has a $49.3 \%$ share. The emission of respiratory inorganics from nitrogen oxide causes $20.3 \%$ of all ecological effects. Climate effective emissions have a $18.3 \%$ share of all ecological effects.

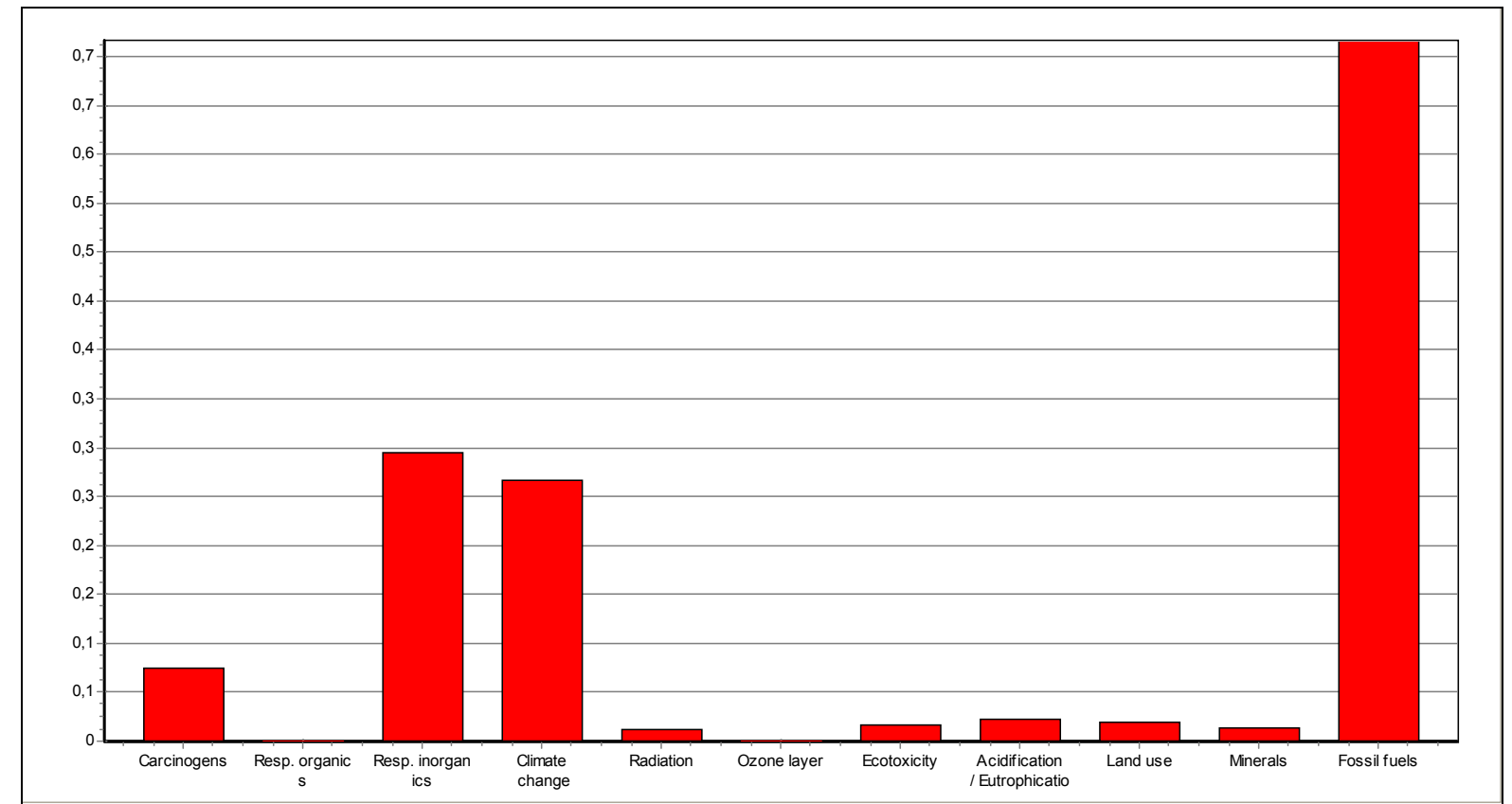

Figure 3.7: Normalised results per impact category of the electricity consumption ( $0.1 \mathrm{TJ})$

In Figure 3.7 the normalised impacts per category are given. As stated above, most ecological impacts are caused by the consumption of fossil fuels, the emission of respiratory inorganics, and the emission of climate effective gases. All other impacts have a relatively small share in their respective impact categories.

The installation and the operation of the two different CHP plants, i.e. conventional gas engine and molten-carbonate fuel cell, cause relatively low impacts on the environment compared to the emissions from these two unit processes (given below).Table 3.12 - Table 3.13 show that the conventional gas engine causes more ecological effects to the environment. This is related to its consumption of fossil lubricants for engine use and transmission purposes. 
Table 3.12: Weighted effects (El ' $99 \mathrm{H}$ ) of installation and operation of a $1.0 \mathrm{MW}_{\mathrm{el}}$ gas engine

\begin{tabular}{|l|l|r|}
\hline \multicolumn{1}{|c|}{ substance } & compartment & points \\
\hline Total of all compartments & & 22.8 \\
\hline Remaining substances & & 1.92 \\
\hline Coal, 18 MJ per kg, in ground & Raw & 1.02 \\
\hline Gas, mine, off-gas, process, coal mining/kg & Raw & 0.368 \\
\hline Gas, natural, 35 MJ per m3, in ground & Raw & 0.847 \\
\hline Gas, natural, in ground & Raw & 0.774 \\
\hline Iron, in ground & Raw & 0.34 \\
\hline Oil, crude, 42.6 MJ per kg, in ground & Raw & 3.02 \\
\hline Oil, crude, in ground & Raw & 8.31 \\
\hline Carbon dioxide & Air & 1.06 \\
\hline Lead & Air & 0.243 \\
\hline Nickel & Air & 0.768 \\
\hline Nitrogen oxides & Air & 1.09 \\
\hline Particulates, <10 um (stationary) & Air & 0.26 \\
\hline Sulfur oxides & Air & 0.901 \\
\hline Zinc & Air & 1.03 \\
\hline Arsenic, ion & Water & 0.798 \\
\hline
\end{tabular}

Table 3.13: Weighted effects (El '99H) of installation and operation of a $1.0 \mathrm{MW}_{\mathrm{el}}$ fuel cell

\begin{tabular}{|l|l|r|}
\hline \multicolumn{1}{|c|}{ substance } & compartment & points \\
\hline Total of all compartments & & 14.9 \\
\hline Remaining substances & & 0.976 \\
\hline Coal, 18 MJ per kg, in ground & Raw & 1.04 \\
\hline Gas, mine, off-gas, process, coal mining/kg & Raw & 0.373 \\
\hline Gas, natural, 35 MJ per m3, in ground & Raw & 0.966 \\
\hline Iron, in ground & Raw & 0.34 \\
\hline Land use II-III & Raw & 0.247 \\
\hline Land use II-IV & Raw & 0.314 \\
\hline Nickel, 1.13\% in sulfide, Ni 0.76\% and Cu & & \\
$0.76 \%$ in crude ore, in ground & Raw & 0.705 \\
\hline Oil, crude, 42.6 MJ per kg, in ground & Raw & 3.42 \\
\hline Oil, crude, in ground & Raw & 0.249 \\
\hline Cadmium & Air & 0.214 \\
\hline Carbon dioxide & Air & -1.12 \\
\hline Lead & Air & 0.247 \\
\hline Nickel & Air & 0.91 \\
\hline Nitrogen oxides & Air & 1.18 \\
\hline Particulates, $<10$ um (stationary) & Air & 0.326 \\
\hline Particulates, <2.5 um & Air & 0.271 \\
\hline Particulates, $>2.5$ um, and <10um & Air & 0.369 \\
\hline Sulfur dioxide & Air & 1.06 \\
\hline Sulfur oxides & Air & 1.01 \\
\hline Zinc & Air & 1.05 \\
\hline Arsenic, ion & Water & 0.802 \\
\hline & &
\end{tabular}

In Figure 3.8 the effects of the installation and operation of a conventional gas engine and a MCFC are compared. All effects are related to one functional unit and normalised. It is noted that in most impact categories, fuel cells cause slightly more effects on the environment. The negative value for the fuel cell in the climate change impact category is caused by the con- 
sumption of activated charcoal. Further effects are caused by the gas engine in the category fossil fuels, which is related to the consumption of lubricants made from fossil resources.

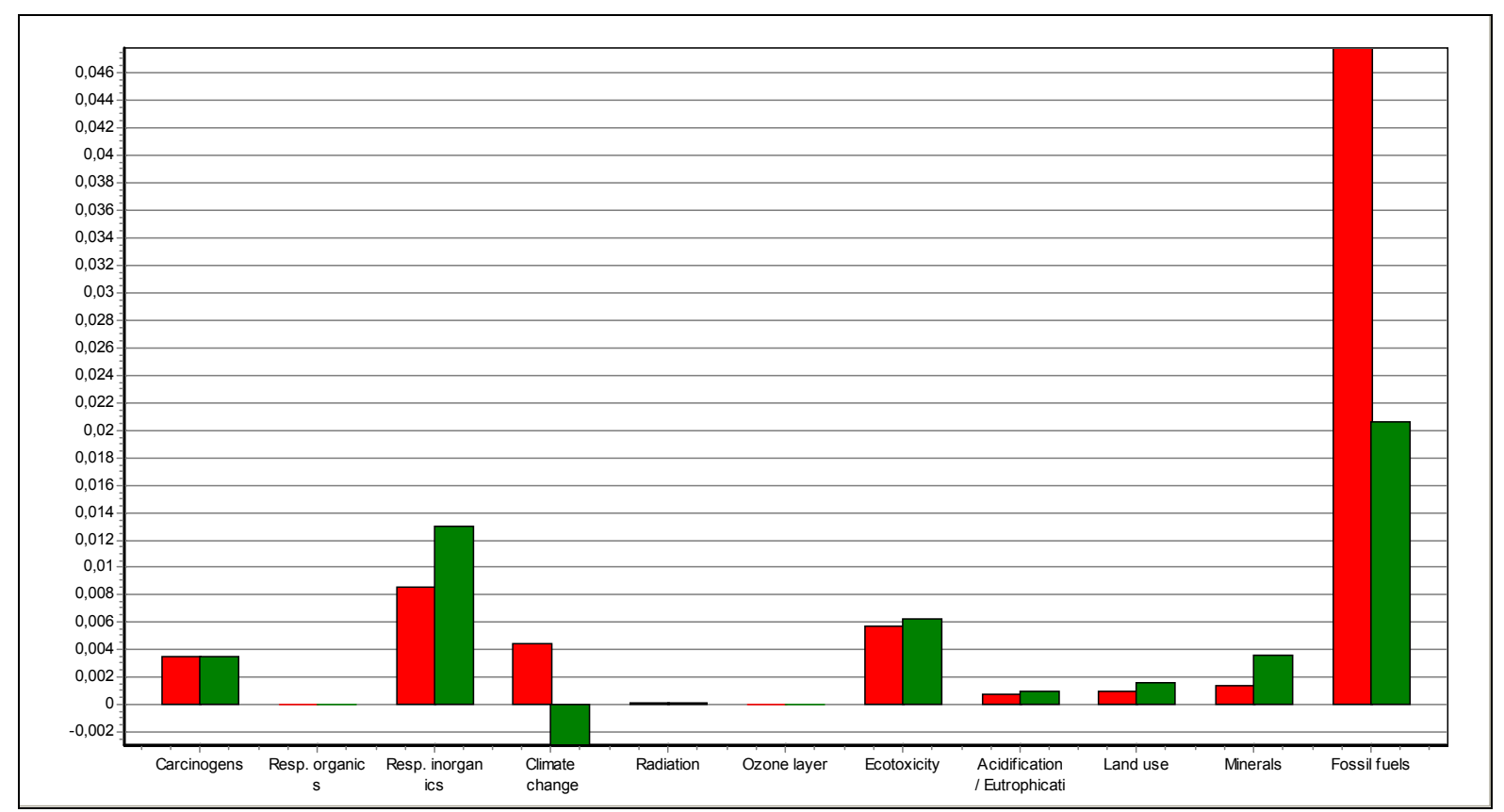

Figure 3.8: Comparison of the ecological effects of a conventional gas engine and fuel cell (normalised)

The red bar symbolises the effects from the gas engine, the green bar symbolises the effects from the fuel cell. Data given in this figure refer to the ecological effects caused by the installation and the operation of the two CHP plants. Supplies, e.g lubricants for the gas engine and activated charcoal for the fuel cell, are considered. The emissions from these plants are not taken into account, as they are separately assessed below.

The effects from the emissions of the combined heat and power plant have a great impact on the overall ecological effects of the module biogas plant. Hence a large share of the total effects of the complete system under analysis is related to the CHP emissions, too. In the standard scenario of the system under analysis a gas engine with an electric power of $1.0 \mathrm{MW}_{\mathrm{el}}$ is considered. The weighted ecological effects from this plant are given in Table 3.14. From this list, it is observed that most ecological effects of this CHP plant are related to the emission of nitrogen oxides (67.9\%). Nitrogen oxide is generated during combustion processes related to the content of oxygen and nitrogen at combustion temperature above $1,250^{\circ} \mathrm{C}$. Catalytic converters can help to reduce the nitrogen oxide emissions from this process. A share of $27.5 \%$ of the ecological effects from this unit process is caused by biogenic carbon dioxid emissions. As this carbon dioxide is related to carbon from non fossil resources, it does not influence the total ecological effects of the biogas process.

Table 3.14: Weighted ecological effects (EI '99H) of the emissions of the conventional CHP per functional unit

\begin{tabular}{|l|l|r|}
\hline \multicolumn{1}{|c|}{ substance } & compartment & \multicolumn{1}{c|}{ points } \\
\hline Total of all compartments & & 1090 \\
\hline Carbon dioxide, biogenic & Air & 253 \\
\hline Carbon monoxide, biogenic & Air & 1.75 \\
\hline Formaldehyde & Air & 1.16 \\
\hline Nitrogen oxides & Air & 788 \\
\hline Particulates, $>2.5$ um, and < 10um & Air & 21.4 \\
\hline Sulfur dioxide & Air & 20.1 \\
\hline
\end{tabular}


The sensitivity analysis technology change, fuel cell in chapter 2.7 .5 considers the ecological effects from the installation and the operation of a fuel cell. The emissions caused by a MCFC (fuel cell) are displayed in Table 3.15.

It is noted that most effects from the fuel cell's gaseous emissions are related to biogenic carbon dioxide. As said above, this carbon dioxide is generated from carbon in plants, which has been adopted by the plant during its growing stages. It can therefore be said that no influence is made on the overall ecological effects by these $\mathrm{CO}_{2}$ emisisons.

Given that the energy generation in fuel cells does not produce a thermal effect, it does not create any temperature dependent emissions. Instead, just small amounts of formaldehyde and carbon monoxide are generated from this process. Especially the purification of the biogas before the fuel cell ensures that no toxic components, especially sulphur oxide, from the biogas are brought into the fuel cell. Hence the generation of toxic emissions is also reduced to a minimum. Only $0.03 \%$ of all ecological effects from the gaseous emissions of the fuel cell are related to carbon monoxide and formaldehyde.

Table 3.15: Weighted ecological effects (El '99H) of the emissions from a $1.0 \mathrm{MW}_{\mathrm{el}}$ fuel cell per functional unit

\begin{tabular}{|l|l|r|}
\hline \multicolumn{1}{|c|}{ substance } & compartment & \multicolumn{1}{c|}{ points } \\
\hline Total of all compartments & & 204 \\
\hline Carbon dioxide, biogenic & Air & 194 \\
\hline Carbon monoxide, biogenic & Air & 0.0351 \\
\hline Formaldehyde & Air & 0.0232 \\
\hline Nitrogen oxides & Air & 9.85 \\
\hline
\end{tabular}

In Figure 3.9 a comparison of the normalised values of the emissions of the two scenarios is given. It can be seen that both scenarios hardly emit any carcinogens and respiratory organics related to the normalisation factor (cf. chapter 2.7.4). The high effect of respiratory inorganics, related to the gas engine, is caused by the nitrogen oxide emissions of this process. The climate change effect is caused by the emission of $\mathrm{CO}_{2}$ and $\mathrm{CO}$. The difference in the effect of these emissions is caused by the higher efficiency of the fuel cell compared to the CHP plant. Acidification and eutrophication are caused by the nitrogen emissions. 


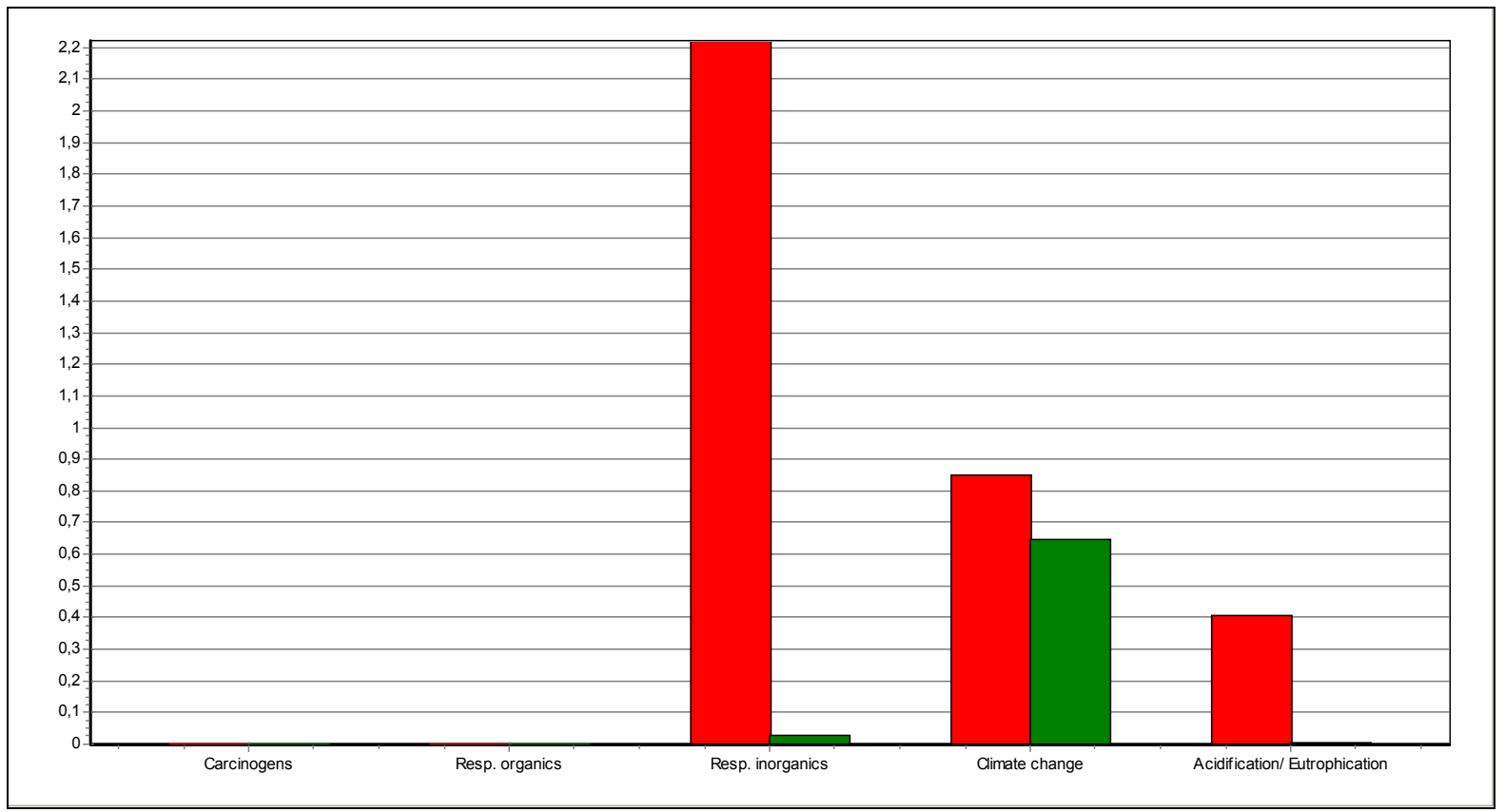

Figure 3.9: Comparison of the normalised values of the emissions from the conventional CHP plant and the fuel cell, both fed with biogas, related to one functional unit

A comparison of the weighted ecological effects from the installations of the biogas plant (138 El '99 points), the consumption of electricity from the grid (436 El '99 points), and the CHP plant emissions (1,090 El '99 points) shows that the strongest threat to the environment from the module biogas plant is caused by the CHP plant emissions (gas enginge). The most important impact categories in this module are the respiratory inorganics emissions, the effects of the climate change, acidification and eutrophication, as well as the consumption of fossil fuels as given in Figure 3.10. All of these categories, except the fossil fuels category, are dominated by the influence of the CHP plant emissions.

With reference to Figure 3.9 it can be seen that changes in the energy conversion technology can lead to drastic reductions in the ecological effects within this impact category. The use of fuel cells or other low-emission technologies e.g. gas turbine (cf. Figure 2.25) for energy generation can help improve the module biogas plants ecological effects. As a first step, the utilisation of catalytic converters and the improvement in their durability help to improve the emission related effects.

The reduction in electricity consumption by biogas plant installations, and the therefore reduction in ecological effects from this unit process, can be achieved by reducing the electricity demand needed for the stirrers and the CHP plant. More efficient processes are classed as processes that need less energy for pumping or less stirring in the fermenters. 


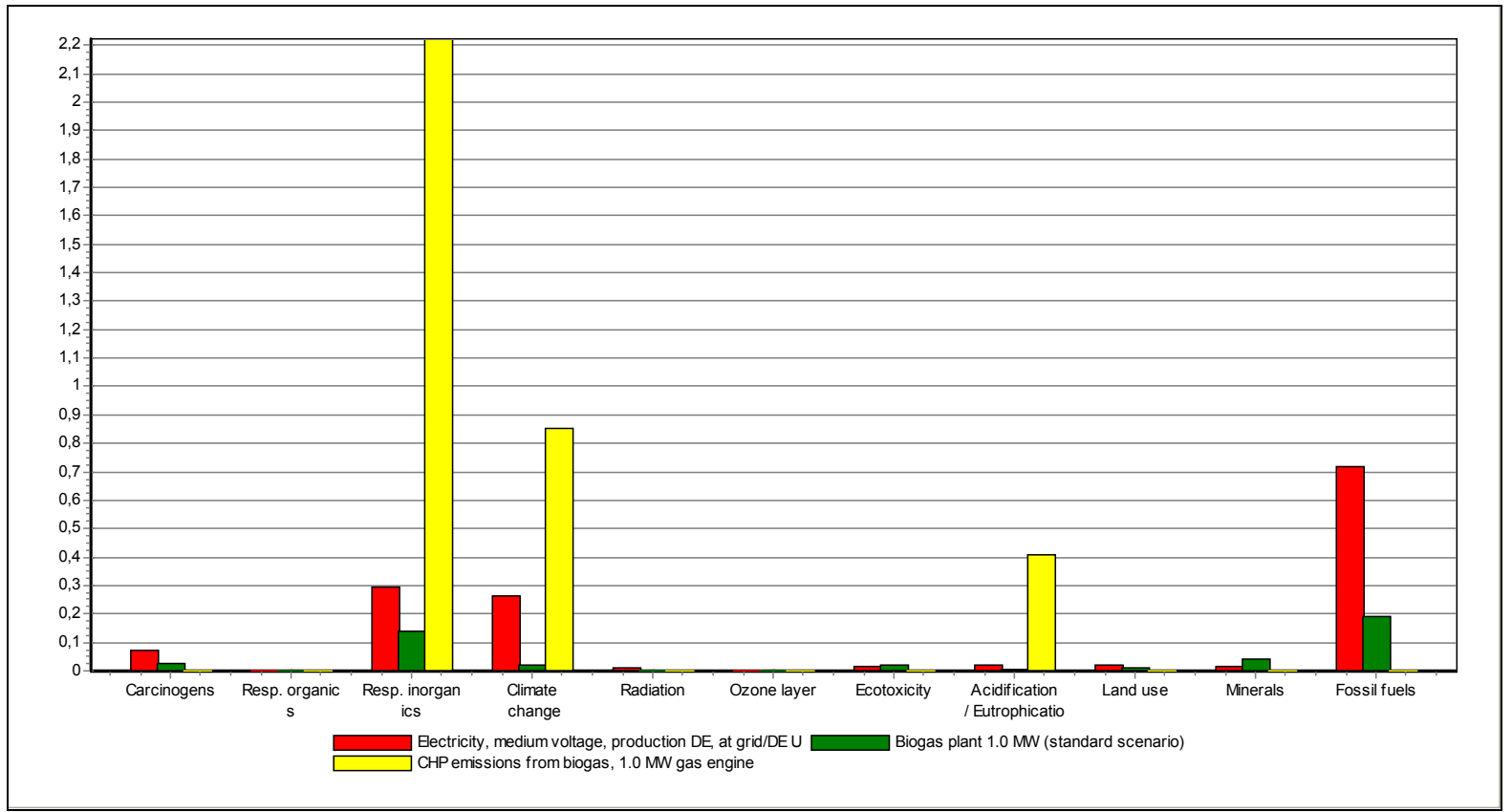

Figure 3.10: Comparison of the normalised results of the impacts to the environment from technical installations, electricity consumption, and emissions from the CHP plant related to the module biogas plant.

\subsection{Application of biogas slurry}

In this chapter the ecological effects from the application of biogas slurry will be presented. This module's effects on the environment are caused by transport and application processes, the nutrient content of the slurry, and gaseous emissions to the air. Three different scenarios are considered in this chapter: standard scenario, non-gap application, and treated biogas slurry.

The scenario concerning food processing industry waste as input is not taken into account with a separate biogas slurry application scenario. An assumption cannot be made regarding the composition of the outputs due to the highly variable composition of the inputs. Therefore, the same data used in the assessment of application of biogas slurry from waste and manure will be once more used as a reference for the standard scenario.

In Figure 3.11 the ecological effects (characterisation step) of the compared scenarios are given per impact category. In all categories, most effects are caused by the application scenario, which does not meet the good agricultural practice standard. Ecological savings are gained in the categories climate change, radiation, ozone layer, minerals, and fossil fuels. These savings are caused by the preservation of mineral fertilisers due to nutrient recycling. More savings, or less impacts on the environment, are caused by this scenario due to the lower emissions of the treated biogas slurry compared to conventional biogas slurry. 


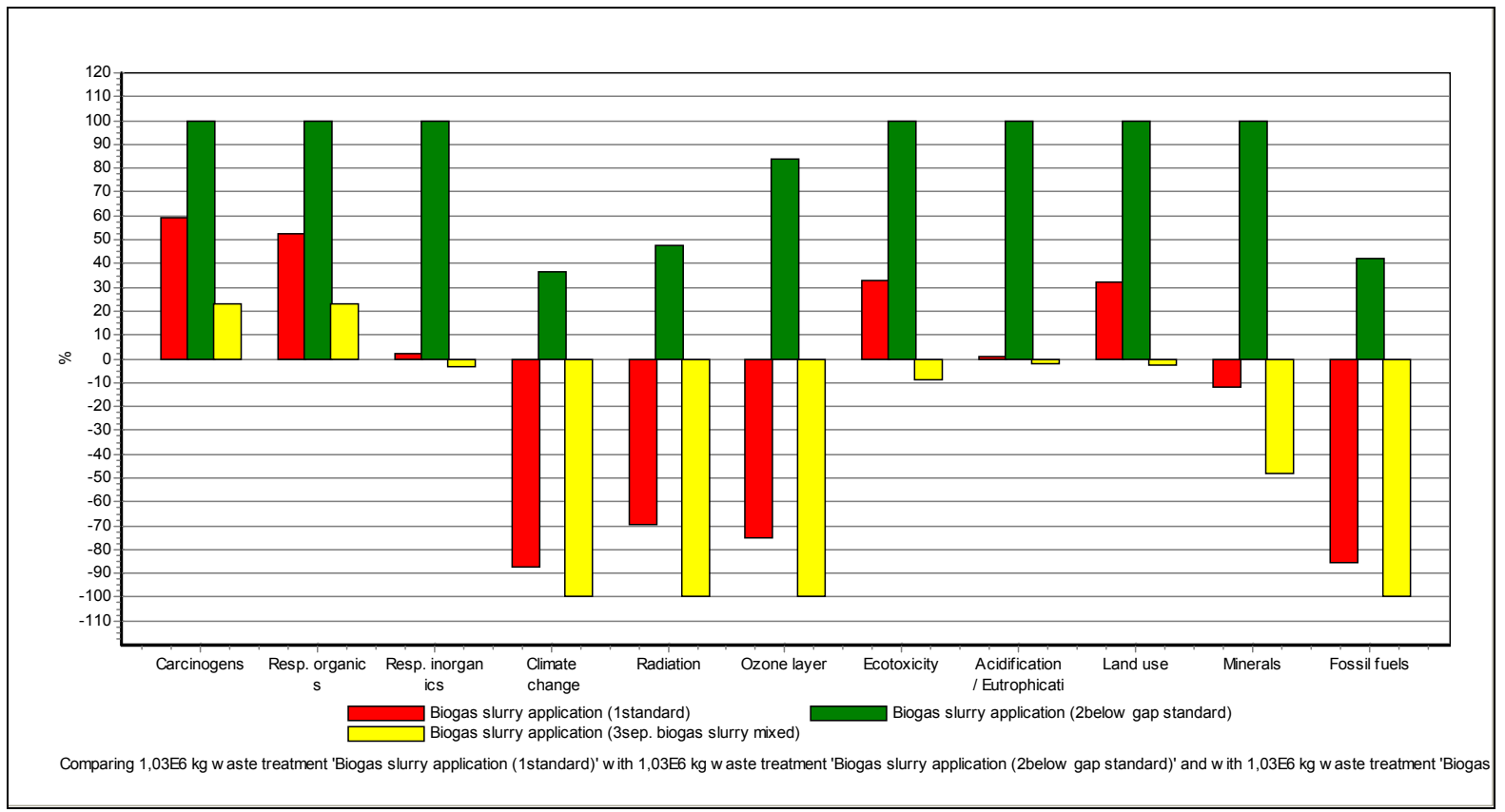

Figure 3.11: Comparison of the characterisation step results of the three objected scenarios

In Table 3.16 the weighted results of the three compared scenarios are given total and per substance. The table shows that the scenarios, which deal with biogas slurry application with trail hose and immediate incorporation (gap standard), cause ecological savings. In comparison to these two scenarios, scenario (2), considering the biogas slurry application below gap standard, causes negative effects to the environment (1,890 El ' $99 \mathrm{H}$ points). The majority of this negative effect $(82.5 \%)$ are caused by ammonia emissions. This result reflects the results of [EDELMANN ET AL.2001], which take into account ammonia emissions of the same magnitude in their LCA study with a comparable biogas slurry application technology below gap standard.

Important ecological savings are achieved from nutrient recycling. By doing this, less artificial fertilisers have to be produced, causing less natural gas and fossil oil consumption. Emissions to the air cause very few effects on the environment, except in the second scenario.

Table 3.16: Weighted results of the biogas slurry treatment scenarios per functional unit

\begin{tabular}{|l|l|r|r|r|}
\hline \multicolumn{1}{|c|}{ substance } & compartment & scenario 1 & scenario 2 & scenario 3 \\
\hline Total of all compartments & & -275 & 1890 & -431 \\
\hline Remaining substances & & -10.1 & 50.5 & -29.5 \\
\hline Gas, natural, in ground & Raw & -296 & -29 & -302 \\
\hline Oil, crude, in ground & Raw & 23.8 & 162 & -16.6 \\
\hline Ammonia & Air & 17 & 1560 & -32.1 \\
\hline Dinitrogen monoxide & Air & -42.5 & 12.1 & -46.8 \\
\hline Nickel & Air & -9.11 & -0.797 & -9.36 \\
\hline Nitrogen oxides & Air & 5.14 & 56.7 & -9.19 \\
\hline Particulates, $<2.5$ um & Air & 17.5 & 48.3 & 7.56 \\
\hline Sulfur dioxide & Air & -8.88 & 0.314 & -10.2 \\
\hline Cadmium, ion & Water & 7.57 & 9.27 & 4.27 \\
\hline Zinc & Soil & 20.9 & 21.2 & 12.5 \\
\hline
\end{tabular}


Scenario (2) causes higher nitrogen emissions including ammonia, which also causes a loss of nutrients. This loss has to be replaced by artificial fertilisers. Therefore scenario (2) has a higher demand of natural gas and fossil oil than the other two scenarios.

In conclusion the important influence of environmentally sound application technics can be seen. Both scenarios $((1)+(3))$ considering trail hose application with immediate incorporation by a grupper provide environmental conservation. These savings are caused by reduced immissions of acidic and eutrohpic gases, as well as reduced immission of respiratory inorganics. Both impact categories are related to the emission of ammonia.

From these results, it can be seen that the application of biogas slurry can cause positive effects on the environment. In contrast to the results of [EDELMANN ET AL.2001] most of the ecological effects of the electricity generation from biogas are not caused in this module. As long as the biogas slurry application is done in an environmentally sound way, this module causes positive ecological effects.

\subsection{Total life cycle}

In this chapter, the different modules are linked together. The amount of the ecological effects per module in relation to the other modules and also the effects from the whole biogas process are given. From this assessment, the ecological hot spots of the electricity generation from industrial scale biogas plants can be determined.

Different variations are done in this chapter. The several sensitivity analyses are related to standard scenarios and combined with other sensitivity analyses. At the beginning of this chapter the standard scenario, as defined in chapter 2.4, will be explained in detail. The standard scenario modifications caused by several sensitivity analyses will be explained separately.

In Figure 3.12 the fraction of each module on the ecological effect per impact category of the electricity generation from biogas, produced in industrial scale biogas plants, is given. It is observed that the majority of the impact categories are dominated by the effects of energy crop production. The CHP emissions have a relevant share in the impact categories considering gaseous emissions (respiratory organics/inorganics) and acidification/eutrophication. The consumption of electricity from the grid causes most effects in the radiation impact category. 


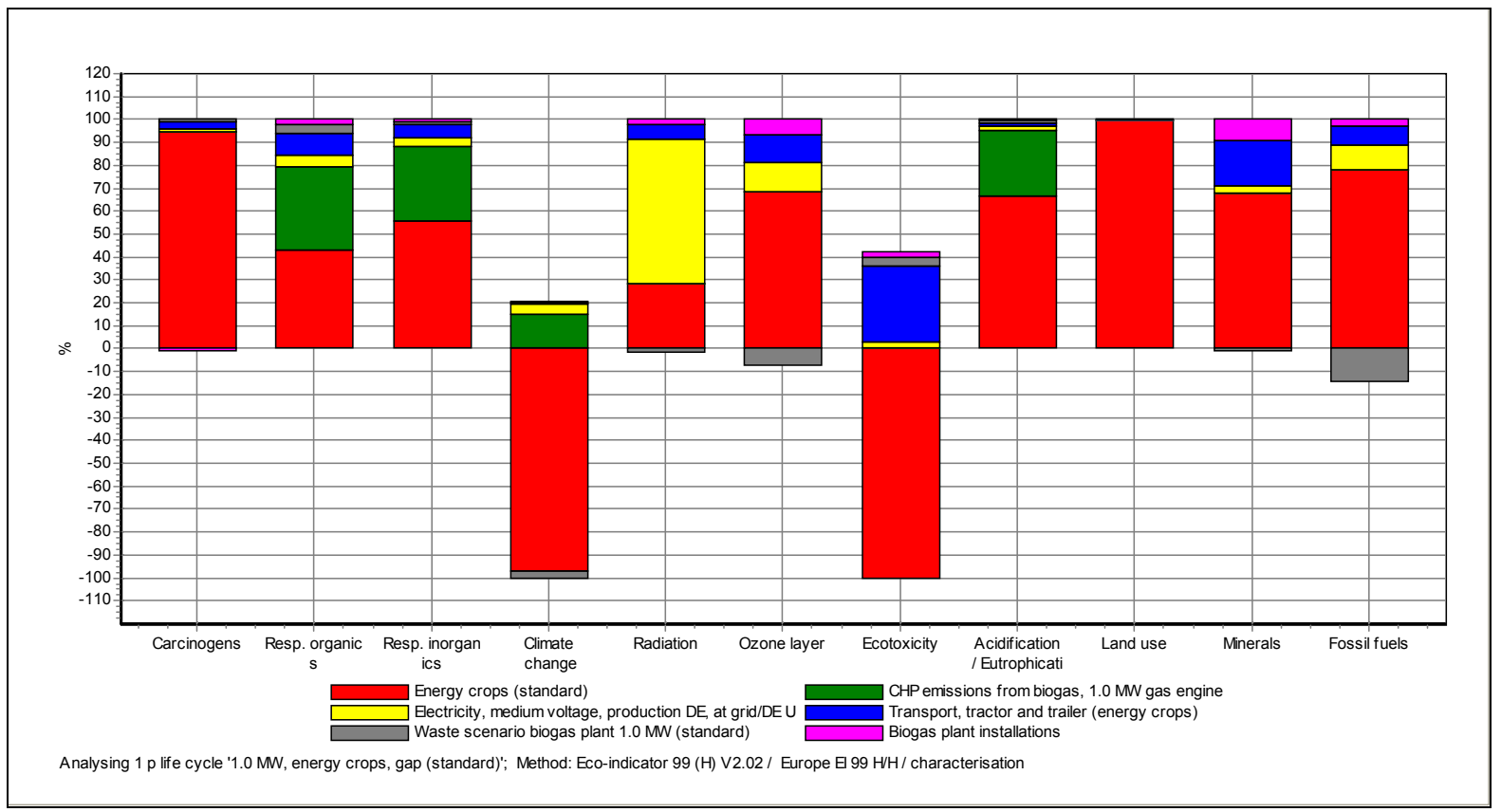

Figure 3.12: Share [\%] of the single modules of the biogas production in industrial scale biogas plants per impact category (characterised), standard scenario

The standard scenario creates total ecological effects of 9,630 El ' $99 \mathrm{H}$ points (cf. Table 3.17). From this total sum 8,040 points $(81.6 \%)$ are caused by energy crops production. $A$ total of 1,090 points $(11.0 \%)$ is created by the CHP emissions, 436 points $(4.4 \%)$ are caused by consumed electricity, 463 points $(4.7 \%)$ are related to transport efforts, ecological conservations of -275 points $(-2,8 \%)$ are related to the biogas slurry utilisation, and 98 points $(1.0 \%)$ are related to the installation of the biogas plant.

Figure 3.13 shows the network of all unit processes, modules, as well as mass and energy flows with their weighted ecological effects. From this figure the influence of the energy crop production in this specific scenario can be seen, whereas the production of maize and rye silage has an important role on the overall effect of this module.

The occupation of non-irrigated arable land (occupation, arable, non-irrigated) has the highest influence on the overall effect. This category creates $5,010 \mathrm{El} ' 99 \mathrm{H}$ points $(50.9 \%)$ of the ecological effects and is directly related to agricultural energy crop production.

The consumption of fossil fuels, especially oil (Oil, crude, in ground) causes 1,270 points (12.9\% of all ecological effects) and is therefore the second most important substance in the object under investigation. The consumption of oil is mainly related to the agricultural energy crop production, $10.9 \%$ of $12.9 \%$ are related to this module.

The emission of ammonia has 711 points $(7.2 \%)$ share on the overall effects and is also mainly related to the agricultural production of energy crops. The emissions of nitrogen oxides have a share of 788 points $(8.0 \%)$. Most of the $\mathrm{NO}_{\mathrm{x}}$ emissions $(63.4 \%)$ are related to the waste gas of the CHP plants. The emission of cadmium to the soil, related to the utilisation of $\mathrm{P}_{2} \mathrm{O}_{5}$ fertilisers, causes 1,020 points $(10.4 \%)$ on the ecological effects and is mainly due to energy crop production. 
Table 3.17: Weighted ecological effects of the standard scenario, electricity generation from biogas produced in industrial scale biogas plants

\begin{tabular}{|c|c|c|c|c|c|c|c|c|}
\hline Substance & $\begin{array}{c}\text { Com- } \\
\text { partment }\end{array}$ & Total & $\begin{array}{l}\text { Energy } \\
\text { crops }\end{array}$ & \begin{tabular}{|c}
$\begin{array}{c}\text { CHP } \\
\text { emissions }\end{array}$ \\
\end{tabular} & Electricity & Transport & $\begin{array}{c}\text { Waste } \\
\text { scenario }\end{array}$ & \begin{tabular}{|l|} 
Biogas plant \\
installations
\end{tabular} \\
\hline Total of all compartments & & 9630 & 8040 & 1090 & 436 & 463 & -275 & 98.4 \\
\hline Remaining substances & & 604 & 455 & 2.91 & 70.2 & 76.1 & -52.1 & 51.5 \\
\hline Carbon dioxide, in air & Raw & -1840 & -1840 & $x$ & -0.87 & -0.874 & -0.176 & -0.341 \\
\hline Gas, natural, in ground & Raw & 312 & 419 & $x$ & 137 & 36.6 & -296 & 15.4 \\
\hline Occupation, arable, non-irrigated & Air & 5010 & 5010 & $x$ & 0.0111 & 0.186 & 0.0582 & 0.00379 \\
\hline Occupation, pasture and meadow, intensive & Raw & 397 & 397 & $x$ & $-1.52 \mathrm{E}-19$ & $x$ & $1.4 \mathrm{E}-17$ & 1.03E-17 \\
\hline Oil, crude, in ground & Soil & 1270 & 1070 & $x$ & 38.8 & 119 & 23.8 & 19.5 \\
\hline Transformation, from arable, non-irrigated & Air & -14600 & -14500 & $x$ & -0.61 & -10.3 & -3.22 & -0.21 \\
\hline Transformation, from pasture and meadow & Raw & -649 & -640 & $x$ & -0.149 & -6.9 & -2.03 & -0.0623 \\
\hline Transformation, from pasture and meadow, intensive & Air & -942 & -942 & $x$ & -0.000486 & -0.00818 & -0.00257 & -0.000167 \\
\hline Transformation, to arable, non-irrigated & Raw & 16200 & 16200 & $\mathrm{x}$ & 0.61 & 10.3 & 3.22 & 0.21 \\
\hline Ammonia & Soil & 711 & 692 & $x$ & 0.868 & 0.276 & 17 & 0.0251 \\
\hline Carbon dioxide, biogenic & Air & 256 & 1.53 & 253 & 0.719 & 0.655 & 0.106 & 0.1 \\
\hline Carbon dioxide, fossil & Air & 168 & 84.1 & $x$ & 75.2 & 15.3 & -8.32 & 1.53 \\
\hline Nitrogen oxides & Air & 1250 & 377 & 788 & 37.3 & 33.5 & 5.14 & 5.42 \\
\hline Particulates, $<2.5$ um & Water & 389 & 286 & $x$ & 24.9 & 58.6 & 17.5 & 2.26 \\
\hline Particulates, $>2.5 \mathrm{um}$, and $<10 \mathrm{um}$ & Air & 185 & 116 & 21.4 & 18.3 & 27.3 & -2.46 & 4.76 \\
\hline Sulfur dioxide & Water & 105 & 68.3 & 20.1 & 16.3 & 8.6 & -8.88 & 0.853 \\
\hline Arsenic, ion & Soil & 124 & 97.5 & $x$ & 14.2 & 10.2 & 2.11 & -0.138 \\
\hline Cadmium, ion & Raw & 105 & 85.4 & $x$ & 2.21 & 12.5 & 7.57 & -2.42 \\
\hline Cadmium & Raw & 1020 & 1010 & $x$ & 0.138 & 4.62 & 1.25 & 0.00753 \\
\hline Chromium & Raw & 258 & 258 & $x$ & 0.0164 & 0.00793 & -0.124 & 0.00217 \\
\hline Zinc & Raw & -519 & \begin{tabular}{|l|}
-609 \\
\end{tabular} & $x$ & 0.4 & 68 & 20.9 & 0.0465 \\
\hline
\end{tabular}




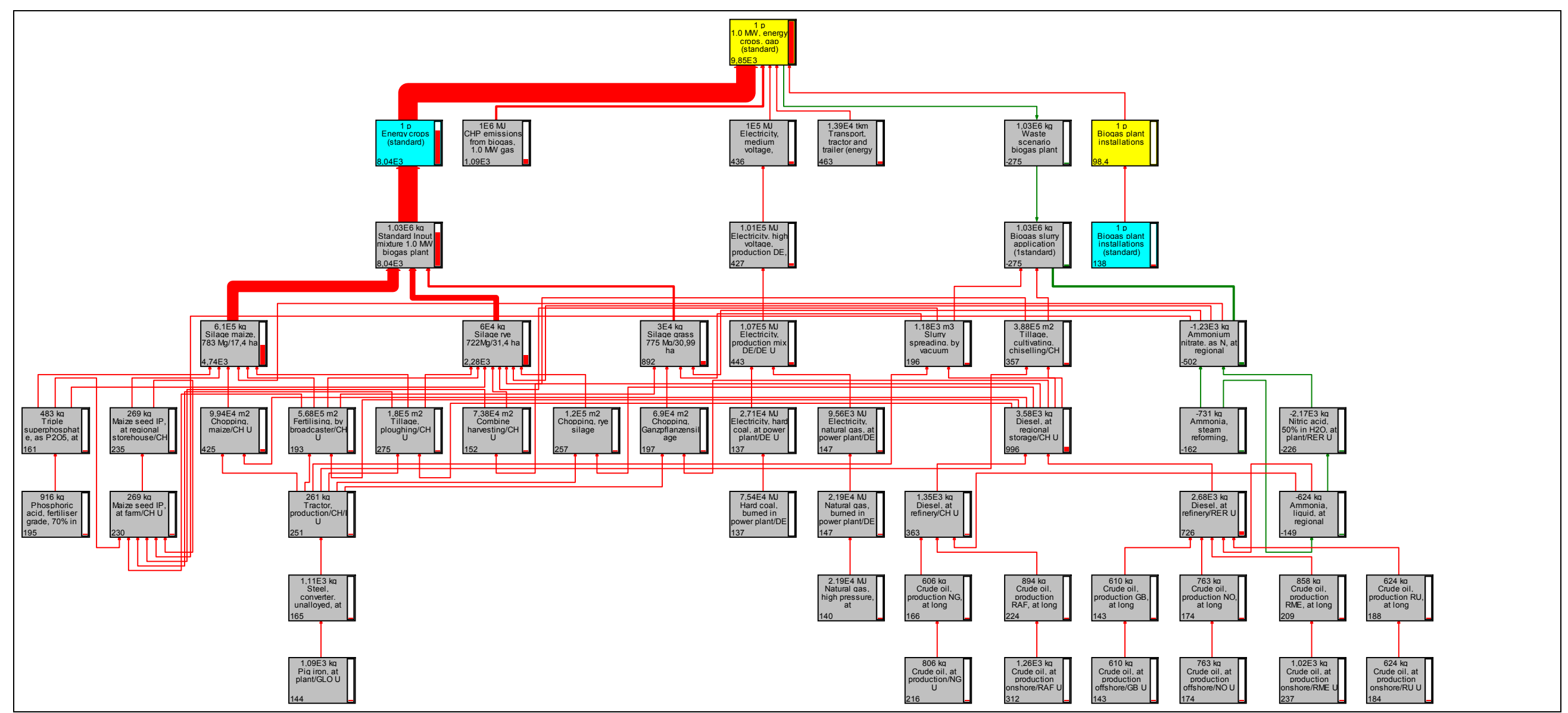

Figure 3.13: Network of the standard scenario (cut-off 1.3\% ecological effect)

Explanation of the colors: yellow, life cycles; blue, assemblies; grey, processes 
In brief, most ecological effects of the standard scenario are related to the agricultural energy crop production module. In this module, most ecological effects are related to the occupation of arable land. The assessment of agricultural land use is a complicated topic and will be considered in this discussion.

The second analysis in this chapter is the land use weighting scenario and its influence on the overall effect of the electricity generation from biogas. As described in the chapter 2.7 .5 no direct land occupation will be taken into account for the production of energy crops. Only indirect impacts on the category land use, e.g. nitrogen emissions from fertile land causing biodiversity changes in the environment, will be considered.

Figure 3.14 shows the share of each module on the impact categories considered in this assessment. It is observed that agricultural energy crop production controls most impact categories. The effects of the CHP plant emissions relevantly influence the categories respiratory organics and inorganics as well as acidification/eutrophication. The radiation impact category is dominated by the impacts from the electricity consumption via grid.

The fact that the categories climate change and ecotoxicity are mainly influenced by the module agricultural crop production must be taken into consideration. It must also be taken into account that these influences have a positive effect on the environment. This means $\mathrm{CO}_{2}$ is taken from the air and heavy metals are incorporated from the soil by the energy crops. The relevant negative effects in these categories are cause by the CHP emissions (climate change) and the transport of energy crops and biogas slurry (ecotoxicity).

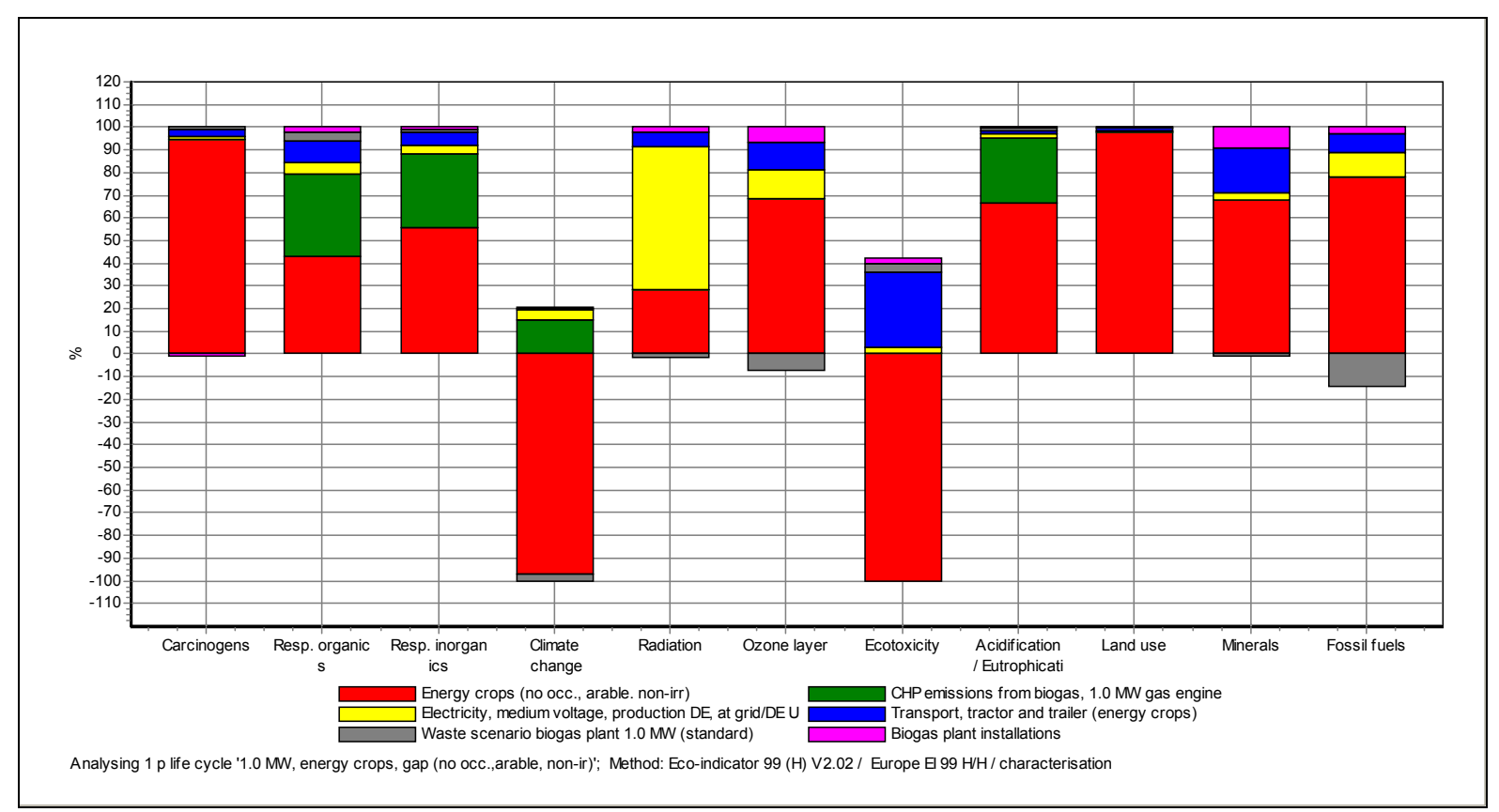

Figure 3.14: Share [\%] of the single modules of the biogas production in industrial scale biogas plants per impact category (characterised), no occ. arable scenario 
The data of all modules in this scenario are the same as in the standard scenario, given in Table 3.17. Only the data of the categories occupation, arable, non-irrigated in the column energy crops has been changed due to the supposition of this scenario. If no direct land use effects are assumed, only indirect effects remain. These indirect effects cause ecological effects of 1,150 El '99 points. Thus, a total of 5,590 El '99 points per functional unit are caused in this scenario. This is a reduction of the total ecological effects of $42 \%$ compared to the standard scenario. Thereby, the share of ecological effects from direct impacts on land use category can be set to $42 \%$

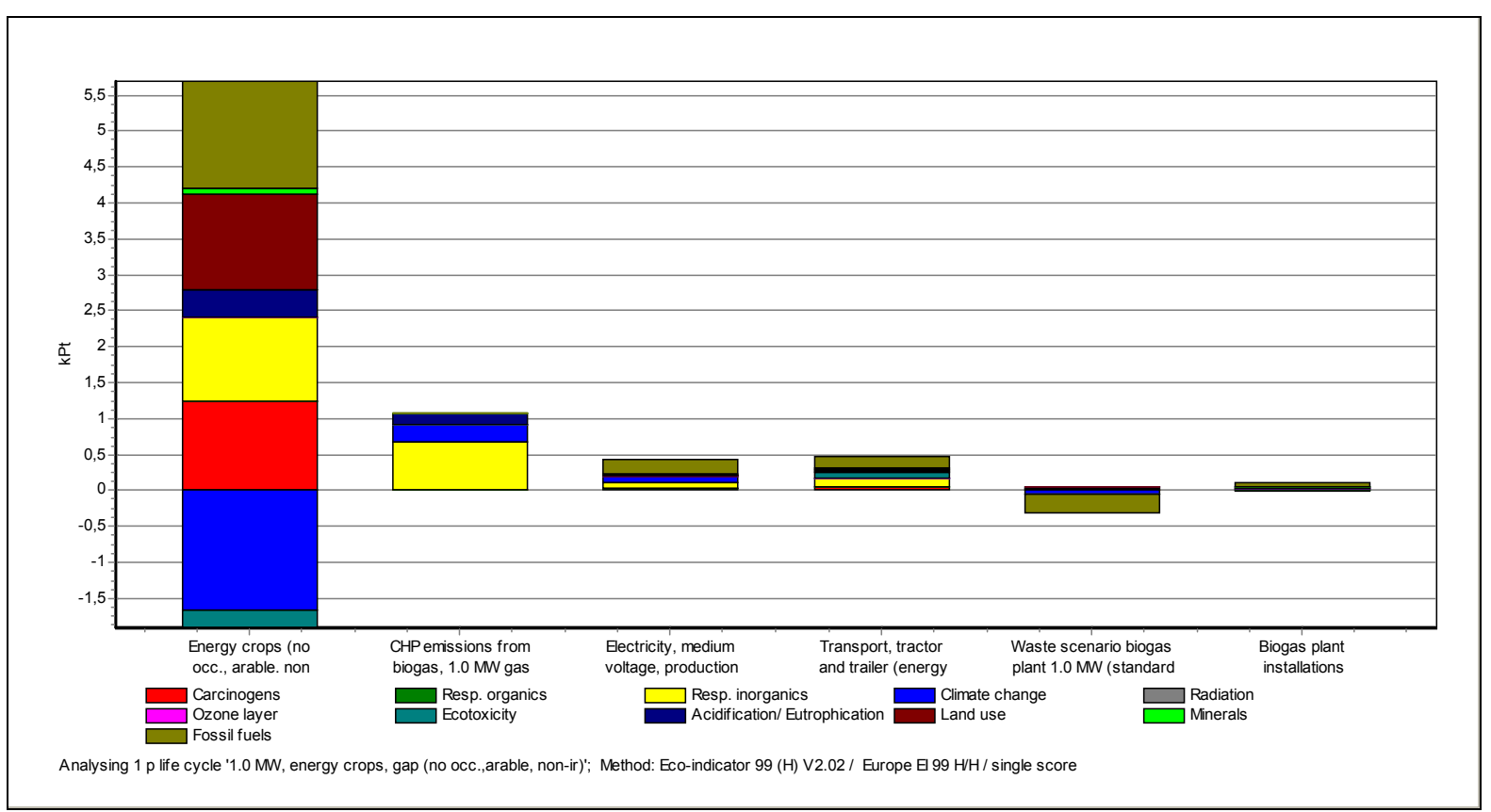

Figure 3.15: Weighted effects (El ' $99 \mathrm{H}$ ) of the electricity generation from biogas, considering no occupation of arable area for the crop production

In the scenario, which deals with no direct occupation of arable area, most ecological effects are caused by the consumption of fossil fuels. These substances have a $22.7 \%$ share of all ecological effects in this scenario (1,270 points). Most fossil fuels (19.1\% of $22.7 \%)$ are consumed in the module energy crop production.

Nitrogen oxide emissions have a $22.3 \%$ (1,250 points) share of total ecological effects. The production of energy crops creates $30.2 \%$ of these emissions, while the exhaust of the CHP plant causes $63.2 \%$ of all $\mathrm{NO}_{\mathrm{x}}$ emissions. The occupation of arable land, from indirect effects, causes $20.6 \%$ of all ecological effects (1,150 points). The emission of cadmium effects $18.2 \%(1,020$ points $)$ and the emission of $\mathrm{NH}_{3}$ to the air has a share of $12.7 \%$ of all ecological effects. 
Table 3.18: Weighted ecol. effects of the no occ. arable area scenario, electricity generation from biogas produced in industrial scale biogas plants

\begin{tabular}{|c|c|c|c|c|c|c|c|c|}
\hline Substance & $\begin{array}{c}\text { Com- } \\
\text { partment }\end{array}$ & Total & $\begin{array}{c}\text { Energy } \\
\text { crops }\end{array}$ & $\begin{array}{c}\text { CHP } \\
\text { emissions }\end{array}$ & Electricity & Transport & $\begin{array}{c}\text { Waste } \\
\text { scenario }\end{array}$ & $\begin{array}{l}\text { Biogas plant } \\
\text { installations }\end{array}$ \\
\hline Total of all compartments & & 5590 & 3780 & 1090 & 436 & 463 & -275 & 98.4 \\
\hline Remaining substances & & 547 & 398 & 2.91 & 70.2 & 76.1 & -52 & 51.5 \\
\hline Carbon dioxide, in air & Raw & -1840 & -1840 & $\mathrm{x}$ & -0.87 & -0.874 & -0.176 & -0.341 \\
\hline Gas, natural, in ground & Raw & 312 & 419 & $\mathrm{x}$ & 137 & 36.6 & -296 & 15.4 \\
\hline Occupation, arable, non-irrigated & Raw & 1150 & 1150 & $\mathrm{x}$ & 0.0111 & 0.186 & 0.0582 & 0.00379 \\
\hline Oil, crude, in ground & Raw & 1270 & 1070 & $\mathrm{x}$ & 38.8 & 119 & 23.8 & 19.5 \\
\hline Transformation, from arable, non-irrigated & Raw & -281000 & -281000 & $\mathrm{x}$ & -0.61 & -10.3 & -3.22 & -0.21 \\
\hline Transformation, from pasture and meadow & Raw & -649 & -640 & $\mathrm{x}$ & -0.149 & -6.9 & -2.03 & -0.0623 \\
\hline Transformation, from pasture and meadow, intensive & Raw & -942 & -942 & $\mathrm{x}$ & -0.00049 & -0.00818 & -0.00257 & -0.00017 \\
\hline Transformation, to arable, non-irrigated & Raw & 283000 & 283000 & $\mathrm{x}$ & 0.61 & 10.3 & 3.22 & 0.21 \\
\hline Ammonia & Air & 711 & 692 & $\mathrm{x}$ & 0.868 & 0.276 & 17 & 0.0251 \\
\hline Carbon dioxide, biogenic & Air & 256 & 1.53 & 253 & 0.719 & 0.655 & 0.106 & 0.1 \\
\hline Carbon dioxide, fossil & Air & 168 & 84.1 & $\mathrm{x}$ & 75.2 & 15.3 & -8.32 & 1.53 \\
\hline Nitrogen oxides & Air & 1250 & 377 & 788 & 37.3 & 33.5 & 5.14 & 5.42 \\
\hline Particulates, $<2.5$ um & Air & 389 & 286 & $\mathrm{x}$ & 24.9 & 58.6 & 17.5 & 2.26 \\
\hline Particulates, > $2.5 \mathrm{um}$, and $<10 u m$ & Air & 185 & 116 & 21.4 & 18.3 & 27.3 & -2.46 & 4.76 \\
\hline Sulfur dioxide & Air & 105 & 68.3 & 20.1 & 16.3 & 8.6 & -8.88 & 0.853 \\
\hline Arsenic, ion & Water & 124 & 97.5 & $x$ & 14.2 & 10.2 & 2.11 & -0.138 \\
\hline Cadmium, ion & Water & 105 & 85.4 & $x$ & 2.21 & 12.5 & 7.57 & -2.42 \\
\hline Cadmium & Soil & 1020 & 1010 & $x$ & 0.138 & 4.62 & 1.25 & 0.00753 \\
\hline Chromium & Soil & 258 & 258 & $x$ & 0.0164 & 0.00793 & -0.124 & 0.00217 \\
\hline Nickel & Soil & 57.1 & 57.2 & $x$ & 0.00875 & 0.00586 & -0.149 & 0.00215 \\
\hline Zinc & Soil & -519 & -609 & $x$ & 0.4 & 68 & 20.9 & 0.0465 \\
\hline
\end{tabular}


In the following paragraphs the influence of the utilisation of waste heat for heating processes on the overall ecological effects will be considered. This scenario deals with the same data as the standard scenario. An additional module, a thermal heat grid substituting 61.7 $\mathrm{MWh} /$ functional unit, is added. This module conserves natural gas that otherwise would be burned for heating purposes. It is assumed that this heat grid can use $23.7 \%$ of the waste heat of the biogas plant. This scenario leads to a reduction of the ecological effects of the standard scenario of $1,490 \mathrm{El}$ ' $99 \mathrm{H}$ points or $15.1 \%$.

The comparison between Figure 3.12 and Figure 3.16 shows the influence of the heat grid and waste heat utilisation on the standard scenario. The waste heat utilisation causes ecological savings in the impact categories of respiratory organics, radiation, ozone layer, and most importantly in the fossil fuels category.

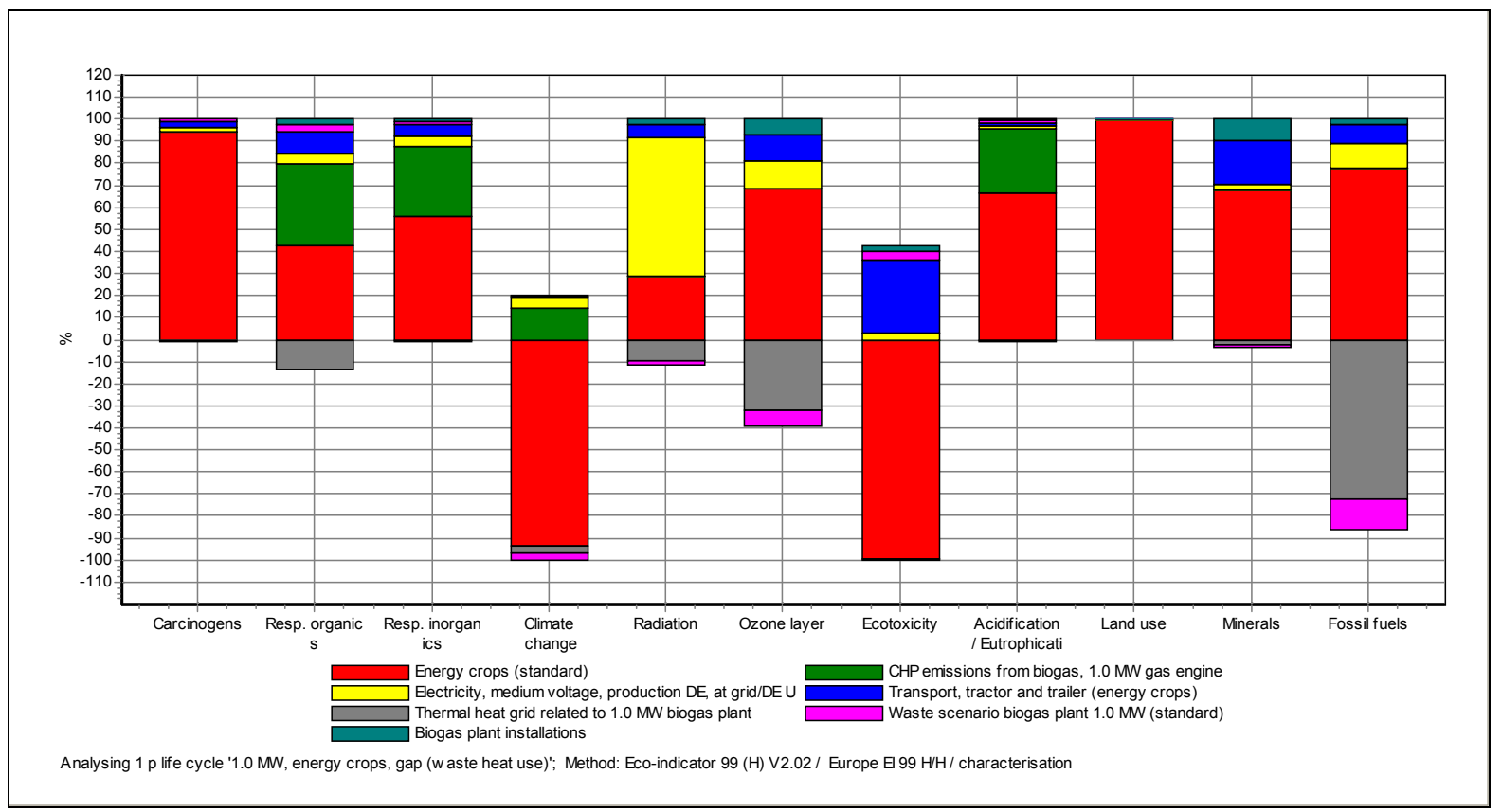

Figure 3.16: Share [\%] of the single modules of the biogas production in industrial scale biogas plants per impact category (characterised), utilisation of waste heat scenario

Conservation of natural gas produces $89.2 \%$ of the savings related to this module $(-1,330$ points). The reduction of $\mathrm{CO}_{2}$ emissions causes $4.0 \%$ of the savings ( -59 points), while $3.4 \%$ of the savings are related to avoided consumption of fossil oil (-51 points). Reduced emissions of nitrogen oxides have a share of $1.5 \%$ of the savings ( -23 points).

If $50 \%$ of waste heat were to be used, more than $30 \%$ of all ecological effects of the electricity generation from biogas could be saved. This stresses the importance of waste heat utilisation concepts in the field of biogas, in addition to any other field of electricity generation from various CHP process. But possible ecological conservation depends on the substituted process. If these processes use waste heat without supplementing fossil fuels no savings can be achieved. It can therefore be said that processes regarding the use of artificial processes, implemented to use waste heat without lowering the consumption of any other fuel, such as wood chip drying, do not lead to the conservation of ecological effects. 
The fuel cell scenario considers possible ecological effects, if the gas engine (CHP plant) of the biogas plant were to be replaced by a molten-carbonate fuel cell (MCFC). As explained in the sensitivity analysis of this scenario, gaseous emissions would be reduced by a large scale. Several other effects are however related to the MCFC. Fuel cells have a higher energy conversion level $(n=47 \%)$ compared to gas engines $(n=36 \%)$. This higher conversion means that fewer inputs are needed to produce one functional unit. Less input masses also mean less input transports, less biogas slurry, and also less output transports. The biogas plant can also be reduced in its size. A $23.4 \%$ reduction rate for the input and output masses and transport efforts is adopted. The biogas plant installations are reduced by $10 \%$ for all unit processes. The consumption of electric energy is reduced by $10 \%$.

Table 3.19 shows the weighted ecological effects of the fuel cell scenario. It is observed that ecological effects of all categories not directly related to the fuel are reduced by the efficiency increase factor given above. In the fuel cell scenario, ecological effects of 6,990 El '99 points per functional unit are present, which have $29 \%$ less effects on the environment than in the standard scenario $(9,850$ points per functional unit). It can be observed from this that the increase of electric conversion efficiency leads to high reduction rates in the ecological effects. Here, it does not matter in which way the conversion level is increased. At present, the prospect of fuel cells combined with gas turbines, is likely to be the best option to convert biogas to electric energy on a high conversion level.

Compared to the gas engine, the fuel cell reduces the CHP emissions to a total of $204 \mathrm{El}$ '99 points $(2.9 \%$ of the total ecological effect). This is an important reduction compared to the standard scenario, in which the gas engine creates 1,090 El '99 points with an $11.0 \%$ share of the overall ecological effects. Most ecological effects in this scenario are due to the $54.9 \%$ (3,840 points) occupation of arable land. The fossil fuel consumption has a share of $14.0 \%$ (978 points), and the emissions of cadmium to the soil have a share of $11.2 \%$ (782 points). Gaseous emissions of ammonia (544 points) together with nitrogen oxide emissions (367 points) have a share of $13.0 \%$. 
Table 3.19: Weighted ecol. effects of the fuel cell scenario, electricity generation from biogas produced in industrial scale biogas plants

\begin{tabular}{|c|c|c|c|c|c|c|c|c|}
\hline Substance & Compartment & Total & $\begin{array}{l}\text { Energy } \\
\text { crops }\end{array}$ & $\begin{array}{l}\text { Fuel cell } \\
\text { emissions }\end{array}$ & Electricity & Transport & $\begin{array}{c}\text { Waste } \\
\text { scenario }\end{array}$ & $\begin{array}{l}\text { Biogas plant } \\
\text { installations }\end{array}$ \\
\hline Total of all compartments & & 6990 & 6160 & 204 & 392 & 355 & -210 & 88.6 \\
\hline Remaining substances & & 544 & 401 & 0.0583 & 77.9 & 64.9 & -46.7 & 47.1 \\
\hline Carbon dioxide, in air & Raw & -1410 & -1410 & $\mathrm{x}$ & -0.783 & -0.669 & -0.135 & -0.307 \\
\hline Gas, natural, in ground & Raw & 259 & 321 & $\mathrm{x}$ & 124 & 28 & -227 & 13.8 \\
\hline Occupation, arable, non-irrigated & Raw & 3840 & 3840 & $\mathrm{x}$ & 0.00995 & 0.142 & 0.0446 & 0.00341 \\
\hline Occupation, pasture and meadow, intensive & Raw & 304 & 304 & $\mathrm{x}$ & $2.92 E-13$ & $\mathrm{x}$ & $-2.2 \mathrm{E}-16$ & $1.36 \mathrm{E}-16$ \\
\hline Oil, crude, in ground & Raw & 978 & 817 & $\mathrm{x}$ & 34.9 & 90.9 & 18.3 & 17.6 \\
\hline Transformation, from arable, non-irrigated & Raw & -11200 & -11100 & $\mathrm{x}$ & -0.549 & -7.86 & -2.46 & -0.189 \\
\hline Transformation, from pasture and meadow & Raw & -497 & -490 & $\mathrm{x}$ & -0.134 & -5.29 & -1.55 & -0.0561 \\
\hline Transformation, from pasture and meadow, intensive & Raw & -722 & -722 & $\mathrm{x}$ & -0.00044 & -0.00627 & -0.00197 & -0.00015 \\
\hline Transformation, to arable, non-irrigated & Raw & 12400 & 12400 & $\mathrm{x}$ & 0.549 & 7.86 & 2.47 & 0.189 \\
\hline Ammonia & Air & 544 & 530 & $\mathrm{x}$ & 0.781 & 0.212 & 13.1 & 0.0226 \\
\hline Carbon dioxide, biogenic & Air & 197 & 1.17 & 194 & 0.647 & 0.502 & 0.0815 & 0.0903 \\
\hline Carbon dioxide, fossil & Air & 139 & 64.4 & $\mathrm{x}$ & 67.7 & 11.7 & -6.37 & 1.38 \\
\hline Nitrogen oxides & Air & 367 & 289 & 9.85 & 33.6 & 25.6 & 3.94 & 4.88 \\
\hline Particulates, $<2.5$ um & Air & 302 & 219 & $\mathrm{x}$ & 22.4 & 44.9 & 13.4 & 2.04 \\
\hline Particulates, $>2.5 \mathrm{um}$, and $<10 \mathrm{um}$ & Air & 129 & 88.7 & $\mathrm{x}$ & 16.5 & 20.9 & -1.88 & 4.28 \\
\hline Arsenic, ion & Water & 96.7 & 74.7 & $\mathrm{x}$ & 12.8 & 7.82 & 1.61 & -0.124 \\
\hline Cadmium, ion & Water & 80.5 & 65.4 & $\mathrm{x}$ & 1.98 & 9.55 & 5.8 & -2.18 \\
\hline Cadmium & Soil & 782 & 777 & $\mathrm{x}$ & 0.124 & 3.54 & 0.957 & 0.00678 \\
\hline Chromium & Soil & 198 & 198 & $\mathrm{x}$ & 0.0147 & 0.00607 & -0.0949 & 0.00195 \\
\hline Zinc & Soil & -398 & -466 & $\mathrm{x}$ & 0.36 & 52.1 & 16 & 0.0418 \\
\hline
\end{tabular}




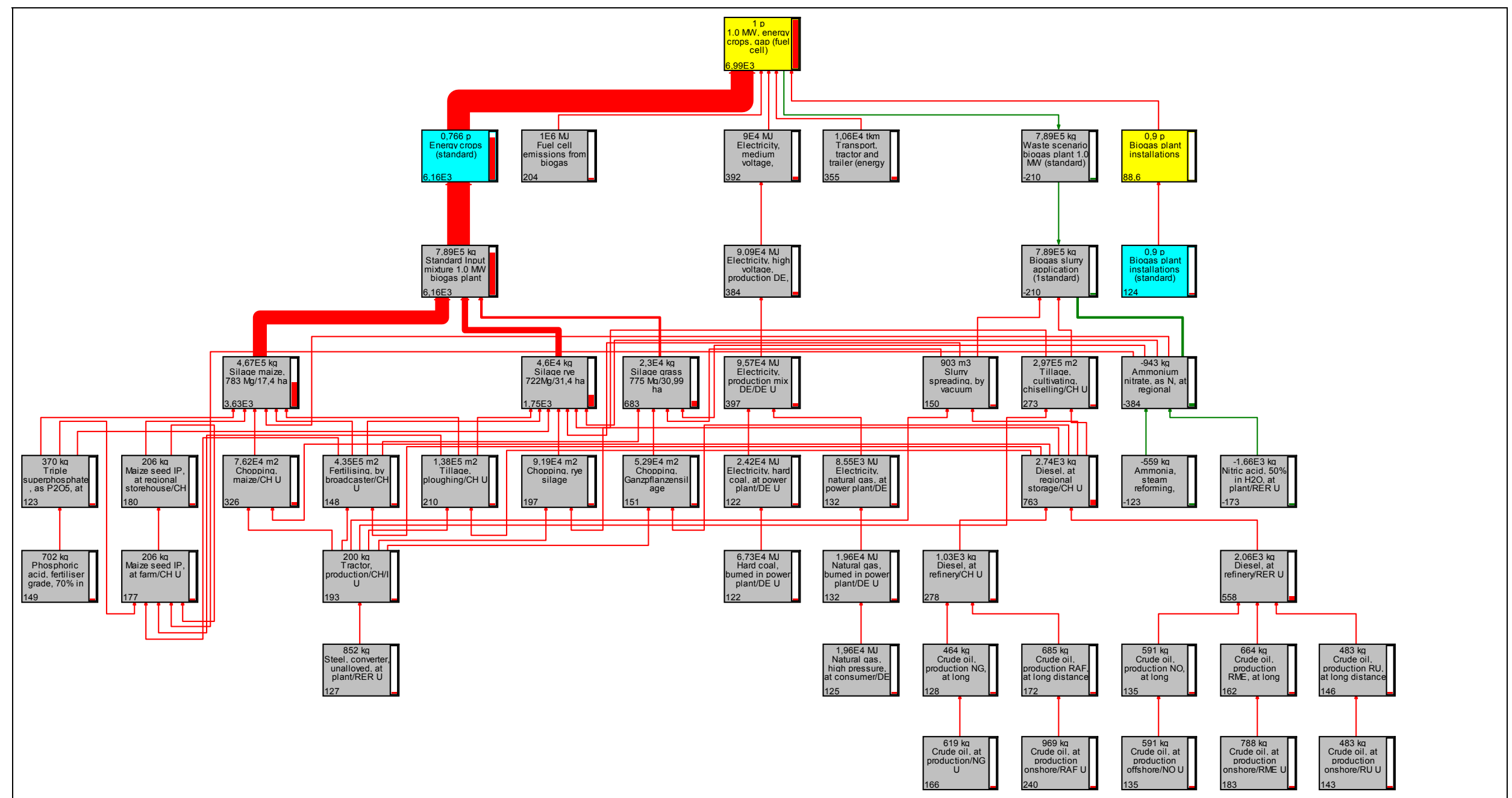

Figure 3.17 Network of the fuel cell scenario (cut-off $1.7 \%$ ecological effect) 
Figure 3.17 shows the network of the fuel cell scenario. In this, the impact of the energy crop production module can be regarded as the most important impact of all compared modules. Due to the proportional decrease of the impact on all related modules, it is not possible to determine any important differences in each module's share in relation to the overall effect. Only the impact share of the CHP plant emissions are, in comparison to the other impacts, reduced.

As explained in the sensitivity analysis (chapter 2.7.5) plant breeders attempt to improve energy crop yields. Maize is one particular plant that can achieve very high yield per area levels. The sensitivity analysis calculates $30.0 \mathrm{Mg} \mathrm{DM} / \mathrm{ha}$; that is twice as much as in the standard scenario. This scenario will therefore consider the effects of high yield energy maize as an input to the biogas plant in this study. For this purpose, the input to the biogas plant will be changed to: $737.0 \mathrm{Mg}$ maize silage, $150.0 \mathrm{Mg}$ cattle slurry, and $120.0 \mathrm{Mg}$ pig slurry. This means, energy crops with low yields per area are not used as input to the biogas plant. This causes an additional reduction to the ecological effects from energy crop production. This input mixture which has been greatly altered, causes input transports of $7,079 \mathrm{tkm}$ and output transports of $6,456 \mathrm{tkm}$.

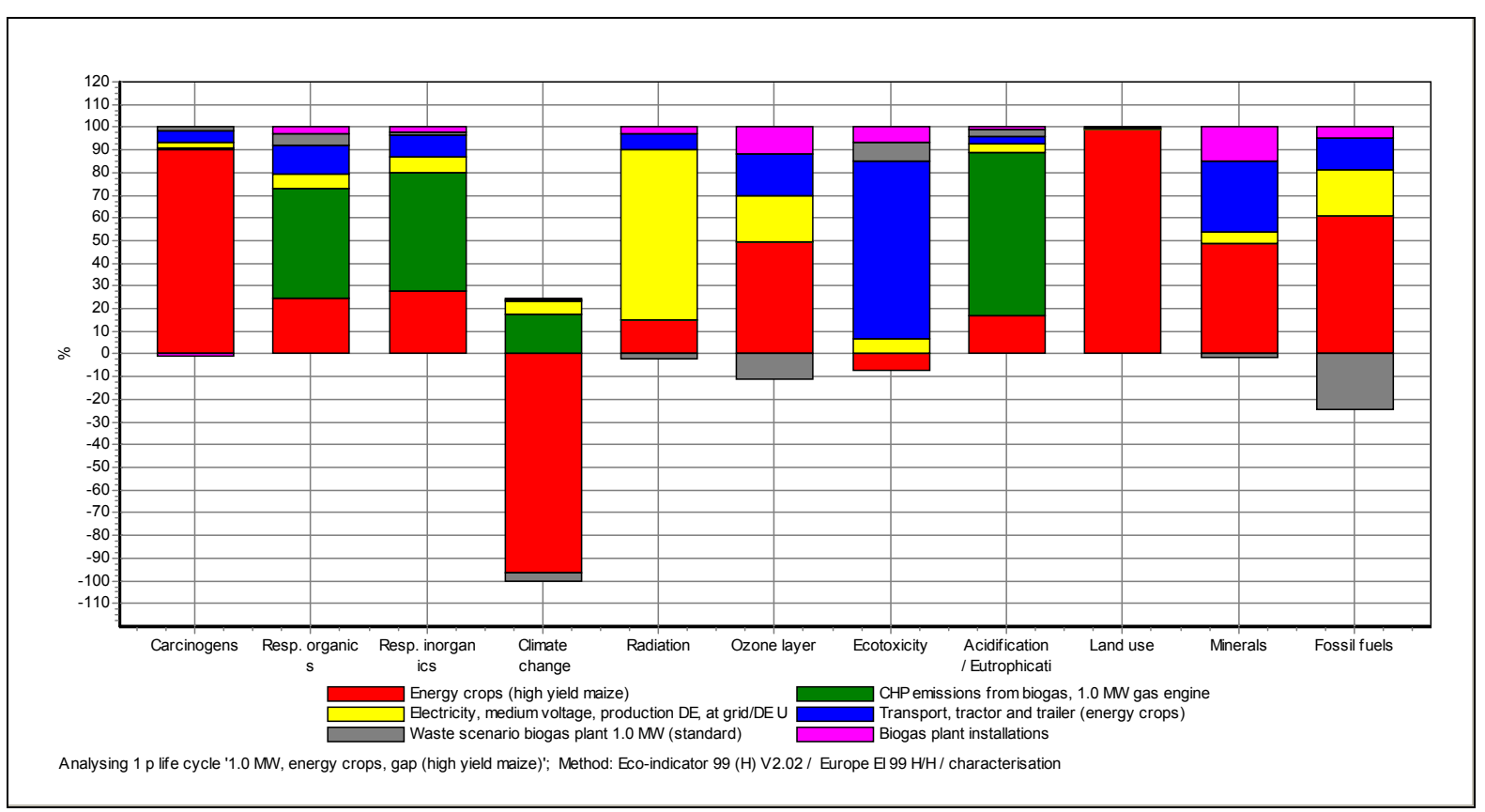

Figure 3.18: Share [\%] of the single modules of the biogas production in industrial scale biogas plants per impact category (characterised), high yield maize scenario

In observing Figure 3.18, the share of the module energy crops on the effects per impact category is evidently lower than in the standard scenario (cf. Figure 3.12). The respiratory organics and inorganics categories, plus the acidification/eutrophication category are not dominated by the effects from the energy crop production, but by effects from CHP emissions in this scenario. The ecotoxicity category causes negative ecological effects, in relation to transport efforts, compared to the standard scenario where ecological savings are taken into account in this category. 
The total ecological effects of this scenario create 4,600 El '99 points, compared to $9,630 \mathrm{El}$ '99 points. This is a reduction of $53.3 \%$ compared to the standard scenario. The total ecological effects are composed of: energy crops 2,800 points $(60.8 \%)$, CHP emissions 1,090 points $(23.6 \%)$, electricity consumption 436 points $(9.5 \%)$, transport efforts 452 points $(9.8 \%)$, waste scenario $-269(5.8 \%)$, and the installation of the biogas plants 98 points $(2.1 \%)$.

From the total effects of this scenario $2,320 \mathrm{El}$ '99 points $(50.5 \%)$ are made up from the occupation of arable land. Nitrogen oxide emissions cause 1,020 points $(22.2 \%)$, while the consumption of fossil oil causes 652 points (14.2\%). In the soil compartment, cadmium emissions create a 579 points $(12.6 \%)$ impact on the total effect.

Two different effects, which lead to ecological conservation, have to be taken into consideration in this scenario. The first effect is the change in the energy crop input mixture. For this scenario no energy crops with low yield per area levels e.g. grass and rye are used, only high yield maize. This leads to some reduction of ecological effects, which can also be viewed in the comparison of the energy crops in chapter 2.4.1. The second effect is a greater yield per area from the high yield maize breed. This greater yield per area level helps reduce the impact category land use and its strong impact on the overall result.

The conclusion drawn from this scenario suggests that energy crops with a high yield per area level reduce the ecological effects of the energy production from biogas. It has to be regarded that this is just true, if the total area under cultivation could be reduced due to the higher yield per area levels. If the area under cultivation maintains the same size and only high-energy crops are produced, more threats to the environment have to be expected.

Another possibility in reducing ecological effects from the upstream processes of the biogas plant is the complete substitution of energy crops to waste from the food processing industry. In this food waste scenario the input mixture as given in Table 2.46 is used. All wastes are calculated without considering any ecological effects from upstream processes. Therefore only the transport efforts of these processes are taken into account. As there are no reliable data for the nutrient content of biogas slurry consisting of food waste and manure, the standard biogas slurry application scenario will be assumed for the slurry application module in this scenario.

In Figure 3.19 the characterised effects per impact category of the food waste scenario are given. In comparison to the standard scenario (cf. Figure 3.12) no single module dominates the effects of each impact category. The CHP plant emissions form most of the effects on the respiratory organics and inorganics impact categories, in addition to having an effect on climate change and acidification/eutrophication. The effects from the transport efforts have large shares in the impact categories carcinogens, ecotoxicity, land use and minerals. Most of the effects in the radiation category are formed by the electricity consumption from the grid. All modules influence the impact categories ozone layer and fossil fuels. 


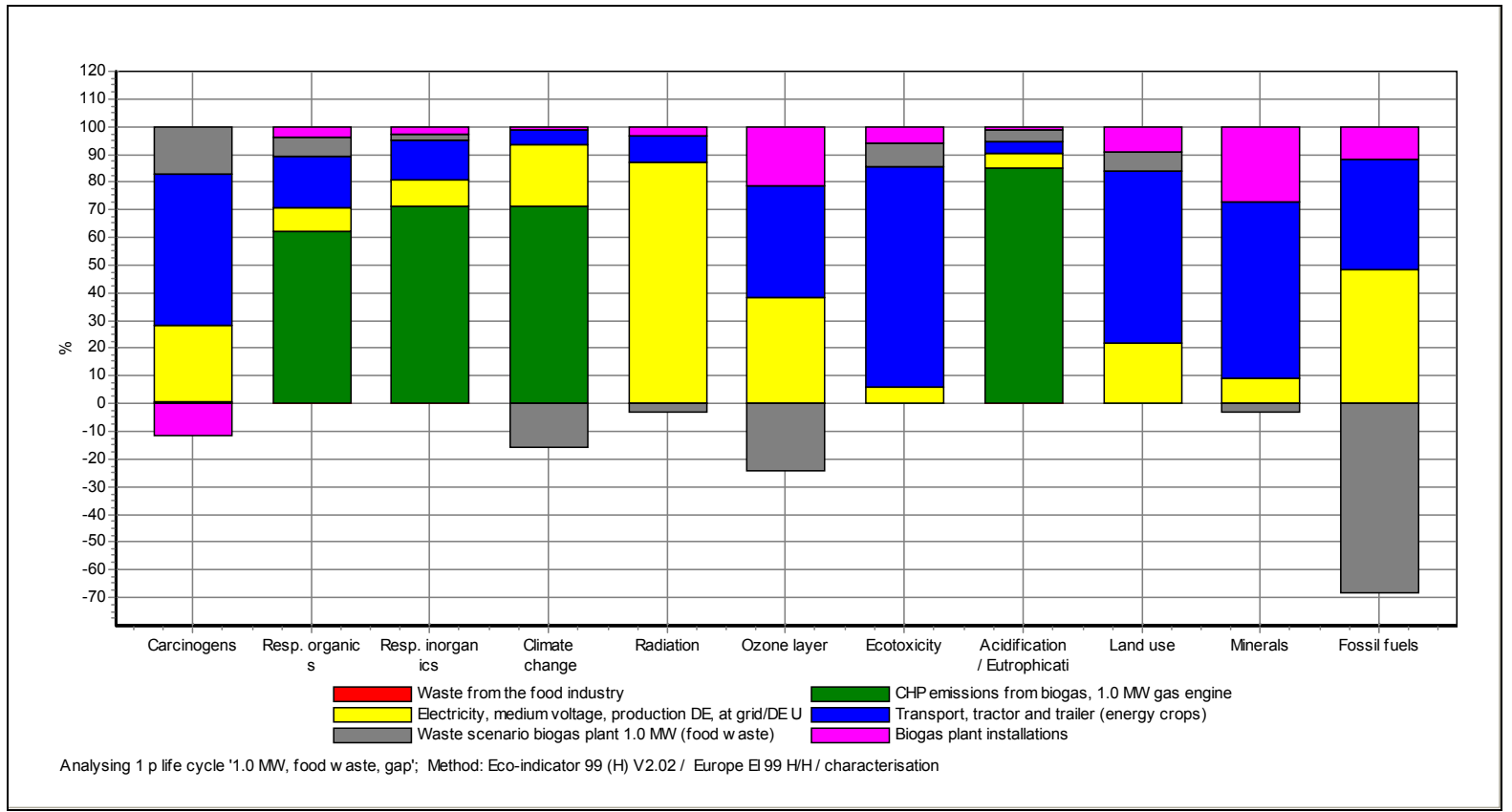

Figure 3.19: Share [\%] of the single modules of the biogas production in industrial scale biogas plants per impact category (characterised), food waste scenario

In Table 3.20 it is shown that the total sum of the ecological effects from this scenario cause $1,830 \mathrm{El}$ ' $99 \mathrm{H}$ points. This makes up $18.6 \%$ of the total ecological effects of the standard scenario. Most of the ecological effects in this scenario are made up from the emissions of the CHP plant with 1,090 El '99H points (59.3\%). The consumption of electric energy causes 436 points $(23.8 \%)$, and the transport effects 517 points $(28.3 \%)$. The waste scenario causes 307 points $(-16.8 \%)$, but as previously mentioned there is no special waste treatment scenario for biogas slurry from food waste and manure. Thus, the effects from this module are not considered reliable. The installations at the biogas plant cause ecological effects of 98.4 points $(5.4 \%)$.

The total ecological effects are made up from nitrogen oxide emissions, causing $47.7 \%$ of all effects. The emission of $\mathrm{CO}_{2}$ causes $13.9 \%$, while the consumption of fossil oil causes $11.9 \%$ of all ecological effects. The influence of other emissions to the air and soil is around $5.0 \%$ of the overall effect and therefore not analysed in detail.

From this assessment it becomes evident that the utilisation of waste, e.g. from the food industry, helps to reduce by more than $80 \%$ the ecological effects of electricity generation from biogas. From an ecological point of view, there should be a greater use of biodegradable wastes. 
Table 3.20: Weighted ecol. effects of the food waste scenario, electricity generation from biogas produced in industrial scale biogas plants

\begin{tabular}{|c|c|c|c|c|c|c|c|c|}
\hline Substance & $\begin{array}{l}\text { Compart- } \\
\text { ment }\end{array}$ & Total & Food waste & $\begin{array}{l}\text { CHP emis- } \\
\text { sions }\end{array}$ & Electricity & Transport & $\begin{array}{l}\text { Waste sce- } \\
\text { nario }\end{array}$ & $\begin{array}{l}\text { Biogas plant } \\
\text { installations }\end{array}$ \\
\hline Total of all compartments & & 1830 & $x$ & 1090 & 436 & 517 & -307 & 98.4 \\
\hline Remaining substances & & 163 & $x$ & 2.91 & 41.2 & 79.5 & -11.6 & 51.2 \\
\hline $\begin{array}{l}\text { Coal, hard, unspecified, in } \\
\text { ground }\end{array}$ & Raw & 28.8 & $x$ & $x$ & 27.3 & 1.98 & -0.236 & -0.213 \\
\hline Gas, natural, in ground & Raw & -137 & $x$ & $x$ & 137 & 40.9 & -330 & 15.4 \\
\hline Oil, crude, in ground & Raw & 217 & $\mathrm{x}$ & $\mathrm{x}$ & 38.8 & 133 & 26.6 & 19.5 \\
\hline Ammonia & Air & 20.2 & $\mathrm{x}$ & $x$ & 0.868 & 0.308 & 19 & 0.0251 \\
\hline Carbon dioxide, biogenic & Air & 255 & $\mathrm{x}$ & 253 & 0.719 & 0.731 & 0.119 & 0.1 \\
\hline Carbon dioxide, fossil & Air & 84.6 & $\mathrm{x}$ & $\mathrm{x}$ & 75.2 & 17.1 & -9.29 & 1.53 \\
\hline Dinitrogen monoxide & Air & -46.3 & $\mathrm{x}$ & $x$ & 0.925 & 0.179 & -47.5 & 0.0593 \\
\hline Nitrogen oxides & Air & 874 & $x$ & 788 & 37.3 & 37.4 & 5.74 & 5.42 \\
\hline Particulates, < 2.5 um & Air & 112 & $x$ & $x$ & 24.9 & 65.4 & 19.5 & 2.26 \\
\hline $\begin{array}{l}\text { Particulates, }>2.5 \text { um, and < } \\
\text { 10um }\end{array}$ & Air & 72.2 & $x$ & 21.4 & 18.3 & 30.5 & -2.74 & 4.76 \\
\hline Sulfur dioxide & Air & 36.9 & $x$ & 20.1 & 16.3 & 9.61 & -9.92 & 0.853 \\
\hline Arsenic, ion & Water & 27.8 & $x$ & $x$ & 14.2 & 11.4 & 2.35 & -0.138 \\
\hline Cadmium, ion & Water & 22.1 & $x$ & $x$ & 2.21 & 13.9 & 8.45 & -2.42 \\
\hline Zinc & Soil & 99.7 & $x$ & $x$ & 0.4 & 75.9 & 23.3 & 0.0465 \\
\hline
\end{tabular}


Larger technical installations in comparison to smaller ones are assumed by the broad public to cause more negative ecological effects. Therefore, the assessment of a $2.0 \mathrm{MW}_{\mathrm{el}}$ biogas plant is done. This plant is $100 \%$ larger than the standard biogas plant in this study. The input substrate mixture, the CHP emissions, the waste scenario, and the biogas plant installations are kept the same as in the standard scenario. The transport efforts and the consumed electricity are adapted as descried in chapter 2.7.5.

These adaptations cause total ecological effects of $10,000 \mathrm{EI}$ ' $99 \mathrm{H}$ points. These are $1.5 \%$ more effects than in the standard scenario. This difference is related to higher transport efforts causing 656 points in the $2.0 \mathrm{MW}_{\text {el }}$ scenario, in comparison to 463 points in the standard scenario. The $2.0 \mathrm{MW}_{\mathrm{el}}$ scenario also causes savings in the electricity consumption of 392 points in the $2.0 \mathrm{MW}_{\text {el }}$ scenario, related to 436 points in the standard scenario.

These minor differences show that there is hardly any difference in the total ecological effects of $1.0 \mathrm{MW}_{\mathrm{el}}$ and $2.0 \mathrm{MW}_{\mathrm{el}}$ biogas plants. In addition, the increased amount of transport efforts, due to the augmented average transport distance, does not cause noticeably influence the overall ecological effect.

In the next assessment, the effects from the biogas slurry treatment scenario on the overall effects will be studied. The biogas slurry treatment leads to a reduction in transport efforts after the biogas production process. The emissions after application of the slurry are also reduced, so fewer emissions to the air are released and therefore fewer nutrients are lost.

From this scenario, just negligible changes to the overall effects are caused. The total ecological effects from this scenario cause $9,560 \mathrm{El}$ ' $99 \mathrm{H}$ points. This is a reduction of $2.9 \%$, when compared to the total ecological effects of the standard scenario. These reductions are related to lower transport efforts causing 326 points (3.4\%) and the waste scenario causing 431 points $(-4.5 \%)$. All other modules are the same as in the standard scenario.

In a scenario where energy crops are used, the biogas slurry treatment, when compared to the overall effects, does not create any significant ecological conservation. Related to a waste input scenario, this reduction potential could have an important influence on the overall results.

In addition, the application of biogas slurry below gap standard should be regarded. When considering the ecological effects from small agricultural biogas plants, this slurry application method and the consequent ammonia emissions caused most of the ecological effects in the LCA study [EDELMANN ET AL.2001]. In this scenario, the slurry application with manure spreader and no additional incorporation of the applied manure is calculated.

This scenario leads to total ecological effects of $12,000 \mathrm{EI} ' 99 \mathrm{H}$ points. These are $21.8 \%$ $(2,150$ points $)$ more effects than in the standard scenario. The ecological effects of all modules, not including the application of the biogas slurry (waste scenario), are the same as in the standard scenario. Therefore this changed result is completely related to this module.

The module waste scenario has a share of $15.7 \%$ on the overall effect. In the standard scenario it has a share of $-2.8 \%$. This explains the differences between the total ecological ef- 
fects of the standard scenario and the scenario considering biogas slurry application below gap standard.

Land use has a share of $41.7 \%$ of the total ecological effects of this scenario. Ammonia emissions are the second most important substance in this scenario with a share of $18.7 \%$. The consumption of fossil oil contributes to $11.7 \%$, while nitrogen oxide emissions cause $10.8 \%$ of all ecological effects. Cadmium emissions to the soil cause $8.5 \%$ of all ecological effects in this scenario.

These results correspond to the results of [EDELMANN ET AL.2001]. If no effects from the energy crop production and transport effects were to be considered, comparable results per module would be given. In Figure 3.20 a comparison of all considered scenarios per impact category is given. This comparison is based on normalised data. 
Table 3.21: Weighted ecol. effects of the application below gap scenario, electricity generation from biogas produced in industrial scale biogas plants

\begin{tabular}{|c|c|c|c|c|c|c|c|c|}
\hline Substance & Compartment & Total & $\begin{array}{l}\text { Energy } \\
\text { crops }\end{array}$ & $\begin{array}{c}\text { CHP e- } \\
\text { missions }\end{array}$ & Electricity & Transport & $\begin{array}{c}\text { Waste } \\
\text { scenario }\end{array}$ & $\begin{array}{l}\text { Biogas plant } \\
\text { installations }\end{array}$ \\
\hline Total of all compartments & & 12000 & 8040 & 1090 & 436 & 463 & 1890 & 98.4 \\
\hline Remaining substances & & 919 & 609 & 23 & 88.8 & 97.2 & 51.4 & 49.9 \\
\hline Transformation, to arable, non-irrigated & Raw & 16200 & 16200 & $\mathrm{x}$ & 0.61 & 10.3 & 3.57 & 0.21 \\
\hline Occupation, arable, non-irrigated & Raw & 5010 & 5010 & $\mathrm{x}$ & 0.0111 & 0.186 & 0.0646 & 0.00379 \\
\hline Ammonia & Air & 2250 & 692 & $x$ & 0.868 & 0.276 & 1560 & 0.0251 \\
\hline Oil, crude, in ground & Raw & 1410 & 1070 & $\mathrm{x}$ & 38.8 & 119 & 162 & 19.5 \\
\hline Nitrogen oxides & Air & 1300 & 377 & 788 & 37.3 & 33.5 & 56.7 & 5.42 \\
\hline Cadmium & Soil & 1020 & 1010 & $\mathrm{x}$ & 0.138 & 4.62 & 1.43 & 0.00753 \\
\hline Gas, natural, in ground & Raw & 579 & 419 & $x$ & 137 & 36.6 & -29 & 15.4 \\
\hline Particulates, < 2.5 um & Air & 420 & 286 & $x$ & 24.9 & 58.6 & 48.3 & 2.26 \\
\hline Occupation, pasture and meadow, intensive & Raw & 397 & 397 & $\mathrm{x}$ & $5.35 \mathrm{E}-13$ & $\mathrm{x}$ & $1.94 \mathrm{E}-15$ & 4.07E-16 \\
\hline Chromium & Soil & 258 & 258 & $\mathrm{x}$ & 0.0164 & 0.00793 & -0.0227 & 0.00217 \\
\hline Carbon dioxide, biogenic & Air & 257 & 1.53 & 253 & 0.719 & 0.655 & 0.196 & 0.1 \\
\hline Particulates, $>2.5 \mathrm{um}$, and $<10 \mathrm{um}$ & Air & 195 & 116 & 21.4 & 18.3 & 27.3 & 7.62 & 4.76 \\
\hline Carbon dioxide, fossil & Air & 185 & 84.1 & $\mathrm{x}$ & 75.2 & 15.3 & 8.82 & 1.53 \\
\hline Arsenic, ion & Water & 126 & 97.5 & $\mathrm{x}$ & 14.2 & 10.2 & 4.27 & -0.138 \\
\hline Zinc & Soil & -519 & -609 & $\mathrm{x}$ & 0.4 & 68 & 21.2 & 0.0465 \\
\hline Transformation, from pasture and meadow & Raw & -649 & -640 & $\mathrm{x}$ & -0.149 & -6.9 & -2.11 & -0.0623 \\
\hline $\begin{array}{l}\text { Transformation, from pasture and meadow, inten- } \\
\text { sive }\end{array}$ & Raw & -942 & -942 & $\mathbf{x}$ & -0.000486 & -0.00818 & -0.00285 & -0.000167 \\
\hline Carbon dioxide, in air & Raw & -1840 & -1840 & $\mathrm{x}$ & -0.87 & -0.874 & -0.271 & -0.341 \\
\hline Transformation, from arable, non-irrigated & Raw & -14600 & -14500 & $\mathrm{x}$ & -0.61 & -10.3 & -3.57 & -0.21 \\
\hline
\end{tabular}




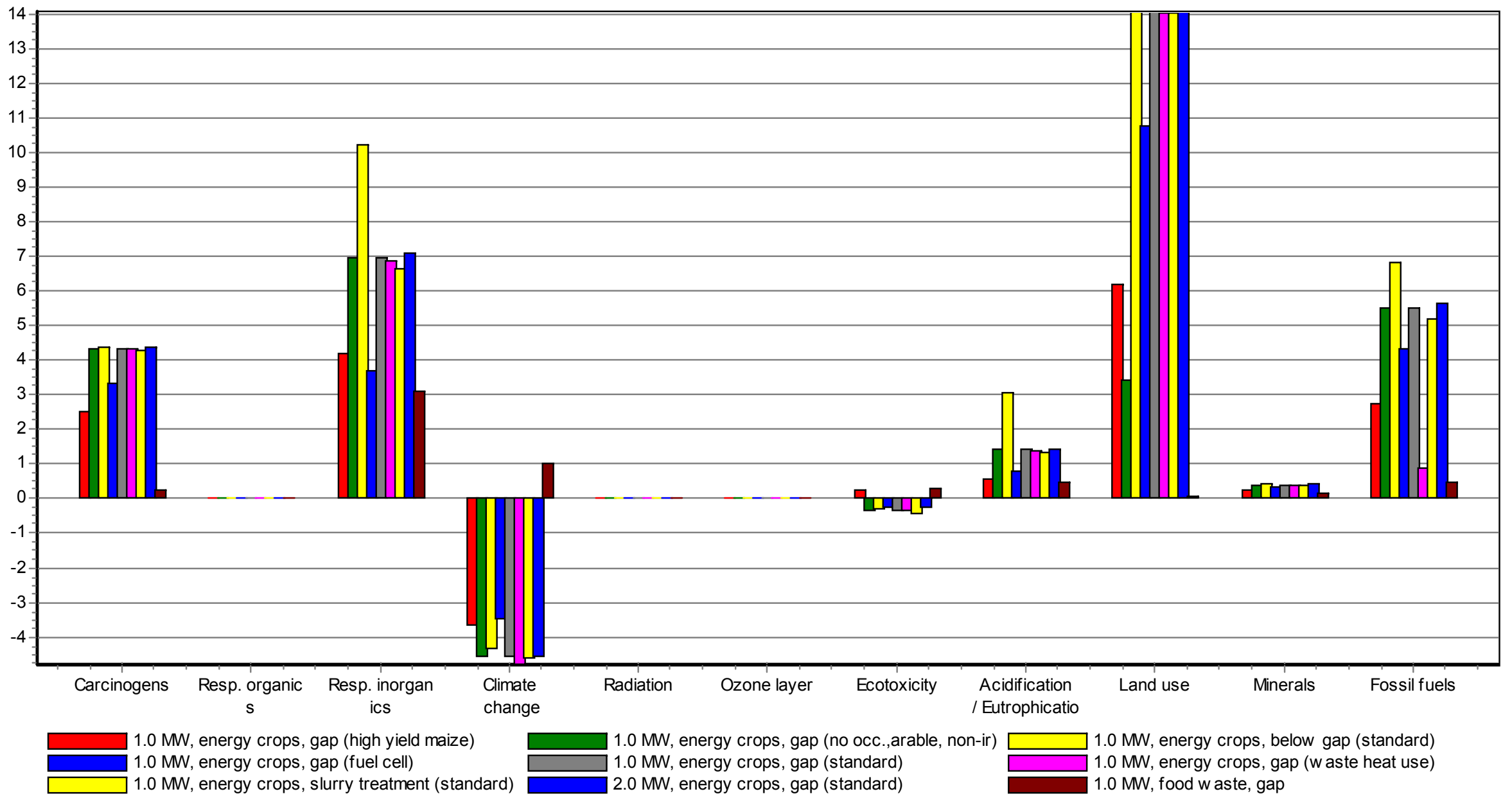

Figure 3.20: Comparison of all scenarios (normalised data) 


\subsection{Cumulative energy demand}

The cumulative energy demand (CED) provides information regarding the energy input needed per functional unit. According to [FRITSCHE ET AL.1999] five sources, two of which are non-renewable and three renewable, are distinguished. All results, tables, and figures given in this chapter are taken from the CED analysis done using the CED V1.1 database software included in SimaPro (cf. chapter 2.7.1).

As conveyed in the previous chapter, hardly any changes in the ecological effects are made from the $2.0 \mathrm{MW}_{\mathrm{el}}$ biogas plant scenario in comparison to the $1.0 \mathrm{MW}_{\mathrm{el}}$ scenario. Moreover, no changes related to the CED are expected from this scenario. Therefore this scenario will not be taken into account in this chapter.

A reference unit is used to compare the results of this assessment. This reference unit is the production of $1.0 \mathrm{TJ}$ electric energy at a medium voltage, fed to the grid and produced in Germany. The data of this reference unit are taken from the data set, Electricity, medium voltage, production DE, at grid/DE U [ECOINVENT2001].

The data of this reference unit are given in Table 3.22. It can be seen that a total of $3,375,600 \mathrm{MJ}$ is needed to produce 1.0 TJ of electricity. The energy conversion process inputs have a share of $335 \%$ of the resulting energy. The reference unit has therefore a total conversion efficiency of $29.9 \%$.

Table 3.22: CED of $1.0 \mathrm{TJ}$ medium voltage electricity

\begin{tabular}{|l|l|r|}
\hline \multicolumn{1}{|c|}{ Impact category } & \multicolumn{1}{c|}{ Unit } & \multicolumn{1}{|c|}{$\begin{array}{c}\text { Electricity, medium voltage, } \\
\text { production DE, at grid/DE U }\end{array}$} \\
\hline Non renewable, fossil & MJ-Eq & $2,190,000$ \\
\hline Non-renewable, nuclear & MJ-Eq & $1,030,000$ \\
\hline Renewable, biomass & MJ-Eq & 23,500 \\
\hline Renewable, wind, solar, geothe & MJ-Eq & 72,000 \\
\hline Renewable, water & MJ-Eq & 60,100 \\
\hline Total & MJ-Eq & $3,375,600$ \\
\hline Total - biomass & MJ-Eq & $3,352,100$ \\
\hline Share & $\%$ & $335 \%$ \\
\hline
\end{tabular}

The standard scenario is explained primarily and will be used as a reference for the proceeding scenarios. In Table 3.23 the composition and the sum of the CED is given for the standard scenario. A sum of $5.76 \mathrm{TJ}$ is needed to produce $1.0 \mathrm{TJ}$ of electricity from biogas in industrial scale biogas plants. The total conversion efficiency of this scenario is $17.4 \%$.

From this total energy needed, a share of $5.03 \mathrm{TJ}$ is contained in the energy crops. When calculating the energy demand, this share will not be taken into account, as this energy is a result of energy accumulated from crops. The only resource required is the sun. Thus, 0.73 TJ of energy from renewable and non-renewable energy sources is required for the production of $1.0 \mathrm{TJ}$ of electricity from biogas. The conversion efficiency is $137.0 \%$ in this scenario. 
Table 3.23: CED of 1.0 TJ electricity, standard scenario

\begin{tabular}{|l|l|r|r|r|r|r|r|}
\hline \multicolumn{1}{|c|}{ Source } & Unit & \multicolumn{1}{c|}{ Total } & $\begin{array}{c}\text { Energy } \\
\text { crops }\end{array}$ & Electricity & Transport & $\begin{array}{c}\text { Waste } \\
\text { scenario }\end{array}$ & $\begin{array}{c}\text { Plant } \\
\text { installati- } \\
\text { ons }\end{array}$ \\
\hline Non renewable, fossil & MJ-Eq & 553,000 & 334,000 & 219,000 & 39,500 & $-58,600$ & 18,400 \\
\hline Non renewable, nuclear & MJ-Eq & 150,000 & 38,100 & 103,000 & 8,290 & $-2,570$ & 3,240 \\
\hline Renewable, biomass & MJ-Eq & $5,030,000$ & $5,020,000$ & 2,350 & 2,400 & 484 & 952 \\
\hline $\begin{array}{l}\text { Renewable, wind, solar, } \\
\text { geothermie }\end{array}$ & MJ-Eq & 7,750 & 555 & 7,200 & 84 & -109 & 19 \\
\hline Renewable, water & MJ-Eq & 22,200 & 11,900 & 6,010 & 3,840 & -88 & 549 \\
\hline Total & MJ-Eq & $5,762,950$ & $5,404,555$ & 337,560 & 54,114 & $-60,883$ & 23,160 \\
\hline Total - biomass & MJ-Eq & 732,950 & 384,555 & 335,210 & 51,714 & $-61,367$ & 22,208 \\
\hline Share & $\%$ & $73 \%$ & $38 \%$ & $34 \%$ & $5 \%$ & $-6 \%$ & $2 \%$ \\
\hline
\end{tabular}

The scenario, which considers the utilisation of waste heat, takes into account the substitution of natural gas by waste heat from the biogas fed CHP plant. In Table 3.24 the composition and the sum of the CED is given for the utilisation of the waste heat scenario. A sum of $5.49 \mathrm{TJ}$ is needed to produce 1.0 TJ of electricity from biogas in industrial scale biogas plants. The total conversion efficiency of this scenario is $18.2 \%$.

From this total energy needed, a share of $5.03 \mathrm{TJ}$ is contained in the energy crops. This share will not be taken into account in the energy demand calculation. Therefore, $0.46 \mathrm{TJ}$ of energy from renewable and non-renewable energy sources is need for the production of 1.0 TJ of electricity from biogas; the conversion efficiency is $217.4 \%$ in this scenario.

Table 3.24: CED of 1.0 TJ electricity, utilisation of waste heat scenario

\begin{tabular}{|l|l|r|r|r|r|r|r|r|}
\hline \multicolumn{1}{|c|}{ Source } & Unit & Total & \multicolumn{1}{c|}{$\begin{array}{c}\text { Energy } \\
\text { crops }\end{array}$} & $\begin{array}{c}\text { Electrici- } \\
\text { ty }\end{array}$ & $\begin{array}{c}\text { Trans- } \\
\text { port }\end{array}$ & $\begin{array}{c}\text { Thermal } \\
\text { heat } \\
\text { grid }\end{array}$ & $\begin{array}{c}\text { Waste } \\
\text { scenario }\end{array}$ & $\begin{array}{c}\text { Plant } \\
\text { installa- } \\
\text { tions }\end{array}$ \\
\hline Non renewable, fossil & MJ-Eq & 293,000 & 334,000 & 219,000 & 39,500 & $-260,000$ & $-58,600$ & 18,400 \\
\hline Non-renewable, nuclear & MJ-Eq & 140,000 & 38,100 & 103,000 & 8,290 & $-9,460$ & $-2,570$ & 3,240 \\
\hline Renewable, biomass & MJ-Eq & $5,030,000$ & $5,020,000$ & 2,350 & 2,400 & $-4.4 \mathrm{E}-08$ & 484 & 952 \\
\hline $\begin{array}{l}\text { Renewable, wind, solar, } \\
\text { geothe }\end{array}$ & MJ-Eq & 7,750 & 555 & 7,200 & 84.3 & $-5.6 \mathrm{E}-09$ & -109 & 18.5 \\
\hline Renewable, water & MJ-Eq & 18,100 & 11,900 & 6,010 & 3,840 & $-4,110$ & -87.8 & 549 \\
\hline Total & MJ-Eq & $5,488,850$ & $5,404,555$ & 337,560 & $54,114.3$ & $-273,570$ & $-60,882.8$ & $23,159.5$ \\
\hline Total - biomass & MJ-Eq & 458,850 & 384,555 & 335,210 & $51,764.3$ & $-275,970$ & $-60,882.8$ & $22,207.5$ \\
\hline Share & $\%$ & $46 \%$ & $38 \%$ & $34 \%$ & $5 \%$ & $-28 \%$ & $-6 \%$ & $2 \%$ \\
\hline
\end{tabular}

The fuel cell scenario considers a technology change in the energy conversion method, which when compared to the standard scenario, leads to a higher energy conversion rate. In Table 3.25 the composition and the sum of the CED is given for the fuel cell scenario. A sum of 4.46 TJ is needed to produce 1.0 TJ of electricity from biogas in industrial scale biogas plants. The total conversion efficiency of this scenario is $22.4 \%$.

From this total energy needed, a share of $3.85 \mathrm{TJ}$ is contained in the energy crops. This share will not be taken into account for the energy demand calculation Thus, 0.61 TJ of energy from renewable and non-renewable energy sources is needed for the production of 1.0 TJ of electricity from biogas, the conversion efficiency is $164.3 \%$ in this scenario. 
Table 3.25: CED of 1.0 TJ electricity, fuel cell scenario

\begin{tabular}{|l|l|r|r|r|r|r|r|}
\hline \multicolumn{1}{|c|}{ Source } & \multicolumn{1}{|c|}{ Unit } & Total & $\begin{array}{c}\text { Energy } \\
\text { crops }\end{array}$ & Electricity & Transport & $\begin{array}{c}\text { Waste } \\
\text { scenario }\end{array}$ & $\begin{array}{c}\text { Plant } \\
\text { installa- } \\
\text { tions }\end{array}$ \\
\hline Non renewable, fossil & MJ-Eq & 455,000 & 256,000 & 197,000 & 30,300 & $-44,900$ & 16500 \\
\hline Non-renewable, nuclear & MJ-Eq & 129,000 & 29,200 & 92,300 & 6,350 & $-1,970$ & 2920 \\
\hline Renewable, biomass & MJ-Eq & $3,850,000$ & $3,850,000$ & 2,110 & 1,840 & 371 & 856 \\
\hline Renewable, wind, solar, geothe & MJ-Eq & 6,910 & 425 & 6,480 & 65 & -84 & 16.7 \\
\hline Renewable, water & MJ-Eq & 17,900 & 9,130 & 5,410 & 2,940 & -67 & 494 \\
\hline Total & MJ-Eq & $4,458,810$ & $4,144,755$ & 303,300 & 41,495 & $-46,650$ & 20,787 \\
\hline Total - biomass & MJ-Eq & 608,810 & 294,755 & 301,190 & 39,385 & $-48,490$ & 20,416 \\
\hline Share & $\%$ & $61 \%$ & $29 \%$ & $30 \%$ & $4 \%$ & $-5 \%$ & $2 \%$ \\
\hline
\end{tabular}

The high yield energy maize scenario considers dry matter yields from maize that are twice as great as in the standard scenario. This means that savings are gained in the energy inputs in the crop production module. In Table 3.26 the composition and the sum of the CED is given for the high yield energy maize scenario. A sum of $4.45 \mathrm{TJ}$ is needed to produce 1.0 TJ of electricity from biogas in industrial scale biogas plants. The total conversion efficiency of this scenario is $22.5 \%$.

From this total energy needed, a amount of $3.93 \mathrm{TJ}$ is contained in the energy crops. This share will not be taken into account in the energy demand calculation. Therefore, $0.52 \mathrm{TJ}$ of energy from renewable and non-renewable energy sources is needed for the production of 1.0 TJ of electricity from biogas, the conversion efficiency is $192.7 \%$ in this scenario.

Table 3.26: CED of $1.0 \mathrm{TJ}$ electricity, high yield energy maize scenario

\begin{tabular}{|l|l|r|r|r|r|r|r|}
\hline \multicolumn{1}{|c|}{ Impact category } & \multicolumn{1}{|c|}{ Unit } & Total & $\begin{array}{c}\text { Energy } \\
\text { crops }\end{array}$ & Electricity & Transport & $\begin{array}{c}\text { Waste } \\
\text { scenario }\end{array}$ & $\begin{array}{c}\text { Plant } \\
\text { installa- } \\
\text { tions }\end{array}$ \\
\hline Non renewable, fossil & MJ-Eq & 368,000 & 149,000 & 219,000 & 38,500 & $-57,300$ & 18,400 \\
\hline Non-renewable, nuclear & MJ-Eq & 128,000 & 16,400 & 103,000 & 8,080 & $-2,510$ & 3,240 \\
\hline Renewable, biomass & MJ-Eq & $3,930,000$ & $3,930,000$ & 2,350 & 2,340 & 473 & 952 \\
\hline Renewable, wind, solar, geothe & MJ-Eq & 7,460 & 263 & 7,200 & 82 & -107 & 18.5 \\
\hline Renewable, water & MJ-Eq & 15,500 & 5,250 & 6,010 & 3,740 & -86 & 549 \\
\hline Total & MJ-Eq & $4,448,960$ & $4,100,913$ & 337,560 & 52,742 & $-59,530$ & 23,160 \\
\hline Total - biomass & MJ-Eq & 518,960 & 170,913 & 335,210 & 50,392 & $-61,870$ & 22,687 \\
\hline Share & $\%$ & $52 \%$ & $17 \%$ & $34 \%$ & $5 \%$ & $-6 \%$ & $2 \%$ \\
\hline
\end{tabular}

The food waste scenario considers the substitution of the energy crops by wastes from the food industry. No energy inputs from the production of crops are included in this scenario. In Table 3.27 the composition and the sum of the CED is given for the food waste scenario. A sum of $0.35 \mathrm{TJ}$ is required to produce $1.0 \mathrm{TJ}$ of electricity from biogas in industrial scale biogas plants. The total conversion efficiency of this scenario is $283.7 \%$. 
Table 3.27: CED of 1.0 TJ electricity, food waste scenario

\begin{tabular}{|l|l|r|r|r|r|r|}
\hline \multicolumn{1}{|c|}{ Impact category } & \multicolumn{1}{c|}{ Unit } & \multicolumn{1}{c|}{ Total } & Electricity & Transport & $\begin{array}{c}\text { Waste } \\
\text { scenario }\end{array}$ & $\begin{array}{c}\text { Plant installa- } \\
\text { tions }\end{array}$ \\
\hline Non renewable, fossil & MJ-Eq & 216,000 & 219,000 & 44,200 & $-65,400$ & 18400 \\
\hline Non-renewable, nuclear & MJ-Eq & 112,000 & 103,000 & 9,260 & $-2,870$ & 3240 \\
\hline Renewable, biomass & MJ-Eq & 6,520 & 2,350 & 2,680 & 541 & 952 \\
\hline Renewable, wind, solar, geothe & MJ-Eq & 7,190 & 7,200 & 94 & -122 & 18.5 \\
\hline Renewable, water & MJ-Eq & 10,800 & 6,010 & 4,290 & -98 & 549 \\
\hline Total & MJ-Eq & 352,510 & 337,560 & 60,524 & $-67,949$ & 23,160 \\
\hline Total - biomass & MJ-Eq & 345,990 & 335,210 & 58,174 & $-70,629$ & 22,619 \\
\hline Share & $\%$ & $35 \%$ & $34 \%$ & $6 \%$ & $-7 \%$ & $2 \%$ \\
\hline
\end{tabular}

The biogas slurry treatment scenario considers the solid-liquid separation and the addition of sulphuric acid to the biogas slurry. Reductions in gaseous emissions, leading to a decline in nutrient losses after application of the slurry are gained. In Table 3.28 the composition and the sum of the CED is given for this scenario. A sum of $5.73 \mathrm{TJ}$ is required to produce $1.0 \mathrm{TJ}$ of electricity from biogas in industrial scale biogas plants. The total conversion efficiency of this scenario is $17.5 \%$.

From this total energy needed, a share of $5.03 \mathrm{TJ}$ is contained in the energy crops. This share will not be taken into account in the energy demand calculation. Thereby, 0.70 TJ of energy from renewable and non-renewable energy sources is needed for the production of 1.0 TJ of electricity from biogas. In this scenario, the conversion efficiency is $142.9 \%$.

Table 3.28: CED of 1.0 TJ electricity, biogas slurry treatment scenario

\begin{tabular}{|l|l|r|r|r|r|r|r|}
\hline \multicolumn{1}{|c|}{ Source } & Unit & Total & $\begin{array}{c}\text { Energy } \\
\text { crops }\end{array}$ & Electricity & Transport & $\begin{array}{c}\text { Waste } \\
\text { scenario }\end{array}$ & $\begin{array}{c}\text { Plant } \\
\text { installati- } \\
\text { ons }\end{array}$ \\
\hline Non renewable, fossil & MJ-Eq & 530,000 & 334,000 & 219,000 & 27,800 & $-69,000$ & 18,400 \\
\hline Non-renewable, nuclear & MJ-Eq & 146,000 & 38,100 & 103,000 & 5,830 & $-3,700$ & 3,240 \\
\hline Renewable, biomass & MJ-Eq & $5,030,000$ & $5,020,000$ & 2,350 & 1,690 & 217 & 952 \\
\hline Renewable, wind, solar, geothe & MJ-Eq & 7,710 & 555 & 7,200 & 59 & -123 & 18.5 \\
\hline Renewable, water & MJ-Eq & 20,700 & 11,900 & 6,010 & 2,700 & -449 & 549 \\
\hline Total & MJ-Eq & $5,734,410$ & $5,404,555$ & 337,560 & 38,079 & $-73,055$ & 23,160 \\
\hline Total - biomass & MJ-Eq & 704,410 & 384,555 & 335,210 & 35,729 & $-74,745$ & 22,943 \\
\hline Share & $\%$ & $70 \%$ & $38 \%$ & $34 \%$ & $4 \%$ & $-7 \%$ & $2 \%$ \\
\hline
\end{tabular}

This scenario takes into account the effects from the biogas slurry application with technology which does not meet the gap standard. An increase of gaseous emissions, leading to greater losses of nutrients after application of slurry, is taken into account. In Table 3.29 the composition and the sum of the CED is given for the biogas slurry below gap application scenario. A sum of $5.86 \mathrm{TJ}$ is needed to produce $1.0 \mathrm{TJ}$ of electricity from biogas in industrial scale biogas plants. The total conversion efficiency of this scenario is $17.1 \%$.

From this total energy needed, a share of $5.03 \mathrm{TJ}$ is contained in the energy crops. This share will not be taken into account in the energy demand calculation. Thus, $0.83 \mathrm{TJ}$ of energy from renewable and non-renewable energy sources is required for the production of 1.0 TJ of electricity from biogas. The conversion efficiency is $121.2 \%$ in this scenario. 
Table 3.29: CED of 1.0 TJ electricity, biogas slurry application below gap standard scenario

\begin{tabular}{|l|l|r|r|r|r|r|r|}
\hline \multicolumn{1}{|c|}{ Source } & Unit & Total & $\begin{array}{c}\text { Energy } \\
\text { crops }\end{array}$ & Electricity & Transport & $\begin{array}{c}\text { Waste } \\
\text { scenario }\end{array}$ & $\begin{array}{c}\text { Plant } \\
\text { installati- } \\
\text { ons }\end{array}$ \\
\hline Non renewable, fossil & MJ-Eq & 640,000 & 334,000 & 219,000 & 39,500 & 28,900 & 18,400 \\
\hline Non-renewable, nuclear & MJ-Eq & 154,000 & 38,100 & 103,000 & 8,290 & 1,770 & 3240 \\
\hline Renewable, biomass & MJ-Eq & $5,030,000$ & $5,020,000$ & 2,350 & 2,400 & 745 & 952 \\
\hline Renewable, wind, solar, geothe & MJ-Eq & 7,860 & 555 & 7,200 & 84 & -1 & 18.5 \\
\hline Renewable, water & MJ-Eq & 23,100 & 11,900 & 6,010 & 3,840 & 810 & 549 \\
\hline Total & MJ-Eq & $5,854,960$ & $5,404,555$ & 337,560 & 54,114 & 32,224 & 23,160 \\
\hline Total - biomass & MJ-Eq & 824,960 & 384,555 & 335,210 & 51,764 & 29,824 & 22,415 \\
\hline Share & $\%$ & $82 \%$ & $38 \%$ & $34 \%$ & $5 \%$ & $3 \%$ & $2 \%$ \\
\hline
\end{tabular}

In

Figure 3.21 a comparison of the CED (without the biomass share) of the considered scenarios is given. From this figure, the amount of energy input that is needed for the production of one functional unit $(1 . E+06)$ can be seen. The lowest energy input is required in the waste utilisation scenario (3.5.E+05). In addition, low energy inputs are needed in the waste heat utilisation scenario (4.6.E+05). Medium energy inputs of $50 \%-60 \%$ of the resulting functional unit are needed in the high yield maize scenario $(5.2 . E+05)$ and the fuel cell scenario (6.1.E+05). High-energy inputs are related to the slurry treatment scenario $(7.0 . \mathrm{E}+05)$, the standard scenario (7.3.E+05), and the application below gap scenario $(8.2 \mathrm{E}+05)$. 
All considered biogas scenarios need energy inputs that are lower in value than the resulting functional unit. This is due to the fact that the crops' energy content is not considered in this assessment. The chemical bound energy in the crops is a result of the photosynthesis process in the crops, which converts light into chemical bound energy. This energy cannot be taken into account during the assessment of the energy demand needed in producing one functional unit, as this energy does not consume non-renewable resources. In its entirety, electricity generation from biogas produced in industrial scale biogas plants is a technology that assists in conserving non-renewable energy sources. Depending on the scenario taken into account, 1.22TJ - 2.86 TJ per TJ energy input can be generated.

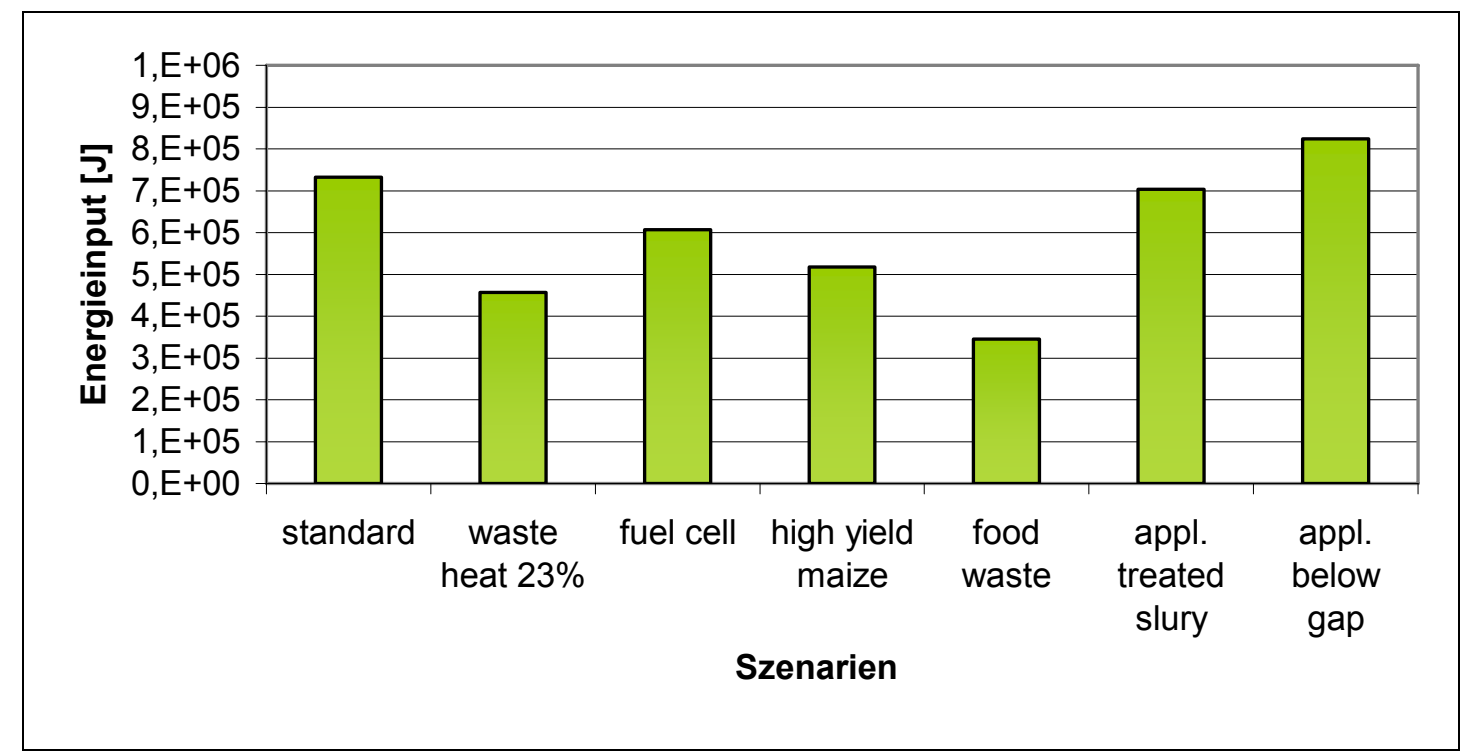

Figure 3.21: Comparison of the CED values of the different scenarios 


\section{Discussion}

At the beginning of this study, the question regarding the ecological effects from the biogas production was set. This question was answered by carrying out an analysis of the ecological effects caused by this process. In order to do this, a hypothetical biogas plant with an installed electric power of $1.0 \mathrm{MW}_{\mathrm{el}}$ and the related up- and downstream processes was developed. Several sensitivity analyses considering the biogas plant, the inputs and outputs of the plant and additional energy utilisation concepts were accomplished in order to locate the ecological hot spots of the biogas electricity generation.

The methodology of this assessment will be discussed in this chapter. Issues concerning the methodological standards of the LCA according to ISO 14040 will be regarded in detail [CEN1997]. The reliability of the data used in this assessment will be checked. There will be a discussion of the results and conclusions shall be drawn. Finally an outlook, including suggestions for further ecological development of the biogas conversion technology, will be given.

\subsection{Discussion of LCA method}

Various ecological assessment methods are presented in chapter 2.1. All of these methods mentioned are already in use to assess ecological effects in different fields of work. Data collection with an additional interpretation of these data is an integral part of all of these assessment methods. While the first step is based on natural science, the second step is a normative step, considering influences from social science. A clear division between these two steps is needed to secure the reliability of the collected data.

The here done ecological assessment is special as it takes into account two different production systems, an industrial and an agricultural one. Assessment approaches that cannot consider both systems such as KUL and REPRO are regarded as unpractical for this assessment. They are specialised in agricultural production system assessment and cannot be adapted to the industrial part of the object under investigation. These highly developed agricultural production systems assessment methods are only developed for this field of work. Other production systems are not compatible to the assessment methods of these two approaches.

The combination of agricultural and industrial production systems causes problems to the methodology. One of these issues is soil assessment within the land use impact category. Within the object under investigation, soil is both a safeguard subject and a production factor. Production systems and safeguard subjects are typically two different parts of LCA. This leads to the question regarding if damages to the soil should be considered. As a safeguard subject, damages to the soil have to be taken into account; otherwise they would not be calculated. By taking into account that $53 \%$ of the area in Germany is used for agricultural production systems and keeping in mind the high population density in Germany, it becomes understandable why farming cannot only be seen as a production system but also why it has 
an important role in rendering ecological services [DESTATIS2006a, GEIER2000]. From this standpoint, it seems that agricultural production systems can be blamed for ecological damages related to the production process and look upon soils as a safeguard subject in this LCA. The panel approach of [METTIER in GOEDKOOP\&SPRIENSMA2001] also stresses this assumption.

The common assessment of industrial and agricultural production systems also causes some methodological differences. Whilst environmental impacts are almost completely measurable as mass and energy flows or endpoint emissions in industrial production systems, in arable farming systems important emissions are diffuse and therefore cannot be calculated. Furthermore, emissions from farming systems are highly variable depending on specific effects on site [BRENTRUP2003]. This underlines the fact that the industrial part of this LCA uses a large variety of data, which are directly or indirectly based on measured data from specific plants, whilst the agricultural production system is based on standard or estimated data from literature in large parts of the LCl. It should be emphasised that the best available data for each part of the LCA were used in order to gain meaningful results.

It has already been tried in the past to include specialised methods for the assessment of agricultural production systems into LCA [GEIER2000, ARMAN2004]. A more appropriate development of these approaches would help improve the quality of LCA results in combined production systems, analysing agricultural and industrial systems in one study. A applicable way should consider that data collection is the most time consuming and costly part of a LCA in the field of agriculture and processes in this field are influenced by a large variety of factors [ZACHARIASSE1999]. These influences prevent comparisons between different LCAs due to different scopes. Therefore it is considered better, wherever possible, to take standard or calculated values for the assessment of ecological effects in agricultural production systems. This would improve the data reliability for these systems. This is in contrast to industrial production systems, where measured values from single unit processes have a higher reliability than standard or calculated values.

The LCA method was selected from the variety of existing ecological assessment methods. In comparison to other approaches, the LCA approach contains the most developed methodology, taking into account ecological effects from cradle-to-grave of the system under investigation. While the safeguard subjects, human health, ecosystem quality, and resources are included, social and economical aspects are not calculated. Thus meaning that only ecological aspects are included in this method. For this, LCA study results can be interpreted in further detail than in mixed systems e.g. balanced scorecard. The step-by-step approach with its clear documentation rules, consisting of goal and scope definition, data collection, and data assessment, leads to clear interpretation of used methods for collecting and assessing data. This is an advantage of the LCA as the Environmental Impact Assessment, does not include statistical methods and without these statistical methods no information of the influence of the data interpretation on the collected data can be given. This causes problems when the results of the assessment are reproduced. A further method, the risk analysis, suffers from the same problem. 
The simplicity of the LCA methodology allows data and the results of the study to be compared with further LCAs. The aggregation of different scientific fields of work within LCA results in a holistic view on the system under investigation. This collaboration allows different impacts and ecological concerns to be taken into account all together, but can also cause an insufficient inclusion of special cases in certain production systems (see below). The normalisation step done in the impact assessment phase is a unique tool to show the impact category influence on the calculated results related to the same impact category on a broader reference. In using this method, the importance of the impact category results can be explained more easily. Finally, LCA is a rather flexible method that does not require special borders or assessment systems. So, the method can be adapted to the system under investigation unlike strict assessment methods [cf. GEIER2000].

The goal and scope definition is adapted to one single study. Therefore it is not valid to compare results from LCA studies with different goals and scopes. From the goal definition in this study it can be seen, that this study was not carried out with the purpose of comparing electricity generation processes. The goal of this study, which was to give a summary of the environmental effects caused by the electricity generation from biogas in industrial scale biogas plants, has been accomplished. The ecological effects caused by biogas plants were analysed thoroughly.

The scope definition in this study is regarded as sufficient for this above purpose. All relevant impact categories and impacts were taken into account. The functional unit of this study reflects the purpose and the electricity generation, of the biogas production. If the purpose of the biogas production were to change in the future, e.g. feeding biogas to the natural gas grid, an adapted functional unit would have to be chosen. The chosen data quality requirements caused some difficulties, as the quality parameters of some of the existing data sets were not defined, even if it was clear, that this dataset fulfilled the quality requirements. In order to carry out further assessments the scope definition should be loosen.

All kinds of data categories were applicable within the chosen scope. Due to the database software used for the calculation, this broad scope did not present a technical problem. LCA studies, which do not use software calculation, should probably reduce the variety of data categories in order to maintain the data manageable.

The object under investigation is defined as an artificial biogas plant. In the standard scenario, this plant has an electrical output of $1.0 \mathrm{MW}$ and is fed with energy crops and manure. The plant consists of the biogas plant installations itself, agricultural energy crop production, application of the biogas slurry, and the thereby caused transport efforts. In the standard scenario energy crops and manure from agricultural production systems are considered the input to the biogas process. One module, the agricultural crop production, in this LCA concerns the production of these inputs and their related upstream processes. As it is the goal of this assessment to give universally valid answers concerning the ecology of biogas, general data from literature have been used in this module. Specific data from single plants would have probably altered the results in this module, if related to a broader scope. As can be seen from the results, the ecological effects from the agricultural crop production greatly influence the overall results. For this reason, it is essential that these data are analysed in de- 
tail. The assessment of the energy crops shows, that most of the ecological effects derive from the weighting of the land use in this module. Additionally, the consumption of fossil fuels and the emission of heavy metals into the soil have a relevant impact on the results. The influence that fuel consumption and heavy metals have on the ecological effects of the crop production is also stated in other publications [ARMAN2004, GEIER2000]. The land use impact category used for the assessment of land occupation in agricultural production systems is relatively new. Due to the used weighting method (Eco indicator ' $99 \mathrm{H}$ ) this impact category has a strong influence on the overall results of the crop production module. Below, in the discussion of the land use impact category, the influence of the land use category will be discussed in detail.

Manure, as a basic material, is used as input to the biogas production. Manure accumulates as waste of livestock husbandry. Therefore, it can be calculated without any ecological burden. If the manure were not used in the biogas process, it would be used as organic fertiliser. The nutrient content of the manure and the emissions from the manure are taken into account in the $\mathrm{LCl}$, according to this alternative utilisation. Given that no data considering the heavy metal content of manure were available for this study, it was not calculated. The consideration of heavy metals that are not dispersed in to the soil but instead brought into the biogas process would lead to an ecological savings of this input material. In due course, the heavy metals from manure are released back into the fields, when the biogas slurry is applied. Therefore, by not calculating heavy metals from manure as an input to the biogas process the overall result of the system under analysis does not alter. Only the share of the single modules is changed. In further LCA studies on the biogas production, this defect should be corrected in order to assure even more precise results of the single modules.

One sensitivity analysis in the field of input materials takes into account the utilisation of waste from the food processing industry. Waste is calculated without any ecological burden, as all ecological effects related to its production are taken into account from the main product from which this waste derives. This can be done, on the condition that there is no other way of using these waste materials. If any other alternative exists for the utilisation of this waste, the ecological burden of the alternative process has to be calculated, if the waste is used as input to the biogas production. Pomace, pulp, slope, and expired food can alternatively be used as input to the animal foodstuff producing industry. If so, the ecological burden of process substitute should be calculated when using these waste materials. This is not done in this study, as at present, there is a surplus of waste that can be used for foodstuff production. The market value of these waste materials is below their nutritional value. In the case of a LCA study for a single biogas plant, the market situation for these materials has to be checked. Depending on regional facts, it is possible that these alternative effects have to be taken into account. For example, potato pulp can partially substitute grass silage as foodstuff for cows. If this is done in a specific region, the potato pulp used in the biogas plant has to be charged with the additional grass silage, which has to be produced to substitute the pulp that cannot be used as foodstuff [HARTMANN2006].

Data concerning the transport efforts for the input and output mass flows are gathered from an existing biogas plant in Lüchow (Lower-Saxony, Germany), which is analysed in a de- 
tailed LCA study [HARTMANN2006]. The average transport distance from this study reflects precise regional facts. Other regions can have different land types, resulting in different arable production systems and therefore different transport distances. For the purpose of this study it was assumed that the data gained from the existing LCA study (mentioned above), used in the calculation of the average transport distance, reflects the biogas related transports average facts. Due to this module's comparably minor influence on the overall ecological effects of the system under analysis, this assumption was seen as suitable. Most of the ecological effects of this module are caused by fossil fuel consumption and gaseous emissions. It is advised that further LCA studies should therefore check the influence of different fuels, e.g. bio diesel or vegetable oil, on the overall effects of the agricultural production system. These fuels from renewable sources are assumed to reduce the influence from this module on the overall effects.

The module biogas plant consists of data derived from different sources. Data regarding the fermenter, pumps, stirrers, hygienisation, the electricity consumption, the biogas treatment facility, and the management and technology building are gathered from an existing plant. Data concerning the CHP plant are taken from different CHP plant producers. The CHP plant emissions are based on measured data as well as data from literature. Installation data of the MCFC are based on literature data; the emissions from the MCFC are taken from literature data. All of these data have been adapted to the object under analysis. Given that the installations from the biogas plant have a small impact on the overall results and that most biogas plants are produced with similar components, means that this approach is deemed suitable. No significant changes of the effects from this module are assumed, even if the fermenters were produced from concrete or if horizontal fermenters were used. The consumption of electricity by the object under analysis, compared to the manufacturer's data, is chosen to be high. This value was chosen from operation data from existing plants. The high dry matter content of the energy crops could cause this higher demand. Finally, due to the wide influence of the CHP emissions, an increased amount of data from this unit process should be collected to improve reliability.

At the beginning of this assessment, the module slurry application was viewed as the most important influence from literature [EDELMANN ET AL.2001]. Data collection for this module was based on literature and own field trials. No heavy metal emissions from the biogas slurry to the soil were calculated as no data about the heavy metal content of the biogas slurry was available The mass flow conveys that energy crops take in heavy metals from the soil. This leads to the assumption that all heavy metals from the energy crops are returned to the soil via the biogas slurry. This would lead to an increased ecological conservation from this scenario. The application of biogas slurry delivers nutrients to the soil, which also cause nutrient leaching and gaseous emissions. As no data regarding the emissions from biogas slurry made up from energy crops existed at the beginning of this study, field trials were therefore performed. The results of this trial are widely influenced by the soil, temperature, precipitation, and incorporation. The emissions of $\mathrm{N}_{2} \mathrm{O}$ and $\mathrm{CH}_{4}$ are of the same magnitude as extrapolations from literature data. The $\mathrm{NH}_{3}$ emissions are much lower. In the field trials the biogas slurry was applied with a trial hose and incorporated immediately after application. 
These two influences, together with low temperature and soil structure could reduce the emissions to less than $5.0 \%$ of the theoretical possible emissions based on the $\mathrm{NH}_{4}$ content of the biogas slurry. Due to the importance of the emissions from applied slurry, these trials should be repeated to achieve more reliable data for further assessments.

The definition of data collection assures that collected data are precise, complete and keep to the methodology as closely as possible. Therefore quality parameters and indicators were defined for this study. All requirements shown in Table 2.1 are met in this study. No problems were found in these specifications. Where specific data, e.g. from a single plant or trials, were used, these data were checked for representation in literature or extrapolations. All used data in this study can therefore be seen as representative, within the scope definitions. The goal definition of this study was not changed. In the course of the study, it proved to be suitable in answering the research question. In the case of the majority of the modules, the scope of the study was not changed. For the energy crop production the land use impact category was checked several times and its scope was defined more precisely than it was at the start.

The required flow charts and the description of modules were completed for the preparation of data collection The module description was changed for energy crop production. In the definition phase, the land use was not considered. This impact category was implemented after the weighting step of the first iteration of the $\mathrm{LCl}$ data. Due to the application of database software, no special efforts for the generation of a list of units were needed. This software can process various units, so that no problems were caused. Allocation is a complicated step within LCA and therefore should be avoided wherever possible. In this assessment, one allocation process exists. Nutrients needed for the energy crop production are adopted by these energy crops, brought into the fermenter with the energy crops, and applied to the field in the biogas slurry, which is a result from the fermenting process. Substituted mineral fertilisers were taken into account to quantify the effect of nitrogen and phosphate nutrients from biogas slurry in this allocation. The ecological effects from different artificial fertilisers were assumed to be of the same magnitude. For this reason, no checks were carried out with different kinds of fertilisers in order to control the influence of different substituted fertilisers.

Life-cycle-impact-assessment ( $\mathrm{LCIA}$ ) summarises the categorisation, characterisation, normalisation, and weighting of the collected data. All steps of the LCIA were done according to the Eco indicator ' $99 \mathrm{H}$ method. No methodological issues are presented with reference to categorisation, characterisation, and normalisation, as these three steps are based on natural science methods. In order to improve the understanding of the results an additional weighting step, representing the view of the European society, is used. In contrast to the first three steps of the LCIA, weighting steps have a normative character as they are based on social science methods and not on natural science ones. Therefore these weighted results are seen as going against natural science. If a different assessment method based on different weighting of the safeguard subjects were to be used, it would lead to different results. On this account, the data of this study are given as normalised values as well as weighted val- 
ues for most of the results. The influence of the weighting can be determined from an overview of the differences between weighted and normalised results.

The chosen impact categories are predefined in the used Eco indicator ' $99 \mathrm{H}$ method. The used impact categories proved to be suitable in representing the ecological effects of the system under analysis. The normalised LCl data show that the impact categories respiratory organics, radiation, and ozone layer have hardly any share on the overall results. Therefore, in further assessments their inclusion does not seem necessary.

The indicators of most of the impact categories are easy to understand and applicable. No problems occurred regarding these indicators. The land use category indicator is more complicated than the other indicators. The hemeroby concept was chosen to assess the use of land. In this method, the use of land is related to the remaining natural state of the used land. The hemeroby level of an area is selected from a list of land use types. This kind of assessment causes various problems; one being that it is impossible to validate the category land use from a scientific point of view [HEIJUNGS ET AL.1997]. The same source also states that the characterisation methods for land use are much less objective and scientific than those for most output-related impact categories.

The hemeroby concept was not designed as a method to assess the agricultural use of land; it is a more general tool to assess different kinds of land and for this reason this method was chosen. The object under analysis has to consider an agricultural and industrial production system. An assessment method, which is more adapted to the agricultural use of land, would not meet the requirements of industrial production systems. The chosen land use concept with the hemeroby assessment method is therefore seen as a compromise. As will be seen later, this compromise has to be reconsidered.

In this method a top-down designed, problem oriented method (Eco indicator ' $99 \mathrm{H}$ ) was used for the assessment of the $\mathrm{LCl}$ data. This problem-orientated method first considers the safeguard subjects; afterwards the impact categories are chosen. This makes sure that all safeguard subjects are considered in an adapted way. Alternatively, problem oriented methods could be used. These problem oriented methods result in impact category values, which are complicated to interpret. Results that are formulated as safeguard subjects are easier to understand than impact category results. This top-down approach requires a weighting step to relate the impact category results to the safeguard subject. Weighting of impact category results is seen as a controversial step as discussed above.

The normalisation step used in this study depends on the used weighting system and is based on the Europe normalisation values [BLONK ET AL.1997]. This standard method uses the West European territory, concerning all environmental interventions in one year related to human activities on West European territory, as a reference unit for the calculated impact category data. No problems or critical issues arise from the use of this methodology.

The subsequent weighting step is done in accordance with the Eco indicator ' $99 \mathrm{H}$ approach. Two methodological issues occur with the weighting step. The first issue being the general discussion about the utilisation of weighting in LCA studies, as previously mentioned. There is no general method that is accepted on a wide level, for consistently and accurately associ- 
ating inventory data with specific potential environmental impacts. Therefore the ISO 14040 standard mentions that clarity is critical to impact assessment in order to ensure that assumptions are clearly described and reported [CEN1997]. The weighting step was applied as explained in chapter 2.7.4; more details about this method are given in [GOEDKOOP\&SPRIENSMA2001, MOH2000]. The detailed description of this method clears out this first issue, because the influence of the weighting step on the data from the normalisation step can clearly be seen from the explanations of the method. Also all data from the normalisation step are given for the overall results together with the weighted data.

The second weighting step issue concerns the suitability of the Eco indicator ' $99 \mathrm{H}$ method. This method was created for the development of environmentally sound products and the ecological improvement of these products [MOH2000]. As discussed earlier, a weighting method that is suitable for the assessment of agricultural and industrial production systems is needed in this study. As these production systems stress the importance of different impact categories and safeguard subjects, the weighting method used must cover all of these aforementioned categories and subjects. This particular method was previously used in the assessment of the ecological effects from agricultural biogas plants in another LCA study [EDELMANN ET AL.2001]. In this study, the method was deemed suitable for assessing the ecological effects from biogas production. But this study did not consider the production of energy crops; only manure and waste were used. Therefore the wide influence of the impact category land use, found in this study, was not stated in the earlier study. The Eco Indicator ' $99 \mathrm{H}$ method highlights the influence of the impact category land use, which has a $30.8 \%$ relative share of all impact categories when weighting all results. This is why the sensitivity analysis considering the influence of the weighting method and the impact category land use was carried out. From the results of this sensitivity analysis the influence of the weighted land use impact category on the overall effects can be assumed. Whether this influence should be considered when interpreting the overall data of the electricity generation from biogas in industrial scale biogas plants depends on the reader of this study.

From an agricultural point of view, the aggregation assessment method Eco indicator '99 has to be criticised. Special agricultural related impact categories are not dealt with in a detailed manner. This is due to the fact that there are no existing LCA weighting methods specifically designed for agricultural production systems. Most of them are combined within the safeguard subject ecosystem quality and therein added up to common indicator results. Special agricultural impact categories e.g. landscape, soil quality, humus content, soil density, species and biotope diversity are not separately calculated but taken into account by different land-use intensity indicators. As mentioned in [GEIER2000] qualitative indicators e.g. landscape, need different assessment methods instead of the quantitative assessment methods of industrial material and energy flows. Regional impacts on drinking water quality, due to the influence of eutrophication, should be considered more detailed with special regard to the area of arable land if possible. Further investigation should be done in order to assess the results from these categories in more detail.

On the whole, the weighting step of the LCA study remains a controversial step. Further LCA studies that consider the ecological effects from biogas production should take into account 
different weighting methods so that the influence of the weighting effects of single methods is verified. It is noted, that weighting is a useful tool in making the results of the normalisation step more comprehensible. A further important aspect of this study is that even if doubts in the weighting step methodology are debated among experts, they should be ignored for the purpose of this study. To avoid misinterpretation, the weighted and the normalised results of a study should be presented together in LCA studies.

\subsection{Discussion of results}

In the standard scenario $87.6 \%$ of all ecological effects are caused by the agricultural energy crop production. In the scenario considering no direct use of land $67.7 \%$ of all ecological effects are caused by the energy crop mixture used as input to the biogas plant. From this the importance of this module on the overall effects can be observed.

The normalised and the weighted results in the comparison of energy crops show that most ecological effects per functional unit are caused by the production of grass and rye silage. Fewer ecological effects are caused by the production of silage from forage beets, maize silage and the assumed production of maize silage with a yield of $30.0 \mathrm{Mg}$ dry matter per ha. A conclusion can be drawn in which production systems with a higher yield per area level cause less ecological effects compared to energy crops yielding lower dry matter contents per unit area. The smallest number of weighted ecological effects per functional unit were caused by forage beets $(3,120 \mathrm{El} \cdot 99 \mathrm{H}$ points), most were caused by rye silage $(27,500 \mathrm{EI} ' 99 \mathrm{H})$.

Taken from the weighted results, it is evident that most effects per energy crop are caused by the use of land, which is in this case land occupation for the production of crops. The influence of the impact category land use is discussed above in detail. The weighted results of this impact category have a strong influence on the overall results. That is why crop production systems with high yield per area levels cause less ecological effects per functional unit than low yield production systems produce. This same reason is the cause for the higher consumption of fossil resources, i.e. grass and rye, in comparison to maize or beets. The energy consumption per unit area of cultivated soil is set at the same scale for all production systems. Therefore, the yield per unit area creates the percentage of fossil resources consumed for the production of one functional unit. Comparable results, stressing the ecological advantages of maize compared to other energy crops, support the findings of this assessment [TENTSCHER2004].

The production of grass silage produces the majority of effects in the impact categories respiratory inorganics and acidification/eutrophication. This is caused by higher emission of nitrogen $\left(\mathrm{NH}_{3}, \mathrm{~N}_{2} \mathrm{O}, \mathrm{NO}_{\mathrm{x}}\right)$ to the air compared to the other systems. These higher emissions are based on the fact that fertilisers, which are applied to grassland, cannot be incorporated to the soil; so mainly $\mathrm{NH}_{3}$ emissions are produced.

It should be highlighted that these results are based on a functional unit; in this case 1.0 TJ electricity produced from these energy crops. If energy crops are used as input to the biogas process very few ecological effects are created, compared to a certain amount of produced 
biogas or electricity. In this instance, the output of the biogas process is constant. If the area under cultivation is stable the results can change. If the production of energy crops in an invariable number of unit areas is used as input to the biogas process, fewer ecological effects are caused by extensive production systems [GAILLARD\&NEMECEK2002, HAAS ET AL.2000]. The goal of the production system must be discussed in the assessment of ecological effects from the production. Very few overall ecological effects are produced by low input systems. The smallest amount of ecological effects per unit of energy output are caused by production systems with a maximum number of dry matter yields per unit area.

Due to the complex assessment and debate concerning the land use impact category and its weighting, it was decided to carry out a sensitivity analysis on this impact category. It takes into account the standard scenario based on the Eco indicator ' $99 \mathrm{H}$ method; a modification of this method using an extensive production system as a reference system, as a substitute for the potential natural vegetation originally used, in addition to a system that does not calculate effects from the occupation of the land but from indirect effects.

The standard scenario of maize silage production causes $6,080 \mathrm{El}$ ' $99 \mathrm{H}$ points, the extensive reference system scenario 2,180 El ' $99 \mathrm{H}$ points, and the scenario without occupation of land $1,400 \mathrm{El}$ ' $99 \mathrm{H}$ points. Thus, the consideration of effects from direct land use in agricultural production systems causes 5,630 El ' $99 \mathrm{H}$ points for the production of maize silage. These are $77.0 \%$ of the total effects of the standard scenario. Regarding the overall ecological effects from the standard scenario of biogas production, $57.1 \%$ of all weighted ecological effects are associated with the direct effects of land use. In the scenario, which does not take into account the effects from direct use of land, only $24.4 \%$ of all ecological effects are related to this impact category.

From a methodological point of view, none of the three alternatives can be considered as right or wrong. It always depends on the reader's opinion on the results. If nature conservation is an important safeguard subject for the reader, he will tend to take into account the ecological effects from the direct use of land. From a pragmatic point of view, no ecological effects from the occupation of fertile land should be taken into consideration. This pragmatic point of view can be justified by the fact that the energy crop producing areas under cultivation, considered in this study, would be used to produce crops, even if no energy crops would be produced. The overall effects on the environment would not change, if no energy crops were produced. The ecological effects would only be related to another agricultural production system. If there were a contention between the production of energy crops and another arable production system, it would be compulsory to consider the ecological effects from the direct use of land.

The transport of energy crops and biogas slurry causes weighted effects of $242 \mathrm{EI}$ ' $99 \mathrm{H}$ points and $222 \mathrm{El} \mathrm{'} 99 \mathrm{H}$ points respectively. Compared to the overall effects of the system under analysis this module causes a share of $4.7 \%$ (8.3\% in the system without effects from the direct use of land). Most effects in this module are caused by the consumption of fossil fuels (34\%) and the emission of respiratory inorganics (25.9\%). This result reflects the data results found in literature and are therefore regarded as valid [BORKEN ET AL.1999]. The waste input scenario causes slightly more ecological effects compared to the standard sce- 
nario; the 2.0 MW biogas plant causes further ecological effects. Only the biogas slurry treatment scenario leads to noticeable transport effort savings on the output side of the biogas plant.

In this assessment, the assumption is made that all transports are done with a dead head. In existing biogas production systems, it can be assumed that some of these transports will be done carry cargo to and from the plant. This leads to ecological savings within this module. In conclusion, it can be said that the transport module has a minor input on the overall ecological effects of the system under analysis.

The results from the module biogas plant are divided into three sub modules: installations, electricity consumption, and CHP emissions. The installations cause $138 \mathrm{El}$ ' $99 \mathrm{H}$ points per functional unit; this is a $1.0 \%$ share of the overall effects. The influence of this sub module is therefore seen as negligible compared to the overall results.

The electricity consumption of the biogas plant causes a share of 4.4\% (436 El '99H points) in the standard system under analysis. In the system, which considers no direct land use impacts, the share of this module is $7.8 \%$ of the overall ecological effects. This is a comparable amount to the effects from the transport system. The effects from this category depend on the used data set for the assessment of consumed electricity. In this study, medium voltage electricity data from the grid in Germany were taken into account. If the same amount of electricity with the same voltage produced in France were to be taken into account then only $50 \%$ of these overall ecological effects would be caused. The electricity from the European mix would cause ecological effects of the same magnitude as the German electricity mix, but it would be made up from a higher consumption of fossil fuels, but would have less radiation and land use [ECOINVENT2004]. Therefore, in further assessments, this influence should be considered when selecting the goal and scope of the object under analysis.

The CHP plant emissions are the third sub module within the biogas plant module. In this sub module, two different technologies are calculated. The standard technology is classed as a gas engine, which causes emissions of $1,090 \mathrm{El} ' 99 \mathrm{H}$ points. These are $11.0 \%$ of the overall effects of the biogas standard scenario and $19.4 \%$ of the scenario, which does not calculate direct land use effects. Thus, this module has a noticeable effect on the overall results of the biogas production. The used data are taken from measurements from three CHP plants, which had been operating for two years at the time of investigation. In the case of further assessments, data from CHP plants within the scope definition of the object under analysis should be used, as the emissions vary depending on the kind and size of the biogas plant. It should also be taken into account that catalytic converters can help to save emissions from biogas fed CHP plants. These converters are sensitive to sulphur contents from the exhaust and could be destroyed by them [SKLORZ ET AL.2003]. The assumption is made that most converters at CHP plants are inoperable due to this influence. A better gas purification upstream in the CHP plant can reduce the deterioration of the converter and therefore reduce the emissions from this module.

The ecological effects from a fuel cell are checked within the sub module CHP emissions. The considered MCFC would cause ecological effects of around 204 El '99 points. These are 
$80 \%$ less ecological effects as caused in the standard scenario. The data used are taken from literature. The first MCFC used for the conversion of biogas will be put into operation in summer 2006 in Böblingen, Germany. Data from this plant could help to validate data in literature. If these were to be validated, remarkable amounts of ecological conservation would be gained.

The application of biogas slurry causes ecological effects of $-275 \mathrm{El}$ ' $99 \mathrm{H}$ points $(-2.8 \%)$ in the standard scenario and $-4.9 \%$ in the scenario that does not consider land use. Herein ammonia emissions cause $7.2 \%$, and $12.7 \%$ of the total ecological effects respectively. The positive ecological effects in this module are derived from the nutrient recycling. From literature, a share of $40.0 \%$ on the overall effects was assumed for this module [DOLMAN ET AL.2001]. This difference is caused by the storage of the biogas slurry and the application technology used. In literature, an open vessel is assumed for storage. This causes a high level of $\mathrm{CH}_{4}$ and $\mathrm{NH}_{3}$ emissions. In addition, the application with a broadcaster and instead of an additional incorporation method is assumed. This leads to high $\mathrm{NH}_{3}$ emissions, which cause most of the overall ecological effects in this study. In the here done study, the biogas slurry is stored in a gas-tight vessel. A trail-hose is used to apply it and the slurry is incorporated directly after application. The emissions created by this method were tested in a field trial, from which the data for this LCA study come from. The $\mathrm{NH}_{3}$ emissions of this trial are 95\% below the data from literature. This is possible due to the type of application used and the incorporation method.

Furthermore, the emissions from biogas slurry, which was applied with a broadcaster and not incorporated, were calculated. The results of this module, related to the overall effects of the scenario not considering direct land use effects, are of a comparable scale $(29.0 \%$ of the overall effects) as the results from literature [EDELMANN ET AL.2001]. At this point, it must be emphasised that this scenario considers indirect effects from land use with an amount of $14.8 \%$ of the overall effect. By subtracting this influence, which is not even considered in literature, the same importance on the overall ecological effect is given. Relating these $\mathrm{NH}_{3}$ emissions to the scenario, which does not calculate direct land use impacts but instead good agricultural practice for slurry application, shows that ammonia emissions have an influence of $18.7 \%$ on the overall effect. Therefore the ammonia emissions still prove to be a serious problem.

Finally, an evaluation was made on treated biogas slurry emissions. The effect of this scenario compared to the standard scenario leads to minor ecological savings; the share of the ammonia emissions on the overall result is $0.3 \%$ less in the treated biogas scenario than in the standard scenario. This influence is insignificant when compared to the influence of the application using an incorporation method.

The emissions from applied biogas slurry are dependant on a wide variety of factors. These emissions cause direct damage to the environment and also nutrient losses. Therefore exact data of the emission rates are demanded. 
This trial reflects data from just one situation. For further assessments the data from this trial should be repeated with different soils, weather conditions, and biogas slurries to obtain more information on biogas slurry emissions.

The comparison of all the scenarios shows the influence of the single impact categories per scenario, in addition to the influence of the assumptions in each scenario in comparison to other scenarios. Taking into account the different energy crop production systems and the different weighting methods of the impact category land use, it can be concluded that most ecological effects of the biogas production are caused by the agricultural production of energy crops.

The results of the scenario considering waste as an input to the biogas process are conspicuous. Once having considered most impact categories as well as the overall ecological effects, it is obvious that this scenario causes the least ecological effects. This scenario compared to the standard scenario causes only $12.2 \%$ of the overall ecological effects. Even if the content of heavy metals in the biogas slurry resulting from these inputs and no substitution effects such as animal foodstuff are considered in this scenario, the utilisation of biodegradable wastes is more environmentally sound than the utilisation of energy crops.

The breeding efforts, resulting in a $30.0 \mathrm{Mg}$ dry matter yield per ha, would cause ecological savings of $53.3 \%$ compared to the standard scenario. Therefore the breeding of high yield energy crops could lead to dramatic ecological savings in biogas production systems.

The utilisation of a MCFC instead of a conventional gas engine reduces the ecological effects of all impact categories. The higher conversion efficiency of the fuel cell causes fewer inputs to the biogas process and therefore related fewer transport efforts. Altogether, $29.0 \%$ of all ecological effects are saved by the utilisation of a fuel cell compared to the standard scenario.

If the waste heat of the biogas process were to be used to substitute fossil fuels, then considerable savings of ecological effects would be achieved. If only $25 \%$ of the available waste heat of a biogas plant were to be used to replace natural gas for heating purposes, $15.1 \%$ of the overall ecological effects of the standard scenario would be saved. That is why, the utilisation of waste heat from biogas CHP plants, as well as any other CHP process, should be promoted. It is an easy, sometimes expensive way, of saving ecological effects by state of the art technology.

When comparing the weighted overall results of all systems under analysis, the most environmental friendly biogas production system that stands out is the scenario using waste as an input (1,830 El ' $99 \mathrm{H}$ points). Moreover, the scenario considering the utilisation of high yield maize as an input causes few ecological effects (4,600 El ' $99 \mathrm{H}$ points). The utilisation of a fuel cell would cause 6,990 $\mathrm{El}$ ' $99 \mathrm{H}$ points; and the waste heat utilisation 8,360 $\mathrm{El}$ ' $99 \mathrm{H}$ points. The standard scenario causes $9,850 \mathrm{El}$ ' $99 \mathrm{H}$ points. 


\subsection{Outlook}

As said in the goal and scope definition of this assessment, this LCA is made to compare different biogas scenarios. It was not made to be compared to the ecological effects from other electricity generating effects. Just to get a picture of a comparison between the electricity generation from biogas and the standard medium voltage electricity in the German grid the following comparison should be done.

Taken from the Ecoinvent data base, the production of $1.0 \mathrm{TJ}$ of electric energy at medium voltage causes weighted ecological effects of $4,360 \mathrm{El}$ ' $99 \mathrm{H}$ points. If this value should be compared to the ecological effects from electricity generated from biogas, the direct land use effects should not be considered in the energy crop using scenarios, as discussed before. In the standard scenario of biogas production $5,590 \mathrm{EI} ' 99 \mathrm{H}$ points of ecological effects would be considered. Around 4,000 El ' $99 \mathrm{H}$ points would occur from the high yield maize scenario. Around 2,800 El ' $99 \mathrm{H}$ points would be considered in the fuel cell scenario and 4,100 El ' $99 \mathrm{H}$ points would be created by the waste heat using scenario. As already stated 1,830 El ' $99 \mathrm{H}$ points are caused by the food waste using scenario.

From this it can be assumed that electricity generated from biogas causes comparable ecological effects as the state of the art electric energy mixture in Germany. The standard scenario causes $28.2 \%$ more ecological effects; the utilisation of a fuel cell would reduce to overall effects to $64.2 \%$ of the average ecological effects from the state of the art electricity mixture from the grid. If wastes are used as input or waste heat can be used to substitute fossil fuels, ecological saving potentials are realised.

Feeding purified biogas to the gas distribution system to substitute natural gas is widely discussed among experts at the moment. If biogas is used to replace natural gas, much higher energetical conversion levels could be gained, around $85 \%$ in heating systems compared to $36 \%$ assumed in the standard scenario. Therefore biogas could replace much more fossil fuels when used as a substitute for natural gas for heating instead of conversion to electric energy at the biogas plant.

For feeding biogas to the gas distribution system, it would have to be purified from all trail gases and $\mathrm{CO}_{2}$ would have to be separated, so that only $\mathrm{CH}_{4}$ remains. The mass and energy flows needed for this purification cannot be assessed within this study. It is assumed that they will be of the same magnitude, as the mass and energy flows of a conventional biogas plant. In this case the CHP plant would be replaced by a gas compressor, which is assumed to cause the same energy and mass flows when in operation. Also gas losses from the purification process of $5.0 \%$ have to be assumed. No energetic conversion efficiency is taken into account, as the $\mathrm{CH}_{4}$ from biogas is not converted in any way.

One functional unit (1.0 TJ) from this study includes the production of $771,606 \mathrm{kWh}$ of chemically bonded energy in biogas. This equals the energy content of $79,139 \mathrm{~m}^{3}$ of natural gas. The amount of $79,139 \mathrm{~m}^{3}$ of natural gas, assessed by the data set Natural gas to UCPTE $U$ from the Eco Invent database, causes 16,600 El ' $99 \mathrm{H}$ points. These are $68.5 \%$ more ecological effects as calculated for the standard scenario of biogas production. 
From an ecological point of view, electricity generation from biogas with a CHP plant at the site of the biogas plant is probably not the best way of using the energy from biogas. As this is just an outlook, the assumptions from this outlook should be checked within a separate LCA study. If they turn out to be correct, this way of biogas utilisation should be enforced in the future. 


\section{Summary}

Sustainable energy supply is considered to be one of the most important worldwide challenges of the future. When concerning energy supply, three aspects have to be taken into account regarding sustainability. The first aspect is the limitation of fossil and nuclear resources. It is generally accepted that these resources will run out within the next decades and centuries. As a secondary aspect, due to this limitation, there is a rise in energy prices. This is contrary to the concept that energy should be affordable to every human being. The third aspect involves the emissions of the state of the art energy conversion technology harming the environment. These must therefore be reduced in the future, especially greenhouse gas emissions.

Renewable energy sources are considered an answer to these problems. They are in endless supply and thought to be environmental friendly. Biomass, e.g. crops and biodegradable waste, is one kind of renewable energy sources. Biogas production is one possibility to produce electricity and heat from this biomass. Within the biogas process bacteria in an anaerobe atmosphere degrade carbon-hydrogen compounds. Methane, carbon dioxide, some trace gases, and a nutrient rich slurry result from this biogas process. The originated methane can finally be used for heating, electricity generation or fuel production. Within the last years, the government has assisted the energy production from renewable energy sources, especially biogas. This has led to a particular increase in industrial-scale biogas plants using energy crops as input.

The utilisation of renewable energies aims at the protection of human health, nature, and resources. However, like any other kind of energy conversion, the biogas process causes effects on the environment. Energy conversion plants using renewable energy sources such as biomass are considered to be environmentally friendly by a wide public. Considerations of the environmental friendliness of renewable resources consuming processes are based on the one hand, on the conservation of fossil resources on the input side of the system and on the other hand on the emission of carbon dioxide, which is not enhancing the green house effect due to its renewable sources offspring on the output side of the process. In this case environmental friendliness is solely seen as a question of sustainability in the fields of fossil resources and climate. Here, it is not considered that the production and transport of energy crops consumes mass and energy flows, uses land and produces emissions.

All of these effects have to be taken into account, when assessing the environmental effects of electricity generation from biogas produced by an industrial scale biogas plant. Furthermore, manure and organic waste must be transported, leading to fuel consumption and emissions. The production and consumption of biogas lead to gaseous emissions, which threatens human health and the environment. Mass and energy flows are caused for the construction and demolishing of the biogas plant itself. Ultimately, waste is generated by the biogas plant, which has to be disposed of. This is why, for the further development of energy technologies, it is important to know the kind and amount of ecological effects caused. 
The object under investigation is a hypothetical biogas plant with a capacity of $1.0 \mathrm{MW}$ electric power, fed by biomass from energy crops and manure. The ecological effects shall be determined from start to finish and are determined by mass and energy balances resulting in a life-cycle-assessment (LCA). This assessment is done according to the rules of ISO 1404014043, which gives a universally valid plan for this method. Data for the mass and energy balances are taken from measured data of existing biogas plants, calculations from similar objects, and estimations where no adoptable data are available. The object under investigation is the biogas plant itself as well as up- and downstream processes related to the power plant. The scope of the data collection will be determined and adjusted within the LCA; also all single unit processes will be defined in the life-cycle-assessment.

The only purpose of this study is to give information on the composition of the ecological effects from biogas production in industrial scaled biogas plants. Thereby ecological hot spots are determined and suggestions for ecological improvements are made. The results of this study should not be used for comparisons with results from LCA studies of different energy production systems e.g. electricity from lean coal, as the scope of this study is not designed for such a comparison.

As the results of a LCA study are very complex and hard to interpret, due to the variety of impact categories, an additional interpretation step is included. At this stage, the Eco Indicator '99 approach of [GOEDKOPP\&SPRIENSMA2001] will be used. This step is not part of the rules of ISO14040-43 and must be acknowledged as an additional interpretation tool. The use of such interpretation methods is hardly discussed among experts, due to its social science based background. The results gained from the LCA done according to the ISO rules are therefore clearly separated from the results of the further interpretation, so that the influence of the interpretation method can be regarded separately. The results of the ecological assessment are given for each unit process, per module, and for the overall process. All results are related to the generation of one Terra Joule of electric energy from the biogas plant.

Beginning with the production of energy crops, it can be seen that energy plants with a high productivity per area unit e.g. maize and forage beets have a better ecological performance than crops like rye or grass. The ecological effects of the crop production are mainly caused by energy inputs e.g. fuels and artificial nitrogen fertiliser production. Relevant effects are also caused from heavy metals inserted into the system by phosphate fertilisers. A specific effect from crop production is the impact category land use. More than $80 \%$ of the ecological effects of the crop production and more than $60 \%$ of the overall effects are related to this category. As this category is a qualitative and not a quantitative indicator like the other mass and energy flows, its implementation into the overall assessment is quite complicated.

For the production of energy crops, mainly crops with a high yield of organic dry matter mass per unit area should be used in order to reduce the ecological effects from this module. Whenever possible, biodegradable waste should be used instead of specially produced crops to reduce the ecological effects on the input side of the system, as this waste is taken into account without any ecological burden. 
Within the agricultural production system the influence of the impact category land use is very strong, in comparison to all other ecological effects in their influences on the overall result. On the one hand, large areas are needed for the production of energy crops. This has a multiplying effect on the results per unit area. The intensive arable production leads to a decrease in biodiversity, which is close to the decrease caused by a sealed surface. Therefore this form of production is calculated with heavy ecological burdens. On the other hand it must be recognised that there would also be arable production, even if no energy crops would be produced. Hence, stopping the production of energy crops would not lead to an overall reduction of ecological effects from arable farming. Therefore this impact category should be taken into account, showing that improvements of the ecological effect from biogas production are mainly improvements of the biodiversity in the energy crop production. But they should not be accounted for, if the ecological effects of the biogas production are compared to other kinds of electricity generation.

The transport caused by the input and output flows of the biogas plant have only a small influence on the overall ecological effects. Most ecological effects are herein derived from the consumption of fossil fuels. From a theoretical analysis the result gained can show that larger biogas plants do not cause an equivalent increase of transport efforts as two smaller biogas plants would cause. When biogas plants and related areas for energy crop production increase, the transport efforts increase subproportionally due to the circular area/radius nature of the area around the biogas plant. Therefore, the crops in areas around a biogas plant always grow faster, however transport distances have yet to be covered.

The construction and demolition of installations in a biogas plant produce hardly any damages to the environment. Only two ecological hot spots occur at the biogas plant: the emissions of the CHP plant and the consumption of electricity from the grid. Gas engines with oxidising converters are calculated as CHP plants, which emit the lowest emission rates out of all conventional CHP plants. Lower emissions rates can only be realised with a change of technology e.g. use of fuel cells. The share of ecological effects from electricity consumption is related to the fact that biogas plants, which use energy crops, need up to $10 \%$ of the energy that they generate to run the process. Facilities using less energy can be helpful to reduce this influence on the overall ecological effect from this hot spot.

The biogas slurry is applied to fields, where it is used as an organic fertiliser. The application of biogas slurry has two different ecological effects. The nutrient content of the slurry leads to a reduced consumption of artificial fertiliser. The emissions from the biogas slurry the influence of the change in input material can be seen contribute mainly to the impact categories acidification/eutrophication and greenhouse effect. These negative effects, especially the acidification from gaseous $\mathrm{NH}_{3}$ emissions, contribute to around $25 \%$ of the total ecological effects. This threat to the environment can be reduced through application and incorporation methods in keeping with good agricultural practice. Thereby, very low emission levels of the applied biogas slurry can be achieved. These emissions levels are below the emissions from manure, which is used as input to the plant, and would alternatively spread to the fields, where it would cause emissions. 
In brief, electricity generation from biogas produced in industrial scale biogas plants can be regarded as a durable way of generating electricity. On considering the biogas production from start to finish, it is shown that most ecological effects are related to the agricultural production system. Just some parts of these effects can be manipulated. Qualitative aspects, e.g. land use, cannot be influenced and will always occur, even if no energy crops were to be produced. 


\section{Sources}

AID2003

AMON ET AL.2002

ARMAN2004

ARLT\&EGGERS1997

ASUE2005

AUDSLEY ET AL.2003

BAL ET AL.1995

PICKERT2004

BECKER1997

BERG ET. AL.1999

BERGER2006 aid Infodienst Verbraucherschutz, Ernährung, Landwirtschaft e.V. (Herausgeber): Ammoniak-Emissionen in der Landwirtschaft mindern - Gute fachliche Praxis, aid infodienst e.V., Bonn 2003 - ISBN 3-8308-0341-9

Amon, B., Moitzi, V., Kryvoruchko, V., Amon, T., Hackl, E., Zechenmeister-Boltenstern, S.: Emissionen von NH3, N2O und $\mathrm{CH} 4$ nach Ausbringung von Rinderflüssigmist und Einfluss der Flüssigmistbehandlung, In: KTBL/UBA, Emissionen der Tierhaltung - Grundlagen, Wirkungen, Minderungsmaßnahmen, KTBL-Schrift 406 (2002), 331 - 332

Arman, B.: Die Ökobilanz zur Abschätzung von Umweltwirkungen in der Pflanzenproduktion: dargestellt anhand von Praxisversuchen zur konservierenden Bodenbearbeitung und von unterschiedlich intensiv wirtschaftenden konventionellen Betrieben, Dissertation, Universität Hohenheim, online Publikation

Arlt K., Eggers T.: Natürliche Vegetation - AckerunkrautVegetation, In „Angewandte Wissenschaft" Schriftenreihe des BML Heft 465 „Biologische Vielfalt in Ökosystemen“ (1997), 20-28

Arbeitsgemeinschaft für sparsamen und umweltfreundlichen Energieverbrach e.V. (Ed.): BHKW Kenndaten 2005 Module Anbieter Kosten, Verlag Rationeller Erdgaseinsatz, Kaiserslautern 2005

Audsley E., Alber S., Clift R., Cowell S., Crettaz P., Gaillard G., Hausheer J., Jolliett O., Kleijn R., Mortensen B., Pearce D., Roger E., Telon H., Weidema B., van Zeijts H.: Harmonisation of environmental life cycle assessment for agriculture, Final Report Concerted Action AIR3-CT94-2028, European Commission DG VI Agriculture, (UK) Silsoe 2003

Bal D., Beije H.M., Hoogeveen Y.R., Jansen S.R.J., van der Reest P.J.: Handboek natuurdoeltypen in Nederland, IKC, NL-Wageningen 1995

Pickert J.: Leitfaden erfolgreicher Maisanbau, Bayer CropScience Deutschland GmbH, Langenfeld 2004

Becker H.: Der Begriff „Biologische Vielfalt“, In: Biologische Vielfalt in Ökosystemen, Schriftenreihe des BML „Angewandte Wissenschaft" Heft 465 (1997), 9-17

Berg, van den N. W., Huppes G., Lindijer E. W., Ven van der B.L., Wrisberg M. N.; Quality Assessment for LCA, CML Report 152, NL-Leiden, September 1999

Berger P.: Brennstoffzellen zur Biogasverwertung Stand der Technik und Perspektiven, MTU CFC Solutions GmbH, München 2006 
BERGMANN1999

BI2006

BLFU2004

BLONK ET AL.1997

BMLF2003

BMU2006

BIMSCHV2001

BOCKSTALLER ET AL.1997

BORKEN ET AL.1999

BRENTRUP2000

BRENTRUP ET AL.2002

BRENTRUP2003

CEN1997

CEN1998
Bergmann S.: Klimarelevante Spurengase nach Ausbringung unterschiedlich aufbereiteter Rindergülle, Diplomarbeit im Fach Geoökologie, Universität Bayreuth Lehrstuhl für Biogeographie/Agrarökologie, Bayreuth 1999

Brennstoffzellen Initiative (Ed.): Biokatalysatoren sollen Brennstoffzellen ohne teures Platin ermöglichen (10.05.2006), online: http://www.initiative-brennstoffzelle.de /ibz/live/nachrichten/sho $\mathbf{w}$.php3?id=154\&nodeid=0

Bayrisches Landesamt für Umwelt (Ed.): Biogashandbuch Bayern - Materialienband (Stand 12/2004), Augsburg 2004

Blonk T. J., Davidson M. D., Lafleur M. C. C.: Feasibility of operationalization of depletion of abiotic resources in LCA via the key resources energy and land, IVAM Environmental Research, University of Amsterdam 1997

Bayrisches Staatsministerium für Landwirtschaft und Forsten (Hrsg.): Merkblatt Verminderung gasförmiger Emissionen in der Tierhaltung, RB-Nr. 08/03/16, Freising 2003

Bundesministerium für Umwelt, Naturschutz und Reaktorsicherheit (Ed.): Errichtung und Betrieb einer MCFC-

Brennstoffzelle mit Biogas in der Vergärungsanlage Leonberg (02.03.2006), online: http://www.bmu.de/ foerderungsprogramme/pilotprojekte_inland/doc/35863.php

Vierte Verordnung zur Durchführung des BundesImmissionsschutzgesetzes, BGBI. I 2001, 1979 - 2001

Bockstaller C., Girardin P., van der Werf H.M.G.: Use of agroecological indicators fort he evaluation of farming systems, In: European Journal of Agronomy 7 (1997), 261-270

Borken J., Patyk A., Reinhardt G.A.: Basisdaten für die ökologische Bilanzierung - Einsatz von Nutzfahrzeugen in Transport, Landwirtschaft und Bergbau, Vieweg Verlag, Wiesbaden 1999 - ISBN 3-528-03118-2

Brentrup F.: Methods to estimate on-field nitrogen emissions from crop production as input to LCA in the agricultural sector, In: Int. J. of LCA 5 (2000), 349-357

Brentrup F., Küsters J., Lammel J., Kuhlmann H.: Life Cycle Impact Assessment of Land use Based on the Hemeroby Concept, in: Int. J. of LCA 7 (6) (2002), 339-348

Brentrup F.: Life Cycle Assessment to Evaluate the Environmental Impact of Arable Crop Production, Cuvillier Verlag, Göttingen 2003 - ISBN 3-89973-662-8

Europäisches Komitee für Normung, Umweltmanagement Ökobilanz - Prinzipien und allgemeine Anforderungen - Deutsche Fassung, Brüssel 1997

Europäisches Komitee für Normung, Umweltmanagement Ökobilanz - Festlegung des Ziels und des Untersuchungsrahmens sowie Sachbilanz - Deutsche Fassung, Brüssel 1998 
CEN2000a

CEN2000b

CHAPMAN\&ROBERTS1983

CIRCOTH2001

Clemens et Al.2002

DEFFEYES1964

DE HOLLANDER1999

DESTATIS2004

DESTATIS2005a

DESTATIS2005b

DESTATIS2006a

DESTATIS2006b

DMK2006

DÖHLER ET AL.2002

DUBSKY ET AL.1997
Europäisches Komitee für Normung, Umweltmanagement Ökobilanz - Wirkungsabschätzung - Deutsche Fassung, Brüssel 2000

Europäisches Komitee für Normung, Umweltmanagement Ökobilanz - Auswertung - Deutsche Fassung, Brüssel 2000

Chapman P.F., Roberts F.: Metal Resources and Energy. Butterworths Monographs in Materials, (GB) Thetford 1983 ISBN 0-408-10801-0

Circoth A.: Fehlerrechnung in Ökobilanzen, Fakultät III Prozesswissenschaften Universität Berlin, Dissertation, Berlin 2001

Clemens J., Wolter M., Wulf S., Ahlgrimm H.-J.: Methan- und Lachgas-Emissionen bei der Lagerung und Ausbringung von Wirtschaftsdüngern, In: KTBL/UBA, Emissionen der Tierhaltung - Grundlagen, Wirkungen, Minderungsmaßnahmen, KTBL-Schrift 406 (2002), 331 - 332

Deffeyes K.: Uranium Distribution in Mined Deposits and in the Earth Crust, Department of Energy, Grand Junction Colorado, see also Scientific American 242 (1980), 50 - 62

De Hollander A.: An Aggregate Public Health Indicator to Represent the Impact of Multiple Environmental Exposures, Epidemiology 10 (1999), 606-617

Statistisches Bundesamt (Ed.): Rekordernte von 12,6 Mill. t bei Kartoffeln erwartet, Pressemeldung des Statistischen Bundesamts vom 13.10.2004, online: http://www.destatis.de/ presse/deutsch/pm2004/p4340144.htm

Statistisches Bundesamt (Ed.): Zunahme der Siedlungs- und Verkehrsfläche: 115 ha/Tag (20.12.2005), online: http:// www.destatis.de/presse/deutsch/pm2005/p5320112.htm

Statistische Bundsamt (Ed.): Bodenflächen nach Art der tatsächlichen Nutzung in Deutschland (20.12.2005), online: http://www.destatis.de/basis/d/umw/ugrtab7.php

Statistisches Bundesamt (Ed.): Nutzung der Bodenfläche Flächenerhebung 2004 nach Art der Flächennutzung, Wirtschaft und Statistik 3 (2006), Wiesbaden 2006

Statistisches Bundesamt (Ed.): Feldfrüchte - Anbauflächen, Hektarerträge, Erntemengen (06.04.2006), online:

http://www.destatis.de/basis/d/forst/forsttab7.php

Deutsches Maiskomitee e.V. (Ed.): Anbaufläche Silomais (01.05.2006), online: http://www.maiskomitee.de/fb_fakten 103_02_03_03.htm

Döhler H., Menzi H., Schwab M.: Emissionen bei der Ausbringung von Fest- und Flüssigmist und Minderungsmaßnahmen, In: KTBL/UBA, Emissionen der Tierhaltung Grundlagen, Wirkungen, Minderungsmaßnahmen, KTBLSchrift 406 (2002), 163 - 178

Dubsky G., Hülsbergen K.J., Diepenbrock W.: REPRO Stoff- und Energiebilanzierung landwirtschaftlicher Betriebe, 
DÜNGMG

EC2002

ECOINVENT2004

ECKERT ET AL.1999

EDELMANN ET AL.2001

EDER\&SCHULZ2006

EEA2002

EEA2003

EEG2000

EEG2004

EHRENGARD2005

ERHARDT2005

FDZ2006
In: Werkzeuge für Modellbildung und Simulation in Umweltanwendungen 7. Treffen der Arbeitsgruppe, Oldenburg 1997

Düngemittelgesetz (idF v. 15.11.1977) GI.-Nr. 7820-2

European Communities (Ed.): Regulation (EC) no. 1774/2002 of the European Parliament and the council, Bruxelles 2002

Eco invent Centre (Hrsg.): The Life Cycle Inventory Data (Version 1.1), Swiss Centre for Life Cycle Inventories, $(\mathrm{CH})$ Dübendorf, Juni 2004

Eckert H., Breitschuh G., Sauerbeck D.: Kriterien umweltgerechter Landbewirtschaftung (KUL) - ein Verfahren zur ökologischen Bewertung von Landwirtschaftsbetrieben, In:

Agribiological research Zeitschrift für Agrarbiologie - Agrikulturchemie 52 (1) (1997), 57-76

Edelmann W., Schleiss K., Engeli H., Baier U.: Ökobilanz der Stromgewinnung aus landwirtschaftlichen Biogasanlagen, Studie im Auftrag des Bundesamt für Energie (Office fédéral de l'énergie), ( $\mathrm{CH}$ ) Bern 2001

Eder B., Schulz H.: Biogas Praxis. Grundlagen - Planung Anlagenbau - Beispiele - Wirtschaftlichkeit (3. Auflage), ökobuch Verlag, Freiburg 2006 - ISBN 3-936896-13-5

European Enviroment Agency (Ed.): EU-Land take by roads and railways as percentage of country surface (29.12.2005), online: http://themes.eea.eu.int/Sectors_and_activities /tranport/indicators/consequences/TERM̄08,2002/index_html

European Environment Agency (Ed.): Europe's environment The third assessment - Environmental Assessment Report no.10, European Environment Agency, Copenhagen 2003 ISBN 92-9167-574-1

Gesetz für den Vorrang Erneuerbarer Energien ErneuerbareEnergien-Gesetz (29.03.2000), BGBI. I 2000, 305 ff.

Gesetz zur Neuregelung des Rechts der Erneuerbaren Energien im Strombereich (21.07.2004), BGBI. I 2004, 1918ff. last time changed (13.06.2005), BGBI. I 2005, $2015 \mathrm{ff.}$

Ehrengard K.: Biotechnische Prozesse bei der Silierung Möglichkeiten ihrer Steuerung, Vortrag am 21.11.2005, Inst. f. Tierzucht und Haustiergenetik Universität Göttingen, Göttingen 2005

Erhardt N.: Landessortenversuche Futterrüben 2004 (23.01. 2005), online: http://www.landwirtschaftskammer.de/fachan gebot/ackerbau/zuckerrueben/futterrueben-sv-2004.htm

Fabrik der Zukunft (Hrsg.): PUIS und ihre Eigenschaften, (14.02.2006) Online:

http://fabrikderzukunft.at/puis/kap04_4.htm 
FINKE ET AL.1999

FLESSA ET AL.1998

FNR2004

FNR2005

FRAUZ ET AL.2005

FRISCHKNECHT\&JUNGBLUTH.2003

FRITZ2006

FÜRST\&SCHOLLES2001

GAILLARD\&NEMECEK2002

GEHRIG\&FRITZ2006

GEIER2000
Finke C., Möller K., Schlink S., Gerowitt B., Isselstein J.: The environmental impact of maize cultivation in the European Union: Practical options for the improvment of the environmental impact - Case study Germany -, Forschungs- und Studienzentrum Landwirtschaft und Umwelt in Zusammenarbeit mit der Abteilung Futterbau \& Graslandwirtschaft des Institutes für Pflanzenbau und Pflanzenzüchtung, GeorgAugust-Universität Göttingen, Göttingen 1999

Flessa H., Beese F., Brumme R., Priesack E., Przemeck E., Lay J.-P.: Freisetzung und Verbrauch der klimarelevanten Spurengase $\mathrm{N}_{2} \mathrm{O}$ und $\mathrm{CH}_{4}$ beim Anbau nachwachsender Rohstoffe, Deutsche Bundesstiftung Umwelt (Hrsg.) Initiativen zum Umweltschutz 11, Zeller Verlag, Osnabrück 1998 ISBN 3-535-02486-2

Fachagentur Nachwachsende Rohstoffe e.V. (Hrsg.): Handreichung Biogasgewinnung und -nutzung, Eigenverlag, Leipzig 2004 - ISBN 3-00-014333-5

Fachagentur Nachwachsende Rohstoffe e.V (Ed.): Ergebnisse des Biogas Messprogramms, Eigenverlag, Gülzow 2005

Frauz B., Weinmann U., Oechsner H., Drochner W.: Untersuchung zur Deaktivierung von Schadpilzen während der Fermentation in Biogasanlagen - Versuche im Labormaßstab, Poster auf der 15. Jahrestagung des Fachverband Biogas Wirtschaftsmotor Biogas 25.-27. 01.2006, Hannover

Frischknecht R., Jungbluth N.: Implementation of Life Cycle Impact Assessment Methods Final report ecoinvent 2000, Swiss Centre for LCl, (CH) Duebendorf 2003

Fritz T.: mündl. Auskunft zu den Ergebnissen verschiedener durchgeführter Gasertragsmessungen, HAWK Fakultät Ressourcenmanagement (12.03.2006), Göttingen 2006

Fürst D., Scholles F.: Grundfragen der Bewertung, In: Gesellschaftswissenschaftliche Grundlagen Planungsmethoden (Vorlesungsskript SS 2001), Universität Hannover Institut für Umweltplanung 2001

Gaillard G., Nemecek T.: Ökobilanzierung des Extensoanbaus von Getreide und Raps, in AGRARForschung 9 (11-12) pp. 490-495, Eidgenössische Forschungsanstalt für Agrarökologie und Landbau Reckenholz (FAL), 2002

Gehrig S., Fritz T.: mündliche Auskunft zum Einfluss von Gülle auf die Stabilität des Biogasprozess, HAWK Fakultät Ressourcenmanagement (18.01.2006), Göttingen 2006

Geier U.: Anwendung der Ökobilanz-Methode in der Landwirtschaft - dargestellt am Beispiel einer Prozeß-Ökobilanz konventioneller und organischer Bewirtschaftung, Inauguraldissertation an der Hohen Landwirtschaftlichen Fakultät der Rheinischen Friedrich-Wilhelms-Universität zu Bonn, Schriftenreihe Institut für Organischen Landbau, Verlag Dr. Köster, Berlin 2000 - ISSN 1431-052x 
GOEDKOOP\&SPRIENSMA2001

GREEN1987

GRÖBLINGHOFF2006

GRONAUER1993

GRONAUER ET AL.2003

GUINĖE2001

HAAS ET AL.2000

HAASE2005

HAMERS ET AL.1996

HANSEN2002

HÄRDTLEIN2003

HARTMAN1999

HARTMANN2006
Goedkoop M., Spriesma R.: The Eco-indicator 99 A damage oriented method for Life Cycle Impact Assessment Methodology report (Third Edition), PRé Consultants B.V., NL Amersfoort 2001

Green M.B.: Energy in Pesticide Manufacture, Distribution and Use, In: Energy in Plant Nutrition and Pest Control (Vol.2), Helsel (Ed.), Elsevier, Amsterdam 1987, 165-177

Gröblinghoff F.-F.: Aktuelle Erfahrungen und Ergebnisse aus Nordrhein-Westfalen (10.05.2006), online: http://www.kwsenergie.de/media/downloads/22/aktuelle_erfahrungen_nrw. pdf

Gronauer A.: Einflussfaktoren auf die Ammoniakfreisetzung aus Flüssigmist als Grundlage verfahrenstechnischer Verbesserungen, Dissertation am Institut für Landtechnik der Technischen Universität München in Weihenstephan, München 1993

Gronauer A., Effenberg M., Kaiser F., Schlattmann M.: Biogasanlagen Monitoring und Emissionsverhalten von BiogasBlockheizkraftwerken Abschlussbericht, StMLU (Ed.), München 2003

Giunèe J.B. (Ed.): Life Cycle Assessment: An operational guide to the ISO standards, Centre of Environmental Science (CML), Leiden University, (NL) Leiden 2001

Haas G., Wetterich F., Köpke U.: Comparing intensive, extensified and organic grassland farming in southern Germany by process life cycle assessment, In: Agriculture, Ecosystems and Environment 83 (2001), 43-53

Haase Energietechnik AG (Ed.): Biogas-BHKW als Container-Aggregate, Informationsbroschüre, Neumünster 2005

Hamers T., Aldenberg T., van de Meent D.: Definition report Indicator Effects Toxic Substances ( ltox $_{\text {to }}$, RIVM report number 607128001

Hansen M.: Grassilage - Wichtigstes Grundfuttermittel in der Rindviehhaltung, Unterlagen Grünlandtag Erpeldingen 2002, Lycée Technique Agricole, (L) Ettelbruck 2002

Härdtlein M.: Basisdaten Biogas Deutschland, Biomasse InfoZentrum am IER Universität Stuttgart, Stuttgart 2003

Hartman M.: Using Fall Rye for Pasture, Hay and Silage (29.04.2006), online: http://www1.agric.gov.ab.ca/ \$department/deptdocs.nsf/all/agdex4461

Hartmann K.: Stoffstromanalyse einer Biogasanlage mit angeschlossener Gärsubstratkonditionierung der Firma BioEnergie-Konditionierungssysteme $\mathrm{GmbH}$ unter ökologischen, ökonomischen und energetischen Aspekten (Zuwendungsbescheid 206.2-3234/1-5(3)), Studie der HAWK im Auftrag der BioEnergie-Konditionierungssysteme $\mathrm{GmbH}$ (unveröffentlicht), Göttingen 2006 
HARTMANN\&NELLES2006

HARTUNG\&MONTENEY20000

HARTUNG2002

HASSAN2003

HEIDLER2002

HEILDER2006

HEIJUNGS ET AL.1992

HEINEKEN2001

HERMANN ET AL.2000

HEYER\&CHRISTEN2005

HOCHFELD\&JENSEIT1998

HOFSTETTER1999
Hartmann K., Nelles M.: Ökobilanz großtechnischer Biogasanlagen, In: Biogas - Wirtschaftsmotor Biogas Tagungsband 15. Jahrestagung des Fachverbands Biogas e.V. mit großer Biogasfachmesse Lehrfahrt ; 25. bis 27. Januar 2006, Convention Center Hannover, Hannover 2006

Hartung E., Monteney G.-J.: Emission von Methan $\left(\mathrm{CH}_{4}\right)$ und Lachgas $\left(\mathrm{N}_{2} \mathrm{O}\right)$ aus der Tierhaltung, Agrartechnische Forschung 6 (2000), 62-69

Hartung E.: Ammoniak-Emissionen der Rinderhaltung und Minderungsmaßnahmen, In: KTBL/UBA, Emissionen der Tierhaltung - Grundlagen, Wirkungen, Minderungsmaßnahmen, KTBL-Schrift 406 (2002), 63 - 71

Hassan E.: Biogas production from forage and sugar beets Process Control and Optimization - Ecology and Economy, Dissertation at the University of Kassel Faculty of Ecological Agricultural Sciences, Kassel 2003

Heidler B.: Förderantrag gemäß der Richtlinie über die Gewährung von Zuwendungen zur Förderung von Forschungsund Entwicklungsvorhaben in Niedersachsen, Lüchow 20.06.2002

Heilder B.: mündl. Auskunft zur Prozessstabilität verschiedener Biogasanlagen (23.03.2006), BioWend GmbH\&Co. KG, Lüchow 2006

Heijungs R., Guinée J., Huppes G., Lankreijer R, Udo de Haes H., Wegener Sleeswijk A, Eggels P.G., Duin van R., Goede de H.P.: Environmental live cycle assessment of products, Centre of Environmental Science, (NL) Leiden 1992

Heineken A.: Vegetationsentwicklung von Auengrünland nach Wiederüberflutung (30.12.2005), online unter http://edoc.hu-berlin.de/dissertationen/heinken-andreas2001-07-09/HTML/chapter2.html; Tabelle 1

Hermann A., Pickel P., Fröba N.: Transportgeschwindigkeit von Traktoren, In: Landtechnik Fachzeitschrift für Agrartechnik und ländliches Bauen 5 (2000), Landwirtschaftsverlag $\mathrm{GmbH}$, Münster 2000

Heyer W., Christen O.: Landwirtschaft und Biodiversität Zusammenhänge und Wirkungen in Agrarökosystemen, Book 8/2005, Institut für Landwirtschaft und Umwelt (Ed.), Bonn 2005 - ISBN 3-926898-22-4

Hochfeld C., Jenseit W.: Allokation in Ökobilanzen und bei der Berechnung des kumulierten Energieaufwands (KEA), Arbeitspapier des Ökoinstituts, Darmstadt 1998

Hofstetter P.: Perspectives in Life Cycle Impact Assessment A Structured Approach to Combine Models of the Technosphere, Ecosphere and Valuesphere, Kluwers Academic Publishers 1999 - ISBN 0-7923-8377-X 
HOLLANDER ET AL.1999

HORLACHER\&MARSCHNER1990

HÖTKER2004

HÖTKER ET AL.2005

HÜLSBERGEN\&DIEPENBROCK1997

HUPPMANN2006

HÜTHER1999

IEA2005

IER2004

ISERMANN1994

JACKOWIAK1998

JÄKEL\&MAU1999
Hollander de A.E.M., Melse J.M., Lebret E., Kramers P.G.N.: An aggregate public health indicator to represent the impact of multiple environmental exposures, In: Epidemiology Volume 10 (1999), 606-17

Horlacher D., Marschner H.: Schätzrahmen zur Beurteilung von Ammoniakverlusten nach Ausbringung von Rinderflüssigmist, In: Zeitschrift für Pflanzenernährung und Bodenkunde 153 (1990), 107-115

Hötker H.: Vögel der Agrarlandschaft Bestand, Gefährdung, Schutz, NABU e.V., Bonn 2004

Hötker H., Thomsen K.-M., Köster H.: Auswirkungen regenerativer Energiegewinnung au fdi ebiolgische Vielfalt am Beispiel der Vögel und der Fledermäuse, BfN-Skripten 142, Bundesamt für den Naturschutz (Hrsg.), Bonn 2005

Hülsenbergen K.J., Diepenbrock W.: Das Modell REPRO zur Analyse und Bewertung von Stoff- und Energieflüssen in Landwirtschaftsbetrieben, In: Umweltverträgliche Pflanzenproduktion - Indikatoren, Bilanzierungsansätze und ihre Einbindung in Ökobilanzen, Diepenbrock (Ed.), Osnabrück 1997, 43-54- ISBN 3-535-02476-5

Huppmann G.: Kraft-Wärme-Kopplung und Verwendung von Sekundärgas in Industrie und kommunalen Bereich, Das MTU Hochtemperatur-Brennstoffzellen Hot Module (15.02.2006), online: http://www.uni-duisburg.de/FB7/FG02 /KWK-Symposium/ Sympos- ium 03/Folien-Huppmann.pdf

Hüther L.: Entwicklung analytischer Methoden und Untersuchungen von Einflussfaktoren auf Ammoniak-, Methan- und Distickstoffmonoxidemissionen aus Flüssig- und Festmist, Landbauforschung Völkenrode Sonderheft 200, Braunschweig 1999

International Energy Agency (Ed.): World Energy Outlook 2005, International Energy Agency, (F) Paris - ISBN 92-6410949-8

Institut für Energetik und Umwelt (Ed.): Fortschreibung der Daten zur Stromerzeugung aus Biomasse, Bericht für die Arbeitsgruppe Erneuerbare Energien-Statistik, März 2004

Isermann K.: Agriculture's share in the emission of trace gases affecting the climate and some cause-oriented proposals for sufficiently reducing this share, In: Environmental Pollution Volume 83 (1994), 95 -111

Jackowiak B.: The hemeroby concept in the evaluation of human influence on the urban flora of Vienna, Phytocoenosis 10 (1998), Supplementum Cartographiae Geobotanicae 9, $79-96$

Jäkel K. Mau S.: Abschlußbericht zum Forschungsprojekt Umweltwirkungen von Biogasgülle, Sächsische Landesanstalt für Landwirtschaft, Dresden 1999 
JALAS1955

JENBACHER2002

JOHNSON1998

KALTSCHMITT\&REINHARDT1997

KAUPENJOHANN\&VANDRÈ1998

KISSEL ET AL.2001

KÖLLNER2000

KORFF ET AL.2005

KORNECK\&SUKOPP1988

KOWARIK1999

KRETSCHMER ET AL.1997
Jalas J.: Hemerobie und hemerochore Pflanzenarten Ein terminologischer Reformversuch, In: Acta Societatis pro Fauna et Flora Fennica 72 Volume 11 (1955), 1-15 - ISSN 0373-6660

Jenbacher AG (Ed.): Datenblätter der BHKWs STAMFORD $\mathrm{HCl} 734 \mathrm{~F} 1$ und STAMFORD $\mathrm{HCl} 734 \mathrm{~F} 2$, (A) Jenbach 2002

Johnson K.: Forage Grasses and Legumes, Purdue Forage Information, Purdue University, (USA) West Lafayette 1998

Kaltschmitt M., Reinhardt G.A. (Ed.): Nachwachsende Energieträger - Grundlagen, Verfahren, ökologische Bilanzierung, Verlag Vieweg, Wiesbaden 1997

Kaupenjohann M., Vandrè R.: In situ Measurement of ammonia emissions from organic fertilizers in plot experiments, In: Soil Science Society of America Journal, 62 (1998), 467-473

Kissel R., Schattner S., Gronauer A., Schilcher A., Keymer U.: Wirtschaftlichkeit des Einsatzes von nachwachsenden Rohstoffen als Co-Substrate zur Erzeugung von Biogas, Bayrische Landesanstalt für Landtechnik (Ed.), Weihenstephan 2001

Köllner T.: Species-pool effect potentials (SPEP) as a yardstick to evaluate land-use impacts on diversity, In: Journal of Cleaner Production 8 (2000) Issue 4, 293-311

Korff J., Taschner I., Sip J.: Graskraftwerk Seifhennersdorf Vorbereitung des Modellprojekts deutsch-tschechisches Graskraftwerk Seifhennersdorf, Abschlußbericht, Dresden 2005

Korneck D., Sukopp H.: Rote Liste der in der Bundesrepublik Deutschland ausgestorbenen, verschollenen und gefährdeten Farn- und Blütenpflanzen und ihre Auswertung für den Artenund Biotopschutz, Schr. Reihe Vegetationskunde 19 (1988), $1-210$

Kowarik I.: Natürlichkeit, Naturnähe und Hemerobie als Bewertungskrieterien, In: Konold W., Böcker R., Hampicke U. Handbuch Naturschutz und Landschaftspflege, 18. Erg. Lfg. 2/06, ecomed, Landsberg am Lech 1999 - ISBN 3-609$72771-3$

Kretschmer H., Hoffmann J., Wenkel K.: Einfluss der landwirtschaftlichen Flächennutzung auf Artenvielfalt und Artenzusammensetzung, In: Schriftenreihe des BML „Angewandte Wissenschaft“ Band 465 „Biologische Vielfalt in Ökosystemen“ (1997), 266-280 
KTBL2005a

KTBL2005b

LANGE2005

LAURENZ2005

LEICK2003

LOMBORG2001

LWK WE1999

MÄHNERT ET AL.2002

MOERSCHNER2000

MOERSCHNER\&GEROWITT1999

MOERSCHNER\&LÜCKE2000

$\mathrm{MoH} 2000$
Kuratorium für Technik und Bauwesen in der Landwirtschaft e.V. (Ed.): Faustzahlen für die Landwirtschaft 13. Auflage, Landwirtschaftsverlag, Münster-Hilltrup 2005 - ISBN 3-78432194-1

Kuratorium für Technik und Bauwesen in der Landwirtschaft e.V. (Ed.): Gasausbeuten in landwirtschaftlichen Biogasanlagen, Landwirtschaftsverlag, Münster-Hilltrup 2005

Lange (Hrsg.): Chemische Pflanzenschutzmittel, Online unter: http://www.hof-lange.de/agrar/seite6.htm, Online am 12.12.2005

Laurenz L.: Pflanzenbauliche Aspekte der NawaRoBeschaffung und der Verwertung der Gärsubstrate, Vortrag im Rahmen der Beratung Pflanzenproduktion der Landwirtschaftskammer NRW (09.11.2005), Münster 2005

Leick B. C. E.: Emission von Ammoniak $\left(\mathrm{NH}_{3}\right)$ und Lachgas $\left(\mathrm{N}_{2} \mathrm{O}\right)$ von landwirtschaftlich genutzten Böden in Abhängigkeit von produktionstechnischen Maßnahmen, Hohenheim, Universität, Fakultät Agrarwissenschaften, Dissertation 2003

Lomborg Bjørn: The sceptical environmentalist: measuring the real state of the world, Cambridge University Press, Cambridge 2001 - ISBN 0-521-80447-7

Landwirtschaftskammer Weser-Ems (Ed.): Ergebnisse von Prüfungen und Feldversuchen mit Mais Erntejahr 1998, OIdenburg 1999

Mähnert P., Schelle H., Heiermann M.: Futtergräser als Kosubstrat für die Biomethanisierung, In: Biogas und Energielandwirtschaft - Potential, Nutzung, Grünes Gas ${ }^{\mathrm{TM}}$, Ökologie und Ökonomie, Bornimer Agrartechnische Berichte Heft 32, Potsdam 2002

Moerschner E.J.: Stoff- und Energiebilanzen von Ackerbausystemen unterschiedlicher Intensität: eine Untersuchung an den Rapsfruchtfolgen des Göttinger INTEX-Systemversuchs, Forschungsbericht Agrartechnik des Arbeitskreises Forschung und Lehre der Max-Eyth-Gesellschaft 389, dissertation.de Verlag, Berlin 2002 - ISBN 3-89825-423-2

Moerscher E.J., Gerowitt B.: Direct and indirect energy use in arable farming - an example on winter wheat in Northern Germany, In: Agricultural data for Life Cycle Assessment, Weidema B.P.(ed.) Meeusen M.J.G. (ed.), Agricultural Economics Research Institute (LEI), (NL) Le Hague 1999 - ISBN 90-5242-563-9

Moerschner J., Lücke W.: Stoffstromanalysen in der Pflanzenproduktion, In: Landtechnik Fachzeitschrift für Agrartechnik und ländliches Bauen 3 (2000), Landwirtschaftsverlag $\mathrm{GmbH}$, Münster 2000

Ministry of Housing (Ed.): Eco indicator '99 Manual for designers A damage orientated method for impact assessment, MoH Spatial Planning and Development, (NL) The Hague 2000 
MÜLLER-WENK1998a

MÜLLER-WENK1998b

MÜLLER-WENK2004

NemeCEK et AL.2001

NEMECEK ET AL.2003

NemeCEK ET AL.2004

ODPM2006

ÖKO-CONTROL2004

OTT\&TAMM2003

PATYK/REINHARDT1997

PINGEL2006

PRECHTL ET AL.2005
Müller-Wenk R.: Land use - Them main threat to species, How to include land use in LCA, in IWÖ-Diskussionsbeitrag Nr. 64 (1998), Institute for Economy and Ecology, St. Gallen University (CH) - ISBN 3-906502-66-X

Müller-Wenk R.: Depletion of Abiotic Resources Weighted on the Base of "Virtual" Impacts of Lower Grade Deposits in Future, IWÖ Diskussionsbeitrag Nr. 57 (1998), University of St. Gallen - ISBN 3-906502-57-0

Müller-Wenk Ruedi: A Method to Include in LCA Road Traffic Noise and ist Health Effects, In: Int. J LCA 9 (2) (2004), 76-85

Nemecek T., Gaillard G., Frick C.: Ökobilanzierung von Silo und Körnermais, In: Maisanbau wohin? Fachtagung der RAC (1.2.01) und der FAL (28.2.01), FAL Reckenholz, CH - Reckenholz 2001

Nemecek, T., Heil A., Huguenin, O., Meier, S., Erzinger S., Blaser S., Dux. D., Zimmermann A.: Life Cycle Inventories of Agricultural Production Systems. Final report ecoinvent 2000. Volume: 15. Swiss Centre for LCI, FAL \& FAT, $(\mathrm{CH})$ Dübendorf 2003

Nemecek T., Heil A., Huguenin O., Meier S., Erzinger S., Blaser S., Dux D., Zimmermann A.: Life Cycle Inventories of Agricultural Production Systems. Final report ecoinvent 2000. Volume: 15. Issue: 0. Swiss Centre for LCI, FAL \& FAT, (CH) Dübendorf 2004

Office of the Deputy Prime Minister (ed.): An introduction to environmental impact assessment (04/10/2006), Online: http://www.odpm.gov.uk/index.asp?id=1143249

öko - control GmbH (Ed.): Bericht über die Durchführung von Emissionsmessungen, öko - control $\mathrm{GmbH}$, Ingenieurbüro für Arbeitsplatz- und Umweltanalyse, Berichtsnummer 2-041-086.1, 28.10.2004

Ott M., Tamm D.: Anforderungen beim Einsatz von Biogas in Brennstoffzellen, In: Gülzower Fachgespräche Band 21, Workshop „Aufbereitung von Biogas“, Fachagentur Nachwachsende Rohstoffe (FNR), Gülzow 2003

Patyk A., Reinhardt A.: Düngemittel - Energie- und Stoffstrombilanzen, Vieweg Verlag, Braunschweig/Wiesbaden 1997 - ISBN 3-528-06885-X

Pingel L.: Technische und ökonomische Analyse der Brennstoffzellennutzung in der Biogastechnik (Diplomarbeit), HAWK Fakultät Ressourcenmanagement, Göttingen 2006

Prechtl S., Anzer T., Schneider R., Faulstich M.: Biogasaufbereitung zu Wasserstoff, Vortrag im Rahmen des OTTIProfiforum Stationäre und portable Brennstoffzellensysteme 16. und 17. Februar 2005, Regensburg 
REINHARDT1997

REMMERT1992

RINALDI\&GAILLARD1999

RINALDI\&STADLER2002

RINALDI ET AL.2005

RODE ET AL.2005

ROEDENBECK2004

RÜHLE2005

RÜHS2001

SCHINDLER2004

SCHOLLES2001

SCHÖN ET AL.1993
Reinhardt G., Bilanzen über die gesamten Lebenswege, In: Kaltschmitt M., Reinhardt G. (Hrsg.) Nachwachsende Energieträger - Grundlagen, Verfahren, ökologische Bilanzierung, Vieweg Verlag, Braunschweig/Wiesbaden 1997

Remmert H.: Ökologie, 5. Auflage, Springer-Verlag Berlin Heidelberg New York 1992

Rinaldi M., Gaillard G.: Treibstoffverbrauch und Abgase landwirtschaftlicher Traktoren, In: Agrarforschung 6 (6) 1999, Bundesamt für Landwirtschaft (Schweiz), 212-214

Rinaldi M., Stadler E.: Trends im Abgasverhalten landwirtschaftlicher Traktoren, In: FAT Berichte 577 (2002), FAT Tänikon, $(\mathrm{CH})$ Ettenhausen 2002

Rinaldi M., Erzinger S., Stark R.: Treibstoffverbrauch und Emissionen von Traktoren bei landwirtschaftlichen Arbeiten. Ausführliche Darstellung der Methoden, Messungen und Ergebnisse, FAT Schriftenreihe Nr. 65, FAT Tänikon, $(\mathrm{CH})$ Ettenhausen 2005

Rode M., Scheider C., Ketelhake G., Reißhauer D.: Naturschutzverträgliche Erzeugung und Nutzung von Biomasse zur Wärme- und Stromgewinnung, BfN-Skripten 136, Bundesamt für Naturschutz (Hrsg.), Bonn-Bad Godesberg 2005

Roedenbeck I.A.E.: Bewertungskonzepte für eine nachhaltige und umweltverträgliche Landwirtschaft, BIOGUM-

Forschungsbericht Nr. 8, Universität Hamburg, Hamburg 2004 - ISBN 3-9806859-7-7

Rühle A.: Wasserstoff und Wirtschaft Investieren in eine saubere Zukunft, $\mathrm{H}_{2}$ ydrogeit-Verlag, Kremmen 2005 ISBN 3-937863-02-8

Rühs, M.: Anwendung des Hemerobie-Konzeptes in Agrarlandschaften am Beispiel des Biosphärenreservates Scharfheide-Chorin, Agrarökologie (40), Verlag Agrarökologie, Bern Hannover 2001 - ISBN 3-909192-20-3

Schindler M.: Wirtschaftlichkeit von Biogasanlagen, Vortrag im Rahmen der Bioenergieregion Göttinger Land 28.04.2004, Bioenergiehof Obernjesa, Obernjesa 2004

Scholles F.: Die ökologische Risikoanalyse und ihre Weiterentwicklung, In: Gesellschaftswissenschaftliche Grundlagen Planungsmethoden (Vorlesungsskript SS 2001), Universität Hannover Institut für Umweltplanung 2001

Schön M., Walz R., Angerer G., Bätcher K., Böhm E., Hillenbrand T., Hiessl H., Reichert J.: Emissionen der Treibhausgase Distickstoffoxid und Methan in Deutschland Emissionsbilanz, Identifikation von Forschungs- und Hanlungsbedarf sowie die Erarbeitung von Handlungsempfehlungen, Berichte 9/93 Umweltbundesamt Berichtsnummer 93121, Erich Schmidt Verlag Berlin, ISBN 3-50303495-1 
SCHNEIDER ET AL.2003

SCHNELL2003

SCHMIDT2006

SCHRÖTER2005

SCHUMACHER1999

SCHWAB2004

SCHREINER ET AL.2001

SETAC1993

SETAC1994

SIB2006

SIMAPRO2006

SKLORZ ET AL.2003
Schneider R., Prechtl S., Anzer T., Faulstich M.: Mikrobiologische Entschwefelung von Biogas, In: Gülzower Fachgespräche Band 21, Workshop „Aufbereitung von Biogas“, Fachagentur Nach- wachsende Rohstoffe (FNR), Gülzow 2003

Schnell H.-J.: Störstoffe im Biogas, In: Gülzower Fachgespräche Band 21, Workshop „Aufbereitung von Biogas“, Fachagentur Nach- wachsende Rohstoffe (FNR), Gülzow 2003

Schmidt W.: Energiemais - Aktueller Stand und Perspektiven aus Sicht der Pflanzenzüchter (10.05.2006), online:

http://www.kws-energie.de/media/downloads/22/ energiemais_aktuell.pdf

Schröter F.: Flächenverbrauch in der Bundesrepublik Deutschland (29.12.2005), Online unter: http://www-public.tubs.de:8080/ schroete/Bodenverbrauch/Aktueller_Stand.htm

Schumacher I.: Vorläufiger Versuchsbericht zur Lagerung von Gülle und Kofermentationssubstraten im Rahmen des DBU Vorhabens „Untersuchungen der Emissionen direkt und indirekt klimawirksamer Spurengase $\left(\mathrm{NH}_{3}, \mathrm{~N}_{2} \mathrm{O}\right.$ und $\left.\mathrm{CH}_{4}\right)$ nach Ausbringung von Kofermentationsrückständen sowie Entwicklung von Verminderungsstrategien“.

Schwab M.: Wirtschaftsdüngeranfall in der Bundesrepublik Deutschland, Kuratorium für Technik und Bauwesen in der Landwirtschaft e.V., Darmstadt, 2004

Schreiner J., Prüter J., Evers M.: Leitbilder des Naturschutzes und deren Umsetzung mit der Landwirtschaft Ziele, Instrumente und Kosteneiner umweltschonenden und nachhaltigen Landnutzung im niedersächsischen Elbetal, Alfred-Töpfer-Akademie für Naturschutz, Schneverdingen 2001

Setac (Ed.): Guidelines for Life-Cycle Assessment A "Code of Practice", Society of Environmental Toxicology and Chemistry, (B) Brussel, 1993

J. Fava, R.F. Weston, A.A. Jensen, et. al.: Life-Cycle Assessment Data Quality: A Conceptual Framework, Oktober 1994, Wintergreen Virginia USA

Science in the box (Ed.): Life cycle impact assessment (LCIA) (14.02.2006), Online unter: http://www.scienceinthe box.com/en_UK/sustainability/lcia_en.html

Sima Pro 7.0.0, PRé Consultants 2006

Sklorz M., Schnelle-Kreis J., Gottlieb A., Kühner N., Schmid B.: Untersuchungen zum Einsatz von Oxidationskatalysatoren an landwirtschaftlichen Biogas-Verbrennungsmotoren (Schlussbericht), BlfA GmbH (Ed.), Augsburg 2003 
SOMMER ET AL.2001

SPIEKERS2005

SRU1985

STEFFEN2006

SUKOPP\&LANGER1996

TENTSCHER2004

THOMPSON ET AL.1990

TI AIR2002

TLL2005

TRINNAMAN2004

TSCHACHTLI ET AL.2004

TSCHEPE/KROHMER2003

UBA1999
Sommer S-G., Petersen S.-O., Moller H.-B.: Reduktion af dirvhusgasemission fra gylle og organisk affald ved biogasbehandling, DJF raport Husdyrbrug Nr. 31 (Danmarks JordbrugsForskning), (DK) Tjele 2001

Spiekers H.: Kartoffelpülpe neu bewertet, Information der Landwirtschaftskammer Rheinland (Hrsg.), Online unter: http://www.futtermittel.net/pdf/kartoffelpuelpe.pdf, Online am 15.12.2005

Rat von Sachverständigen für Umweltfragen (SRU): Umweltprobleme der Landwirtschaft Sondergutachten, Der Bundesminister des Innern (Ed.), Bonn 1985 - ISSN 0343-1312

Steffen H.-P.: Anbautechnik Futterrüben (30.04.2006), online: http://www.samensteffen.ch/deutsch/futterrueben-anbau.htm

Sukopp H, Langer A.: Campanula rapunculoides - ein Apophyt in der Vegetation Mitteleuropas, In. Festschrift für Reinhard Bornkamm, Gesellschaft für Ökologie, Berlin 1996, 261-276

Tentscher W.: The best biogas partner for slurry, In: agrifuture European agribusiuness magzine 3 (2004), Max-Eyth Verlag, 31-33

Thompson M., Ellis R., Wildavsky A.: Cultural Theory, Westview Press, (USA) Boulder 1990 - ISBN 0-8133-7863-x

Technical Instrucitions on Air Quality Control, 30. Juli 2002, GMBI. 2002, Heft 25-29, S.511-605

TLL (Ed.): Umweltsicherung Landwirtschaft Das Indikatorensystem USL (actualised 2005), Thüringische Landesanstalt für Landwirtschaft, Online: http://www.tll.de/kul/ub_idx.htm

Trinnaman J. (Ed.): 2004 Survey of Energy Resources, Word Energy Council, Elsevier Science, (GB) Oxford 2004 - ISBN 0-08-044410-5

Tschachtli R., Dubois D., Padruot M.F.: Ertrag und Qualität der Ackerkulturen, In: Integrierter und biologischer Anbau im Vergleich - Anbausystemversuch Burgrain Resultate aus 12 Jahren Forschung (1991 - 2002), Schriftenreihe der FAL (52), (CH) Tänikon 2004 - ISBN 3-905608-73-1

Tschepe M., Krohmer K-H.: Verfahrenstechnik der Ausbringung von Kofermentationssubstraten Teilbericht C: Ausbringungstechnik, In: Untersuchung der Emission direkt und indirekt klimawirksamer Spurengase $\left(\mathrm{NH}_{3}, \mathrm{~N}_{2} \mathrm{O}\right.$ und $\left.\mathrm{CH}_{4}\right)$ während der Lagerung und nach der Ausbringung von Kofermentationsrückständen sowie Entwicklung von Verminderungsstrategien (DBU-AZ 08912) Abschlussbericht, Bonner Agrikulturchemische Reihe, Band 16, Bonn 2003

Umweltbundesamt (Hrsg.): Bewertung in Ökobilanzen Methode des Umweltbundesamtes zur Normierung von Wirkungsindikatoren, Ordnung (Rangbildung) von

Wirkungskategorien und zur Auswertung nach ISO 14042 und 14043, Version `99, Umweltbundesamt, Berlin 1999 
VDI1997

VITLOX\&MICHOT1999

WAMHOFFF1997

WEGENER2005

WEGENER SLEESWIJK ET AL.1996

WEILAND2003a

WEILAND2003b

WEILAND2004

WHO1946

WHO1987

WHO2005

WIKIPEDIA2006
Verein Deutscher Ingenieure (Ed.): Cumulative Energy Demand: Terms, Definitions, Methods of Calculation VDI 4600, Beuth Verlag GmbH, Düsseldorf 1997

Vitlox O.W.C, Michot B.: Energy consumption in agricultural mechanisation, In: Agricultural data for Life Cycle Assessment, Weidema B.P.(ed.) Meeusen M.J.G. (ed.), Agricultural Economics Research Institute (LEI), (NL) Le Hague 1999 ISBN 90-5242-563-9

Wamhoff W.: Schlußbetrachtung, In: Umweltverträgliche Pflanzenproduktion - Indikatoren, Bilanzierungsansätze und ihre Einbindung in Ökobilanzen, Diepenbrock (Ed.), Osnabrück 1997, 313-314 - ISBN 3-535-02476-5

Wegener J.: Einfluss der Silagequalität auf die Gasausbeute, Vortrag im Rahmen des Biogasanlagen Betreiber Seminars, Ländliche Erwachsenenbildung Niedersachsen, Fallingbostel 2005

Wegener Sleeswijk A., Kleijn R., Meeusen-von Onna M.J.G., Leneman H., Sengers H.H.W.J.M, Zeits van H., Reus

J.AW.A.: Application of LCA to agricultural products, Centrum voor Milieukunde, CML Report 130, Leiden 1996

Weiland P.: Wissenschaftliche Bewertung einer Pilotanlage zur Herstellung von hochkonzentrierten Biodüngern aus anaerobem Gärsubstrat 1. Zwischenbericht, Institut für Technologie und Biosystemtechnik (FAL), Braunschweig 2003

Weiland P.: Eigenschaften und Zusammensetzung von Biogas, In: Gülzower Fachgespräche Band 21, Workshop „Aufbereitung von Biogas", Fachagentur Nachwachsende Rohstoffe (FNR), Gülzow 2003

Weiland P.: Wissenschaftliche Bewertung einer Pilotanlage zur Herstellung von hochkonzentrierten Biodüngern aus anaerobem Gärsubstrat 2. Zwischenbericht, Institut für Technologie und Biosystemtechnik (FAL), Braunschweig 2004

World Health Organisation (Ed.): Preamble to the Constitution of the World Health Organization as adopted by the International Health Conference, New York, 19-22 June, 1946; signed on 22 July 1946 by the representatives of 61 States (Official Records of the World Health Organization, no. 2, p. 100) and entered into force on 7 April 1948

World Health Organisation (Ed.): The IPCS Conceptual Framework for Cancer Risk Assessment (24.03.2006), Online: http://www.who.int/ipcs/methods/harmonization/ en/MOA_text.pdf

World Health Organisation (Ed.): Energy, sustainable development and health (19.04.2006), Online:

http://www.euro.who.int/globalchange/topics/20030310_7

Wikipedia (Ed.): Plough (27.04.2006), Online:

http://en.wikipedia.org/wiki/Ploughing 
WILFERT ET AL.2004

WINKELMANN2005

WLV2005

WULF ET AL.2002

WULF ET AL.2003

WULF ET AL.2003

ZACHARIASSE1999

ZSCHEISCHLER1990
Wilfert R., Nill M., Schattauer A.: Biogasgewinnung aus Gülle, organischen Abfällen und aus angebauter Biomasse - Eine technische, ökologischen und ökonomische Analyse -, Institut für Energetik und Umwelt gGmbH (IE), Leipzig 2004

Winkelmann J.: Biotechnische Siliermittel in der Anwendung Stand und Entwicklungstendenzen, Vortrag am 28.11.2005, Inst. f. Tierzucht und Haustiergenetik Universität Göttingen, Göttingen 2005

Westfälisch-Lippischer Landwirtschaftsverband e.V. (Hrsg.): Raps, Online unter:

http://www.bauernhof.net/lexikon/lex_pqr/raps.htm, Online am 14.12.2005

Wulf S., Maeting M., Clemens J.: Application technique and slurry co-fermentation effects on ammonia, nitrous oxide and methane emissions after spreading: I. Ammonia Volatilization, In. Journal of Environmental Quality 31 (2002), 17891794

Wulf S., Maeting M., Brenner A., Clemens J.: Emissionen bei Ausbringung Teilbericht $D$ : Einfluss von Substrateigentschaften und Applikationstechnik auf die Emissionen von $\mathrm{NH}_{3}, \mathrm{~N}_{2} \mathrm{O}$ und $\mathrm{CH}_{4}$ nach Ausbringung von Kofermentationsrückständen, In: Untersuchung der Emission direkt und indirekt klimawirksamer Spurengase $\left(\mathrm{NH}_{3}, \mathrm{~N}_{2} \mathrm{O}\right.$ und $\left.\mathrm{CH}_{4}\right)$ während der Lagerung und nach der Ausbringung von

Kofermentationsrückständen sowie Entwicklung von Verminderungsstrategien (DBU-AZ 08912) Abschlussbericht, Bonner Agrikulturchemische Reihe, Band 16, Bonn 2003

Wulf S., Brenner A., Clemens J., Döhler H., Jäger P., Krohmer K.-H., Maeting M., Rieger C., Schumacher I., Tschepe M., Vandré R., Weiland P.: Untersuchung der Emission direkt und indirekt klimawirksamer Spurengase $\left(\mathrm{NH}_{3}, \mathrm{~N}_{2} \mathrm{O}\right.$ und $\left.\mathrm{CH}_{4}\right)$ während der Lagerung und nach der Ausbringung von Kofermentationsrückständen sowie Entwicklung von Verminderungsstrategien (DBU-AZ 08912) Abschlussbericht, Bonner Agrikulturchemische Reihe Band 16, Bonn 2003 - ISBN 3933865-32-8

Zachariasse L.C.: Preface, In: Agricultural data for Life Cycle Assessment, Weidema B.P.(ed.) Meeusen M.J.G. (ed.), Agricultural Economics Research Institute (LEI), (NL) Le Hague 1999 - ISBN 90-5242-563-9

Zscheischler J.: Handbuch Mais: umweltgerechter Anbau; wirtschaftliche Verwertung, 4. vollkommen überarbeitete Auflage, DLB Verlag, Frankfurt/Main 1990 - ISBN 3-7690-04736 


\section{Annex}

Table 7.1: List of abbreviations

\begin{tabular}{|c|c|}
\hline Abbreviation & full title \\
\hline$\sigma_{g}^{2}$ & Squared geometric standard deviation \\
\hline $\mathrm{a}$ & anno, year \\
\hline atd & Average transport distance \\
\hline CED & Cumulative Energy Demand \\
\hline CEN & European Committee for Standardization \\
\hline CFC & Chlorofluorcarbons \\
\hline $\mathrm{CH}_{4}$ & Methane \\
\hline $\mathrm{CHP}$ & Combined-heat-and-power-plant \\
\hline $\mathrm{CO}_{2}$ & Carbon dioxide \\
\hline DALY & Disability-adjusted life years \\
\hline $\mathrm{dB}$ & Decibel \\
\hline DM & Dry matter \\
\hline DQI & Data quality indicatot \\
\hline EDIP & Environmental design of industrial products \\
\hline EIA & Environmental impact assessment \\
\hline EN ISO & European norm international standardisation organisation \\
\hline$E Q$ & Ecosystem Quality \\
\hline ES & Environmental statement \\
\hline gap & Good agricultural practice \\
\hline $\mathrm{HCl}$ & Hydrogen Chloride, Chlorane \\
\hline ITOX & Indicator Effects Toxic substances \\
\hline $\mathrm{KEA}_{\mathrm{H}}$ & $\begin{array}{l}\text { Cumulative energy demand, production (dt. Kumulierter Energieaufwand der Herstel- } \\
\text { lung) }\end{array}$ \\
\hline $\mathrm{KEA}_{\mathrm{N}}$ & $\begin{array}{l}\text { Cumulative energy demand, utilisation (dt. Kumulierter Energieaufwand der Nut- } \\
\text { zung) }\end{array}$ \\
\hline $\mathrm{KEA}_{\mathrm{E}}$ & $\begin{array}{l}\text { Cumulative energy demand, disposal (dt. Kumulierter Energieaufwand der Entsor- } \\
\text { gung) }\end{array}$ \\
\hline KUL & $\begin{array}{l}\text { Criteria for an environmentally compatibel agriculture (dt. Kriterien umweltverträgli- } \\
\text { cher Landwirtschaft) }\end{array}$ \\
\hline kWh & Kilowatt hour \\
\hline LCA & Life-cycle-assessment \\
\hline $\mathrm{LCl}$ & Life-cycle-inventory \\
\hline LCIA & Life-cycle-inventory-analysis \\
\hline LCU & Large cattle units \\
\hline $\mathrm{m}$ & Million \\
\hline MCFC & Molten carbonate fuel cell \\
\hline NEL & net energy lactation (dt. Nettoenergielaktation) \\
\hline $\mathrm{N}_{2}$ & Nitrogen \\
\hline $\mathrm{N}_{2} \mathrm{O}$ & Laughing gas, Dinitrogen Oxide \\
\hline NDP & Naturalness degradation potentials \\
\hline $\mathrm{NH}_{3}$ & Ammonia \\
\hline $\mathrm{NH}_{4}$ & Ammonium \\
\hline $\mathrm{NO}_{2}$ & Nitrogen dioxide \\
\hline $\mathrm{NO}_{\mathrm{x}}$ & Nitrogen oxide \\
\hline $\mathrm{NO}_{3}$ & Nitrate \\
\hline NOEC & No observable effect level \\
\hline $\mathrm{N}_{\text {tot }}$ & Total nitrogen \\
\hline $\mathrm{O}_{3}$ & Ozone \\
\hline oDM & Organic dry matter content \\
\hline ODP & Ozone depletion potential \\
\hline PAF & Potentially affected fraction \\
\hline PDF & Potentially disappeared fraction of vascular plants \\
\hline $\mathrm{pH}$ & $-\log _{10}\left[\mathrm{H}^{+}\right]$ \\
\hline
\end{tabular}




\begin{tabular}{|l|l|}
\hline PNV & Potential natural vegetation \\
\hline $\mathrm{PO}_{4}-\mathrm{P}$ & Phosphate phosphor \\
\hline REPRO & Reproduction of soil productivity (dt. Reproduktion der Bodenfruchtbarkeit) \\
\hline $\mathrm{SF}_{6}$ & Sulfur Hexafluoride \\
\hline $\mathrm{SO}_{2}$ & Sulfur dioxide \\
\hline $\mathrm{SPM}$ & Suspended particulate matter \\
\hline $\mathrm{TSP}$ & Total suspended particulate \\
\hline $\mathrm{UV}$ & ultraviolet \\
\hline VDI & The Association of German Engineers (dt. Verein deutscher Ingenieure) \\
\hline VOC & Voluntile organic compounds \\
\hline WHO & World Health Organisation \\
\hline YLD & Years leved Disabled \\
\hline YLL & Years life lost \\
\hline & \\
\hline & \\
\hline
\end{tabular}

Table 7.2: List of units

\begin{tabular}{|l|r|l|l|}
\hline \multicolumn{1}{|c|}{ Name } & Factor & \multicolumn{1}{c|}{ Unit } & \multicolumn{1}{c|}{ Quantity } \\
\hline$\%$ & 0.01 & $\mathrm{n}$ & Dimensionless \\
\hline$\mu \mathrm{Bq}$ & 0.000001 & $\mathrm{~Bq}$ & Radioactivity \\
\hline$\mu \mathrm{g}$ & 0.000000001 & $\mathrm{~kg}$ & Mass \\
\hline$\mu \mathrm{m}$ & 0.000001 & $\mathrm{~m}$ & Length \\
\hline$\mu \mathrm{Pt}$ & 0.000001 & $\mathrm{Pt}$ & Indicator \\
\hline $\mathrm{Bq}$ & 1 & $\mathrm{~Bq}$ & Radioactivity \\
\hline $\mathrm{cm}$ & 0.01 & $\mathrm{~m}$ & Length \\
\hline $\mathrm{cm} 2$ & 0.0001 & $\mathrm{~m} 2$ & Area \\
\hline $\mathrm{cm} 2 \mathrm{a}$ & 0.0001 & $\mathrm{~m} 2 \mathrm{a}$ & Land use \\
\hline $\mathrm{cm} 3$ & 0.000001 & $\mathrm{~m} 3$ & Volume \\
\hline $\mathrm{cm} 3 \mathrm{y}$ & 0.000001 & $\mathrm{~m} 3 \mathrm{y}$ & Volume.Time \\
\hline $\mathrm{day}$ & 86400 & $\mathrm{~S}$ & Time \\
\hline $\mathrm{dB}$ & 1 & $\mathrm{~dB}$ & Noise \\
\hline $\mathrm{dm}$ & 0.1 & $\mathrm{~m}$ & Length \\
\hline $\mathrm{dm} 2$ & 0.01 & $\mathrm{~m} 2$ & Area \\
\hline $\mathrm{g}$ & 0.001 & $\mathrm{~kg}$ & Mass \\
\hline $\mathrm{GJ}$ & 1000 & $\mathrm{MJ}$ & Energy \\
\hline $\mathrm{GPt}$ & 1000000000 & $\mathrm{Pt}$ & Indicator \\
\hline $\mathrm{hr}$ & 3600 & $\mathrm{~s}$ & Time \\
\hline $\mathrm{J}$ & 0.000001 & $\mathrm{MJ}$ & Energy \\
\hline $\mathrm{kBq}$ & 1000 & $\mathrm{~Bq}$ & Radioactivity \\
\hline $\mathrm{kg}$ & 1 & $\mathrm{~kg}$ & Mass \\
\hline $\mathrm{kgkm}$ & 0.001 & $\mathrm{tkm}$ & Transport \\
\hline $\mathrm{kJ}$ & 0.001 & $\mathrm{MJ}$ & Energy \\
\hline $\mathrm{km}$ & 1000 & $\mathrm{~m}$ & Length \\
\hline $\mathrm{km} 2$ & 1000000 & $\mathrm{~m} 2$ & Area \\
\hline $\mathrm{km} 2 \mathrm{a}$ & 1000000 & $\mathrm{~m} 2 \mathrm{a}$ & Land use \\
\hline $\mathrm{kmy}$ & 1000 & $\mathrm{my}$ & Length.Time \\
\hline $\mathrm{kPt}$ & 1000 & $\mathrm{Pt}$ & Indicator \\
\hline $\mathrm{ktkm}$ & 1000 & $\mathrm{tkm}$ & Transport \\
\hline $\mathrm{kWpk}$ & 1 & $\mathrm{kWpk}$ & Power \\
\hline $\mathrm{I}$ & 0.001 & $\mathrm{~m} 3$ & Volume \\
\hline $\mathrm{m}$ & 1 & $\mathrm{~m}$ & Length \\
\hline $\mathrm{M} \$$ & 1 & $\mathrm{~m} 2$ & Area \\
\hline $\mathrm{m} 2$ & $\mathrm{~m} 2 \mathrm{a}$ & Land use \\
\hline $\mathrm{m} 2 \mathrm{a}$ & & \\
\hline & & & \\
\hline
\end{tabular}




\begin{tabular}{|l|r|l|l|}
$\mathrm{m} 3$ & 1 & $\mathrm{~m} 3$ & Volume \\
\hline $\mathrm{m} 3 \mathrm{y}$ & 1 & $\mathrm{~m} 3 \mathrm{y}$ & Volume.Time \\
\hline $\mathrm{mBq}$ & 0.001 & $\mathrm{~Bq}$ & Radioactivity \\
\hline $\mathrm{mg}$ & 0.000001 & $\mathrm{~kg}$ & Mass \\
\hline $\mathrm{Mg}$ & 1000 & $\mathrm{~kg}$ & Mass \\
\hline $\mathrm{min}$ & 60 & $\mathrm{~s}$ & Time \\
\hline $\mathrm{MJ}$ & 1 & $\mathrm{MJ}$ & Energy \\
\hline $\mathrm{mm}$ & 0.001 & $\mathrm{~m}$ & Length \\
\hline $\mathrm{mm} 2$ & 0.000001 & $\mathrm{~m} 2$ & Area \\
\hline $\mathrm{mm} 2 \mathrm{a}$ & 0.000001 & $\mathrm{~m} 2 \mathrm{a}$ & Land use \\
\hline $\mathrm{mm} 3$ & 0.00000001 & $\mathrm{~m} 3$ & Volume \\
\hline $\mathrm{mPt}$ & 0.001 & $\mathrm{Pt}$ & Indicator \\
\hline $\mathrm{MPt}$ & 1000000 & $\mathrm{Pt}$ & Indicator \\
\hline $\mathrm{my}$ & 1 & $\mathrm{my}$ & Length.Time \\
\hline $\mathrm{n}$ & 1 & $\mathrm{n}$ & Dimensionless \\
\hline $\mathrm{nBq}$ & 0.00000001 & $\mathrm{~Bq}$ & Radioactivity \\
\hline $\mathrm{ng}$ & $1 \mathrm{E}-12$ & $\mathrm{~kg}$ & Mass \\
\hline $\mathrm{nPt}$ & 0.00000001 & $\mathrm{Pt}$ & Indicator \\
\hline $\mathrm{p}$ & 1 & $\mathrm{p}$ & Amount \\
\hline $\mathrm{personkm}$ & 1 & $\mathrm{personkm}$ & Person.Distance \\
\hline $\mathrm{pg}$ & $1 \mathrm{E}-15$ & $\mathrm{~kg}$ & Mass \\
\hline $\mathrm{PJ}$ & 100000000 & $\mathrm{MJ}$ & Energy \\
\hline $\mathrm{Pt}$ & 1 & $\mathrm{Pt}$ & Indicator \\
\hline $\mathrm{s}$ & 1 & $\mathrm{~s}$ & Time \\
\hline $\mathrm{TJ}$ & 1000000 & $\mathrm{MJ}$ & Energy \\
\hline $\mathrm{tkm}$ & 1 & $\mathrm{tkm}$ & Transport \\
\hline & & \\
\hline
\end{tabular}




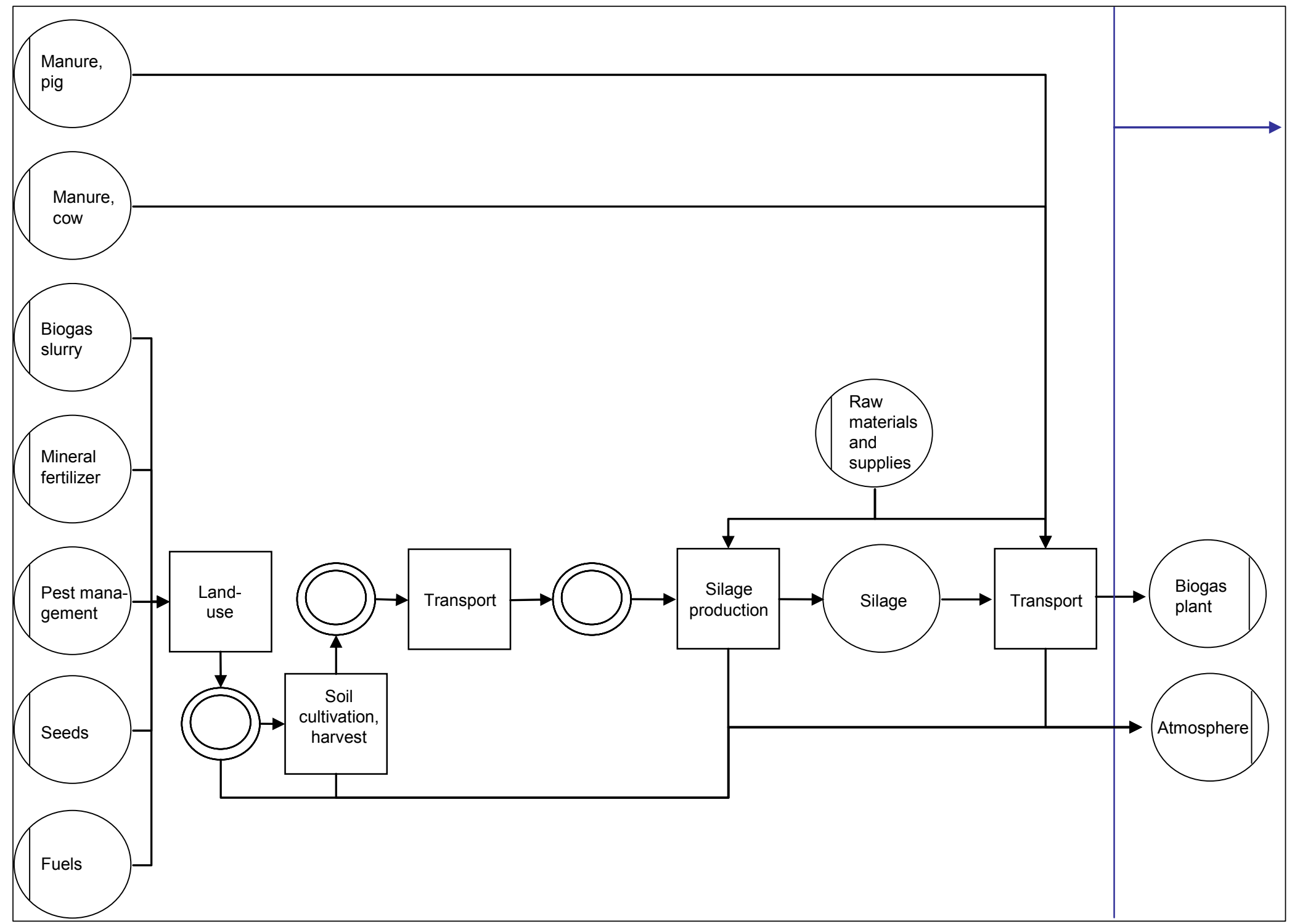

Figure 7.1: Relevant mass and energy flows of the input module 


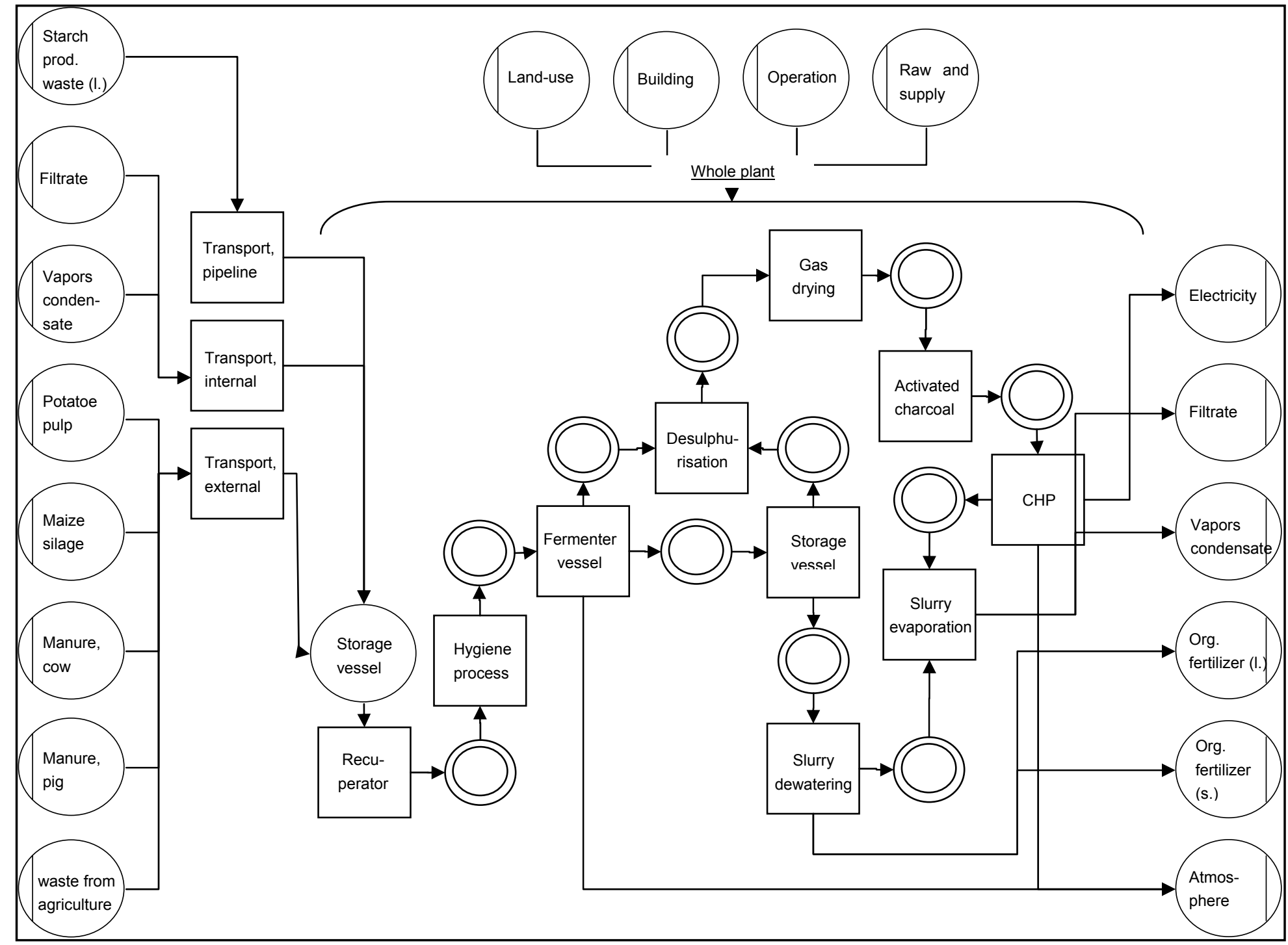

Figure 7.2: Scheme of a possible biogas plant configuration for $\mathrm{LCl}$ data collection 


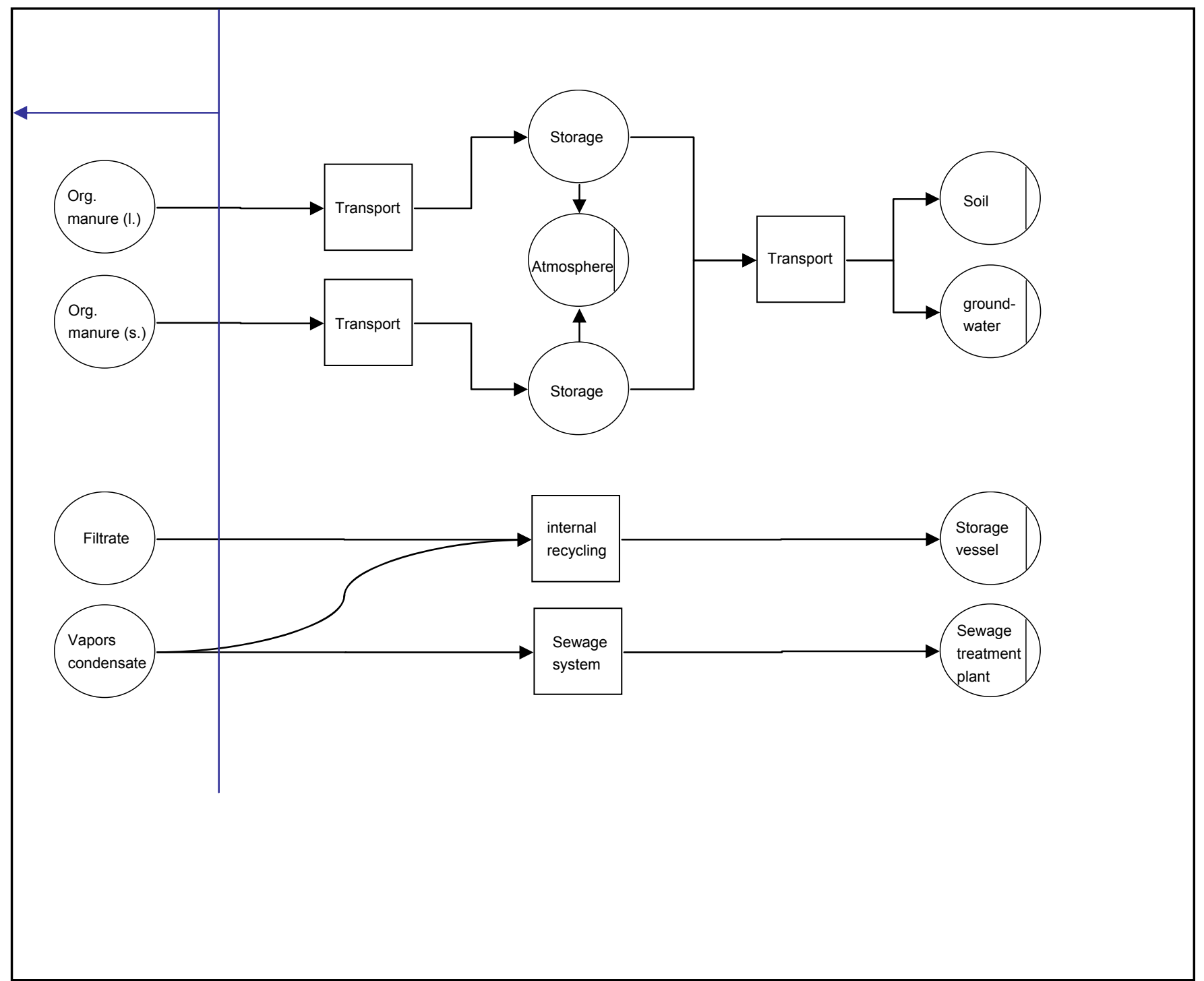

Figure 7.3: Scheme of biogas slurry utilisation after slurry treatment 
Table 7.3: Definition and description of Hemeroby classes and the Natural Degradation Potential (NDP) [KoWARIK1999, RüHS2001]

\begin{tabular}{|c|c|c|}
\hline $\begin{array}{l}\text { Hemeroby code (Hx), use } \\
\text { intensity }(\%) \text {, NDP }\end{array}$ & Hemeroby class & $\begin{array}{l}\text { Description (typical ecosystems and } \\
\text { vegetation, types of human influence) }\end{array}$ \\
\hline $\begin{array}{l}\mathrm{HO} \\
0 \% \\
\mathrm{NDP}=0.0\end{array}$ & Ahemerobic & $\begin{array}{l}\text { No human influence, e.g.: } \\
\text { - untouched rocky, peatbog and tundra re- } \\
\text { gions in some parts of Europe }\end{array}$ \\
\hline $\begin{array}{l}\mathrm{H} 1 \\
10 \% \\
\mathrm{NDP}=0.1\end{array}$ & Oligohemerobic & $\begin{array}{l}\text { Small human influence, e.g.: } \\
\text { - only indirect human influence through } \\
\text { deposition of airborne emissions } \\
\text { - salt meadows, growing dunes and peat- } \\
\text { bogs }\end{array}$ \\
\hline $\begin{array}{l}\mathrm{H} 2 \\
20 \% \\
\mathrm{NDP}=0.2\end{array}$ & $\begin{array}{l}\text { Oligo- to meso- } \\
\text { hemerobic }\end{array}$ & $\begin{array}{l}\text { Small to moderate human influence, e.g.: } \\
\text { - extensively managed forests (i.e. only little } \\
\text { removal of timber, trees of different age at } \\
\text { the same site, "Altersstufenwald", introduc- } \\
\text { tion of site-atypical species possible) } \\
\text { - extensively drained wetlands } \\
\text { - restored peatbogs } \\
\text { - some wet pastures }\end{array}$ \\
\hline $\begin{array}{l}\mathrm{H} 3 \\
30 \% \\
\mathrm{NDP}=0.3\end{array}$ & Mesohemerobic & $\begin{array}{l}\text { Moderate human influence, e.g.: } \\
\text { - moors and heathland } \\
\text { - managed forests } \\
\text { - moderately managed nutrient-poor grass- } \\
\text { land and extensive meadows } \\
\text { - shrubs and herbaceous vegetation along } \\
\text { unspoilt lakes and rivers } \\
\text { - permanent fallow land, fallow pasture (i.e. } \\
\text { rare mulching and mowing (o.2-0.5/year) }\end{array}$ \\
\hline $\begin{array}{l}\mathrm{H} 4 \\
40 \% \\
\mathrm{NDP}=0.4\end{array}$ & $\begin{array}{l}\text { Meso- to } \\
\text { euhemerobic }\end{array}$ & $\begin{array}{l}\text { Moderate to strong human influence, e.g.: } \\
\text { - intensively managed forests and young } \\
\text { secondary forests, frequented forests near } \\
\text { recreation areas, forest with unnatural high } \\
\text { share of conifers } \\
\text { - woods and bushes in parks, shrubs and } \\
\text { hedges in agricultural areas, shrubs and } \\
\text { herbaceous vegetation along rebuilt lakes } \\
\text { and rivers } \\
\text { - extensive orchard meadows } \\
\text { - extensively used permanent grassland (i.e. } \\
0.5-1.0 \text { cuts/year), no fertiliser, no pesti- } \\
\text { cides) }\end{array}$ \\
\hline $\begin{array}{l}\mathrm{H} 5 \\
50 \% \\
\mathrm{NDP}=0.5\end{array}$ & $\beta$-euhemerobic & $\begin{array}{l}\text { Strong human influence, e.g.: } \\
\text { - site-atypical coniferous forests, younger } \\
\text { reforestation } \\
\text { - orchard meadows } \\
\text { - ruderal vegetation of perennials } \\
\text { - permanent grassland (pasture or meadow) } \\
\text { managed with medium intensity (i.e. 1.5- } \\
3.0 \mathrm{LU} / \mathrm{ha} \text {, no ploughing, } 1-2 \text { cuts/year, fer- } \\
\text { tilisation according to nutrient removal) }\end{array}$ \\
\hline $\begin{array}{l}\mathrm{H} 6 \\
60 \% \\
\mathrm{NDP}=0.6\end{array}$ & $\begin{array}{l}\beta \text {-eu- to } \\
\text { euhemerobic }\end{array}$ & $\begin{array}{l}\text { Strong to very strong human influence, e.g.: } \\
\text { - plantation of hedges and bushes (e.g. in } \\
\text { gardens, along roads etc.) } \\
\text { - ruderal meadows, lawns with meadow } \\
\text { species } \\
\text { - permanent grassland (pasture or meadow) } \\
\text { managed with higher intensity (i.e. 1.5-3.0 } \\
\text { LU/ha, ploughing max. 0.2/year, 2-3 } \\
\text { cuts/year, fertilisation exceeds nutrient, }\end{array}$ \\
\hline
\end{tabular}




\begin{tabular}{|c|c|c|}
\hline & & removal slightly) \\
\hline $\begin{array}{l}\mathrm{H} 7 \\
70 \% \\
\mathrm{NDP}=0.7\end{array}$ & $\alpha$-euhemerobic & $\begin{array}{l}\text { Very strong human influence, e.g.: } \\
\text { - tree nurseries } \\
\text { - intensive gardening and cultivation of spe- } \\
\text { cial crops (e.g. fruits, vine) } \\
\text { - annual ruderal vegetation } \\
\text { - pasture under rotation, arable land, gar- } \\
\text { dens, which are managed according to the } \\
\text { principles of organic or extensive inte- } \\
\text { grated farming (i.e. }>3 \text { LU/ha, ploughing } \\
0.2-3.0 / y e a r, ~>3 \text { cuts/year, fertilisation ex- } \\
\text { ceeds nutrient removal slightly, application } \\
\text { of pesticides max. } 0.3 / \text { year) }\end{array}$ \\
\hline $\begin{array}{l}\mathrm{H} 8 \\
80 \% \\
\mathrm{NDP}=0.8\end{array}$ & $\begin{array}{l}\alpha \text {-eu- to poly- } \\
\text { hemerobic }\end{array}$ & $\begin{array}{l}\text { Very strong human influence to mainly artifi- } \\
\text { cial, e.g.: } \\
\text { - larger relicts of vegetation within urban or } \\
\text { industrial areas, vegetation of gravelled } \\
\text { surfaces } \\
\text { - intensively managed arable land and gar- } \\
\text { dens (i.e. ploughing }>3 / \text { year, fertilisation } \\
\text { exceeds nutrient removal significantly, ap- } \\
\text { plication of pesticides }>0.3 / \text { year) }\end{array}$ \\
\hline $\begin{array}{l}\mathrm{H} 9 \\
90 \% \\
\mathrm{NDP}=0.9\end{array}$ & Polyhemerobic & $\begin{array}{l}\text { Mainly artificial, e.g.: } \\
\text { - landfill and dump sites } \\
\text { - partly built-up areas railways, streets etc) } \\
\text { - surfaces covereds with new materials } \\
\text { - strong and long-term modification of bio- } \\
\text { topes }\end{array}$ \\
\hline $\begin{array}{l}\mathrm{H} 10 \\
100 \% \\
\mathrm{NDP}=1.0\end{array}$ & Metahemerobic & $\begin{array}{l}\text { Purely artificial, e.g.: } \\
\text { - completely sealed, built-up or contami- } \\
\text { nated surfaces (i.e. no habitat for plants) }\end{array}$ \\
\hline
\end{tabular}


Table 7.4: Transport efforts biogas plant

\begin{tabular}{|c|c|c|c|c|c|c|c|c|c|c|c|}
\hline date & output & \begin{tabular}{c|} 
input (incl. \\
precipitation)
\end{tabular} & $\begin{array}{c}\text { output/ } \\
\text { input }\end{array}$ & output & input & output & input & output & input & output & input \\
\hline Aug 03 & 8.182 .260 & 9.356 .060 & 0,875 & 6.659 & 8.317 & 296,0 & 369,6 & & & & \\
\hline Okt 03 & 7.545 .550 & 9.871 .268 & 0,764 & 5.048 & 5.042 & 224,4 & 224,1 & & & & \\
\hline Nov 03 & 6.183 .330 & 10.738 .496 & 0,576 & 5.143 & 3.588 & 228,6 & 159,5 & & & & \\
\hline Dez 03 & 3.205 .270 & 10.259 .992 & 0,312 & 3.134 & 5.485 & 139,3 & 243,8 & & & & \\
\hline Mrc 04 & 13.456 .680 & 12.723 .032 & 1,058 & 12.628 & 5.985 & 561,2 & 266,0 & & & & \\
\hline Apr 04 & 11.991 .170 & 13.809 .012 & 0,868 & 9.044 & 7.223 & 401,9 & 321,0 & & & & \\
\hline May 04 & 5.829 .210 & 6.192 .016 & 0,941 & 5117 & 5.997 & 227,4 & 266,5 & & & & \\
\hline Jun 04 & 5.310 .020 & 4.411 .024 & 1,204 & 3.402 & 6.801 & 151,2 & 302,3 & & & & \\
\hline Jul 04 & 5.556 .130 & 5.447 .852 & 1,020 & 3.925 & 6.366 & 174,5 & 282,9 & & & & \\
\hline Aug 04 & 7.663 .650 & 3.921 .970 & 1,954 & 5.463 & 4.449 & 242,8 & 197,7 & $1.036,5$ & $1.032,8$ & 490.192 & 678.130 \\
\hline Feb 05 & 2.815 .440 & 3.261 .984 & 0,863 & 2.333 & 3.886 & 103,7 & 172,7 & & & & \\
\hline Mrc 05 & 6.599 .620 & 4.400 .162 & 1,500 & 6.699 & 5.833 & 297,7 & 259,2 & & & & \\
\hline Apr 05 & 4.428 .520 & 3.299 .012 & 1,342 & 4.262 & 3.626 & 189,4 & 161,1 & & & & \\
\hline May 05 & 4.858 .360 & 4.522 .196 & 1,074 & 4.151 & 5.046 & 184,5 & 224,3 & & & & \\
\hline Jun 05 & 3.265 .330 & 4.176 .074 & 0,782 & 2.846 & 3.715 & 126,5 & 165,1 & & & & \\
\hline Jul 05 & 1.970 .260 & 4.259 .392 & 0,463 & 1.957 & 5.221 & 87,0 & 232,1 & & & & \\
\hline Aug 05 & 2.149 .780 & 4.008 .060 & 0,536 & 1.376 & 4.213 & 61,2 & 187,2 & & & & \\
\hline Sep 05 & 2.878 .390 & 3.758 .452 & 0,766 & 1.632 & 3.960 & 72,5 & 176,0 & 499,2 & 759,7 & 301.829 & 497.129 \\
\hline Okt 05 & 1.768 .040 & 715.288 & 2,472 & 1.159 & 542 & 51,5 & 24,1 & & & & \\
\hline
\end{tabular}


Table 7.5: Precipitation [HEINEKEN2001]

\begin{tabular}{|l|r|r|}
\hline \multicolumn{1}{|c|}{ month } & $\begin{array}{c}\text { averag. monthly } \\
\text { precipitation }\left[\mathbf{m m} / \mathbf{m}^{2}\right]\end{array}$ & precipitation [kg/month] \\
\hline January & 41 & 247.312 \\
\hline February & 32 & 193.024 \\
\hline March & 36 & 217.152 \\
\hline April & 41 & 247.312 \\
\hline May & 48 & 289.536 \\
\hline June & 62 & 373.984 \\
\hline Juli & 66 & 398.112 \\
\hline August & 55 & 331.760 \\
\hline September & 41 & 247.312 \\
\hline Oktober & 34 & 205.088 \\
\hline November & 43 & 259.376 \\
\hline December & 46 & 277.472 \\
\hline Sum & 545 & 3.287 .440 \\
\hline
\end{tabular}

Figure 7.4 shows the real transport efforts of an existing industrial-scale biogas plant with an electric output of more than 3.0 MW. Left abscissa shows the transported mass of inputs and outputs in km per month. Right abscissa shows the transport distances calculated basing on the data of the several deliverers and the weighbridge protocols of the plant operator ( $\mathrm{km} /$ month). It can be seen that output masses and output distances are closely correlated, while there is no close correlation between input masses and distances.

Until spring 2004 the influence of the change in input material can be seen. The inputs of the plant were changed to the regulations of the Renewable-Energies-Act, causing higher shares of energy rich silages instead of low energy waste. This change led to a reduction of input and output mass and energy flows. 


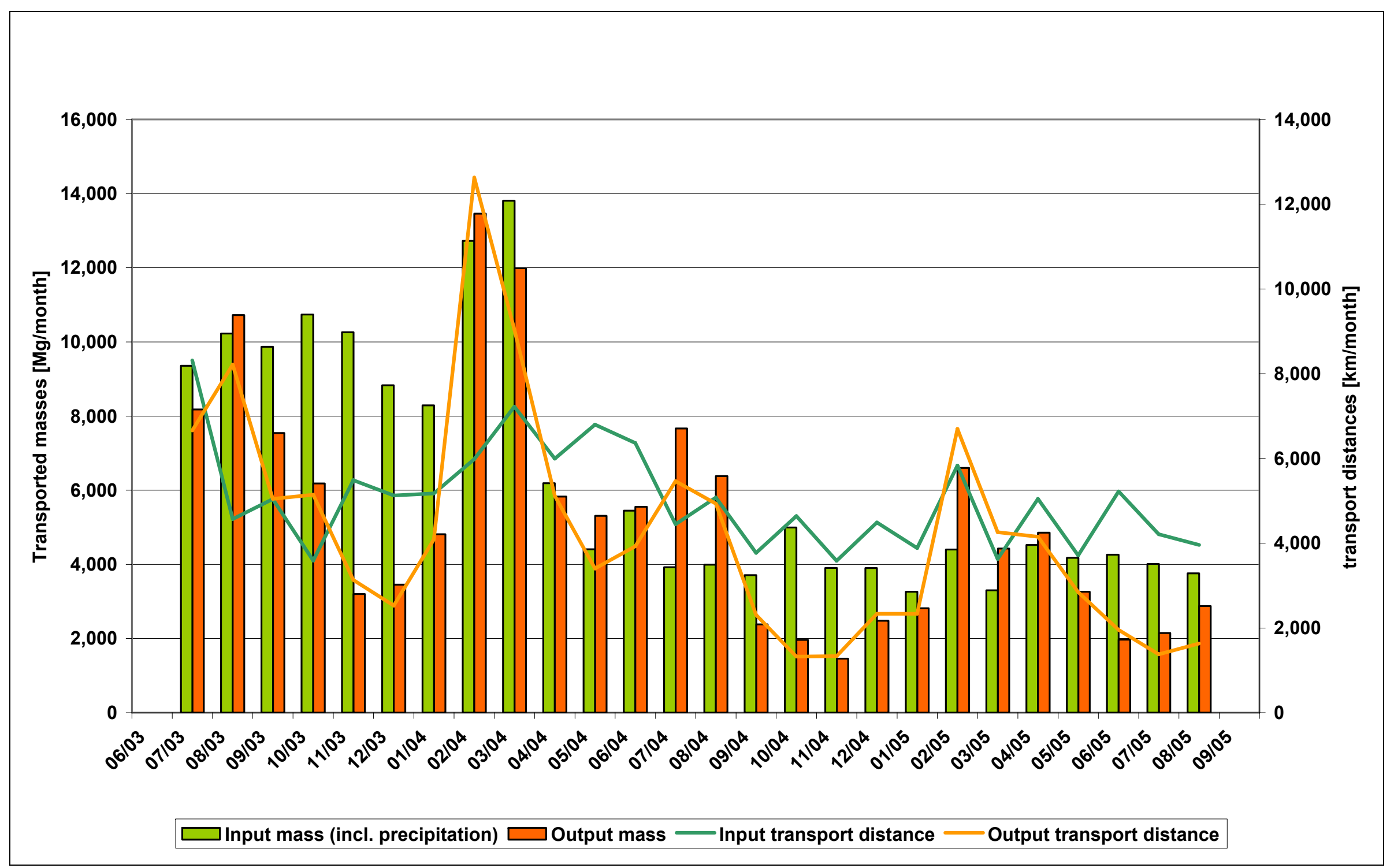

Figure 7.4: Transported masses and transport distances per month [HARTMANN2006] 